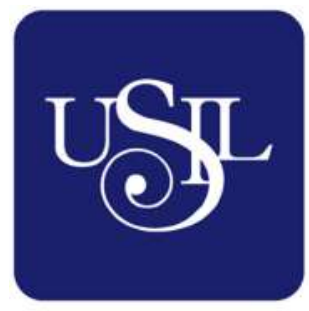

UNIVERSIDAD

SAN IGNACIO

DE LOYOLA

ESCUELA DE POSTGRADO

Maestría en Ciencias Empresariales

\title{
SALÓN DE BELLEZA MÓVIL PARA MUJERES DE LIMA METROPOLITANA
}

Tesis para optar el grado de Maestro en Ciencias Empresariales

\author{
Aramburu Lazo, Claudio Andrés Martin \\ Dávila Alvarado, Jurgens Harold \\ Morales Flores, Paola Milagros \\ Rodríguez Zevallos, Katheryn Paola
}

\author{
ASESOR \\ Dr. Edmundo Casavilca Maldonado
}

Lima - Perú

2017 


\section{Dedicatoria}

Dedicamos esta tesis a nuestras familias quienes día a día nos impulsan a buscar nuevos retos y nos apoyan en las decisiones que tomamos para nuestro desarrollo profesional. 


\section{Agradecimientos}

Agradecemos a cada miembro de nuestro equipo, quienes aportaron lo mejor de sus conocimientos y experiencia laboral para la realización de este proyecto de tesis. Además, agradecemos la autoorganización, lluvia de ideas, tiempo, dedicación y esfuerzo que cada miembro brindó para realizar un trabajo de calidad.

Agradecemos a nuestros familiares, quienes nos dieron sus apreciaciones y recomendaciones cuando compartimos con ellos la idea del proyecto de tesis.

Agradecemos a nuestro asesor Edmundo Casavilca, quien nos ayudó en la elección de nuestro proyecto y nos orientó a través de su experiencia y comentarios para finalizar nuestro documento de tesis.

Agradecemos a la profesora Flor Ríos, quien sesión a sesión nos brindó sus valiosas recomendaciones y herramientas para la preparación de nuestro documento final.

Agradecemos a los participantes de las entrevistas, focus group y encuestas realizadas, quienes aportaron a través de sus respuestas buenas ideas para conocer al consumidor final de este proyecto de negocio.

Agradecemos a la Universidad San Ignacio de Loyola, que nos facilitó recursos, instalaciones y personal. 


\section{Contenido}

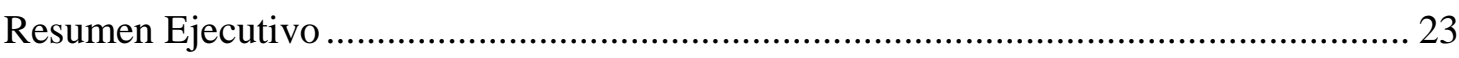

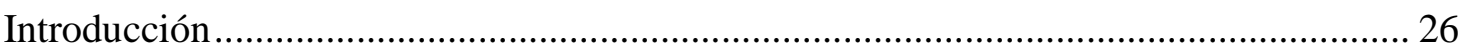

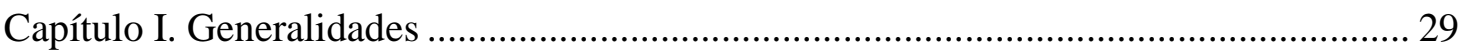

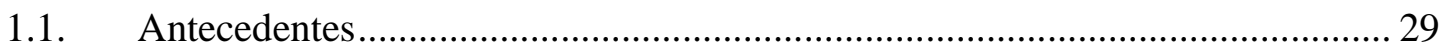

1.2. Determinación del problema u oportunidad ...................................................... 31

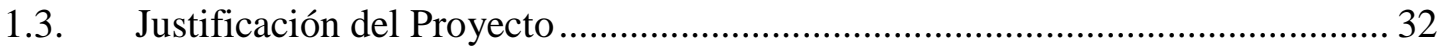

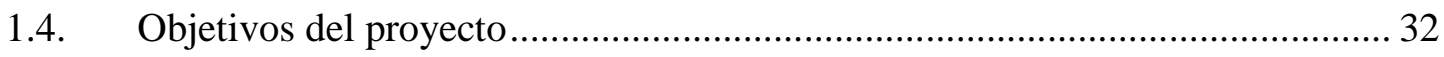

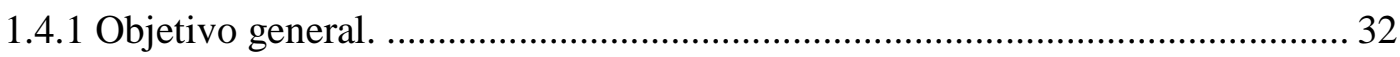

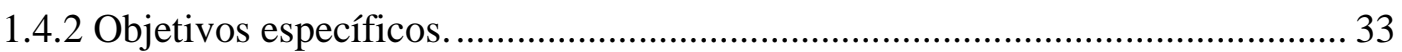

1.5. Alcances y limitaciones de la investigación .................................................... 33

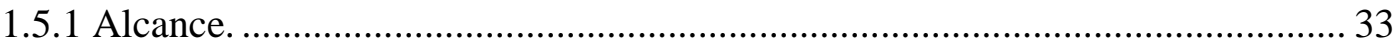

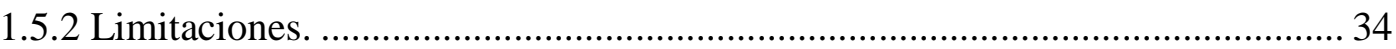

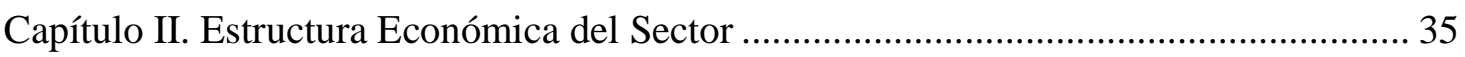

2.1. Descripción del estado actual de la industria............................................................. 35

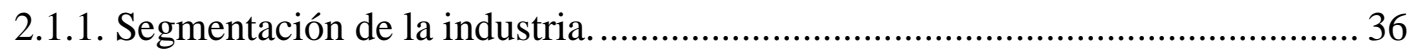

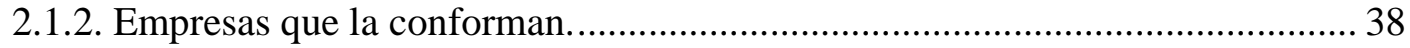

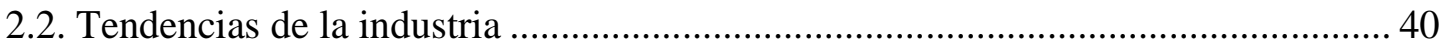

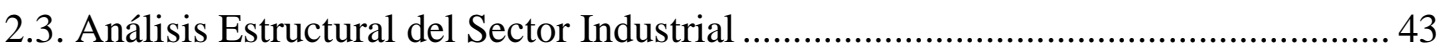


2.3.1. Poder de negociación de los clientes.

2.3.2. Poder de negociación de los proveedores

2.3.3. Amenaza de los nuevos competidores

2.3.4. Amenaza de productos y servicios sustitutos.

2.3.5. La rivalidad entre los competidores existentes.

2.4. Análisis de la Competencia

2.4.1. Empresas que ofrecen el mismo producto o servicio. 54

2.4.2. Participación de mercado de cada uno de ellos 56

2.4.3. Matriz de perfil competitivo. 58

2.5. Análisis del Contexto Actual y Esperado 60

2.5.1. Análisis Político-Gubernamental. 60

2.5.2. Análisis Económico. 62

2.5.3. Análisis Legal. 69

2.5.4. Análisis Cultural. 70

2.5.5. Análisis Tecnológico. 72

2.5.6. Análisis Ecológico. 73

2.6. Oportunidades y Amenazas 74

2.7. Matriz de Evaluación de Factores Externos 75

Capítulo III. Estudio de Mercado 78

3.1. Descripción del servicio o producto 78 
3.2. Selección del segmento de mercado

3.3. Investigación Cualitativa

3.3.1. Proceso de muestreo

3.3.2. Diseño de instrumento

3.3.3. Análisis y procesamiento de datos. 92

3.4. Investigación Cuantitativa

3.4.1. Proceso de muestreo. 97

3.4.2. Diseño de instrumento. 99

3.4.3. Análisis y procesamiento de datos 101

3.5. Conclusiones y recomendaciones del estudio cualitativo y cuantitativo. 128

3.6. Perfil del consumidor tipo y sus variantes.

Capítulo IV. Proyección del Mercado Objetivo.

4.1. El ámbito de la proyección

4.2. Selección del método de proyección

4.2.1. Mercado Potencial.

4.2.2. Mercado Disponible.

4.2.3. Mercado Efectivo.

4.2.4. Mercado Objetivo.

4.3. Pronóstico de Ventas 
Capítulo V. Ingeniería del Proyecto 150

5.1. Estudio de ingeniería 150

5.1.1. Modelamiento y selección de procesos productivos. 150

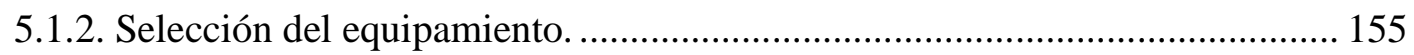

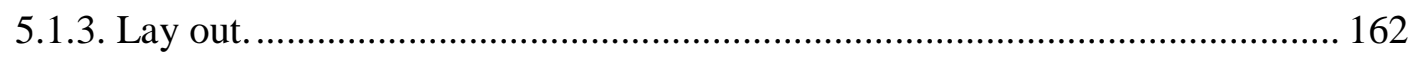

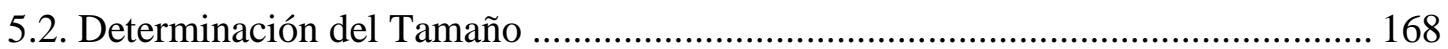

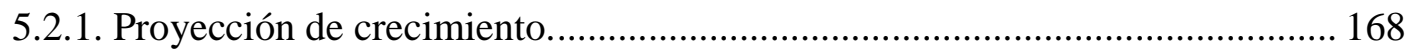

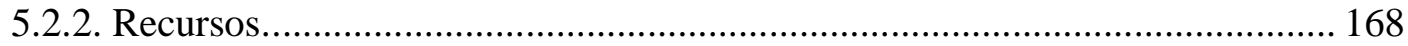

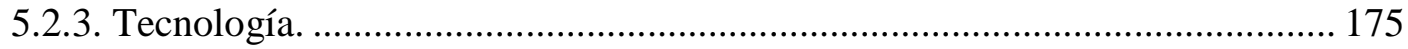

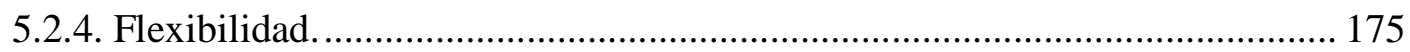

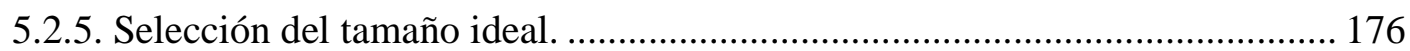

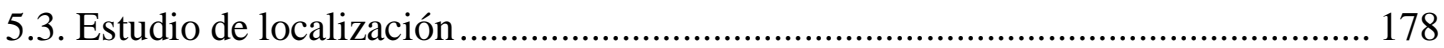

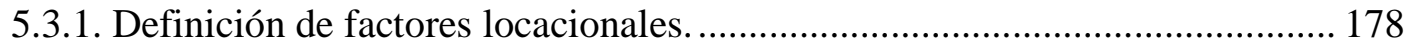

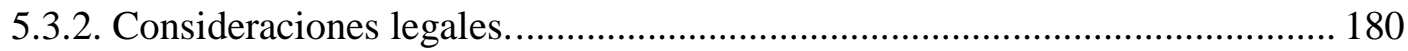

5.4. Determinación de la localización óptima ......................................................... 197

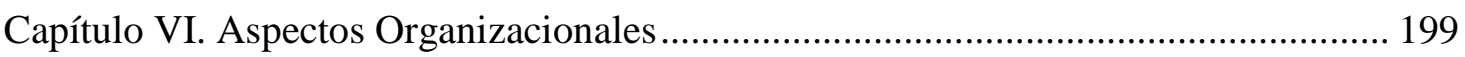

6.1. Caracterización de la cultura organizacional deseada ......................................... 199

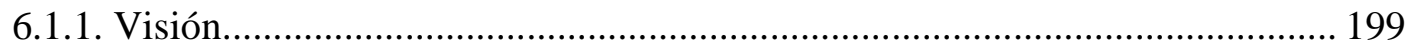

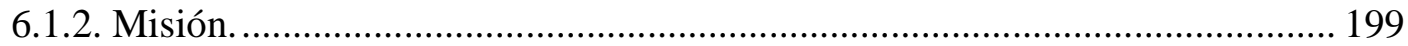

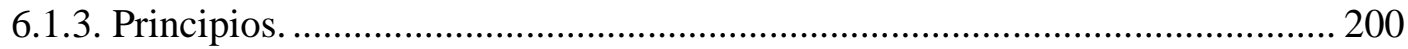


6.2. Formulación de Estrategias del Negocio .................................................................. 201

6.3. Determinación de las ventajas competitivas críticas .............................................. 204

6.4. Diseño de la estructura organizacional deseada ................................................... 206

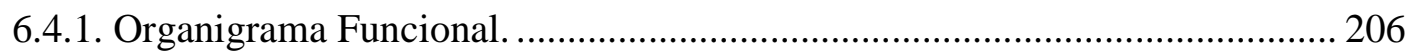

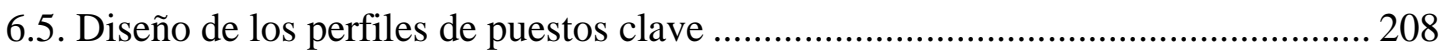

6.6. Remuneraciones, compensaciones e incentivos .............................................. 211

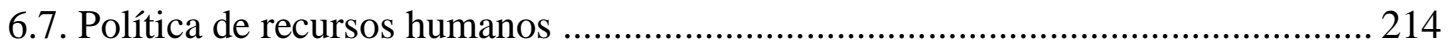

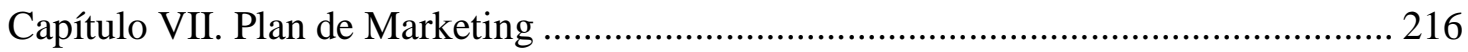

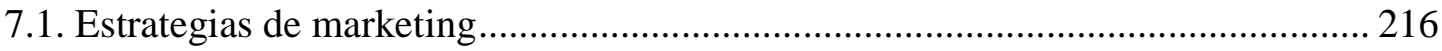

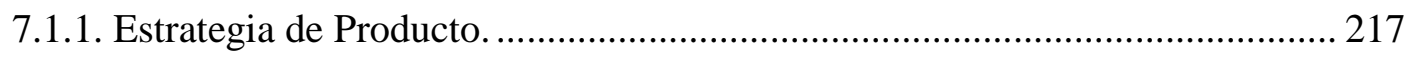

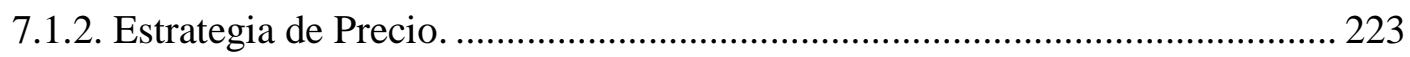

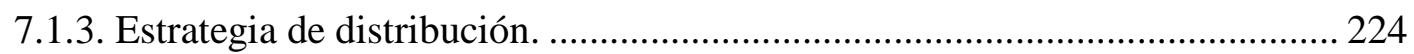

7.1.4. Estrategia de promoción y publicidad. ........................................................ 224

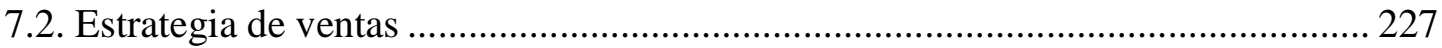

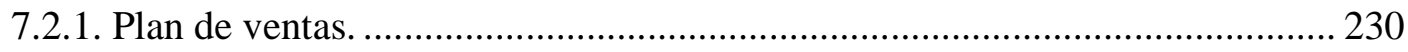

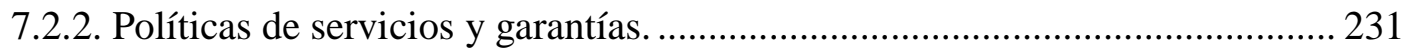

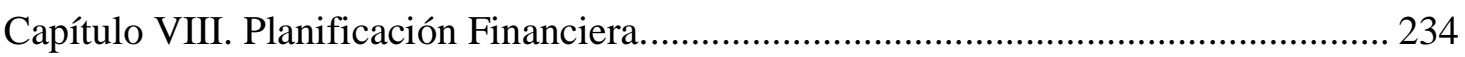

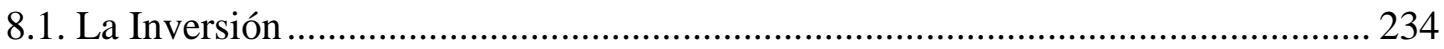

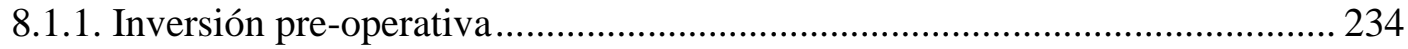

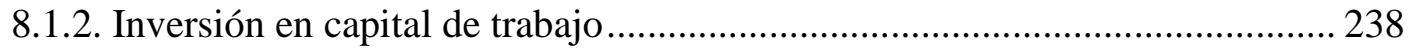


8.1.3. Costo del proyecto

8.1.4. Inversiones futuras

8.2. Financiamiento

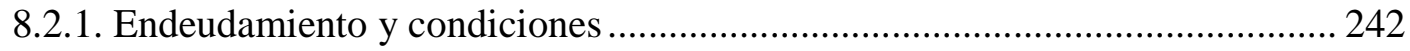

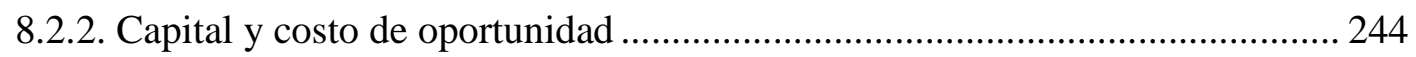

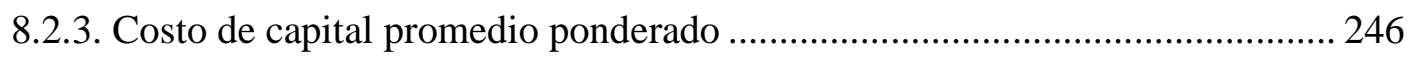

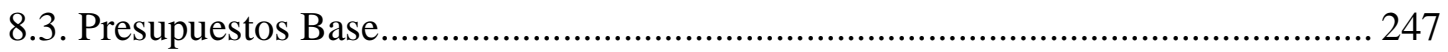

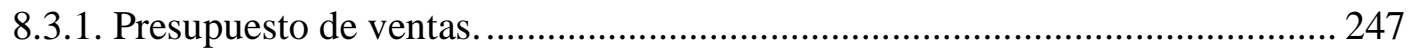

8.3.2. Presupuesto de costos de producción (de servicio). ........................................ 249

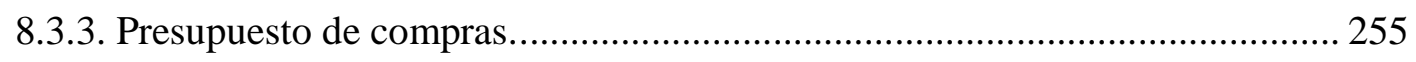

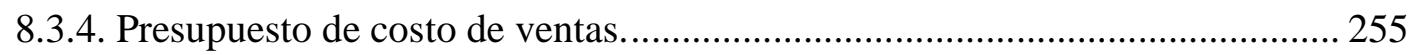

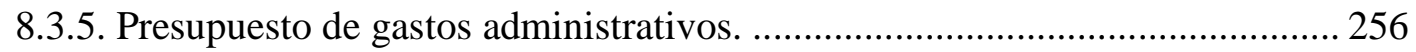

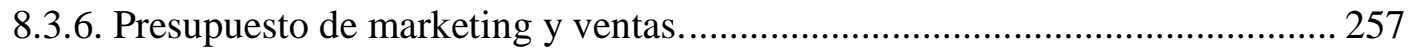

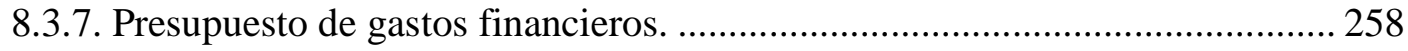

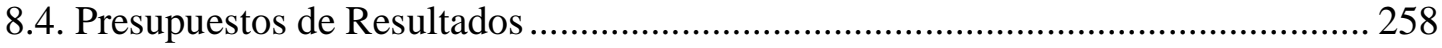

8.4.1. Estado de ganancias y pérdidas proyectado .............................................. 258

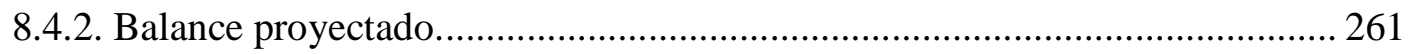

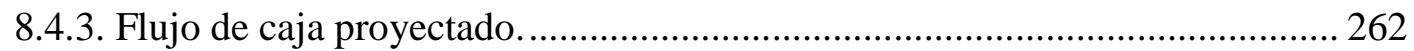

Capítulo IX. Evaluación Económico Financiera ............................................................ 266

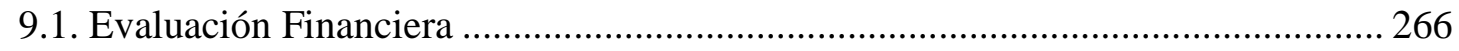


9.1.1. TIR 266

9.1.2. VAN 268

9.1.3. ROE. 269

9.1.4. Ratios. 269

9.2. Análisis de Riesgo 272

9.2.1. Análisis de punto de equilibrio. 273

9.2.2. Análisis de sensibilidad. 274

9.2.3. Análisis de escenarios 276

Conclusiones y recomendaciones 278

Conclusiones. 278

Recomendaciones 279

Anexos 280

Anexo 1. Guías de entrevista a los expertos 281

Anexo 2. Guía de pautas para focus group 289

Anexo 3. Cuestionario para encuesta 295

Anexo 4. Resultado de entrevista a la competencia 304

Anexo 5. Resultado de entrevista al distribuidor. 310

Anexo 6. Resultado de entrevista al experto de belleza en el sector de belleza 313

Anexo 7. Resultado de entrevista al especialista en negocios móviles (Food Trucks) 319

Anexo 8. Resultado de Focus Group No. 1 323 
Anexo 9. Resultado de Focus Group No. 2

Anexo 10. Resultado de Focus Group No. 3

Anexo 11. Resultado de Focus Group No. 4 


\section{Índice de Tablas}

Tabla 1 Segmentación de mercado 37

Tabla 2 Empresas que pertenecen a productores de la industria ............................................ 38

Tabla 3 Empresas que pertenecen a educadores de la industria ................................................. 39

Tabla 4 Empresas que pertenecen a distribuidores de la industria ............................................. 39

Tabla 5 Empresas que pertenecen a peluquería, salones de belleza y otros ............................... 40

Tabla 6 Matriz de atractividad para el poder de negociación de los clientes ............................... 45

Tabla 7 Matriz de atractividad para el poder de negociación de los proveedores ........................ 47

Tabla 8 Matriz de atractividad para la amenaza de los nuevos competidores ............................. 49

Tabla 9 Matriz de atractividad para la amenaza de productos y servicios sustitutos ...................50

Tabla 10 Matriz de atractividad de la rivalidad entre los competidores existentes ..................... 53

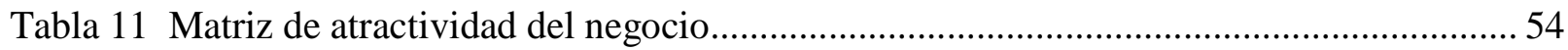

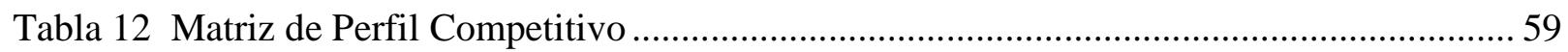

Tabla 13 Oportunidades y Amenazas de Análisis Político Gubernamental ................................. 62

Tabla 14 Oportunidades y Amenazas de Análisis Económico ................................................. 68

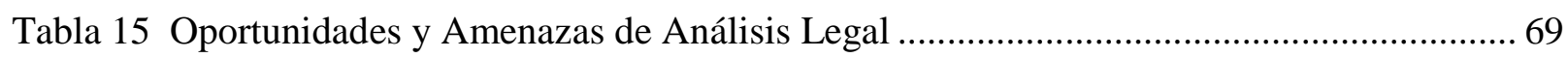

Tabla 16 Oportunidades y Amenazas de Análisis Social y Cultural ......................................... 72

Tabla 17 Oportunidades y Amenazas de Análisis Tecnológico ............................................... 73

Tabla 18 Oportunidades y Amenazas de Análisis Ecológico .................................................... 73

Tabla 19 Oportunidades y Amenazas para el negocio.......................................................... 74

Tabla 20 "Continuación” Oportunidades y Amenazas para el negocio........................................ 75

Tabla 21 Matriz de Evaluación de Factores Externos ................................................................ 76

Tabla 22 Criterios de segmentación de mercados de consumo ……............................................ 79 
Tabla 23 Criterios de segmentación para el salón de belleza móvil

Tabla 24 Criterios de segmentación aplicado 82

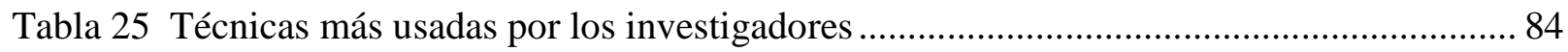

Tabla 26 Ficha Técnica de Entrevistas de Profundidad............................................................. 90

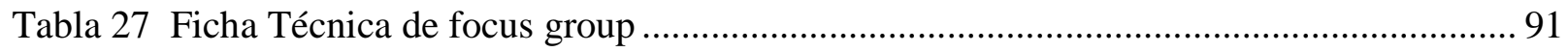

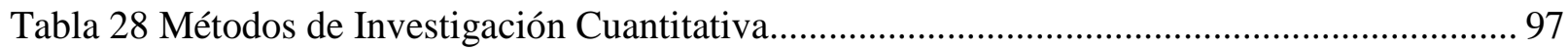

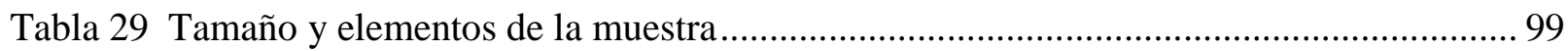

Tabla 30 Ficha técnica de la encuesta.......................................................................................... 100

Tabla 31 Frecuencia de solicitud de servicio de corte ........................................................... 105

Tabla 32 Frecuencia de solicitud de servicio de peinado ....................................................... 105

Tabla 33 Frecuencia de solicitud de servicio de planchado.................................................... 106

Tabla 34 Frecuencia de solicitud de servicio de alisado ......................................................... 106

Tabla 35 Frecuencia de solicitud de servicio de extensiones .................................................... 107

Tabla 36 Frecuencia de solicitud de servicio de coloración ...................................................... 107

Tabla 37 Frecuencia de solicitud de servicio de maquillaje ..................................................... 108

Tabla 38 Frecuencia de solicitud de servicio de depilación ......................................................... 108

Tabla 39 Frecuencia de solicitud de servicio de pestañas postizas.......................................... 109

Tabla 40 Frecuencia de solicitud de servicio de manicure ...................................................... 109

Tabla 41 Frecuencia de solicitud de servicio de uñas acrigel ................................................... 110

Tabla 42 Frecuencia de solicitud de servicio de pedicure ….................................................... 110

Tabla 43 Cantidad y porcentaje de respuestas de frecuencia de solicitud de los servicios de salón

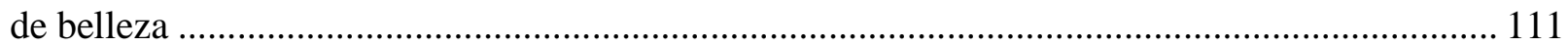

Tabla 44 Frecuencias correspondientes al horario de asistencia ............................................ 113 
Tabla 45 Porcentaje de horario de asistencia por día.

Tabla 46 Porcentaje de respuestas correspondiente al horario de asistencia

Tabla 47 Frecuencia para visita mensual a salones de belleza

Tabla 48 Frecuencia y porcentaje de asistencia a salones de belleza

Tabla 49 Cantidad y porcentajes de medios de reserva de cita

Tabla 50 Frecuencia de tiempo de espera para atención en salones de belleza

Tabla 51 Frecuencia de tiempo de atención para cada servicio

Tabla 52 Porcentaje de tiempo de atención para cada servicio

Tabla 53 Frecuencia de respuestas obtenidas

Tabla 54 Frecuencia por atributo

Tabla 55 Porcentaje por atributo

Tabla 56 Frecuencia y porcentaje de respuestas obtenidas para atributos propuestos

Tabla 57 Frecuencias y porcentajes de encuestados y respuestas recogidas para servicios que solicitarían en el salón de belleza móvil

Tabla 58 Tabla de precios propuestos para el salón de belleza móvil

Tabla 59 Frecuencia de preferencias de precios

Tabla 60 Frecuencia y porcentaje sobre los medios de contacto

Tabla 61 Técnicas de predicción

Tabla 62 Tasa de crecimiento media de la población total

Tabla 63 Proyección Población Total Zona dos de Lima Metropolitana

Tabla 64 Proyección Población por edades de Zona dos de Lima Metropolitana.

Tabla 65 Mercado Potencial Zona dos de Lima Metropolitana

Tabla 66 Mercado Disponible Zona dos de Lima Metropolitana 
Tabla 67 Mercado Efectivo zona dos de Lima Metropolitana

Tabla 68 Porcentaje de mercado objetivo de zona dos de Lima Metropolitana

Tabla 69 Mercado objetivo de zona dos de Lima Metropolitana

Tabla 70 Resumen de Mercados de Zona dos de Lima Metropolitana.

Tabla 71 Frecuencia de Consumo para Corte de Cabello

Tabla 72 Frecuencia de Consumo para Planchado

Tabla 73 Frecuencia de Consumo para Manicure

Tabla 74 Frecuencia de Consumo para Pedicure 140

Tabla 75 Resumen de Frecuencia de Consumo por servicios.

Tabla 76 Resumen proyección de demanda por cantidad de servicio al año.

Tabla 77 Precios de Venta Sugeridos

Tabla 78 Resumen de Programación de ventas anual por servicio

Tabla 79 Estacionalidad por meses enero - junio

Tabla 80 Estacionalidad por meses julio - diciembre

Tabla 81 Programación Mensual de Ventas para el Año 1 (Expresado en servicios)

Tabla 82 Programación Mensual de Ventas para el Año 1 (Expresado en soles)

Tabla 83 Programación Mensual de Ventas para el Año 2 (Expresado en servicios).

Tabla 84 Programación Mensual de Ventas para el Año 2 (Expresado en soles)

Tabla 85 Programación Mensual de Ventas para el Año 3 (Expresado en servicios) 146

Tabla 86 Programación Mensual de Ventas para el Año 3 (Expresado en soles) 146

Tabla 87 Programación Mensual de Ventas para el Año 4 (Expresado en servicios) 147

Tabla 88 Programación Mensual de Ventas para el Año 4 (Expresado en soles) 147

Tabla 89 Programación Mensual de Ventas para el Año 5 (Expresado en servicios) 148 
Tabla 90 Programación Mensual de Ventas para el Año 5 (Expresado en soles)

Tabla 91 Equipamiento para el acondicionamiento del salón de belleza móvil

Tabla 92 Instrumentos para los servicios del salón de belleza móvil

Tabla 93 Insumos necesarios para el servicio de corte

Tabla 94 Insumos necesarios para el servicio de planchado

Tabla 95 Insumos necesarios para el servicio de manicure

Tabla 96 Insumos necesarios para el servicio de pedicure 161

Tabla 97 Requerimiento necesario de equipos y maquinarias para salón de belleza móvil 166

Tabla 98 “Continuación” Requerimiento necesario de equipos y maquinarias para salón de

belleza móvil 167

Tabla 99 Cantidad de servicios proyectados por año. 168

Tabla 100 Productos necesarios para servicio de corte 169

Tabla 101 Productos necesarios para servicio de planchado 170

Tabla 102 Productos necesarios para servicio de manicure 170

Tabla 103 Productos necesarios para servicio de pedicure.

Tabla 104 Datos para cálculo de mano de obra

Tabla 105 Datos para el cálculo de mano de obra directa requerida

Tabla 106 Requerimiento de mano de obra proyectado

Tabla 107 Horario de trabajo de supervisora y cosmetóloga móvil uno

Tabla 108 Horario de trabajo de supervisora y cosmetóloga móvil dos 173

Tabla 109 Requerimiento de equipamiento 174

Tabla 110 Variables para cálculo de capacidad máxima 176

Tabla 111 Capacidad máxima de servicios 
Tabla 112 Cálculo de unidades móviles requeridas.

Tabla 113 Matriz de Localización de oficina administrativa..

Tabla 114 Requisitos y pagos para la licencia de funcionamiento

Tabla 115 Cuadro comparativo Régimen Laboral Especial de la MYPE

Tabla 116 "Continuación”

Tabla 117 Tipos de contrato

Tabla 118 Formas empresariales formales

Tabla 119 Aporte societario de PONTE DIVA S.A.C. 191

Tabla 120. Matriz de las Cuatro Acciones 202

Tabla 121 Análisis VRIO. 205

Tabla 122 Perfil de puesto de jefe administrativo 209

Tabla 123 Perfil de puesto de supervisora cosmetóloga 210

Tabla 124 Perfil de puesto de cosmetóloga

Tabla 125 Derechos de los colaboradores

Tabla 126 Planilla Anual de mano de obra directa para el Año 1 (Soles)

Tabla 127 Planilla Anual de mano de obra directa para el Año 2 (Soles)

Tabla 128 Planilla Anual de mano de obra directa para el Año 3 (Soles)

Tabla 129 Planilla Anual de mano de obra directa para el Año 4 (Soles)

Tabla 130 Planilla Anual de mano de obra directa para el Año 5 (Soles)

Tabla 131 Gastos operativos de personal (Soles) 214

Tabla 132 Lista de precios de Ponte Diva 224

Tabla 133 Plan de Ventas Anual en Soles 231

Tabla 134 Activos tangibles para servicios y operaciones 235 


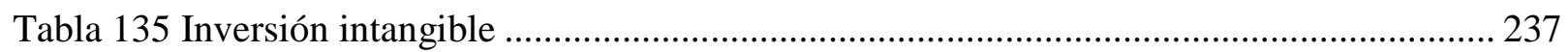

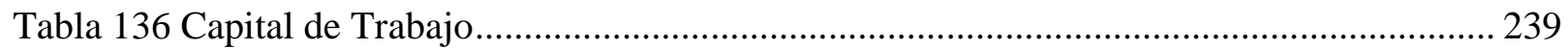

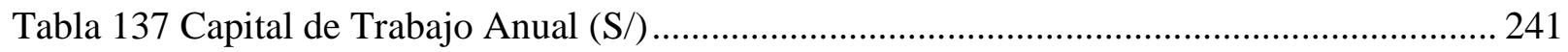

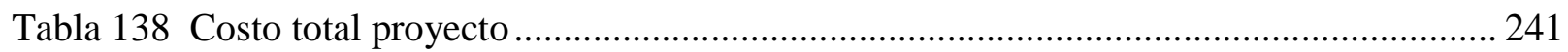

Tabla 139 Estructura de financiamiento ................................................................................... 243

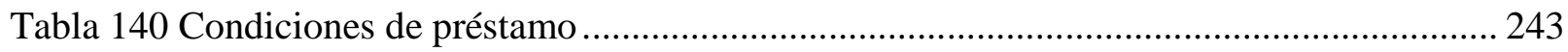

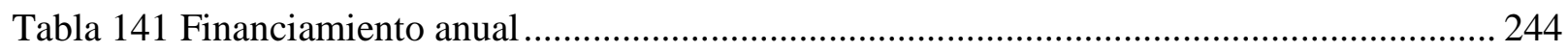

Tabla 142 Información de rendimiento esperado y tasa de libre riesgo ...................................... 245

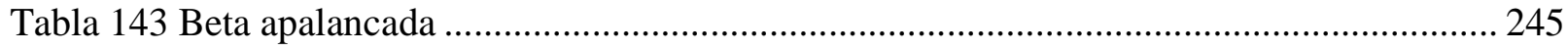

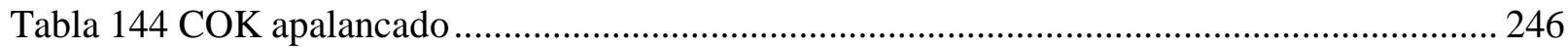

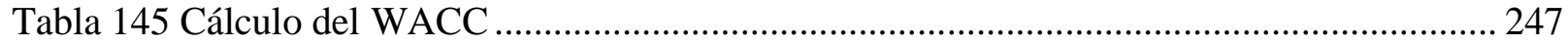

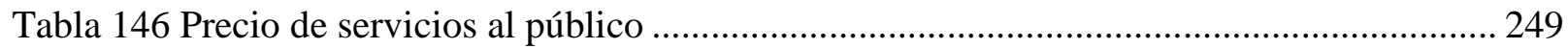

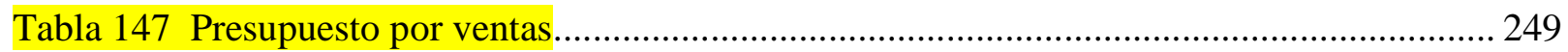

Tabla 148 Costo de producción de servicio de corte de cabello.............................................. 250

Tabla 149 Costo de producción de servicio planchado ............................................................. 251

Tabla 150 Costo de producción de servicio de manicure ......................................................... 252

Tabla 151 Costo de producción de servicio de pedicure …...................................................... 253

Tabla 152 Presupuesto de costo de producción de los servicios .............................................. 254

Tabla 153 Presupuesto de compras anual ....................................................................... 255

Tabla 154 Equipamiento necesario para los servicios (utensilios) ......................................... 255

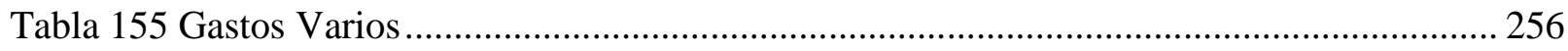

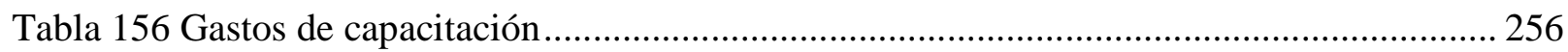

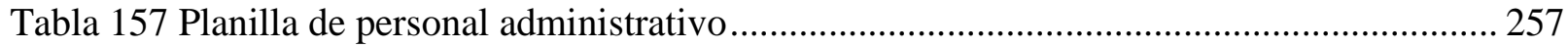




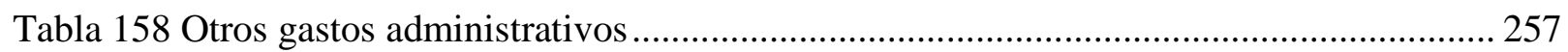

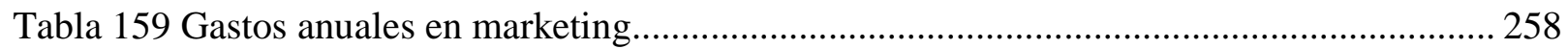

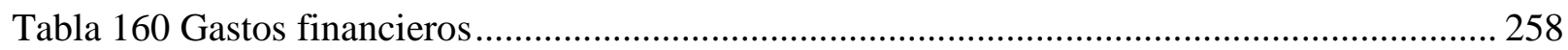

Tabla 161 Estado de ganancias y pérdidas proyectado (sin incluir gastos financieros) .............. 260

Tabla 162 Estado de ganancias y pérdidas proyectado (incluir gastos financieros) .................... 260

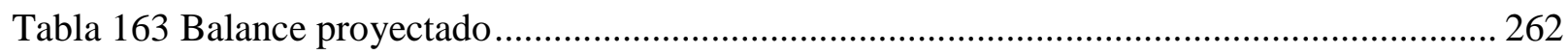

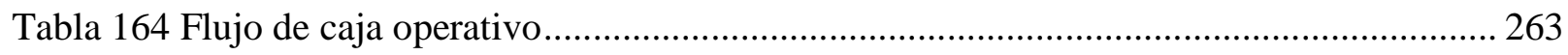

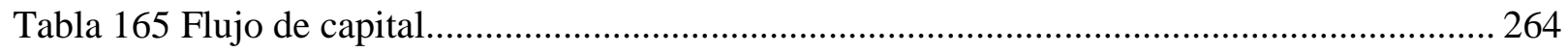

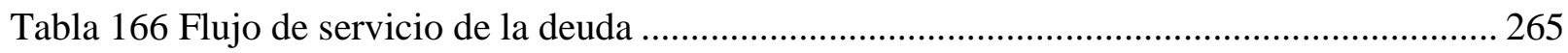

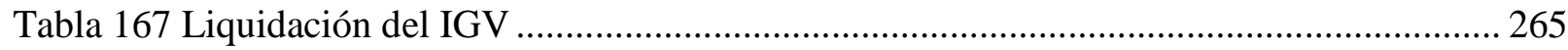

Tabla 168 Tasa interna de retorno económico (TIRE) …......................................................... 267

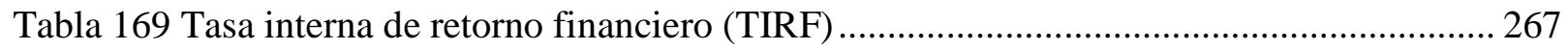

Tabla 170 Valor Actual Neto Económico (VANE) .......................................................................... 268

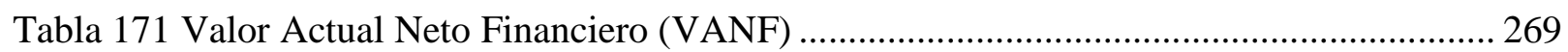

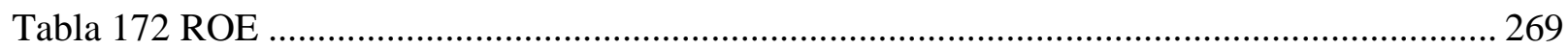

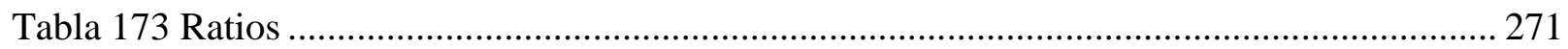

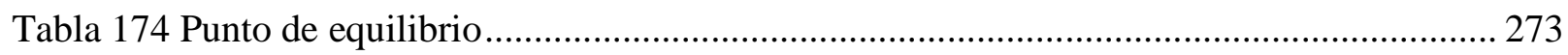

Tabla 175 Análisis de sensibilidad unidimensional para la variable precio .............................. 274

Tabla 176 Análisis de sensibilidad unidimensional para la variable demanda............................ 275

Tabla 177 Análisis de sensibilidad unidimensional para variable costos de material directo ...... 275

Tabla 178 Análisis de sensibilidad unidimensional para variable costo de personal .................. 276

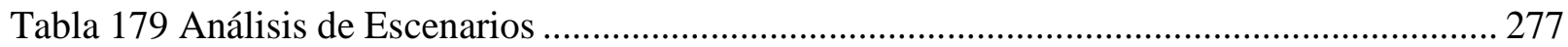




\section{Índice de Figuras}

Figura 1. Participación en el mercado de cadenas de salones y salones de belleza independientes57

Figura 2. Participación en el mercado de cadenas de salones...................................................... 58

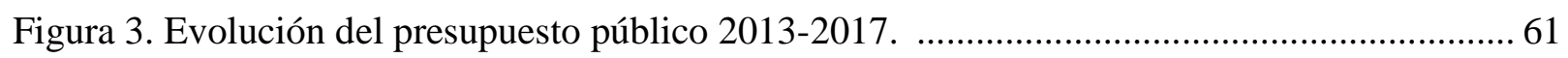

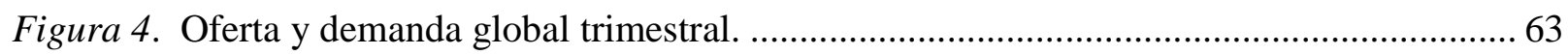

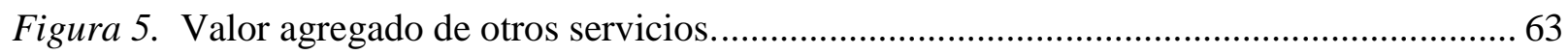

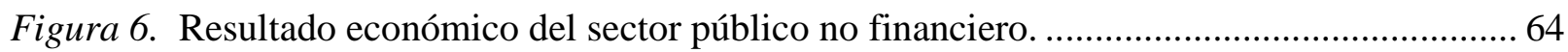

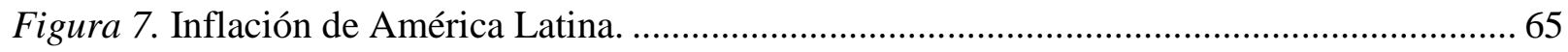

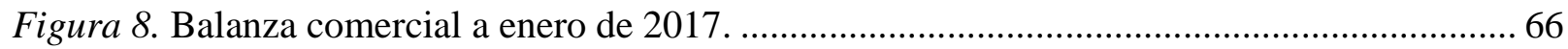

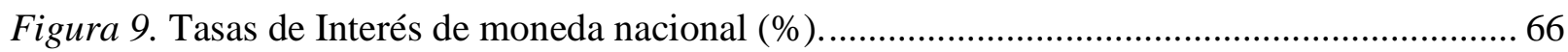

Figura 10. Crecimiento del PBI por regiones en la Economía Mundial. .................................... 67

Figura 11. Población femenina y masculina, según ramas de actividad.................................... 71

Figura 12. Población femenina y masculina, según ramas de actividad....................................... 71

Figura 13. Incremento de nivel socio económico C en lima metropolitana................................. 80

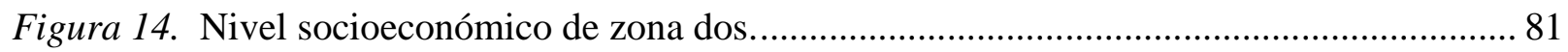

Figura 15. Clasificación de la investigación no experimental. ................................................... 96

Figura 16. Pasos para desarrollar un plan de muestreo....................................................... 98

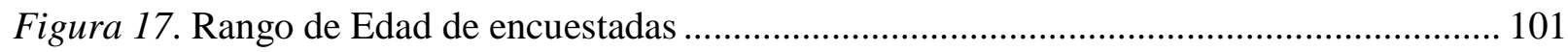

Figura 18. Distrito de residencia de encuestadas ...................................................................... 102

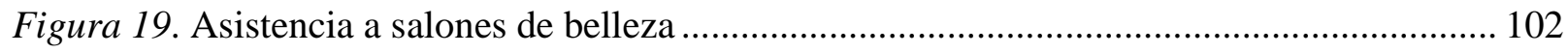

Figura 20. Importancia de asistir a un salón de belleza ........................................................ 103

Figura 21. Razones de asistencia al salón de belleza .............................................................. 104

Figura 22. Tiempo promedio de permanencia en salones de belleza........................................ 112 
Figura 23. Con quién suelen asistir los clientes a salones de belleza.

Figura 24. Disponibilidad de tiempo de espera.

Figura 25. Promedio de gasto mensual en servicios de belleza

Figura 26. Matriz cliente - contacto para proceso de servicio.

Figura 27. Flujograma del proceso de reserva de cita a domicilio..

Figura 28. Flujograma del proceso del servicio de atención.

Figura 29. Unidad móvil tipo furgón, 156

Figura 30. Interior de la unidad móvil tipo furgón 156

Figura 31. Productos e insumos 159

Figura 32. Equipamiento básico para la oficina administrativa. 161

Figura 33. Layout de móvil 163

Figura 34. Layout de oficina (esquema de distribución oficina administrativa). 164

Figura 35. Distribución de estaciones, equipos y maquinaria 165

Figura 36. Consideraciones del proyecto. 182

Figura 37. Logo a registrar 196

Figura 38. Macro localización distrito de Los Olivos 198

Figura 39. Micro localización Calle Carlos de los Heros 160 Urbanización Antares Los Olivos198

Figura 40. Cuadro estratégico del Océano azul para el salón de belleza móvil. 203

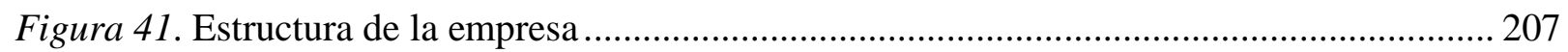

Figura 42. Matriz de Ansoff. Tomado de "Matrix Ansoff. Strategy skills.” ............................. 216

Figura 43. Salón de Belleza móvil cerrado. ....................................................................... 218

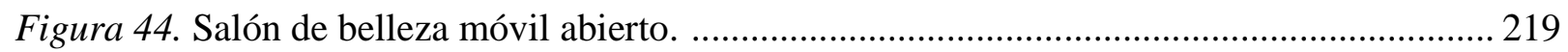

Figura 45. Servicio de Manicure y Pedicure dentro de la móvil................................................ 220 
Figura 46. Servicio de Corte de Cabello y Planchado dentro de la móvil 220

Figura 47. Unidad móvil Ponte Diva Salón 221

Figura 48. Logotipo de Ponte Diva 222

Figura 49. Ofertas de Lanzamiento de Ponte Diva .... 225

Figura 50. Precios de los servicios de Ponte Diva 226 


\section{Resumen Ejecutivo}

La presente tesis tiene como finalidad demostrar que el plan de negocio salón de belleza móvil es viable de implementar.

Con la propuesta del plan de negocio del salón de belleza móvil se pretende satisfacer una necesidad que ha tomado mucha importancia en los últimos tiempos que es el cuidado personal y los deseos de ahorrar costos y tiempos (traslados y espera) que se invierten actualmente en obtener este servicio en los salones de belleza convencionales, el negocio brindará servicios de corte de cabello, planchado, manicure y pedicure a domicilio.

El público objetivo del plan de negocio está formado por mujeres de 20 a 59 años, pertenecientes al NSE C y que viven en la zona dos de Lima Metropolitana que van por lo menos una vez al mes al salón de belleza.

El plan se inicia describiendo la determinación de la oportunidad y la definición del objetivo principal y objetivos secundarios. Luego, se realiza un análisis de la industria, los factores del entorno interno y externo que tienen impacto en el sector de belleza (los aspectos más importantes son el crecimiento de la economía e impulso a las MYPE), una conclusión importante es que el sector de belleza se encuentra en un crecimiento constante.

La investigación de mercado incluyó entrevistas a expertos (asesor de belleza, proveedor, administrador de salón, dueño de salón independiente y especialista de food truck), focus group y encuestas a mujeres que cumplen con los requisitos del público objetivo de la zona dos de Lima Metropolitana; se demostró que el salón de belleza móvil es una idea atractiva y existe una intención de consumo de los servicios, además se detectó muchas oportunidades de valor 
agregado que hay en el sector belleza, ya que existe la necesidad de recibir beneficios adicionales por parte de los clientes.

Con la información del estudio de mercado y del análisis externo se realizó la proyección de la demanda para el periodo de cinco años, aplicando los conceptos de mercado potencial, disponible, efectivo y objetivo; esta información servirá para la proyección de compras y determinación de tamaño ideal, que apoyará al cálculo de la estructura de inversión.

En la ingeniería del proyecto se describe los procesos de solicitud de reserva y de atención dentro del móvil, se determina la necesidad de una oficina administrativa en el distrito de Los Olivos ubicado estratégicamente según el análisis de micro localización. Se describe la necesidad de los recursos materiales, intangibles, insumos y mano de obra para la ejecución de los servicios según la demanda proyectada; se determina que habrá un incremento mensual en la mano de obra (cosmetólogas) por el incremento de la demanda del sector (10\% anual), asimismo, se determina la compra de dos furgones que serán implementados para brindar los servicios como un salón de belleza convencional.

En el plan de marketing se define como objetivo posicionar la marca en la mente del consumidor como innovadora en el servicio de salón de belleza y fortalecer el valor agregado de optimización de tiempos de espera y traslados.

El plan y análisis financiero señala que las fuentes de financiamiento están conformadas por aporte de accionistas con un $63 \%$ y $37 \%$ de deuda con un banco local. Realizado el cálculo de los estados financieros y del flujo de caja, con base en los presupuestos requeridos para tal fin, los criterios de rentabilidad en todos los niveles de sensibilidad determinaron que el negocio es rentable económica y financieramente. 
Por todo ello, se puede concluir que el plan de negocio del salón de belleza móvil es viable y reúne las condiciones para su implementación. 


\section{Introducción}

El presente plan de negocio busca evaluar la implementación de un salón de belleza móvil en la zona dos de Lima Metropolitana. El objetivo principal es plantear, analizar y definir la idea de negocio para así evaluar su rentabilidad.

El presente plan de negocio consta de nueve capítulos, los cuales se detallan a continuación:

El capítulo I realiza un análisis de las actividades de la mujer moderna en la actualidad para el cuidado de belleza personal. Se usó como base los antecedentes encontrados y se plantean los objetivos que se cumplirán en este plan de negocio según los alcances y limitaciones de la investigación.

- $\quad$ El capítulo II describe la industria de la belleza, identificando a la competencia y al mercado en el que el negocio se desenvolverá. Se elaboró una matriz del perfil competitivo respecto a cada uno de los grupos identificados en comparación al plan de negocio. Además, se encuentra una descripción del contexto actual y esperado de nuestro país, teniendo como referencias el estado político, económico y social, etc.

El capítulo III describe el estudio de los potenciales clientes, para tal fin se realizó una descripción del servicio que brindará el plan de negocio, en los sectores económicos y distritos de la ciudad de Lima identificados. Este estudio se realizó de dos maneras, primero mediante una investigación cualitativa y posteriormente sobre una investigación cuantitativa, de los cuales se descubre cómo es percibido actualmente el mercado de la belleza por los consumidores finales y además se analiza la atracción del servicio innovador que se ofrecerá. 
- $\quad$ El capítulo IV determina el mercado objetivo, a través de diferentes herramientas de estudio de mercado, mediante el análisis del mercado potencial, disponible y efectivo. En base al estudio anterior se elaboró el pronóstico de ventas y se identificaron los aspectos críticos que pueden impactar este pronóstico.

El capítulo V detalla los cálculos de inversión y costos, teniendo en cuenta el estudio de ingeniería (procesos productivos, equipamiento, distribución de equipos y maquinarias), determinación de tamaño del negocio (crecimiento, recursos, tecnología). El estudio de localización muestra los aspectos macro y micro localización, permitiendo evaluar la alternativa de adquirir una oficina/almacén para el negocio; asimismo este estudio permitió determinar la localización óptima de la misma.

- El capítulo VI desarrolla la cultura organizacional del plan de negocio, con el fin de establecer la visión, misión y principios. Asimismo, se identificó las ventajas competitivas críticas con el fin de establecer las estrategias del negocio. También se determinó los perfiles de los puestos claves y remuneraciones de acuerdo con el mercado y las leyes del gobierno.

El capítulo VII desarrolla las estrategias de marketing con el fin de poder introducir y posicionar el servicio en el mercado objetivo. Se planteó el plan de ventas y políticas de servicios y garantías con el fin de cumplir los servicios de este negocio.

El capítulo VIII realiza el análisis de la inversión necesaria (capital propio y/o financiamiento) para el plan de negocio. Con esta información se elaboraron los presupuestos bases correspondientes: ventas, costos, compras, gastos administrativos, marketing y gastos financieros; con el fin de desarrollar los flujos de cajas proyectados para el proyecto. 
- El capítulo IX evalúa los indicadores económicos y financieros: tasa interna de retorno (TIR), el valor actual neto (VAN), (ROE) y ratios; además se realizó el análisis de riesgo a través de punto de equilibrio, sensibilidad y escenarios. 


\section{Capítulo I. Generalidades}

\subsection{Antecedentes}

La preocupación de las personas por el cuidado de su imagen personal ha venido incrementándose a través del tiempo, en la forma de vestir, tratamiento del rostro y tratamiento del cuerpo, con el fin de conseguir la "belleza" según la época vigente.

El primer indicio del maquillaje se encontró en los egipcios a través de minerales y pigmentos aplicados en los ojos, frente y manos, también el cuidado de la piel fue de importancia en la época, con el uso de leche, frutas, exfoliación con arena y productos basados en algunos animales. De la misma manera Grecia y Roma le dieron importancia al cuerpo apareciendo por primera vez los kosmetés, cosmetriae y ornatrices, personas dedicadas al cuidado de la belleza corporal y peluquería. En el siglo XVIII, Francia se abre camino como ciudad de la moda y del maquillaje a través de la ostentación en el embellecimiento del cuerpo y cabello, esto cambió poco tiempo después donde el maquillaje recomendado en Inglaterra era sencillo y sutil. (Piergiorgio, 2012)

Alrededor del siglo XX el cuidado de la belleza en la mujer se tornó parte de las costumbres, es así como aparecieron los primeros salones de belleza siendo éste un centro de tratamientos estéticos como corte de cabello, manicure, peinados y maquillajes.

Según Monefel (como se cita en Cohen, 2013), el salón de belleza moderno como idea de negocio fue implementado por Martha Matilde Harper (1857-1950) quien introdujo la idea de belleza como signo de buena salud, fue así como la idea de negocio de los salones de belleza se hizo popular entre las mujeres emprendedoras. 
Ya en la actualidad, el cuidado de la imagen personal ya es una necesidad entre hombres y mujeres en todo el mundo, siendo ahora parte de la canasta familiar. En Perú, los servicios de tratamiento del cabello y tratamientos estéticos para las mujeres de hoy representan el $10 \%$ y $15 \%$ de su sueldo. (elcomercio.pe, 2015)

Por otro lado, el negocio de salones de belleza ha ido evolucionando desde franquicias, salones de belleza premium, barber shops y otros según las necesidades de los consumidores. Además, debido a la poca disponibilidad de tiempo por temas laborales y/o familiares han venido desarrollándose otras alternativas innovadoras para el cuidado personal con la finalidad de satisfacer la demanda en lo que respecta a la imagen ya sea tanto del hombre como de la mujer, el cuidado de las manos, pies, entre otros.

Es por eso, que en diferentes países se están implementando diversas formas de complacer al público teniendo esa comodidad y tiempo que tanto busca y no lo tiene por falta de un servicio que se adecue a sus tiempos libres.

Según Garijo (2014) en las calles de París, Boudoir des Coquetes ofrece a las ciudadanas un salón de belleza cerca a los centros empresariales donde pueden realizar servicios rápidos de belleza en una furgoneta rosa, también Nail Truck, un auto caravana gris ofrece servicios de manicure cerca de lugares con mayor afluencia.

Por otro lado, Garijo también menciona que en las calles de Nueva York el Beauty Bus recorre Manhattan acercando los servicios de un conocido estilista a los lugares con mayor demanda.

México también ofrece algunos servicios de salón de belleza móviles como por ejemplo Oh my polish! que ofrece servicios de manicure y pedicure realizados por una abogada en la ciudad de Veracruz. Pamela Sánchez, profesional de mercadotecnia, echó a andar la idea del 
Beuty Bar Bus brindando servicios de belleza a domicilio, enfatizando en dar una experiencia distinta adaptada a las mujeres trabajadoras de la ciudad de México.

\subsection{Determinación del problema u oportunidad}

La mujer peruana de hoy realiza muchas cosas a la vez; trabaja, estudia, se dedica al hogar y se preocupa por ella misma, además la cantidad de mujeres que trabajan se ha incrementado en un 23,2\% en los últimos 10 años (INEI, 2016).

Por otro lado, la demanda de los servicios de salones de belleza muestra un crecimiento gradual para el año 2017 y según Flores (2015a) menciona que los salones de belleza solo tienen una penetración del mercado de $30 \%$.

Es por lo que se observa una oportunidad de negocio para una demanda parcialmente insatisfecha a la espera de un servicio de calidad que le brinde la satisfacción de cuidado personal. Además, el plan de negocio propone una idea innovadora al brindar una experiencia diferente al ser atendido en un salón de belleza móvil, ya que ofrecerá servicios de corta duración en una ubicación cercana para las mujeres que solo requieran servicios básicos de belleza.

Desde el punto de vista del negocio, se observa también la oportunidad de la flexibilidad de las diferentes ubicaciones permitiendo que el negocio pueda trasladarse de una posición a otra en busca de una captación mayor de clientes, además el plan de negocio considera un ahorro considerable de costos fijos al no tener gastos relacionados a alquiler de local y servicios básicos para brindar los servicios de belleza. 


\subsection{Justificación del Proyecto}

El presente plan de negocio tiene las siguientes justificaciones:

a. Social: Brindar la facilidad de acceder a servicios de belleza de corto tiempo, evitando el estrés por conseguir una cita en horarios que se adecuen a la disponibilidad del usuario, evitando que los clientes tengan que trasladarse a una ubicación lejana. Los salones de belleza móviles también se encontrarán en puntos bastante concurridos y ofrecerán una experiencia distinta de servicios de calidad a precios competitivos.

b. Económico: El plan de negocio permite evaluar la viabilidad del negocio para ofrecer a los inversionistas una rentabilidad mayor a un salón de belleza común, ya que tendrá costos bajos al evitar el alquiler o compra de un local para brindar los servicios y además la ubicación en zonas estratégicas de alto tránsito permitirá acceder a mayor demanda. Por otro lado, este tipo de negocio mitiga el riesgo de poca afluencia de público al salón de belleza, ya que este negocio tiene la ventaja de movilizarse a lugares con una mayor afluencia, para así poder conseguir mayor cantidad de clientes.

c. Académica: El plan de negocio permite a los autores aplicar los conocimientos adquiridos durante el estudio de Maestría de Ciencias Empresariales.

\subsection{Objetivos del proyecto}

\subsubsection{Objetivo general.}

Desarrollar un plan de negocio para la implementación de salones de belleza móviles para las mujeres de la zona dos de Lima Metropolitana. 


\subsubsection{Objetivos específicos.}

a. Identificar las potencialidades y características del sector de salones de belleza validando la existencia de la oportunidad de negocio para los salones de belleza móviles y así poder proyectar el mercado objetivo a atender.

b. Realizar el estudio técnico de la implementación del plan de negocio estableciendo así la inversión y costos basados en los procesos, equipamiento, tamaño, localización y marketing.

c. Definir los aspectos organizacionales de la empresa, así como perfiles de puestos claves y sistema de remuneraciones.

d. Realizar el análisis económico y financiero con el fin de identificar la existencia de rentabilidad para los inversionistas.

\subsection{Alcances y limitaciones de la investigación}

\subsubsection{Alcance.}

El alcance del estudio se limita a la elaboración completa de un plan de negocio para implementar salones de belleza móviles para mujeres de la zona dos de Lima Metropolitana, que concluye en un análisis económico y financiero para validar la existencia de rentabilidad del negocio según los parámetros establecidos en la ingeniería del proyecto, aspectos organizacionales, plan de marketing y otros elementos que componen el presente plan de negocio. 


\subsubsection{Limitaciones.}

- Información actualizada necesaria para el proyecto.

- Acceso a la información de la competencia.

- $\quad$ Acceso a la información del sector.

- Acceso al público para la realización de las encuestas, focus group y entrevistas. 


\section{Capítulo II. Estructura Económica del Sector}

\subsection{Descripción del estado actual de la industria}

El salón de belleza móvil pertenecerá a la actividad económica 9602-Peluquería y otros tratamientos de belleza, según la Clasificación Industrial Internacional Uniforme (CIIU) de INEI. Debido a la mejora económica en el país, la industria de la belleza tiene un crecimiento considerable en los últimos años como consecuencia de la evolución en las tendencias de los diferentes países. La belleza de la persona y el cuidado de la imagen personal tienen una importancia relevante porque representa una oportunidad de negocio en dicho sector.

Luis Goytizolo, gerente general de la cadena peruana Listas, explicó que al no contarse con una base de datos del sector belleza, el Comité Peruano de Cosmética e Higiene Personal (COPECOH), de la Cámara de Comercio de Lima, estima que existen 50 mil salones de belleza en todo el Perú, siendo estas las cadenas de peluquerías y los salones de belleza de forma independiente que darían este servicio. (Flores, 2015b)

Ángel Acevedo presidente de COPECOH menciona que el sector belleza genera \$ 2,200 millones al año, generando una oportunidad de crecimiento para cadenas y salones de belleza independientes. Afirmó también que las mujeres de población urbana entre 20 a 35 años en el Perú consumen un promedio de $\$ 600$ al año en productos de belleza, siendo la mitad del consumo que se genera en Venezuela o Brasil, con un promedio de \$1,200 anuales, representando así una oportunidad de crecimiento en este sector. (rpp.pe, 2015) 
Ángel Acevedo presentó el estudio de inteligencia comercial del sector Cosméticos e Higiene del primer semestre 2016, donde se muestra un crecimiento del 6\% para el año 2016, y de 8\% anual para el año 2017 llegando a un 10\% para el año 2020, ofreciendo una demanda en crecimiento que llegaría a tener un público insatisfecho por la poca disponibilidad del servicio, lo que ayudaría a las cadenas de salones de belleza, peluquerías y spas a presentar ideas innovadoras y crecer mejorando su gestión. (gestion.pe, 2016a)

\subsubsection{Segmentación de la industria.}

Debido al crecimiento acelerado en el sector belleza, los salones de belleza independientes comenzaron a especializarse, además de utilizar productos nuevos y de mejor calidad. Este crecimiento trajo la necesidad de actualizarse y conocer sobre la tendencia de la moda, es por lo que se incrementan los centros de estudio en cosmetología, los productores de los diferentes insumos de la belleza producían en mayores cantidades para atender las demandas, y así poder completar el círculo de la industria de la belleza: productor - educador - distribuidor - salón de belleza. (Ver Tabla 1) 
Tabla 1

Segmentación de mercado

\begin{tabular}{ll}
\hline Segmento & \multicolumn{1}{c}{ Descripción } \\
\hline Productor & $\begin{array}{l}\text { Instituciones que fabrican productos que los especialistas en } \\
\text { cosmetología utilizan para dar un servicio de calidad. }\end{array}$ \\
\hline Educador & $\begin{array}{l}\text { Son las instituciones que brindan cursos de cosmetología y/o brindan } \\
\text { asesoramiento por intermedio de charlas o foros ya sean presenciales } \\
\text { o tutoriales por la web. }\end{array}$ \\
\hline Distribuidor & $\begin{array}{l}\text { Son los encargados de la distribución de los productos a los salones } \\
\text { de belleza, dando como valor agregado del producto algún tipo de } \\
\text { demostraciones de aplicación y uso. }\end{array}$ \\
\hline Salón de belleza & $\begin{array}{l}\text { Lugar donde se realizan todos los servicios de cosmetología: cortes, } \\
\text { tintes, peinados permanentes, alisados, extensiones de cabello, } \\
\text { maquillaje profesional, cuidados de la piel, manicuras, pedicuras, etc. }\end{array}$ \\
\hline
\end{tabular}

Paul Cabrera Plascencia, director general de Expobeauty, menciona que, en el año 2013, de los 30,000 salones de belleza, el 50\% se encuentran en la ciudad de Lima en los distritos de Jesús María, San Juan de Miraflores, San Juan de Lurigancho y San Martín de Porres, siendo estos formales y existiendo un $43 \%$ dentro de la informalidad. Esto es debido a que las personas que terminan estudios en los institutos de belleza tienen la opción de abrir un negocio de salón de belleza, ya que les resulta un negocio muy rentable con una facturación de S/ 10 mil a S/ 15 mil al mes. (Ochoa, 2013)

Con lo que respecta al gasto, una persona gastaría en promedio S/ 90, por ejemplo, en el segmento AB gasta entre S/ 600 a S/ 1200 con tratamientos corporales y coloración, y en el segmento C gasta como mínimo S/ 120 al mes en servicios básicos de un salón de belleza. (Ochoa, 2013)

Esta demanda que viene creciendo en los diferentes Niveles Socio Económicos (NSE), la cual va de la mano con una maduración temprana de los jóvenes debido a sus 
preferencias e imitación de sus ídolos de televisión y musicales, creando una necesidad por verse atractivas y detallistas con su imagen.

\subsubsection{Empresas que la conforman.}

Dentro de las empresas que conforman el segmento de la industria de la belleza se tiene a productores (ver Tabla 2), educadores (ver Tabla 3), distribuidores (ver Tabla 4) y salones de belleza (ver Tabla 5).

Tabla 2

Empresas que pertenecen a productores de la industria

\begin{tabular}{ll}
\hline Empresa & \multicolumn{1}{c}{ Descripción } \\
Kara Natural & $\begin{array}{l}\text { Son productos de cuidado corporal en base a frutos, granos, y plantas } \\
\text { que produce el Perú. Kara Natural crea productos haciendo uso de } \\
\text { ingredientes naturales. }\end{array}$ \\
\hline Laboratorios & $\begin{array}{l}\text { Desde 1975 Laboratorios Valquer investiga desarrolla y fabrica } \\
\text { productos cosméticos (peluquería estética, perfumería, y otros), tiene }\end{array}$ \\
& $\begin{array}{l}550 \text { fórmulas propias y cuenta con una fábrica de más de 12,000 metros } \\
\text { cuadrados. }\end{array}$ \\
\hline Laboratorios & $\begin{array}{l}\text { Desde 1993 esta empresa peruana que produce la marca Cosmética } \\
\text { Lacovat }\end{array}$ \\
& $\begin{array}{l}\text { Profesional Brillant, combina ciencia, arte y tecnología produciendo } \\
\text { cosméticos de tratamientos estéticos y dermatológicos. }\end{array}$ \\
\hline Natura & $\begin{array}{l}\text { Desde 1969, esta empresa de origen brasileño desarrolla productos de } \\
\text { belleza, integrando ciencia y conocimiento de las comunidades }\end{array}$ \\
& $\begin{array}{l}\text { tradicionales para la creación de cosméticos. } \\
\text { Esta empresa trabaja con modelos de venta directas mediante } \\
\text { consultoras de belleza. }\end{array}$ \\
\hline Belcorp & $\begin{array}{l}\text { Empresa peruana con más de 48 años de experiencia que produce las } \\
\text { marcas L'Bel, Ésika y Cyzone. }\end{array}$ \\
& $\begin{array}{l}\text { Presente en 15 países de América con más de 8,500 trabajadores. } \\
\text { Esta empresa trabaja con modelos de venta directas mediante } \\
\text { consultoras de belleza. }\end{array}$ \\
\hline
\end{tabular}


Tabla 3

Empresas que pertenecen a educadores de la industria

\begin{tabular}{ll}
\hline Empresa & \multicolumn{1}{c}{ Descripción } \\
\hline Selene & $\begin{array}{l}\text { Instituto fundado en 1985 que brinda servicios de diseño de modas, } \\
\text { cosmiatría y cosmetología ubicado en distintos distritos de Lima } \\
\text { Metropolitana. }\end{array}$ \\
\hline $\begin{array}{l}\text { Devale - Escuela } \\
\text { Superior de } \\
\text { Belleza }\end{array}$ & $\begin{array}{l}\text { Empresa peruana consolidada en el mercado de la belleza, se ubica en } \\
\text { los distritos de Surco, Lince y San Juan de Lurigancho. }\end{array}$ \\
\hline $\begin{array}{l}\text { Montalvo } \\
\text { Instituto }\end{array}$ & $\begin{array}{l}\text { Centro de educación que pertenece a Montalvo Group, el cual } \\
\text { desarrolla capacidades laborales en estética personal basado en } \\
\text { modelo de competencias a través de conceptos de belleza y } \\
\text { capacitación constante. }\end{array}$ \\
\hline $\begin{array}{l}\text { Cetro Peruana de } \\
\text { Cosmiatría } \\
\text { Brillant (CPCB) }\end{array}$ & $\begin{array}{l}\text { Empresa peruana que forma especialistas en cosmetología, pertenece a } \\
\text { Laboratorios Lacovat. Cuenta con infraestructura certificada. }\end{array}$ \\
\end{tabular}

Tabla 4

Empresas que pertenecen a distribuidores de la industria

\begin{tabular}{|c|c|}
\hline Empresa & Descripción \\
\hline L' Oréal & $\begin{array}{l}\text { Creada en 1907, es una empresa de origen francés que está centrada en } \\
\text { distribuir productos para cuidado de cabello y piel, maquillaje y } \\
\text { perfumes. }\end{array}$ \\
\hline $\begin{array}{l}\text { Distribuidores } \\
\text { locales }\end{array}$ & Diversas empresas que venden productos belleza al por menor y mayor. \\
\hline $\begin{array}{l}\text { Consultoras de } \\
\text { belleza }\end{array}$ & $\begin{array}{l}\text { Personas naturales que distribuyen productos de belleza de empresas } \\
\text { como Natura, Unique, Cyzone, L'bel y otros. }\end{array}$ \\
\hline
\end{tabular}


Tabla 5

Empresas que pertenecen a peluquería, salones de belleza y otros

\begin{tabular}{ll}
\hline Empresa & \multicolumn{1}{c}{ Descripción } \\
\hline Montalvo Spa & Es la cadena de peluquerías y spa más grande del Perú. \\
& Cuenta con más de 42 locales en todo el país, 1,800 operaciones \\
& diarias. Alrededor de 120,000 visitas a los salones por mes, \\
& Montalvo es una de las empresas de mayor crecimiento en el sector \\
& de la peluquería y spa a nivel nacional, proyectándose a abrir cinco \\
& salones por año, una de las modalidades de expansión es el \\
& franquiciado a los salones independientes.
\end{tabular}

\subsection{Tendencias de la industria}

La empresa de investigación de mercado Euromonitor International dio a conocer las principales tendencias a nivel región, resaltando diferencias que sirven para un mejor desarrollo de las empresas, campañas de marketing e innovación de productos. En América Latina la industria de la belleza y el cuidado personal ha venido evolucionando con las nuevas tendencias de cuidado de la imagen personal, debido a cambios de hábitos, interés de algunos hombres por verse mejor, y el crecimiento económico de las clases han ido motivando el desarrollo y han 
vuelto a la región un escenario atractivo para las diferentes marcas extranjeras y sobre todo las de tendencias ecológicas.

Es así, que se menciona a continuación a los países con tendencias y preferencias en cuanto a productos de belleza, cremas corporales y mantenimiento de cabello, y como punto importante en el mercado la inclusión de los hombres en este rubro de la belleza. (Euromonitor International, 2014)

Argentina: Reemplazó a los proveedores extranjeros por nacionales e incrementó las licencias de locales nacionales. A raíz de las dificultades por la cadena logística, los consumidores prefieren el reemplazo del producto que la lealtad a la marca.

Por otro lado, los esmaltes de uñas están desplazando al lápiz labial. De estos productos la marca Maybelline y Avon son las más competitivas y las más vendidas.

Brasil: El sector masculino se está posicionando en el mercado, presentando una gran demanda porque está dispuesto a experimentar con la condición de verse y mantenerse con una presentación personal limpia y tratada para un mejor cuidado de la piel.

Chile: Los productos han tomado un posicionamiento importante, existen marcas y productos de mayor calidad y de lujo logrando un mayor crecimiento en el año 2013.

El cuidado de la piel es un tema en el que tanto mujeres como hombres han prestado interés, debido a que las cifras de la población chilena tienen un índice alto de envejecimiento.

Colombia: La mujer ha reducido el cuidado personal llegando a usar cremas multifuncionales y humectantes con tinte Moiskin de Amway. Se diferencia la clase alta con productos premium y la clase baja con productos de marcas alternativas. 
Ecuador: Se influencia mucho por el cuidado de su apariencia usando productos para el cuidado corporal y presentación personal, inclusive siendo más importante que la alimentación en algunos casos. Los productos de mayor rotación y demanda en el mercado ecuatoriano son brillo labial, delineador de ojos y rímel.

Uruguay: Desarrollo de nuevos productos antienvejecimiento liderados por varias empresas internacionales. Además, los productos para las uñas siguen experimentando un fuerte crecimiento debido a que son usados como accesorio adicional para complementar el estilo personal.

Perú: Incremento de la demanda de productos de belleza, cuidado de la piel y productos más especializados, incluyendo los de higiene íntima.

Los consumidores de sexo masculino se están incrementando en forma progresiva año tras año, siendo uno de los primeros productos los del cuidado del cabello con productos de calidad y premium. Las marcas Unique y Esika se han posicionado como uso diario en maquillaje, protección solar y lápiz de labios de las mujeres limeñas.

Otro tipo de cosméticos usados con mayor cantidad son los esmaltes, las cremas corporales y faciales, las cuales se tiene al alcance de todos en los diferentes centros de cosmetología, centros comerciales, tiendas por departamentos, etc. (Euromonitor International, 2014) 


\subsection{Análisis Estructural del Sector Industrial}

Se aplicará el análisis de Porter de las fuerzas del mercado, en este análisis se usan conceptos de organización industrial y economía en donde se identifican cinco fuerzas que determinan la intensidad de la competencia y el atractivo de un mercado. Porter indica a estas fuerzas como micro entorno, ya que se refieren a fuerzas cercanas a la empresa que impactan en la capacidad de ofrecer a sus clientes y obtener un beneficio; además, un cambio en estas fuerzas lleva como consecuencia que la empresa deba revaluar su situación estratégica en el mercado. (Alonso, 2014)

\subsubsection{Poder de negociación de los clientes.}

El poder de negociación de los clientes es aquel poder que tienen clientes y consumidores para obtener precios y condiciones de su conveniencia, generalmente, mientras menor sea la cantidad clientes, tendrán mayor poder de negociación por la baja demanda que generan y puede condicionar el negocio de una empresa. (Alonso, 2014)

En la industria de la belleza se considera que el poder es bajo ya que los clientes tienen poca capacidad de negociación en los precios establecidos para los servicios ofrecidos, sus exigencias tienen relación con la calidad del servicio que recibe.

a. Opciones de salones de belleza locales

Se debe considerar que existen varios salones de belleza locales en los distritos y estos han aumentado en los últimos años. Los clientes podrían elegir los salones de belleza locales sobre la propuesta de negocio, sin embargo, también los consumidores tendrían que afrontar pérdida de tiempo al trasladarse y/o al esperar ser atendidos. 
b. Único salón de belleza móvil

Ser el primero en ingresar como un salón de belleza móvil permitirá ser posicionado en la mente del consumidor, por lo que el poder de atractividad es alto. Se deberá tener en cuenta que los clientes consideran de importancia tener a un estilista que ya conocen, por lo que se deberá trabajar en la calidad de servicio que los estilistas del salón de belleza móvil ofrecen.

c. Nivel de precio

En muchos sectores la inversión en cuidado de belleza ya se considera dentro de la canasta familiar, sin embargo, el gasto en los servicios de belleza depende de la calidad de productos exigidos por los clientes. Así mismo, se considera que el negocio deberá trabajar en paquetes con precios atractivos para grupos de personas o familiares ya que el servicio se brindará a domicilio y los clientes podrían tomar ventaja que el salón de belleza móvil se encuentra en su ubicación para requerir servicios adicionales para familiares o amigos (as). 
Tabla 6

Matriz de atractividad para el poder de negociación de los clientes

\begin{tabular}{|c|c|c|c|c|c|}
\hline $\begin{array}{l}\text { Elemento de } \\
\text { análisis }\end{array}$ & Poder & $\begin{array}{l}\text { Factor } \\
\text { de } \\
\text { relevan- } \\
\text { cia }\end{array}$ & $\begin{array}{l}\text { Criterios que lo } \\
\text { hacen poco atractivo }\end{array}$ & $\begin{array}{l}\text { Grado } \\
\text { de } \\
\text { Atrac- } \\
\text { tividad }\end{array}$ & $\begin{array}{l}\text { Criterios que lo } \\
\text { hacen muy atractivo }\end{array}$ \\
\hline $\begin{array}{l}\text { Opciones de } \\
\text { salones de } \\
\text { belleza locales }\end{array}$ & Alto & 0.4 & $\begin{array}{l}\text { Salones de belleza } \\
\text { locales pueden } \\
\text { brindar los mismos } \\
\text { servicios }\end{array}$ & 4 & $\begin{array}{l}\text { Cliente puede ahorrar } \\
\text { tiempo ya que no tiene } \\
\text { que trasladarse ni } \\
\text { esperar a ser atendido. }\end{array}$ \\
\hline $\begin{array}{l}\text { Único salón de } \\
\text { belleza móvil }\end{array}$ & Medio & 0.3 & $\begin{array}{l}\text { Al ser un negocio } \\
\text { nuevo los clientes no } \\
\text { tienen un estilista } \\
\text { conocido }\end{array}$ & 4 & $\begin{array}{l}\text { Ser el único salón de } \\
\text { belleza móvil. }\end{array}$ \\
\hline Nivel de precio & Medio & 0.3 & $\begin{array}{l}\text { Margen adicional en } \\
\text { los servicios debido } \\
\text { al traslado del salón } \\
\text { de belleza }\end{array}$ & 2 & $\begin{array}{l}\text { Paquetes por grupos de } \\
\text { personas en el punto de } \\
\text { la cita. }\end{array}$ \\
\hline $\begin{array}{l}\text { Resultado } \\
\text { ponderado }\end{array}$ & Alto & 1 & & 3.4 & \\
\hline
\end{tabular}

Según la Tabla 6, la atractividad para el poder de negociación de los clientes es de 3.4 y presenta un poder bajo para el negocio.

\subsubsection{Poder de negociación de los proveedores.}

Porter hace referencia al poder que tienen los proveedores dentro de la industria para alzar sus precios e imponer sus condiciones en el mercado, mientras menos proveedores existan en el mercado o más particular sea su producto o servicio tendrán mayor poder de negociación. (Alonso, 2014)

Actualmente en la industria de la belleza la oferta de productos y servicios es amplia y tiene muchas variables, esto ocasiona que las empresas deban adaptarse a las 
solicitudes de los potenciales clientes, es por lo que se considera que el poder de negociación de los proveedores es bajo.

a. Cosmetólogas y estilistas especializados

Existe una oferta creciente de personal para salones de belleza debido al incremento de centros de estudios, además los clientes consideran que un factor importante para solicitar el servicio en un salón de belleza son las cosmetólogas y estilistas especializados.

El plan de negocio considera una buena selección de estilistas al momento de la búsqueda de personal.

b. Productos importados

Existe gran variedad de productos importados sin embargo se debe de considerar que estos sean de calidad y a buen precio. Los tratados de libre comercio facilitan la importación de estos productos y que los costos por impuestos sean bajos.

c. Costes de cambio altos para proveedores de servicio

Cada proveedor de servicio genera una relación con el cliente, ya que son ellos quienes brindan el servicio. Se debe considerar que algunos clientes eligen un salón de belleza debido a algún estilista de su preferencia, además si existe cambios de estilistas constantemente esto generará dudas sobre la calidad de servicio que los nuevos estilistas puedan ofrecer. 
Tabla 7

Matriz de atractividad para el poder de negociación de los proveedores

\begin{tabular}{|c|c|c|c|c|c|}
\hline $\begin{array}{l}\text { Elemento de } \\
\text { análisis }\end{array}$ & Poder & $\begin{array}{l}\text { Factor de } \\
\text { relevancia }\end{array}$ & $\begin{array}{l}\text { Criterios que } \\
\text { lo } \\
\text { hacen poco } \\
\text { atractivo }\end{array}$ & $\begin{array}{l}\text { Grado de } \\
\text { atractividad }\end{array}$ & $\begin{array}{l}\text { Criterios que lo } \\
\text { hacen muy } \\
\text { atractivo }\end{array}$ \\
\hline $\begin{array}{l}\text { Cosmetólog } \\
\text { as y } \\
\text { estilistas } \\
\text { especializad } \\
\text { as }\end{array}$ & Alto & 0.4 & $\begin{array}{l}\text { Estilistas } \\
\text { nuevos }\end{array}$ & 4 & $\begin{array}{l}\text { Estilistas } \\
\text { especializados } \\
\text { seleccionados } \\
\text { rigurosamente }\end{array}$ \\
\hline $\begin{array}{l}\text { Productos } \\
\text { importados }\end{array}$ & Alto & 0.4 & $\begin{array}{l}\text { Productos de } \\
\text { baja calidad }\end{array}$ & 3 & $\begin{array}{l}\text { Diversidad de } \\
\text { productos } \\
\text { importados y alta } \\
\text { competencia en } \\
\text { precios }\end{array}$ \\
\hline $\begin{array}{l}\text { Costes de } \\
\text { cambio } \\
\text { altos para } \\
\text { proveedores } \\
\text { de servicio }\end{array}$ & Bajo & 0.2 & $\begin{array}{l}\text { Alta relación } \\
\text { de confianza } \\
\text { entre } \\
\text { estilista- } \\
\text { cliente }\end{array}$ & 2 & $\begin{array}{l}\text { Existe mucha } \\
\text { competencia de } \\
\text { proveedores de } \\
\text { servicio }\end{array}$ \\
\hline $\begin{array}{l}\text { Resultado } \\
\text { ponderado }\end{array}$ & Alto & 1 & & 3.2 & \\
\hline
\end{tabular}

Según Tabla 7, la atractividad para el poder de negociación de los proveedores es de 3.2 y presenta un poder de negociación bajo para la empresa.

\subsubsection{Amenaza de los nuevos competidores.}

Porter refiere que en esta fuerza hay que analizar las barreras de entrada y de salida que existen en la industria para determinar el nivel de competencia, mientras más bajas sean las barreras de entrada y altas las barreras de salida serán mayor la competitividad dentro de la industria (Alonso, 2014).

En la industria de la belleza se determina que las barreras de entrada son bajas ya que la inversión para iniciar un negocio puede ser mínima, además, la cantidad de 
cosmetólogas y estilistas se ha incrementado en la actualidad por el aumento de institutos de belleza, brindándoles la posibilidad de iniciar su negocio propio. Se considera que las barreras de salida son bajas ya que existen mecanismos que facilitan la salida del mercado como el traspaso de negocio o rompimiento de sociedades, en muchos casos, algunos inversionistas esperan culminar el contrato de alquiler para liquidar el negocio.

El nivel de amenaza de ingreso de nuevos competidores en esta industria es medio.

a. Economía nacional

La mejora en la economía del Perú promueve la creación de nuevos negocios para emprendedores.

b. Costos de alquiler de local

El costo de alquiler de local para los nuevos competidores es una barrera de ingreso ya que al ser un costo fijo y ser un negocio nuevo, mantenerse en el mercado al inicio requerirá de un buen financiamiento.

c. Necesidad de capital

El capital al inicio de negocio si bien no es alto es considerable debido a los costos fijos que se deben mantener y a la adquisición de equipamiento para asegurar un buen servicio. 
Tabla 8

Matriz de atractividad para la amenaza de los nuevos competidores

\begin{tabular}{|c|c|c|c|c|c|}
\hline $\begin{array}{l}\text { Elemento de } \\
\text { análisis }\end{array}$ & Poder & $\begin{array}{l}\text { Factor } \\
\text { de } \\
\text { relevan- } \\
\text { cia }\end{array}$ & $\begin{array}{l}\text { Criterios que } \\
\text { lo } \\
\text { hacen poco } \\
\text { atractivo }\end{array}$ & $\begin{array}{l}\text { Grado de } \\
\text { Atrac- } \\
\text { tividad }\end{array}$ & $\begin{array}{l}\text { Criterios que lo } \\
\text { hacen muy } \\
\text { atractivo }\end{array}$ \\
\hline $\begin{array}{l}\text { Economía } \\
\text { nacional }\end{array}$ & Medio & 0.2 & $\begin{array}{l}\text { Nuevos } \\
\text { emprendedore } \\
\mathrm{s}\end{array}$ & 2 & $\begin{array}{l}\text { Las empresas ya } \\
\text { establecidas } \\
\text { pueden crecer. }\end{array}$ \\
\hline $\begin{array}{l}\text { Costos de } \\
\text { alquiler de } \\
\text { local }\end{array}$ & Alto & 0.4 & $\begin{array}{l}\text { Tener un } \\
\text { local permite } \\
\text { que pueda } \\
\text { atender a una } \\
\text { localidad }\end{array}$ & 3 & $\begin{array}{l}\text { No costos en local } \\
\text { debido a que es } \\
\text { móvil }\end{array}$ \\
\hline $\begin{array}{l}\text { Necesidad de } \\
\text { capital }\end{array}$ & Alto & 0.4 & $\begin{array}{l}\text { Facilidades de } \\
\text { financiamient } \\
\text { o para } \\
\text { emprendedore } \\
\text { s }\end{array}$ & 2 & $\begin{array}{l}\text { Tasas más bajas } \\
\text { para empresas ya } \\
\text { establecidas }\end{array}$ \\
\hline $\begin{array}{l}\text { Resultado } \\
\text { ponderado }\end{array}$ & Alto & 1 & & 2.4 & \\
\hline
\end{tabular}

Según Tabla 8, la atractividad para la amenaza de los nuevos competidores es de 2.4 y presenta una amenaza media para el negocio.

\subsubsection{Amenaza de productos y servicios sustitutos.}

Se refiere al análisis del ingreso de potenciales competidores al mercado que ofrecen productos y/o servicios similares dentro de la industria, la presencia de productos y servicios sustitutos puede delimitar los precios de oferta dentro del mercado, esta situación permite a las empresas implementar estrategias para evitar la entrada nuevas empresas.

En la industria se determina como productos sustitutos a las academias de belleza que ofrecen el servicio a un menor precio y calidad, otros productos sustitutos son los 
usados por los mismos clientes en casa que pueden cubrir algunos servicios básicos como peinados, laceados, etc. es por lo que se determina que el nivel de esta fuerza es bajo.

a. Productos/servicios sustitutos existentes

Existen productos sustitutos como equipos que facilitan los cuidados de belleza de las mujeres como cepillo alisador, plancha rizadora, aprendizaje de maquillaje a través de internet, manicure y pedicure en casa.

b. Sustitutos no cubren expectativa del cliente

Sustitutos son usualmente caseros y no realizados por personas especializadas en el cuidado de belleza, los resultados no son los mismos que realizarlos en un salón de belleza y muchas veces no cubren las expectativas de los clientes de la misma manera que un salón.

Tabla 9

Matriz de atractividad para la amenaza de productos y servicios sustitutos

\begin{tabular}{llllll}
\hline $\begin{array}{l}\text { Elemento de } \\
\text { análisis }\end{array}$ & Poder & $\begin{array}{l}\text { Factor } \\
\text { de } \\
\text { relevan- } \\
\text { cia }\end{array}$ & $\begin{array}{l}\text { Criterios que } \\
\text { lo } \\
\text { hacen poco } \\
\text { atractivo }\end{array}$ & $\begin{array}{l}\text { Grado de } \\
\text { Atrac- } \\
\text { tividad }\end{array}$ & $\begin{array}{l}\text { Criterios que lo } \\
\text { hacen muy atractivo }\end{array}$ \\
\hline $\begin{array}{l}\text { Productos/servic } \\
\text { ios sustitutos } \\
\text { existentes }\end{array}$ & Alto & 0.6 & $\begin{array}{l}\text { Sustitutos a } \\
\text { menor costo }\end{array}$ & 4 & $\begin{array}{l}\text { Ahorro de tiempo y } \\
\text { esfuerzo. }\end{array}$ \\
\hline $\begin{array}{l}\text { Sustitutos no } \\
\text { cubren } \\
\begin{array}{l}\text { expectativa del } \\
\text { cliente }\end{array}\end{array}$ & Medio & 0.4 & $\begin{array}{l}\text { No siempre } \\
\text { cubre la } \\
\text { expectativa } \\
\text { esperada }\end{array}$ & 3 & $\begin{array}{l}\text { Servicio realizado } \\
\text { por especialistas }\end{array}$ \\
\hline $\begin{array}{l}\text { Resultado } \\
\text { ponderado }\end{array}$ & Alto & 1 & & 3.6 & \\
\hline
\end{tabular}

Según Tabla 9, la atractividad para la amenaza de los productos y servicios sustitutos es de 3.6 y presenta una amenaza baja para el negocio. 


\subsubsection{La rivalidad entre los competidores existentes.}

Considerada como la fuerza más poderosa de todas ya que se refiere a la rivalidad entre las empresas que compiten en la misma industria, ofreciendo el mismo producto y/o servicio, mientras más fuerte sea la competencia, trae como consecuencia la disminución de ganancia y con ello el ingreso de nuevos competidores, además el análisis de esta rivalidad permite a las empresas la implementación de nuevas estrategias para superar a los rivales.

Para el caso de la industria de la belleza se determina que el impacto de la fuerza es alto ya que actualmente existe mucha oferta en el mercado, originando que las empresas deban innovar en el servicio ofrecido constantemente para cubrir las exigencias de los clientes.

a. Competencia de salones de belleza con local fijo

Los salones de belleza tienen un local fijo, las cadenas de salones pueden estar en varios distritos. El salón de belleza móvil irá al domicilio del cliente y se ubicará en puntos estratégicos de mayor afluencia de clientes potenciales.

b. Competencia de estilistas a domicilio

Los estilistas a domicilio no tienen gastos fijos y también atienden hasta el domicilio del cliente sin embargo hacen uso de recursos del cliente como agua, luz, limpieza, lugar adecuado entre otros. El salón de belleza móvil tendrá todos sus recursos e infraestructura dentro del móvil.

c. Incremento de competidores informales

Los competidores informales pueden manejar precios más bajos para el cliente sin embargo pueden incurrir en multas o cierres temporales. 
d. Diferenciación de servicio

El salón de belleza móvil ofrecerá una diferenciación del servicio basado en la atención a domicilio con infraestructura propia. Además, los clientes podrán encontrar los servicios que brinda el salón de belleza móvil en diferentes puntos de la zona.

e. Crecimiento de la demanda

En las últimas décadas se puede ver un incremento de la demanda de cuidado personal y belleza por parte de hombres y mujeres en Lima Metropolitana. 
Tabla 10

Matriz de atractividad de la rivalidad entre los competidores existentes

\begin{tabular}{|c|c|c|c|c|c|}
\hline $\begin{array}{l}\text { Elemento de } \\
\text { análisis }\end{array}$ & Poder & $\begin{array}{l}\text { Factor } \\
\text { de } \\
\text { relevan- } \\
\text { cia }\end{array}$ & $\begin{array}{c}\text { Criterios que } \\
\text { lo } \\
\text { hacen poco } \\
\text { atractivo }\end{array}$ & $\begin{array}{c}\text { Grado de } \\
\text { Atrac- } \\
\text { tividad }\end{array}$ & $\begin{array}{c}\text { Criterios que lo } \\
\text { hacen muy } \\
\text { atractivo }\end{array}$ \\
\hline $\begin{array}{l}\text { Competencia de } \\
\text { salones de } \\
\text { belleza con local } \\
\text { fijo }\end{array}$ & Alto & 0.3 & Ubicación fija & 3 & $\begin{array}{l}\text { Servicio a } \\
\text { domicilio y } \\
\text { puntos } \\
\text { estratégicos }\end{array}$ \\
\hline $\begin{array}{l}\text { Competencia de } \\
\text { estilistas a } \\
\text { domicilio }\end{array}$ & Medio & 0.2 & $\begin{array}{c}\text { Servicio } \\
\text { dentro de la } \\
\text { intimidad del } \\
\text { hogar }\end{array}$ & 4 & $\begin{array}{l}\text { Uso de recursos e } \\
\text { implementos en } \\
\text { la infraestructura } \\
\text { propia del salón } \\
\text { de belleza }\end{array}$ \\
\hline $\begin{array}{l}\text { Incremento de } \\
\text { competidores } \\
\text { informales }\end{array}$ & Bajo & 0.1 & $\begin{array}{l}\text { Precios más } \\
\text { bajos }\end{array}$ & 2 & $\begin{array}{l}\text { Calidad de } \\
\text { servicio }\end{array}$ \\
\hline $\begin{array}{l}\text { Diferenciación } \\
\text { de servicio }\end{array}$ & Alto & 0.3 & $\begin{array}{l}\text { Variedad de } \\
\text { servicio en el } \\
\text { mercado }\end{array}$ & 2 & $\begin{array}{l}\text { Servicio a } \\
\text { domicilio y } \\
\text { puntos } \\
\text { estratégicos }\end{array}$ \\
\hline $\begin{array}{l}\text { Crecimiento de } \\
\text { la demanda }\end{array}$ & Bajo & 0.1 & $\begin{array}{c}\text { Mayor } \\
\text { demanda para } \\
\text { competidores }\end{array}$ & 1 & $\begin{array}{l}\text { Mayor demanda } \\
\text { para el salón de } \\
\text { belleza móvil }\end{array}$ \\
\hline $\begin{array}{l}\text { Resultado } \\
\text { ponderado }\end{array}$ & Alto & 1 & & 2.6 & \\
\hline
\end{tabular}

Según Tabla 10, la atractividad para la rivalidad entre competidores es de 2.6 y presenta un poder alto en la industria.

A manera de conclusión, se ha elaborado la matriz de atractividad para el análisis de la industria según las cinco fuerzas de Porter en la Tabla 11: 
Tabla 11

Matriz de atractividad del negocio

\begin{tabular}{lcl}
\hline Factores competitivos & $\begin{array}{c}\text { 1 < Atractividad } \\
\text { De 1: Muy poco } \\
\text { atractivo a 5: Muy } \\
\text { atractivo }\end{array}$ & Concepto \\
\hline $\begin{array}{l}\text { Poder de negociación de } \\
\text { los clientes }\end{array}$ & $\mathrm{X}$ & Bajo \\
\hline $\begin{array}{l}\text { Poder de negociación de } \\
\text { proveedores }\end{array}$ & $\mathrm{X}$ & Bajo \\
\hline $\begin{array}{l}\text { Amenaza de nuevos } \\
\text { competidores }\end{array}$ & $\mathrm{X}$ & $\begin{array}{l}\text { Baja posibilidad de ingreso de } \\
\text { competidores }\end{array}$ \\
\hline $\begin{array}{l}\text { Amenaza de productos y } \\
\text { servicios sustitutos }\end{array}$ & $\mathrm{X}$ & $\begin{array}{l}\text { Sector atractivo por la baja } \\
\text { amenaza de productos sustitutos }\end{array}$ \\
\hline $\begin{array}{l}\text { Rivalidad entre } \\
\text { competidores existentes }\end{array}$ & $\mathrm{X}$ & Alto nivel de competitividad \\
\hline Evaluación general & & Industria con buena atractividad \\
\hline
\end{tabular}

Se puede concluir que el negocio es atractivo en la industria de la belleza según el análisis realizado.

\subsection{Análisis de la Competencia}

\subsubsection{Empresas que ofrecen el mismo producto o servicio.}

Se describirá la competencia directa para el presente plan de negocio de salón de belleza móvil analizando tres empresas líderes en el mercado nacional:

a. Montalvo Salón y Spa, su horario de atención es de 10:00 a.m. a 10:00 p.m., su público objetivo es el sector A y B.

Utiliza como herramientas para publicidad su página web, redes sociales, revistas y medios de comunicación.

El catálogo de servicios es el siguiente:

- Segmenta sus servicios en mujer, hombre, teens, kids, novios y spa. 
- Cuidado del cabello y peluquería en general.

- Manicure / Pedicure.

- Estética facial y corporal

- Maquillaje

- Asesoría integral de imagen

b. Marco Aldany, su horario de atención es variable por cada local, dependiendo de la necesidad del mercado, pero se trata de cubrir todo el día, en promedio el horario es de 8:00 am a 10:00 pm, su sector objetivo es A y B.

Los servicios que ofrecen son los siguientes:

- Peluquería

- Estética

- Manicure / Pedicure

- Hidratación Capilar

- Tratamiento de proteínas para cabello

- Tratamiento de reparación de cabello

- Tratamiento anticaída de cabello

c. Soho Color Salón y Spa, su horario de atención es de lunes a domingo de 8:00 am a 9:00 pm, su público objetivo es el sector B y C.

Los servicios que ofrecen son los siguientes:

- Cortes y peinados

- Laceados permanentes

- Reacondicionamientos

- Extensiones 
- Maquillaje

- $\quad$ Manicure / Pedicure

- Depilación

- Spa

En comparación con el plan de negocio, los competidores Montalvo, Marco Aldany y Soho Color Spa ofrecen una diversidad de servicios ya que su inversión en infraestructura es alta, además, cuentan con una mayor cobertura debido a la cantidad de locales en diferentes zonas, sin embargo, el salón de belleza móvil ofrece servicios básicos para clientes de NSE C con la modalidad de la atención a domicilio y ubicación en puntos estratégicos sin hacer una inversión mayor en infraestructura.

d. Los salones independientes locales, aunque las cadenas de salones de belleza se están expandiendo cada vez más, la mayoría de clientes prefieren atenderse en peluquería local, el factor que domina para esta decisión es la confianza que tienen con su estilista y/o cosmetóloga, el precio y la cercanía a su domicilio ya que se ajusta a la agenda y disponibilidad de los clientes.

Estos serían la competencia más fuerte para el plan de negocio, debido a que los servicios y precios son similares y estos salones cuentan con clientes ya fidelizados, para el presente plan de negocio se debe considerar el reto de fidelización de los clientes de este tipo de competencia.

\subsubsection{Participación de mercado de cada uno de ellos.}

Según estudio de Invera, actualmente existen alrededor de 13,000 y 15,000 salones de belleza en Lima, además el sector crece anualmente 10\%. A continuación, usando como 
base este estudio, en la Figura 1 se muestra la participación en el mercado de las principales cadenas de salones y los salones independientes (elcomercio.pe, 2016). Se observa que, aunque los salones de belleza se expanden a un ritmo muy alto, el $80 \%$ de la población aún prefiere atenderse en los salones locales, por la confianza y disponibilidad en sus horarios.

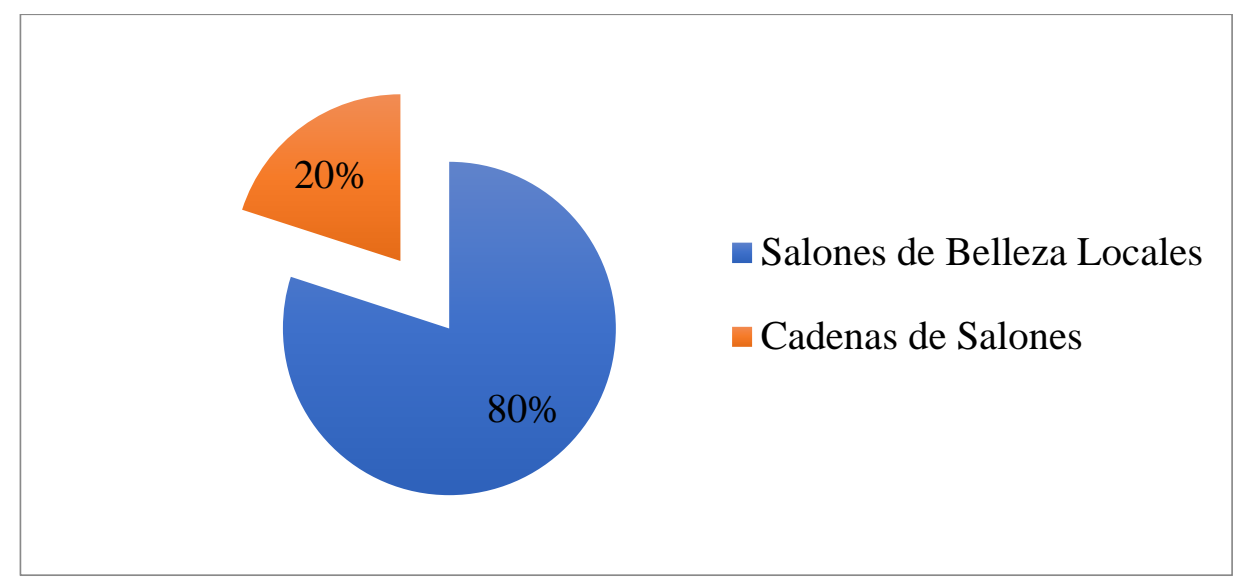

Figura 1. Participación en el mercado de cadenas de salones y salones de belleza independientes

Dentro del 20\% de personas que prefieren atenderse en un salón de belleza quien muestra un liderazgo amplio es Montalvo Spa, la base de su liderazgo es el número de locales que tienen a nivel de Lima y provincias, la segunda cadena que cuenta con la mayoría de clientes es Marco Aldany a pesar de contar con la mitad de locales de Montalvo (ver Figura 2). 


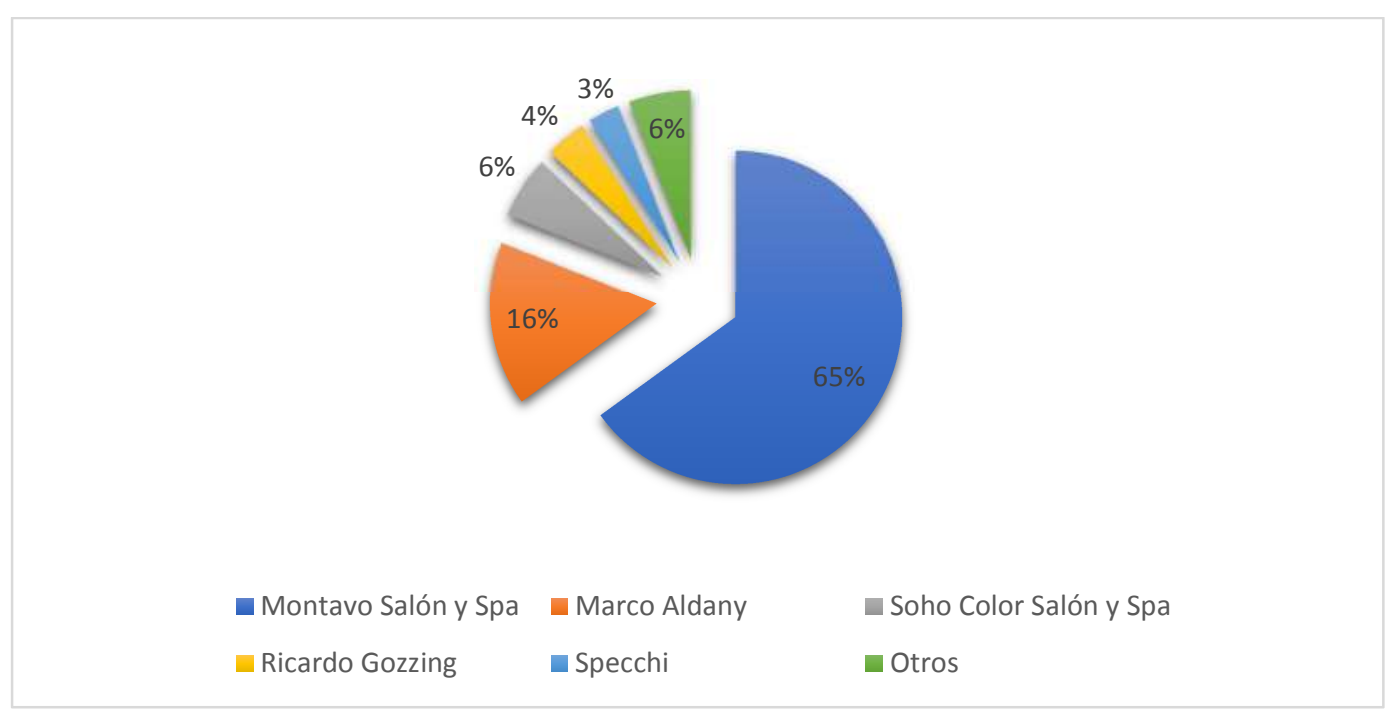

Figura 2. Participación en el mercado de cadenas de salones.

Con este análisis se puede determinar que las características a considerar para obtener la preferencia de los consumidores son ubicación cerca del hogar o trabajo, personal especializado, horarios flexibles y productos de calidad. En este sentido el plan de negocio tiene una ventaja debido a que el concepto móvil permitirá cubrir varios distritos de la capital sin tener que invertir en un nuevo local permitiendo ubicación y horarios flexibles.

\subsubsection{Matriz de perfil competitivo.}

La Matriz de Perfil Competitivo (MPC) es una herramienta que permite identificar a los principales competidores de la empresa, asimismo, es una herramienta que ayuda a establecer las fortalezas y debilidades de cada una de ellas, en ocasiones, es usada como una herramienta de soporte para la toma de decisiones. (David, 2003) 
Para la elaboración del MPC correspondiente a la propuesta de negocio se utiliza como base los factores de éxito indicados por el estudio de Invera mencionado en el análisis de la competencia. (elcomercio.pe, 2016)

Además, se asigna un peso de cero a uno según grado de importancia para el éxito de una empresa en este rubro, sumando los pesos asignados, estos deben ser igual a uno.

Tabla 12

Matriz de Perfil Competitivo

\begin{tabular}{|c|c|c|c|c|c|c|c|}
\hline \multirow{2}{*}{$\begin{array}{lc}N & \\
o & \\
t & \\
a & \text { Factores } \\
: & \text { determinantes } \\
& \text { de Éxito }\end{array}$} & \multirow[b]{2}{*}{ Peso } & \multicolumn{2}{|c|}{ Montalvo } & \multicolumn{2}{|c|}{ Marco Aldany } & \multicolumn{2}{|c|}{$\begin{array}{c}\text { Peluquerías } \\
\text { Independientes }\end{array}$} \\
\hline & & $\begin{array}{l}\text { Califica- } \\
\text { ción }\end{array}$ & $\begin{array}{l}\text { Peso } \\
\text { ponde- } \\
\text { rado }\end{array}$ & $\begin{array}{l}\text { Califica- } \\
\text { ción }\end{array}$ & $\begin{array}{l}\text { Peso } \\
\text { ponde- } \\
\text { rado }\end{array}$ & $\begin{array}{l}\text { Califica- } \\
\text { ción }\end{array}$ & $\begin{array}{c}\text { Peso } \\
\text { ponde- } \\
\text { rado }\end{array}$ \\
\hline $\begin{array}{l}\mathrm{L} \\
\mathrm{a} \text { Participación } \\
\mathrm{a} \text { en el mercado }\end{array}$ & 0.10 & 3 & 0.30 & 2 & 0.20 & 4 & 0.40 \\
\hline $\begin{array}{l}\text { c Competitivida } \\
\text { a d de precios }\end{array}$ & 0.20 & 2 & 0.40 & 2 & 0.40 & 4 & 0.80 \\
\hline $\begin{array}{l}\text { 1 Lealtad del } \\
\text { i cliente }\end{array}$ & 0.25 & 3 & 0.75 & 2 & 0.50 & 4 & 1.00 \\
\hline $\begin{array}{l}\text { f Cercanía a } \\
\text { i clientes }\end{array}$ & 0.20 & 2 & 0.40 & 1 & 0.20 & 3 & 0.60 \\
\hline $\begin{array}{l}\text { c Flexibilidad de } \\
\text { a horarios }\end{array}$ & 0.15 & 3 & 0.45 & 3 & 0.45 & 3 & 0.45 \\
\hline $\begin{array}{l}\text { c Personal } \\
\text { i especializado }\end{array}$ & 0.10 & 4 & 0.40 & 4 & 0.40 & 1 & 0.10 \\
\hline ó Total & 1.00 & & 2.70 & & 2.15 & & 3.35 \\
\hline
\end{tabular}

se asigna $1=$ Debilidad grave, $2=$ Debilidad menor, $3=$ Fortaleza menor y $4=$ Fortaleza mayor.

Con la información de la matriz de perfil competitivo de la Tabla 12 se determina que las peluquerías independientes tienen el mayor puntaje ya que son superiores en los puntos más importantes por el mercado, competitividad de precios, lealtad del cliente y cercanía de clientes, sin embargo, se debe potenciar la especialización del personal que labora en estos 
establecimientos ya que muchos son especializados pragmáticamente, lo que afecta a la calidad del servicio.

El plan de negocio deberá potenciar la participación del mercado la cual evolucionará de acuerdo a las campañas de marketing y expansión que se ejecuten, además, se debe competir con la lealtad y cercanía a los clientes que tienen las grandes cadenas de salones de belleza en Lima Metropolitana.

\subsection{Análisis del Contexto Actual y Esperado}

\subsubsection{Análisis Político-Gubernamental.}

En las últimas décadas el Perú sostiene una estabilidad democrática, sin embargo, en los periodos de elecciones presidenciales y congresales aparece un periodo de inestabilidad debido a la incertidumbre de políticas del nuevo gobierno afectando así la inversión privada.

El Congreso de la República aprobó el presupuesto del sector público para el año fiscal 2017 (ver Figura 3), el cual asciende a un monto de S/ 142,471.5 millones incrementándose en $2.9 \%$ con respecto al año 2016. (gestion.pe, 2017a) 


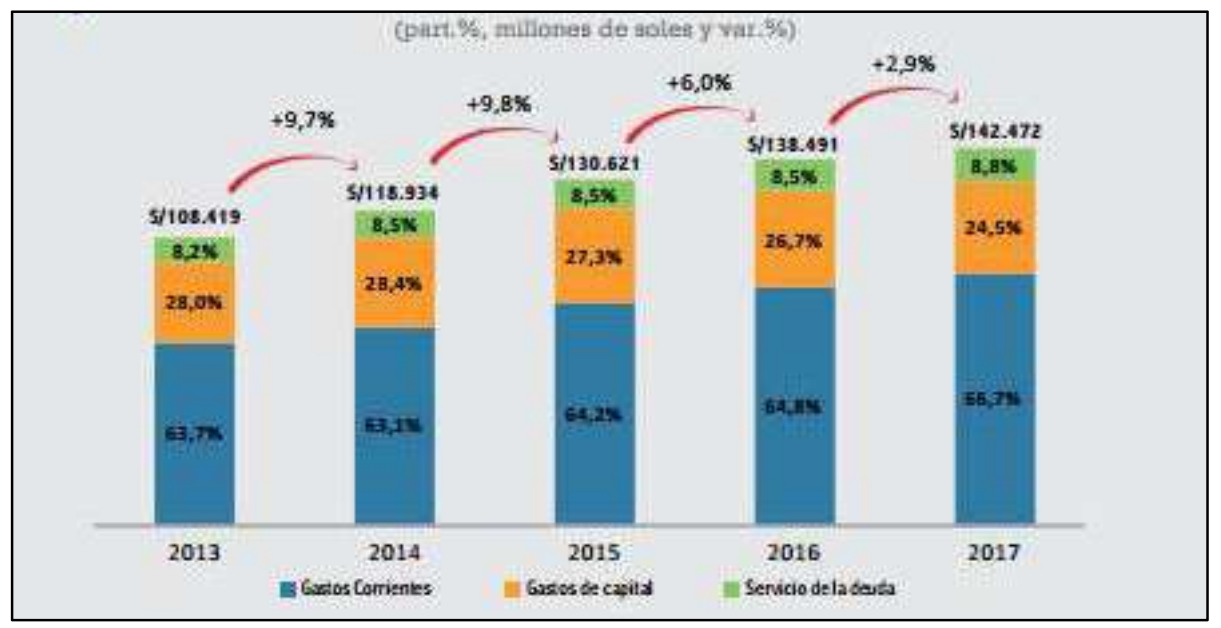

Figura 3. Evolución del presupuesto público 2013-2017. Tomado de "El presupuesto público 2017 al detalle" por Cámara de Comercio de Lima, 2017. Recuperado de http://www.camaralima.org.pe/RepositorioAPS/0/0/par/EDICION742/ED_Digital_742.pdf

Con respecto al impulso de las PYMES por parte del estado, éste tiene tres aspectos: (a) articular el Ministerio de Producción con las demás instituciones y evaluar las barreras burocráticas (b) impulso al emprendimiento mediante la innovación y créditos a través de garantías mobiliarias (c) asistencia técnica y capacitación en gestión, competitividad y productividad. (Cámara de Comercio de Lima, 2016)

Finalmente, los casos de corrupción podrían afectar las tasas de crecimiento estimadas por el estado si es que no se aplican medidas económicas (LaRepublica.pe, 2017). Es importante mencionar que la actual mayoría congresal podría dificultar la velocidad de la ejecución de los planes del Ejecutivo.

En el punto de vista internacional, el nuevo gobierno del presidente de EE. UU., Donald Trump y el retiro de EE. UU. del Tratado Transpacífico (TPP), obligará a Perú a buscar mayor comercio con los otros países miembros como China para evitar consecuencias cómo accesos de la clase media a mercancías más baratas. (bbc.com, 2017). 
En la Tabla 13 se resume las oportunidades y amenazas del análisis político gubernamental.

Tabla 13

Oportunidades y Amenazas de Análisis Político Gubernamental

\begin{tabular}{|c|c|c|c|}
\hline Criterio & Factor & $\mathrm{O} / \mathrm{A}$ & Comentario \\
\hline \multirow[t]{5}{*}{$\begin{array}{l}\text { Análisis Político } \\
\text { Gubernamental }\end{array}$} & $\begin{array}{l}\text { 1. Incertidumbre por } \\
\text { inicio de } \\
\text { gobierno }\end{array}$ & $\mathrm{A}$ & $\begin{array}{l}\text { Posible retracción de inversiones } \\
\text { debido a la incertidumbre. }\end{array}$ \\
\hline & $\begin{array}{l}\text { 2. Incremento de } \\
\text { Presupuesto de } \\
\text { Gobierno }\end{array}$ & $\mathrm{O}$ & $\begin{array}{l}\text { Inversión en Lima y provincias } \\
\text { para la mejora de carreteras, pistas } \\
\text { e infraestructura. } \\
\text { Inversión del Ministerio de } \\
\text { Producción para capacitaciones a } \\
\text { emprendedores. }\end{array}$ \\
\hline & $\begin{array}{l}\text { 3. Impulso de } \\
\text { PYMES }\end{array}$ & $\mathrm{O}$ & $\begin{array}{l}\text { Menos burocracia para trámites, } \\
\text { facilidad de acceso a créditos y } \\
\text { capacitaciones }\end{array}$ \\
\hline & 4. Corrupción & A & $\begin{array}{l}\text { Desaceleración del crecimiento } \\
\text { podría retraer el consumo }\end{array}$ \\
\hline & $\begin{array}{l}\text { 5. Condiciones } \\
\text { Políticas en otros } \\
\text { países. }\end{array}$ & A & $\begin{array}{l}\text { Productos internacionales para } \\
\text { salones de belleza podrían subir sus } \\
\text { precios. }\end{array}$ \\
\hline
\end{tabular}

\subsubsection{Análisis Económico.}

Según INEI (2017a), el Producto Bruto Interno (PBI) del año 2016 con precios de año base 2007 muestra un crecimiento de $3.9 \%$.

La tasa de crecimiento del PBI del año 2016 se produce debido al consumo privado (3.5\%) con mayor proporción que otros tipos de demanda interna y externa, además según actividad económica este crecimiento anual se explica también debido al crecimiento de actividades de servicios (3.9\%) y actividades extractivas (11.5\%). 
El crecimiento del consumo privado se explica debido al incremento en el empleo de $1,2 \%$ y el incremento del ingreso promedio en $4.7 \%$ (ver Figura 4).

\begin{tabular}{|c|c|c|c|c|c|c|c|c|c|c|}
\hline \multicolumn{11}{|c|}{$\begin{array}{l}\text { (Variación porcentual del indice de volumen fisico respecto al mismo periodo del año anterior) } \\
\qquad \text { Año Base } 2007=100\end{array}$} \\
\hline \multirow[b]{2}{*}{ Oferta y Demanda Global } & \multicolumn{5}{|c|}{$2015 / 2014$} & \multicolumn{5}{|c|}{$2016 / 2015$} \\
\hline & 1 Trim. & 11 Trim. & III Trim. & IV Trim. & Aกิ้ & ITrim. & if Trim. & III Trim. & IV Trim. & Año \\
\hline Producto Bruto Interno & 2,0 & 3,2 & 3,2 . & 4,6 & 3,3 & 4,3 & 3,7 & 4,5 & 3,0 & 3,9 \\
\hline Extractivas & 3,5 & 6,9 & 8,0 & 11,9 & 7,6 & 11,5 & 12,6 & 12,9 & 8,8 & 11,5 \\
\hline Transtormacion & $-5,2$ & $-2,4$ & $-4,1$ & $-0,6$ & $\cdot 3,0$ & $-1,4$ & $-5,3$ & 0,1 & $-1,7$ & $-2,1$ \\
\hline Servicios & 4,9 & 4,9 & 4,8 & 5,0 & 4,9 & 4,7 & 4,2 & 3,6 & 3,0 & 3,9 \\
\hline Importaciones: & $-1,4$ & $-2,4$ & 0,6 & $-0,2$ & $-0,8$ & $-0,3$ & $-2,9$ & 1,8 & 2,3 & 0,3 \\
\hline Oferta Y Demanda Global & 1,2 & 1,9 & 2,6 & 3,6 & 2,4 & 3,4 & 2,3 & 3,9 & 2,9 & 3,1 \\
\hline Demanda interna & 2,1 & 2,6 & 2,9 & 2,5 & 2,5 & 3,0 & $-0,6$ & 0,6 & 0,5 & 0,9 \\
\hline Consumo Final Privado & 3,0 & 3,4 & 3,6 & 3,6 & 3,4 & 3,8 & 2,9 & 4,1 & 3,1 & 3,5 \\
\hline Consumo de Gobierno & 3,2 & 7,0 & 5,1 & 7,5 & 5,8 & 12,8 & 9,7 & 2,3 & $-3,1$ & 4,9 \\
\hline Formacien Bruta de Capital & $-0,4$ & $-0,6$ & 0,3 & $-2,4$ & $-0,8$ & $-2,9$ & $-12,7$ & $-8,7$ & $-3,8$ & $-7,1$ \\
\hline Formación Bruta de Capital Fijo & $-7,1$ & $-8,7$ & $-6,4$ & $-3,6$ & $-6,4$ & $-2,3$ & $-3,7$ & $-4,3$ & $-6,1$ & $-4,2$ \\
\hline Publico & $-21,9$ & 2,1 & $-9,7$ & 4,7 & $-5,7$ & 30,3 & 3,9 & 2,2 & $-14,6$ & 3,1 \\
\hline Privado & $-3,1$ & $-11,9$ & $-5,4$ & $-6,0$ & $-6,6$ & $\cdot 9,3$ & $-6,3$ & $-6,1$ & $-3,5$ & $-6,3$ \\
\hline Exportaciones & $-2,4$ & $-1,2$ & 1,4 & 8,3 & 1,6 & 5,0 & 15,8 & 18,1 & 12,3 & 12,9 \\
\hline
\end{tabular}

Figura 4. Oferta y demanda global trimestral. Tomado de "Informe Técnico 01. Producto Bruto Interno Trimestral 2016" por INEI, 2017a. Recuperado de https://www.inei.gob.pe/media/MenuRecursivo/boletines/01-informe-tecnico-n01_productobruto-interno-trim

Por tipo de gasto otros servicios el cual incluye enseres de uso personal y otras actividades de servicios personales, el valor agregado bruto muestra un crecimiento de $4.1 \%$ con respecto al año 2015 (ver Figura 5).

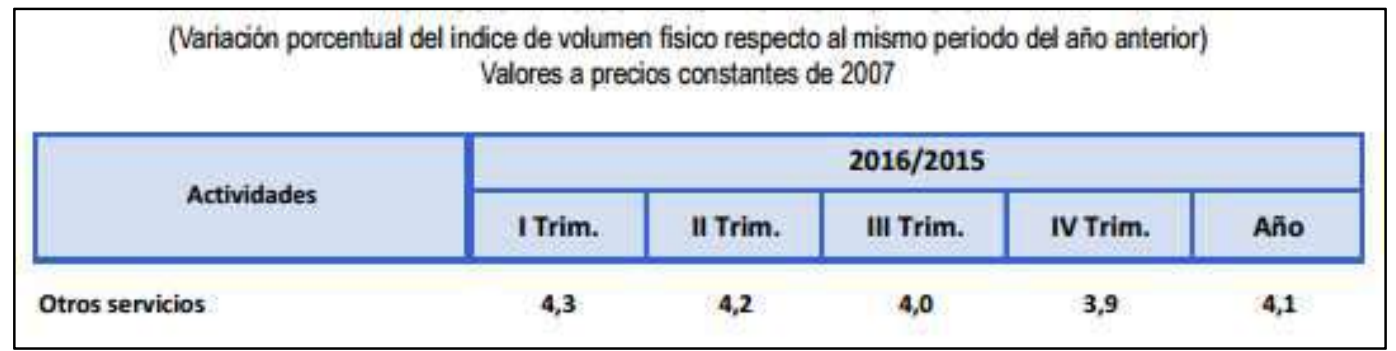

Figura 5. Valor agregado de otros servicios. Tomado de "Informe Técnico 01. Producto Bruto Interno Trimestral 2016" por INEI, 2017a. Recuperado de https://www.inei.gob.pe/media/MenuRecursivo/boletines/01-informe-tecnico-n01_productobruto-interno-trime 
Adicionalmente se proyectó que el crecimiento de los años 2017 y 2018 sería de $4.3 \%$ y $4.2 \%$ respectivamente (bcrp.gob.pe, 2016), sin embargo el ministro de Economía y Finanzas, Alfredo Thorne, expresó que la economía nacional sólo crecería 3.8\% este año, un punto porcentual menos que el estimado oficial, por efecto de la suspensión del Gasoducto Sur Peruano y además por el efecto Odebretch (Semana Económica, 2017a). Con respecto al déficit fiscal del año 2016, éste decreció a 2.7\% del PBI (ver Figura 6), siendo un mejor resultado de lo esperado por el gobierno, lo cual indica que el estado estaría haciendo una buena gestión de sus gastos no financieros y así podría indicar que los precios en general de bienes y servicios se mantendrán. (gestion.pe, 2017b)

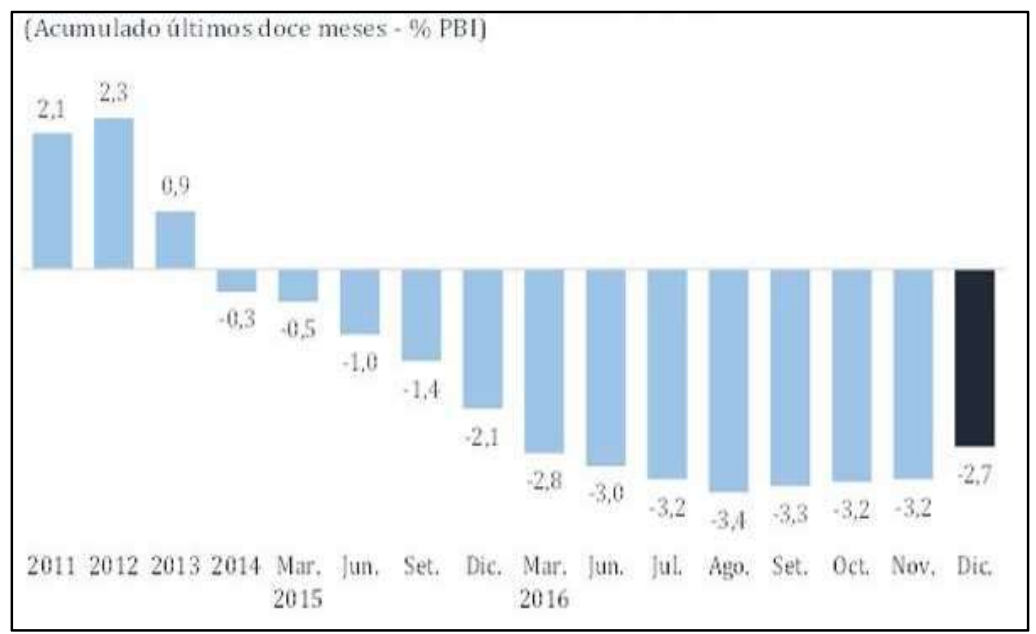

Figura 6. Resultado económico del sector público no financiero. Tomado de "BCR: Déficit fiscal fue de $2.7 \%$ del PBI en el 2016" por gestion.pe, 2017b. Recuperado de http://gestion.pe/economia/bcr-deficit-fiscal-fue-27-pbi-2016-2179503

Por otro lado, el Perú tuvo una inflación de 3.23\% en el año 2016 con tendencia disminuir en los siguientes años (ver Figura 7), según el Banco Central de Reserva del Perú (BCRP), este sería de 2.3\% en 2017 y de 2\% en 2018, reafirmando así la desaceleración de la inflación y la estabilidad de la economía. Perú se ubicaría, así como 
primer país de América Latina con el mejor índice de inflación nacional. (bcrp.gob.pe, 2016)

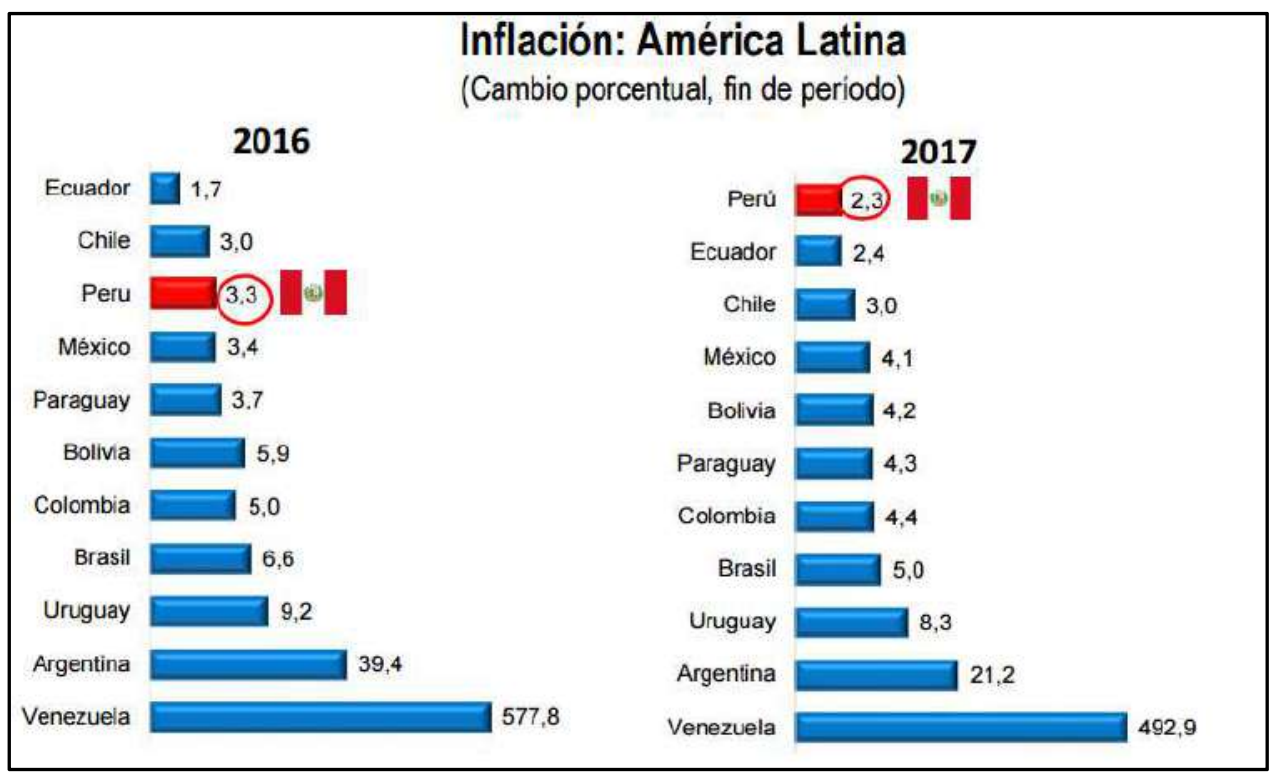

Figura 7. Inflación de América Latina. Tomado de "Reporte de Inflación. Diciembre 2016" por BCRP, 2016. Recuperado de http://www.bcrp.gob.pe/docs/Publicaciones/ReporteInflacion/2016/diciembre/reporte-de-inflacion-diciembre-2016.pdf

Con respecto a la inflación de gasolina y lubricantes este disminuyó en 3.2\% y 4.8\% respectivamente para el año 2016 lo cual avizora una estabilidad en los precios de hidrocarburos en el periodo mencionado.

El BCRP informa que la balanza comercial registró un superávit a enero 2017 aumentando en 656 millones respecto a enero 2016, este panorama se da debido a que las exportaciones han aumentado en un $25.9 \%$ (gestion.pe, 2017c). La balanza comercial proyectada para el año 2017 y 2018 sería de 2,454 millones y 2,252 millones respectivamente (ver Figura 8), lo cual reforzaría la tendencia de crecimiento de la balanza comercial. (bcrp.gob.pe, 2016) 
BANCO CENTRAL DE RESERVA DEL PERÚ

\begin{tabular}{|c|c|c|c|c|}
\hline \multicolumn{5}{|l|}{$\begin{array}{l}\text { Balanza comercial } \\
\text { (Millones US\$) }\end{array}$} \\
\hline & Ene.2016 & Ene.2017 & Dif. & Var. $\%$ \\
\hline 1. Exportaciones & 2476 & 3117 & 641 & 25,9 \\
\hline Productos tradicionales & 1575 & 2168 & 593 & 37,7 \\
\hline Productos no tradicionales & 893 & 937 & 43 & 4,8 \\
\hline Otros & 8 & 12 & 5 & 61,3 \\
\hline 2. Importaciones & 2983 & 2967 & -15 & $-0,5$ \\
\hline Bienes de consumo & 653 & 652 & -1 & $-0,1$ \\
\hline Insumos & 1230 & 1404 & 175 & 14,2 \\
\hline Bienes de capital & 1022 & 885 & -137 & $-13,4$ \\
\hline Otros bienes & 78 & 26 & .53 & $-67,1$ \\
\hline 3. BALANZA COMERCIAL & -507 & 150 & 656 & \\
\hline
\end{tabular}

Figura 8. Balanza comercial a enero de 2017. Tomado de "Balanza comercial registró superávit de US\$ 150 millones en enero" por diario gestion.pe, 2017c. Recuperado de http://gestion.pe/mercados/balanza-comercial-registro-superavit-us-150-millones-enero

La tasa de interés de referencia del BCRP a febrero 2017 se ha mantenido en $4,25 \%$, sin embargo, las tasas de intereses para créditos a pequeñas empresas y para créditos de consumo se ha incrementado (ver Figura 9).

\begin{tabular}{|llcccc|}
\hline & & Set.15 & Dic.15 & Set.16 & Nov.16 \\
\hline \multirow{3}{*}{ Pasivas } & Depósitos hasta 30 dlas & 4,12 & 4,01 & 4,03 & 4,22 \\
& Depósitos a plazo de 31 a 180 dias & 4,41 & 4,67 & 4,98 & 4,79 \\
& Depositos a plazo de 181 a 360 dlas & 4,41 & 4,74 & 5,20 & 5,08 \\
\hline \multirow{4}{*}{ Activas } & Corporativos & 5,87 & 6,18 & 6,07 & 5,64 \\
& Grandes Empresas & 7,16 & 7,12 & 7,23 & 7,21 \\
& Medianas Empresas & 10,19 & 10,23 & 10,74 & 10,30 \\
& Pequehas Empresas & 20,36 & 20,45 & 21,59 & 21,99 \\
& Consumo & 42,4 & 44,03 & 44,01 & 45,64 \\
& Hipotecanio & 8,59 & 8,95 & 8,82 & 8,57 \\
\hline \hline
\end{tabular}

Figura 9. Tasas de Interés de moneda nacional (\%). Tomado de "Reporte de Inflación. Diciembre 2016" por BCRP, 2016. Recuperado de http://www.bcrp.gob.pe/docs/Publicaciones/ReporteInflacion/2016/diciembre/reporte-de-inflacion-diciembre-2016.pdf 
La anunciada reducción del IGV por parte del gobierno en un punto porcentual a 17\% no se daría en este año. El Decreto Legislativo 1347 condiciona la reducción a alcanzar una recaudación neta (que descuenta las devoluciones del impuesto) del IGV de 7.2\% del PBI a mayo de 2017. (Semana Económica, 2017b)

Aumento de la tasa de desempleo del año 2016 llegó a 4.4\% con respecto a 2015, sin embargo, es una de las más bajas en América Latina. (gestion.pe, 2016b)

Con respecto a la economía mundial se proyecta una recuperación para los años 2017-2018, de acuerdo con la Figura 10, América Latina se ubica como la segunda región después de China con mayor crecimiento. (bcrp.gob.pe, 2016)

\begin{tabular}{|c|c|c|c|c|}
\hline & 2015 & $2016^{*}$ & $2017^{*}$ & $2018^{*}$ \\
\hline $\begin{array}{l}\text { Estados } \\
\text { Unidos }\end{array}$ & 2,6 & 1,6 & 2,2 & 2,0 \\
\hline Eurozona & 2,0 & 1,7 & 1,5 & 1,5 \\
\hline China & 6,9 & 6,7 & 6,2 & 6,0 \\
\hline $\begin{array}{l}\text { América } \\
\text { Latina }\end{array}$ & 0,0 & $-0,7$ & 1,8 & 2,4 \\
\hline Mundo & 3,2 & 3,0 & 3,4 & 3,5 \\
\hline
\end{tabular}

Figura 10. Crecimiento del PBI por regiones en la Economía Mundial. Tomado de "Reporte de inflación. Diciembre 2016" por Banco Central de Reserva del Perú, 2016. Recuperado de http://www.bcrp.gob.pe/docs/Publicaciones/Reporte-Inflacion/2016/diciembre/re

En la Tabla 14 se resume las oportunidades y amenazas del análisis económico. 
Tabla 14

Oportunidades y Amenazas de Análisis Económico

\begin{tabular}{|c|c|c|c|}
\hline Criterio & Factor & $\mathrm{O} / \mathrm{A}$ & Comentario \\
\hline \multirow[t]{7}{*}{$\begin{array}{l}\text { Análisis } \\
\text { Económico }\end{array}$} & $\begin{array}{l}\text { 1. Tasa de } \\
\text { crecimiento }\end{array}$ & $\mathrm{O}$ & $\begin{array}{l}\text { Crecimiento de la economía } \\
\text { promueve el consumo. }\end{array}$ \\
\hline & $\begin{array}{l}\text { 2. Déficit fiscal en } \\
\text { descenso }\end{array}$ & $\mathrm{O}$ & $\begin{array}{l}\text { Productos de bienes y servicios } \\
\text { mantendrían sus precios. }\end{array}$ \\
\hline & $\begin{array}{l}\text { 3. Inflación de } \\
\text { gasolina y } \\
\text { lubricantes } \\
\text { decreciente }\end{array}$ & $\mathrm{O}$ & $\begin{array}{l}\text { Estabilidad en precios de } \\
\text { hidrocarburos }\end{array}$ \\
\hline & $\begin{array}{l}\text { 4. Superávit de } \\
\text { Balanza } \\
\text { Comercial }\end{array}$ & $\mathrm{O}$ & $\begin{array}{l}\text { Proyección a negocios en el país } \\
\text { indicaría que las compras son } \\
\text { menores a las ventas, existiendo una } \\
\text { tendencia a las ganancias positivas. }\end{array}$ \\
\hline & $\begin{array}{l}\text { 5. Tasa de interés de } \\
\text { referencia }\end{array}$ & $\mathrm{O}$ & $\begin{array}{l}\text { Acceso a créditos o financiamientos } \\
\text { con tasas moderadas }\end{array}$ \\
\hline & $\begin{array}{l}\text { 6. Reducción de } \\
\text { IGV }\end{array}$ & $\mathrm{O}$ & $\begin{array}{l}\text { Reducción del IGV afectaría } \\
\text { positivamente al flujo de caja }\end{array}$ \\
\hline & $\begin{array}{l}\text { 7. Aumento de tasa } \\
\text { de desempleo }\end{array}$ & A & $\begin{array}{l}\text { Mercado Objetivo tendría menor } \\
\text { poder adquisitivo (servicio de lujo) }\end{array}$ \\
\hline
\end{tabular}




\subsubsection{Análisis Legal.}

El Congreso de la República promulgó la Ley No 30056 la cual promueve la inversión a través del impulso del desarrollo productivo y el crecimiento empresarial. Este establece el marco legal para la competitividad, formalización y el desarrollo de las micro, pequeñas y medianas empresas (MIPYME). (Escalante, 2016)

El Poder Ejecutivo publicó el Decreto Legislativo $N^{\circ} 1200$ que simplifican los trámites para obtener licencias de funcionamiento, entre otros cambios estarían (a) la licencia con más de un giro afines entre ellos y (b) la obtención de licencia no exige el inicio de las actividades de la empresa.

El valor de la Unidad Impositiva Tributaria (UIT) aumentó en S/100, es decir aumenta de S/3,950 a S/4,050 desde enero de 2017, según el Decreto Supremo Nº 353. (rpp.pe, 2016)

No existe regulación para licencia de funcionamiento de negocios móviles, sin embargo, en algunos distritos se emite una licencia temporal.

En la Tabla 15 se resume las oportunidades y amenazas del análisis legal.

Tabla 15

Oportunidades y Amenazas de Análisis Legal

\begin{tabular}{cccl}
\hline Criterio & \multicolumn{1}{c}{ Factor } & O/A & \multicolumn{1}{c}{ Comentario } \\
\hline Análisis Legal & 1. Ley Laboral & $\mathrm{O}$ & $\begin{array}{l}\text { Impulsa el crecimiento económico y } \\
\text { mayor promoción de creación de } \\
\text { nuevos negocios }\end{array}$ \\
\hline & $\begin{array}{l}\text { 2. Simplificación } \\
\text { de trámites }\end{array}$ & $\mathrm{O}$ & $\begin{array}{l}\text { Facilidad para creación de nuevas } \\
\text { empresas }\end{array}$ \\
\hline $\begin{array}{l}\text { 3. Incremento de } \\
\text { UIT }\end{array}$ & $\mathrm{O}$ & $\begin{array}{l}\text { Crece rango de ventas anuales para } \\
\text { categorización de empresas }\end{array}$ \\
\hline $\begin{array}{l}\text { 4. Regulaciones } \\
\text { para negocios } \\
\text { móviles }\end{array}$ & $\mathrm{A}$ & $\begin{array}{l}\text { No existe licencia de } \\
\text { funcionamiento para negocios } \\
\text { móviles. }\end{array}$ \\
\hline
\end{tabular}




\subsubsection{Análisis Cultural.}

Los distritos más poblados de Lima son: San Juan de Lurigancho (1'128 mil), San Martín de Porres (723 mil), Ate (655 mil), Comas (534 mil), Villa El Salvador (478 mil), Villa María del Triunfo (462 mil), San Juan de Miraflores (413 mil), Los Olivos (382 mil), Puente Piedra (369 mil) y Santiago de Surco (355 mil). Cabe señalar, que estos 10 distritos concentran más del 50\% de la población de la provincia de Lima mientras que los menos poblados son: Santa María del Mar (1,675), Punta Hermosa (7,895), San Bartolo $(7,989)$, Punta Negra $(8,271)$ y Pucusana $(17,786)$. (INEI, 2017b)

PEA aumentó en 2\% en el año 2016 respecto al año 2015 en Lima Metropolitana, creciendo la población femenina en 1.8\%, sin embargo, durante el último trimestre de 2016 el empleo de mujeres se incrementó en $2 \%$ mientras que el de varones en $0.5 \%$ lo cual indica que podría existir una tendencia de preferencia de mujeres en Lima Metropolitana. (gestion.pe, 2017d)

Respecto a las ramas de actividad donde se desempeña la población femenina INEI (2017c) muestra que ellas se insertan en su mayoría en actividades de servicios y comercio (ver Figura 11). 


\begin{tabular}{|c|c|c|c|}
\hline Sexo / Ramas de actividad & $\begin{array}{l}\text { Oct-Nov-Dic } \\
2015\end{array}$ & $\begin{array}{c}\text { Oct-Nov-Dic } \\
2016 \mathrm{PI}\end{array}$ & $\begin{array}{c}\text { Variación (puntos } \\
\text { porcentuales) }\end{array}$ \\
\hline Mujer & 100,0 & 100,0 & \\
\hline Agricultura/ Pesca/ Mneria & 8,6 & 8,7 & 0,1 \\
\hline Manufactura & 10,1 & 10,4 & 0,3 \\
\hline Construcción & 0,7 & 0,8 & $0,1$. \\
\hline Comercio & 28,8 & 29,1 & 0,3 \\
\hline Transportes y Comunicaciones & 2,4 & 2,7 & 0,3 \\
\hline Otros Servidos $1 /$ & 49,5 & 48,3 & $-1,2$ \\
\hline Hombre & 100,0 & 100,0 & \\
\hline Agricultura/ Pesca/ Mineria & 14,7 & 14,9 & 0,2 \\
\hline Manufactura & 11,9 & 11,9 & 0,0 \\
\hline Construcción & 14,1 & 11,5 & $-2,6 \quad \cdots$ \\
\hline Comercio & 16,0 & 15,8 & $-0,2$ \\
\hline Transportes y Comunicaciones & 15,3 & 16,4 & 1,1 \\
\hline Otros Servicios $1 /$ & 28,1 & 29,5 & 1,4 \\
\hline
\end{tabular}

Figura 11. Población femenina y masculina, según ramas de actividad. Tomado de "Informe Técnico $N^{\circ} 01$. Estadísticas con Enfoque de Género" por INEI, 2017c. Recuperado de https://www.inei.gob.pe/media/MenuRecursivo/boletines/01-informe-tecnico-n01_estadis

Con respecto al ingreso promedio de mujeres en el año 2016, éste muestra un ligero decrecimiento con respecto al año 2015, existiendo además una diferencia de 566.5 soles menos con respecto a los ingresos de los hombres (ver Figura 12).

\begin{tabular}{l|c|c|c|}
\hline Sexo / Grupos de edad & Oct-Nov-Dic 2015 & Oct-Nov-Dic 2016 PI & $\begin{array}{c}\text { Variación } \\
\text { (porcentual) }\end{array}$ \\
\hline Mujer & 1269,8 & 1263,9 & $-0,5$ \\
De 14 a 24 antos & 862,7 & 877,4 & 1,7 \\
De 25 a 44 ahtos & 1441,5 & 1351,8 & $-6,2$ \\
De 45 y mas años & 1187,5 & 1295,1 & 9,1 \\
Hombre & 1735,0 & 1830,4 & 5,5 \\
De 14 a 24 anics & 943,2 & 1099,5 & 16,6 \\
De 25 a 44 años & 1852,0 & 1938,0 & 4,7 \\
De 45 y más años & 1935,4 & 1992,7 & 3,0 \\
\hline
\end{tabular}

Figura 12. Población femenina y masculina, según ramas de actividad. Tomado de "Informe Técnico N01. Estadísticas con Enfoque de" por INEI, 2017c. Recuperado de https://www.inei.gob.pe/media/MenuRecursivo/boletines/01-informe-tecnico-n01_estadisticas-g

La gastronomía peruana es una de las más variadas del mundo, siendo considerada como la poseedora de más platos típicos del continente. Es el resultado de la fusión de 
elementos incaicos, amazónicos, españoles y africanos, así como también japoneses, italianos y franceses. Por lo tanto, se iniciaron los negocios de food truck en el Perú, los carritos de sándwich, comidas y bebidas alcohólicas.

La inseguridad ciudadana se ha incrementado en los últimos años, el 29\% de empresas peruanas fueron víctimas de la delincuencia.

En la Tabla 16 se resume las oportunidades y amenazas del análisis cultural

Tabla 16

Oportunidades y Amenazas de Análisis Social y Cultural

\begin{tabular}{llcl}
\hline Criterio & \multicolumn{1}{c}{ Factor } & O/A & \multicolumn{1}{c}{ Comentario } \\
\hline $\begin{array}{l}\text { Análisis } \\
\text { Social y } \\
\text { Cultural }\end{array}$ & 1. PEA ocupada & $\mathrm{O}$ & Mayor poder adquisitivo \\
\hline $\begin{array}{l}\text { 2. Empleo de } \\
\text { mujeres } \\
\text { incrementa }\end{array}$ & $\mathrm{O}$ & $\begin{array}{l}\text { Mayor poder adquisitivo de las mujeres } \\
\text { promueve mayor gasto en cuidado } \\
\text { personal. }\end{array}$ \\
\hline $\begin{array}{l}\text { 3. Nuevos negocios } \\
\text { móviles }\end{array}$ & $\mathrm{O}$ & $\begin{array}{l}\text { Gracias al crecimiento cultural se pueden } \\
\text { elaborar nuevas ideas de negocios como } \\
\text { los servicios móviles (food trucks) }\end{array}$ \\
\hline $\begin{array}{l}\text { 4. Inseguridad } \\
\text { ciudadana }\end{array}$ & $\mathrm{A}$ & $\begin{array}{l}\text { Actos de delincuencia podría ocasionar } \\
\text { pérdidas para el negocio. }\end{array}$ \\
\hline
\end{tabular}

\subsubsection{Análisis Tecnológico.}

En la actualidad, el Perú tiene mayor acceso a una gran diversidad de productos y servicios de alta tecnología y calidad, que permiten minimizar y agilizar los procesos.

Hoy en día con el avance de la tecnología, permite tener llegada a los clientes potenciales, mediante redes sociales, entre otros. El $88 \%$ de los peruanos acceden a internet a través de un smartphone esto permite una mejor comunicación con el público objetivo. (larepublica.pe, 2015) 
En la Tabla 17 se resume las oportunidades y amenazas del análisis tecnológico.

Tabla 17

Oportunidades y Amenazas de Análisis Tecnológico

\begin{tabular}{lccl}
\hline Criterio & \multicolumn{1}{c}{ Factor } & O/A & \multicolumn{1}{c}{ Comentario } \\
\hline $\begin{array}{l}\text { Análisis } \\
\text { Tecnológico }\end{array}$ & $\begin{array}{l}\text { 1. Equipamiento } \\
\text { de última } \\
\text { generación }\end{array}$ & $\mathrm{O}$ & $\begin{array}{l}\text { Brindar un servicio de calidad a un } \\
\text { menor tiempo }\end{array}$ \\
\hline $\begin{array}{l}\text { 2. Empleo de } \\
\text { Tecnología }\end{array}$ & $\mathrm{O}$ & $\begin{array}{l}\text { Factibilidad para el cliente para } \\
\text { reservas o citas y ubicación del } \\
\text { negocio y pagos on-line } \\
\text { Conexión con el mercado objetivo } \\
\end{array}$ & \\
& & $\begin{array}{l}\text { a través de redes sociales } \\
\end{array}$
\end{tabular}

\subsubsection{Análisis Ecológico.}

Un estudio global sobre las decisiones de compra relacionadas al cuidado medioambiental revela que de cada tres personas uno busca productos de empresas con cuidado en el impacto medioambiental, siendo los países emergentes los que mostraron una mayor preocupación que los países desarrollados. (ElIntransigente.com, 2017)

Según estudio del Instituto de Opinión Pública (como se cita en Prado, 2013), el $23 \%$ de la población limeña compra frecuentemente productos ecológicos.

En la Tabla 18 se resume las oportunidades y amenazas del análisis ecológico.

Tabla 18

Oportunidades y Amenazas de Análisis Ecológico

\begin{tabular}{|c|c|c|c|}
\hline Criterio & Factor & $\mathrm{O} / \mathrm{A}$ & Comentario \\
\hline $\begin{array}{l}\text { Análisis } \\
\text { Ecológico }\end{array}$ & $\begin{array}{l}\text { 1. Compra con } \\
\text { sostenibilidad }\end{array}$ & $\mathrm{O}$ & $\begin{array}{l}\text { Aplicar marketing verde para atraer a } \\
\text { consumidores ecológicos y apoyar el } \\
\text { cuidado del medio ambiente. }\end{array}$ \\
\hline
\end{tabular}




\subsection{Oportunidades y Amenazas}

En la Tabla 19 se resume las oportunidades y amenazas del análisis del contexto actual.

Tabla 19

Oportunidades y Amenazas para el negocio

\begin{tabular}{|c|c|c|c|}
\hline Criterio & Factor & $\mathrm{O} / \mathrm{A}$ & Comentario \\
\hline \multirow[t]{5}{*}{$\begin{array}{l}\text { Análisis Político } \\
\text { Gubernamental }\end{array}$} & $\begin{array}{l}\text { 1. Incertidumbre por } \\
\text { inicio de } \\
\text { gobierno }\end{array}$ & A & $\begin{array}{l}\text { Posible retracción de inversiones debido } \\
\text { a la incertidumbre. }\end{array}$ \\
\hline & $\begin{array}{l}\text { 2. Incremento de } \\
\text { Presupuesto de } \\
\text { Gobierno }\end{array}$ & $\mathrm{O}$ & $\begin{array}{l}\text { Inversión en Lima y provincias para la } \\
\text { mejora de carreteras, pistas e } \\
\text { infraestructura. } \\
\text { Inversión del Ministerio de Producción } \\
\text { para capacitaciones a emprendedores. }\end{array}$ \\
\hline & $\begin{array}{l}\text { 3. Impulso de } \\
\text { PYMES }\end{array}$ & $\mathrm{O}$ & $\begin{array}{l}\text { Menos burocracia para trámites, } \\
\text { facilidad de acceso a créditos y } \\
\text { capacitaciones }\end{array}$ \\
\hline & 4. Corrupción & A & $\begin{array}{l}\text { Desaceleración del crecimiento podría } \\
\text { retraer el consumo }\end{array}$ \\
\hline & $\begin{array}{l}\text { 5. Condiciones } \\
\text { Políticas en otros } \\
\text { países. }\end{array}$ & A & $\begin{array}{l}\text { Productos internacionales para salones } \\
\text { de belleza podrían subir sus precios. }\end{array}$ \\
\hline \multirow[t]{7}{*}{$\begin{array}{l}\text { Análisis } \\
\text { Económico }\end{array}$} & $\begin{array}{l}\text { 1. Tasa de } \\
\text { crecimiento }\end{array}$ & $\mathrm{O}$ & $\begin{array}{l}\text { Crecimiento de la economía promueve } \\
\text { el consumo. }\end{array}$ \\
\hline & $\begin{array}{l}\text { 2. Déficit fiscal en } \\
\text { descenso }\end{array}$ & $\mathrm{O}$ & $\begin{array}{l}\text { Productos de bienes y servicios } \\
\text { mantendrían sus precios. }\end{array}$ \\
\hline & $\begin{array}{l}\text { 3. Inflación de } \\
\text { gasolina y } \\
\text { lubricantes } \\
\text { decreciente }\end{array}$ & $\mathrm{O}$ & Estabilidad en precios de hidrocarburo. \\
\hline & $\begin{array}{l}\text { 4. Superávit de } \\
\text { Balanza } \\
\text { Comercial }\end{array}$ & $\mathrm{O}$ & $\begin{array}{l}\text { Proyección a negocios en el país } \\
\text { indicaría que las compras son menores a } \\
\text { las ventas, existiendo una tendencia a } \\
\text { las ganancias positivas. }\end{array}$ \\
\hline & $\begin{array}{l}\text { 5. Tasa de interés de } \\
\text { referencia }\end{array}$ & $\mathrm{O}$ & $\begin{array}{l}\text { Acceso a créditos o financiamientos con } \\
\text { tasas moderadas }\end{array}$ \\
\hline & $\begin{array}{l}\text { 6. Reducción de } \\
\text { IGV }\end{array}$ & A & $\begin{array}{l}\text { Podría no reducirse el IGV lo cual } \\
\text { impactaría flujo de caja de la empresa. }\end{array}$ \\
\hline & $\begin{array}{l}\text { 7. Aumento de tasa } \\
\text { de desempleo }\end{array}$ & A & $\begin{array}{l}\text { Mercado objetivo tendría menor poder } \\
\text { adquisitivo (servicio de lujo) }\end{array}$ \\
\hline
\end{tabular}


Tabla 20 "Continuación”

Oportunidades y Amenazas para el negocio

\begin{tabular}{|c|c|c|c|}
\hline Criterio & Factor & $\mathrm{O} / \mathrm{A}$ & Comentario \\
\hline \multirow[t]{4}{*}{ Análisis Legal } & 1. Ley Laboral & $\mathrm{O}$ & $\begin{array}{l}\text { Impulsa el crecimiento económico y } \\
\text { mayor promoción de creación de } \\
\text { nuevos negocios }\end{array}$ \\
\hline & $\begin{array}{l}\text { 2. Simplificación de } \\
\text { trámites }\end{array}$ & $\mathrm{O}$ & $\begin{array}{l}\text { Facilidad para creación de nuevas } \\
\text { empresas }\end{array}$ \\
\hline & 3. Incremento de UIT & $\mathrm{O}$ & $\begin{array}{l}\text { Crece rango de ventas anuales para } \\
\text { categorización de empresas }\end{array}$ \\
\hline & $\begin{array}{l}\text { 4. Regulaciones para } \\
\text { negocios móviles }\end{array}$ & A & $\begin{array}{l}\text { No existe licencia de funcionamiento } \\
\text { para negocios móviles. }\end{array}$ \\
\hline \multirow[t]{3}{*}{$\begin{array}{l}\text { Análisis Social } \\
\text { y Cultural }\end{array}$} & $\begin{array}{l}\text { 1. Empleo de mujeres } \\
\text { incrementa }\end{array}$ & $\mathrm{O}$ & $\begin{array}{l}\text { Mayor poder adquisitivo de las } \\
\text { mujeres promueve mayor gasto en } \\
\text { cuidado personal. }\end{array}$ \\
\hline & $\begin{array}{l}\text { 2. Nuevos negocios } \\
\text { móviles }\end{array}$ & $\mathrm{O}$ & $\begin{array}{l}\text { Gracias al crecimiento cultural se } \\
\text { pueden elaborar nuevas ideas de } \\
\text { negocios como: Los servicios móviles } \\
\text { (Food Trucks) }\end{array}$ \\
\hline & $\begin{array}{l}\text { 3. Inseguridad } \\
\text { ciudadana }\end{array}$ & A & $\begin{array}{l}\text { Actos de delincuencia podría ocasionar } \\
\text { pérdidas para el negocio. }\end{array}$ \\
\hline \multirow[t]{2}{*}{$\begin{array}{l}\text { Análisis } \\
\text { Tecnológico }\end{array}$} & $\begin{array}{l}\text { 1. Equipamiento de } \\
\text { última generación }\end{array}$ & $\mathrm{O}$ & $\begin{array}{l}\text { Brindar un servicio de calidad a un } \\
\text { menor tiempo }\end{array}$ \\
\hline & $\begin{array}{l}\text { 2. Empleo de } \\
\text { Tecnología }\end{array}$ & $\mathrm{O}$ & $\begin{array}{l}\text { Factibilidad para el cliente para } \\
\text { reservas o citas y ubicación del } \\
\text { negocio y pagos on-line } \\
\text { Conexión con el mercado objetivo a } \\
\text { través de redes sociales }\end{array}$ \\
\hline $\begin{array}{l}\text { Análisis } \\
\text { Ecológico }\end{array}$ & $\begin{array}{l}\text { 1. Compra con } \\
\text { sostenibilidad }\end{array}$ & $\mathrm{O}$ & $\begin{array}{l}\text { Aplicar marketing verde para atraer a } \\
\text { consumidores ecológicos y apoyar el } \\
\text { cuidado del medio ambiente. }\end{array}$ \\
\hline
\end{tabular}

\subsection{Matriz de Evaluación de Factores Externos}

Se elaboró la Matriz de Evaluación de Factores Externos considerando el análisis de oportunidades y amenazas en la Tabla 19 y 20. Para la realización de la matriz se ordenó los factores por orden de importancia para alcanzar el éxito en el rubro y se asigna un peso basado en 
dicha importancia los cuales deberán sumar uno, luego se asignó una calificación del uno al cuatro.

Tabla 21

Matriz de Evaluación de Factores Externos

\begin{tabular}{|c|c|c|c|}
\hline Factores Externos & Peso & Calificación & Peso Ponderado \\
\hline \multicolumn{4}{|l|}{ Oportunidades } \\
\hline Nuevos negocios móviles & 0.12 & 4 & 0.48 \\
\hline Empleo de mujeres incrementa & 0.11 & 3 & 0.33 \\
\hline Tasa de crecimiento & 0.10 & 2 & 0.20 \\
\hline $\begin{array}{l}\text { Inflación de gasolina y lubricantes } \\
\text { decreciente }\end{array}$ & 0.09 & 4 & 0.36 \\
\hline Impulso de PYMES & 0.08 & 2 & 0.16 \\
\hline Ley Laboral & 0.07 & 2 & 0.14 \\
\hline Déficit fiscal en descenso & 0.06 & 3 & 0.18 \\
\hline Superávit de Balanza Comercial & 0.05 & 2 & 0.10 \\
\hline Incremento de Presupuesto de Gobierno & 0.04 & 3 & 0.12 \\
\hline Empleo de Tecnología & 0.03 & 2 & 0.06 \\
\hline Tasa de interés de referencia & 0.03 & 3 & 0.09 \\
\hline Incremento de UIT & 0.02 & 3 & 0.06 \\
\hline Simplificación de trámites & 0.01 & 2 & 0.02 \\
\hline Equipamiento de última generación & 0.01 & 2 & 0.02 \\
\hline Compra con sostenibilidad & 0.01 & 1 & 0.01 \\
\hline \multicolumn{4}{|l|}{ Amenazas } \\
\hline Regulaciones para negocios móviles & 0.05 & 1 & 0.05 \\
\hline Aumento de tasa de desempleo & 0.03 & 2 & 0.06 \\
\hline Reducción de IGV & 0.03 & 2 & 0.06 \\
\hline Inseguridad ciudadana & 0.02 & 2 & 0.04 \\
\hline Condiciones Políticas en otros países. & 0.02 & 3 & 0.06 \\
\hline Corrupción & 0.01 & 2 & 0.02 \\
\hline Incertidumbre por inicio de gobierno & 0.01 & 2 & 0.02 \\
\hline Total & 1.00 & & 2.64 \\
\hline
\end{tabular}

Nota: $4=$ la respuesta es superior, $3=$ la respuesta está por encima del promedio, $2=$ la respuesta es promedio y $1=$ la respuesta es deficiente. 
Según la Matriz de Evaluación de Factores Externos (EFE) en la Tabla 21 el nuevo negocio podría tener una buena respuesta a las oportunidades y amenazas, de acuerdo con el puntaje obtenido 2.64 en esta matriz.

Se observa que el factor externo más relevante para tener éxito en este negocio es nuevos negocios móviles. 


\section{Capítulo III. Estudio de Mercado}

\subsection{Descripción del servicio o producto}

El plan de negocios consiste en implementar un salón de belleza móvil a domicilio que ofrecerá servicios de manicure, pedicure, planchado y corte de cabello, dirigido a las mujeres de 20 a 59 años que viven en la zona dos de Lima Metropolitana de NSE C.

El cliente podrá realizar sus reservas a través de la página web, redes sociales o por teléfono donde indicará día, hora y dirección donde se ejecutará el servicio, como requisito para la atención, el cliente deberá asegurar el lugar de estacionamiento para la móvil.

La móvil llegará al lugar indicado en la reserva a la hora pactada (eliminando tiempo de espera y traslado del cliente), la móvil estará acondicionada con el equipamiento de un salón de belleza convencional, en el que el cliente será atendido por cosmetólogas calificadas según el(los) servicio(s) requerido(s).

Adicionalmente se ofrecerá los siguientes beneficios: minibar, snack bar, radio, televisión y servicios streaming (Netflix, YouTube, Spotify).

\subsection{Selección del segmento de mercado}

La segmentación es un proceso mediante el cual se divide el mercado en grupos homogéneos con el fin de aplicar estrategias de manera más efectiva. Existen dos tipos de segmentación: (a) segmentación de mercados de consumo y (b) segmentación de mercados industriales (Santesmases, 2012).

Para el plan de negocio se utilizó una segmentación de mercados de consumo ya que los productos y/o servicios propuestos van orientados al cliente final. 
También Santesmases (2012) indica que dentro de la segmentación de mercados de consumo existen diferentes tipos de criterios de segmentación:

- Generales, que son criterios independientes al producto y al proceso de compra.

- Específicos, que son criterios con relación al producto y proceso de compra.

Cada uno de ellos se dividen en objetivos y subjetivos, el primer tipo es medible y la medición del segundo tipo es más complicada, cruzando estos tipos de criterio, se puede obtener los criterios a usar para la segmentación, resumidas en la Tabla 22 (Santesmases, 2012):

Tabla 22

Criterios de segmentación de mercados de consumo

\begin{tabular}{lll}
\hline Criterios & Generales & Específicos \\
\hline Objetivos & - Demográficos: sexo, edad, etc. & - Estructura de consumo (grande, \\
& - Socioeconómicos: renta, & mediano, etc.). \\
& ocupación, etc. & - Uso del producto. \\
& - Geográficos: región, hábitat, etc. & - Fidelidad/lealtad a la \\
& & marca/empresa. \\
& & - Tipo de compra: primera o \\
& repetición. \\
& & - Situaciones de compra. \\
\hline Subjetivos & - Personalidad (liderazgo, & - Lugar de compra. \\
& autoridad, autonomía). & - Actitudades. \\
& - Estilos de vida (centros de & - Percepciones. \\
& interés, opiniones, etc.). & - Actitudes. \\
\hline
\end{tabular}

Nota: Adaptado de Marketing: Conceptos y Estrategias, por M. Santesmases, 2012, España, Madrid, Ediciones Pirámide 
En la segmentación de mercado para el plan de negocio del salón de belleza móvil consideró la siguiente información:

\section{Segmentación Geográfica}

Perú es el tercer mejor país en América Latina para emprender negocios, los salones de belleza se encuentran entre los doce negocios más rentables en la ciudad de Lima Metropolitana (Polo, 2015). La población de Lima Metropolitana al 2015 según INEI es de 8’894,412 personas.

Como señaló APEIM (apeim.com.pe, 2016), Lima Metropolitana está conformada por 10’012,437 habitantes, el 68.90\% pertenece a los niveles socio económicos A, B y C (ver Figura $13)$.

DISTRIBUCIÓN DE PERSONAS SEGÚN NSE 2016 - LIMA METROPOLITANA

\begin{tabular}{|c|c|c|c|c|c|c|}
\hline \multirow[b]{3}{*}{ NSE A } & \multicolumn{2}{|c|}{$\mathrm{N}^{0}$ PERSONAS $10^{\prime} 012,437^{*}$} & \multirow{3}{*}{$\begin{array}{c}\text { NSE } \\
\text { A }\end{array}$} & \multirow{2}{*}{$\begin{array}{c}\text { Estrato } \\
\text { A1 } \\
\end{array}$} & \multicolumn{2}{|c|}{ Porcontaje } \\
\hline & \multirow{2}{*}{4.8} & \multirow[b]{4}{*}{$68.9 \%$} & & & 0.7 & \multirow{2}{*}{4.8} \\
\hline & & & & A2 & 4.1 & \\
\hline \multirow{2}{*}{ NSE $B$} & \multirow{2}{*}{21.7} & & \multirow{2}{*}{ B } & B1 & 8.3 & \multirow{2}{*}{21.7} \\
\hline & & & & B2 & 13.4 & \\
\hline \multirow{2}{*}{ NSE C } & \multirow{2}{*}{42.4} & & \multirow{2}{*}{ c } & C1 & 27.9 & \multirow{2}{*}{42.4} \\
\hline & & & & $\mathrm{C} 2$ & 14.5 & \\
\hline NSE D & \multicolumn{2}{|l|}{23.8} & D & D & 23.8 & 23.8 \\
\hline NSE E & \multicolumn{2}{|l|}{7.3} & E & E & 7.3 & 7.3 \\
\hline
\end{tabular}

Figura 13. Incremento de nivel socio económico C en lima metropolitana. Tomado de "Niveles Socio Económico 2016" por APEIM, 2016. Recuperado de http://www.apeim.com.pe/wpcontent/themes/apeim/docs/nse/APEIM-NSE-2016.pdf

2. Segmentación Demográfica

Se usó la variable demográfica edad, seleccionando a las personas cuya edad pertenecen al grupo con mayor PEA en Lima Metropolitana, edades entre 20-59 años. 
Además, se sabe que el 75\% de clientes en los salones de belleza son mujeres (peru21.pe, 2013) por lo cual se consideró la variable demográfica mujeres quienes representan el $51.5 \%$ de la población total de Lima Metropolitana. (limacomovamos.org, 2015).

3. Segmentación Socio Económica

Según la orientación del servicio se eligió el NSE C, ya que cuenta con mayor población en Lima Metropolitana (apeim.com.pe, 2016).

Debido a la naturaleza del servicio, por ser a domicilio, se consideró acotar las zonas de entrega del servicio, por lo cual se determinó la zona dos en Lima Metropolitana. Según APEIM el 52.1\% de personas representan el NSE C de la zona dos (ver Figura 14).

DISTRIBUCIÓN DE NIVELES POR ZONA APEIM 2016 - LIMA METROPOLITANA PERSONAS - (\%) HORIZONTALES

\begin{tabular}{|c|c|c|c|c|c|c|}
\hline \multirow{2}{*}{ Zona } & \multirow[b]{2}{*}{ TOTAL } & \multicolumn{5}{|c|}{ Niveles Socioeconómicos } \\
\hline & & NSE A & NSE B & NSE C & NSE D & NSE E \\
\hline Total & 100 & 4.8 & 21.7 & 42.4 & 23.8 & 7.3 \\
\hline Zona 1 (Puente Piedra, Comas, Carabayllo) & 100 & 0.5 & 10.9 & 46.6 & 29.8 & 12.2 \\
\hline Zona 2 (Independencia, Los Olivos, San Martin de Porras) & 100 & 2.0 & 23.7 & 52.1 & 19.8 & 2.4 \\
\hline Zona 3 (San Juan de Lurigancho) & 100 & 0.0 & 19.1 & 44.2 & 26.7 & 10.0 \\
\hline Zona 4 (Cercado, Rimac, Breña, La Victoria) & 100 & 4.3 & 27.1 & 44.6 & 20.2 & 3.8 \\
\hline $\begin{array}{l}\text { Zona 5(Ate, Chaclacayo, Lungancho, Santa Anita, San Luis, EI } \\
\text { Agustino) }\end{array}$ & 100 & 2.1 & 12.3 & 42.6 & 34.0 & 8.9 \\
\hline Zona 6 (Jesús María, Lince, Pueblo Libre, Magdalena, San Miguel) & 100 & 13.7 & 58.0 & 22.2 & 5.4 & 0.8 \\
\hline Zona 7 (Miraflores, San Isidro, San Borja, Surco, La Molina) & 100 & 35.9 & 43.2 & 14.9 & 4.5 & 1.4 \\
\hline Zona 8 (Surquillo, Barranco, Chorrillos, San Juan de Miraflores) & 100 & 3.9 & 26.6 & 44.5 & 20.5 & 4.4 \\
\hline Zona 9 (Villa El Salvador, Villa Maria del Triunfo, Lurín, Pachacamác) & 100 & 0.0 & 6.3 & 45.7 & 36.6 & 11.4 \\
\hline $\begin{array}{l}\text { Zona } 10 \text { (Callao, Bellavista, La Perla, La Punta, Carmen de la Legua, } \\
\text { Ventanilla) }\end{array}$ & 100 & 1.2 & 19.7 & 44.3 & 23.8 & 11.1 \\
\hline Otros & 100 & 0.0 & 8.1 & 47.6 & 25.4 & 18.9 \\
\hline
\end{tabular}

Figura 14. Nivel socioeconómico de zona dos. Tomado de "Niveles Socio Económico 2016" por APEIM, 2016. Recuperado de http://www.apeim.com.pe/wpcontent/themes/apeim/docs/nse/APEIM-NSE-2016.pdf

En resumen, en la Tabla 23 se muestran los criterios usados en la segmentación del plan de negocio: 
Tabla 23

Criterios de segmentación para el salón de belleza móvil

\begin{tabular}{ll}
\hline \multicolumn{1}{c}{ Criterio } & \multicolumn{1}{c}{ Descripción } \\
\hline Geográfica & - Ubicación: Lima Metropolitana \\
& - Sector: 2 \\
\hline Demográfica & - Sexo: Mujeres \\
& - Edad: $20-59$ años \\
\hline Socio Económico & - NSE: C \\
\hline
\end{tabular}

En la Tabla 24 se calcula la población según los criterios de segmentación elegidos

\section{Tabla 24}

Criterios de segmentación aplicado

\begin{tabular}{ccccc}
\hline Zona & $\begin{array}{c}\text { Población } \\
\text { total (2017) }\end{array}$ & $\begin{array}{c}\text { Población por } \\
\text { edades }(20-59 \\
\text { años })\end{array}$ & $\begin{array}{c}\text { Población mujeres } \\
(51.50 \%)\end{array}$ & $\begin{array}{c}\text { Población por NSE } \\
\text { "C" }(52.10 \%)\end{array}$ \\
\hline Total zona dos & $1,326,938$ & 751,509 & 387,027 & 201,641 \\
\hline
\end{tabular}

Nota. Fuente: Adaptado de INEI (2017d). Población total al 30 de junio, por grupos quinquenales de edad, según departamento, provincia y distrito.

Por lo tanto, se concluye que el universo muestral usado fue de 201,641 personas.

\subsection{Investigación Cualitativa}

Según Hair, Robert y Otinau (2010), el objetivo de esta investigación es obtener conocimientos preliminares y poder entender a los participantes de la investigación.

En el caso del plan de negocio los objetivos de la investigación cualitativa son los siguientes:

- Conocer los gustos y preferencias de los consumidores de salones de belleza

- Identificar los salones de belleza de la competencia

- Determinar la frecuencia de consumo

- Conocer el salón de belleza ideal 
- Identificar el nivel de aceptación de la idea de negocio.

Comprender la estructura, factores de diferenciación, tendencias y comportamiento del sector de belleza que se deberán tomar en cuenta para el desarrollo del plan de negocio.

- Objetivos específicos

- Determinar los aspectos de importancia (productos, infraestructura, precios) que se deben tener en cuenta para implementar un salón de belleza.

- Determinar oportunidades de innovación del servicio tomando como base la oferta actual en el mercado.

- Develar las tendencias de los servicios ofrecidos en locales móviles.

- Determinar el grado inicial de aceptación del plan de negocio.

- Develar las preferencias del mercado potencial con respecto al nuevo servicio para definir algunos aspectos dentro de la investigación cuantitativa.

Según Hair et al. (2010), en la investigación cualitativa existen dos grupos de técnicas que son las siguientes:

- Observación, que consiste en mirar y registrar la conducta de personas.

- Las entrevistas, que sirven para recolectar datos cualitativos primarios, existen varias técnicas, el resumen de ellas se puede visualizar en la Tabla 25: 
Tabla 25

Técnicas más usadas por los investigadores

\begin{tabular}{lr}
\hline Principal método cualitativo & Frecuencia de Uso \\
\hline Grupo de enfoque tradicional (Focus Group) & $51.80 \%$ \\
\hline Híbridos (dos o más métodos) & 14.3 \\
\hline Entrevistas exhaustivas & 7.8 \\
\hline Netnografía & 4.2 \\
\hline Etnografía & 2 \\
\hline Grupos de enfoque en salas de plática en línea & 1.2 \\
\hline Grupos de enfoque en video en línea & 1 \\
\hline Otro & 5 \\
\hline Ninguno & 21.7 \\
\hline
\end{tabular}

Nota: Tomado de "Tendencias del sector de la investigación” por Pionner Marketing Research, GreenBook, Rockhooper Research y Dialtech, 2006.

a. Entrevistas Exhaustivas (Profundidad):

Según Hair et al. (2010) es una técnica en la que un entrevistador hace un conjunto de preguntas semiestructuradas de sondeo para obtener información del entrevistado sobre sus nociones preliminares, comentarios, sentimientos, conductas y conocimientos sobre algún tema en particular.

b. Entrevista de grupos de enfoque (focus group):

Según Kotler y Amstrong (2012) el focus group consiste en reunir un grupo de seis a 10 personas que son guiadas por un moderador en la que se discute un tema en específico de manera semiestructurada, el moderador promueve la libre discusión del producto o servicios. Los objetivos del focus group son los siguientes:

- Obtener información para definir problemas de marketing.

- Información para el entendimiento de estudios cuantitativos.

- Determinar actitudes de consumidores respecto a servicios y/o productos.

- Crear ideas sobre nuevos productos y/servicios. 
Para el plan de negocio, en la investigación cualitativa se usaron las técnicas de focus group y entrevista de profundidad.

Se ejecutaron cuatro focus group de seis personas cada uno, las personas a seleccionar deberán cumplir con los detalles de la segmentación para el plan de negocio, que son potenciales clientes para conocer sus expectativas y disposición de consumo.

Se ejecutaron cinco entrevistas de profundidad considerando a los expertos relacionados con el plan de negocio.

\subsubsection{Proceso de muestreo}

La población, según McDaniel y Gates (2016), es un grupo entero de personas de las cuales se obtendrá información antes de realizar el muestreo.

El muestreo, según McDaniel y Gates (2016), es el proceso de obtener un subconjunto de un grupo mayor (población), este subconjunto (muestra) posteriormente se podrá proyectar a la población.

Hair et al. (2010) indica que la investigación cualitativa usa los métodos de muestreo no probabilístico que son los siguientes:

- Muestreo por conveniencia, la muestra es extraída en base a la comodidad del investigador (población homogénea).

- Muestreo por juicio, la muestra es extraída según la experiencia del investigador.

- Muestreo por cuota, la muestra es extraída en perspectiva conforme a cuotas pre especificadas de características demográficas, actitudes específicas o de comportamientos específicos. 
- Muestreo de bola de nieve, donde se identifica un grupo inicial y luego este grupo ayuda al investigador a identificar personas adicionales para el estudio.

Para la entrevista de profundidad, se usó el muestreo por conveniencia ya que se investigó a algunos actores claves relacionados al plan de negocio, logrando acordar entrevistas con ellos, considerando la reserva adecuada en información sensible para sus negocios, se determinaron cinco expertos vinculados al sector de la belleza y de los negocios móviles:

- Se escogió a un dueño de un salón de belleza independiente. Se entrevistó a una persona con experiencia en el sector de belleza por más de ocho años, con grado de instrucción en cosmetología, estética y peluquería, que sea propietario de un local en la zona dos de Lima Metropolitana.

- Se escogió a un funcionario de una de las cadenas más importantes de Lima, profesional en administración, con experiencia en el sector de belleza por más de tres años, con especialización en marketing de servicios y que sea administrador de un local en la Zona dos de Lima Metropolitana.

- Se seleccionó a un proveedor de productos para salones de belleza, persona con experiencia en ventas de productos para sector de belleza por más de ocho años, cursando las carreras de administración y que labore como ejecutiva comercial o vendedora de un distribuidor en productos de belleza de Lima Metropolitana.

- Un experto en el sector belleza, un encargado de salón. Se entrevistó a un profesional en administración, con experiencia en el sector de belleza por más de diez años, con especialización en marketing de Servicios y que sea administrador de un local en cualquier distrito de Lima Metropolitana. 
- Un experto en negocios de food truck. Se entrevistó a un profesional en administración hotelera, con experiencia en el sector por más de cinco años y que sea propietario de un Food Truck en cualquier distrito de Lima Metropolitana.

Para los focus group se usó el muestro de bola de nieve, se contactó a personas que desarrollan actividades y asisten a salones de belleza dentro de la zona dos (universidades, centros comerciales, urbanizaciones de los distritos) y se pudo armar los grupos para las sesiones, las personas cumplen con el segmento seleccionado, mujeres de la ciudad de Lima Metropolitana, de la zona dos, entre 20 a 59 años de edad y que actualmente asistan por lo menos una vez al mes a salones de belleza.

Se realizó cuatro focus group de seis personas cada uno, en total la muestra fue de 24 personas.

\subsubsection{Diseño de instrumento}

Según Soonthorndhada (1989), para poder cumplir con los objetivos de la investigación cualitativa se deben tener en cuenta tres clases de preguntas distintas:

- Descriptivas; el investigador puede evaluar el conocimiento de una persona, centradas en información personal, familiar o comunitarias.

- Estructuradas; ayudan al investigador a buscar respuestas de actitudes, de creencia, conductuales y atribución.

- De contrastación; el entrevistador obtiene beneficios a partir de esta clase de preguntas ya que descubre cómo la gente diferencia los eventos y objetos en sus propias palabras y perspectivas. 
Estos tipos de preguntas pueden ser desarrolladas de diferentes formas dentro de la guía de entrevistas, dependiendo de los objetivos planteados, estas formas son las siguientes:

- Abiertas, permite contestar con un lenguaje real, expresar sus sentimientos y experiencias sin interferencia del entrevistador o respuestas preestablecidas.

- Presuposición, apuntan a inducir un aumento de significado a medida que la entrevista progresa. Esta clase de preguntas es de utilidad cuando las preguntas estructuradas son esperadas, ya que el entrevistador presupone que la persona tiene algo más que decir, sirven para dos funciones (a) estimular a las personas a hablar más y (b) facilitar la conversación.

- Role playing, pueden ser usadas también en entrevistas abiertas en orden a facilitar preguntas difíciles cuando la discusión está en progreso o cuando las personas se cansan de pensar en respuestas apropiadas. El efecto de estas preguntas es mejorar la atmósfera de la entrevista.

- Encuesta de seguimiento, son usadas habitualmente para ahondar en las respuestas dadas a una pregunta. Dos clases de exploraciones pueden ser desarrolladas, (a) exploraciones de detalle orientado, consisten en preguntas que apuntan a llenar los espacios en blanco de una respuesta y (b)exploración de elaboración, es usada cuando el entrevistador quiere entrevistar a las personas para que digan más si es que no pueden entender las preguntas.

Según Hair et al. (2010), los pasos para realizar una entrevista exhaustiva (profundidad) son los siguientes: 
- Determinar el problema a investigar.

- Preparar las preguntas orientadas al objetivo de la investigación.

- Determinar el entorno óptimo para ejecutar la entrevista.

- Seleccionar a las personas a entrevistar.

- Iniciar con una breve introducción al entrevistado.

- Realizar la entrevista.

- Analizar las respuestas del entrevistado y elaborar informe.

Siguiendo las pautas indicadas se determinó el problema o tópico a investigar los cuales son (a) tendencias, (b) comportamiento de la oferta y demanda, (c) aspectos que determinan la diferenciación en el servicio y (d) relación con la tendencia de los negocios móviles.

De acuerdo a lo indicado anteriormente, se prepararon las preguntas para cada una de las entrevistas, según la información que se necesitó de cada entrevistado, con esta información se elaboró la guía de preguntas.

Se acordó con cada entrevistado el lugar de la entrevista, todos coincidieron en que era más óptimo realizar la entrevista en su centro de labores, esto también sirvió para experimentar el comportamiento del negocio en momentos previos o posteriores a la entrevista.

Con esta información y la recogida anteriormente se tiene la ficha técnica para las entrevistas en la Tabla 26.

Finalmente, se elaboró las guías de entrevistas a expertos, que se encuentra adjunto en el Anexo 1. 
Tabla 26

Ficha Técnica de Entrevistas de Profundidad

\begin{tabular}{|c|c|}
\hline Técnica empleada & Entrevista de Profundidad \\
\hline Localización & Lima Metropolitana, zona dos \\
\hline Técnica de reclutamiento & Preguntas abiertas y entrevista personal \\
\hline Supervisión & Supervisión continua \\
\hline $\mathrm{g}$ Objetivo del estudio & $\begin{array}{l}\text { Obtener información de las tendencias y } \\
\text { consumo de los salones de belleza, demanda, } \\
\text { crecimiento del mercado, innovaciones en este } \\
\text { sector, ventajas y desventajas de los negocios } \\
\text { móviles. }\end{array}$ \\
\hline Temas estudiados & $\begin{array}{l}\text { a) Aspectos generales sobre las tendencias del } \\
\text { sector de belleza }\end{array}$ \\
\hline & b) Demanda del sector \\
\hline $\mathrm{H}$ & $\begin{array}{l}\text { c) Diferenciación de los servicios de salones } \\
\text { de belleza }\end{array}$ \\
\hline $\mathrm{a}$ & $\begin{array}{l}\text { d) Información de los servicios o productos } \\
\text { móviles }\end{array}$ \\
\hline i & e) Investigación de otros negocios móviles \\
\hline Fecha de estudio & $\begin{array}{l}\text { Del } 12 \text { de marzo de } 2017 \text { al } 10 \text { de marzo de } \\
2017\end{array}$ \\
\hline Hora de inicio & $8: 00 \mathrm{pm}$ \\
\hline Duración & $30-50$ minutos \\
\hline
\end{tabular}

et al. (2010), los focus group se suelen dividir en tres fases lógicas: (a) Planeamiento del

estudio del producto o servicio, (b) Efectuar las discusiones del focus group, (c) Analizar y reportar los resultados para obtener las preferencias del consumidor elegido.

Según APEIM (2016), dentro de la fase de planeamiento del estudio se debe tener en cuenta el reclutamiento de los participantes, considerando: (a) cumplir con las variables muestrales, (b) obtener variedad dentro de la homogeneidad necesaria para cumplir con la muestra, (c) rechazar perfiles que puedan ocasionar tendencias en la participación dentro del focus (profesionales del sector, marketing, competencia, etc.). 
También se debe considerar la elaboración de la guía de pautas que debe ser flexible en relación con la presentación de temas, ya que debe facilitar la discusión y espontaneidad de los participantes, asimismo, debe permitir la incorporación de nuevos temas en la discusión, siempre y cuando sean relevantes.

Para el plan de negocio se consideró el muestreo tipo bola de nieve donde se contactó a personas que viven en la zona dos de Lima Metropolitana y que cumplen con la edad detallada en la muestra, se contactó a personas que viven en cada distrito, con estas personas se armaron dos grupos; luego se consideró un grupo de personas que trabajan dentro de la zona y otro grupo de personas que estudian en la zona, con esto se obtuvieron los cuatro grupos para el estudio.

Se elaboró la guía de pautas para el moderador de los focus group, que se encuentra adjunto en el Anexo 2.

A continuación, se presenta la ficha técnica para los focus group en la Tabla 27

Tabla 27

Ficha Técnica de focus group

\begin{tabular}{ll}
\hline \multicolumn{1}{c}{ Tipo de estudio } & \multicolumn{1}{c}{ Cualitativo } \\
\hline Técnica & Focus group \\
\hline Instrumento & Guía de Pautas \\
\hline Periodo Base & 2017 \\
\hline $\begin{array}{l}\text { Periodo de referencia de las } \\
\text { ponderaciones }\end{array}$ & Del 10 al 13 marzo de 2017 \\
\hline Método de recogida & Sesión de grupo de seis personas \\
\hline Objetivo del estudio & $\begin{array}{l}\text { Recopilar información exploratoria } \\
\text { acerca del sector de belleza y/o cuidado } \\
\text { personal para el desarrollo del nuevo } \\
\text { producto/servicio. }\end{array}$ \\
\hline Cantidad de entrevistados & 24 Personas \\
\hline
\end{tabular}




\subsubsection{Análisis y procesamiento de datos.}

Los resultados del estudio de cualitativo se muestran de acuerdo a los objetivos detallados anteriormente:

- Conocer los gustos y preferencias de los consumidores de salones de belleza.

La gran mayoría de los participantes indicaron que si van a los salones de belleza para mantener el cuidado de sus manos, pies y cabello.

Entre las razones de ir a salones de belleza es porque deben cuidar su imagen personal debido a que la mayoría trabajan en empresas comerciales.

Para los participantes es muy importante que el estilista sea un profesional de carrera y que puedan tener empatía entre ambos, además debe estar capacitado con las nuevas tendencias y aconsejar siempre a sus clientes.

Dentro de los motivos de los participantes en ir a un salón de belleza es el tiempo ya que solo cuentan con una o dos horas para dedicarle a su cuidado personal, debido a que trabajan, estudian y realizan labores de la casa.

Para los participantes es importante ofrecer los paquetes, promociones que se brinden para manos, pies y cabellos.

- Identificar los salones de belleza de la competencia.

La mayoría de los participantes asisten al salón de belleza Montalvo, debido a que tiene mayor cobertura de instalaciones en la zona dos de Lima Metropolitana. Luego asisten a Soho Color u otros cuando hay ofertas.

Los participantes indicaron que la publicidad en redes sociales es importante ya que por ese medio se informan de nuevos salones de belleza.

- Determinar la frecuencia de consumo: 
Los participantes indicaron utilizar las campañas y ofertas durante los meses más claves donde hay mayor demanda y los precios se puedan mantener: enero, febrero, mayo, julio, noviembre y diciembre.

Principalmente indicaron los participantes que acuden a los salones de belleza tres veces por semana, o sino los fines de semana, eso dependerá de la carga laboral, estudiantil o de la casa.

Para los participantes el gasto promedio es desde S/ 25 hasta S/. 400, dependiendo el mantenimiento y servicios que se van a realizar en las manos, pies y cabello.

- Conocer el salón de belleza ideal.

Los participantes desearían un establecimiento con los siguientes servicios: TV, radio, multimedia, snack o bar juntos, iluminado, espacioso, con productos de calidad. Para los participantes es importante los estilistas, las personas que se van a encargar de realizarle los servicios, deben ser profesionales y mantener una relación cordial y amical.

- Identificar el nivel de aceptación de la idea de negocio.

Los participantes indicaron que, con respecto al servicio a domicilio, es muy solicitado, pero no es de mucha confiabilidad para los estilistas debido a que no cuentan con la infraestructura ni comodidades para brindar un buen servicio, ya que se deben adaptar a los espacios del hogar del cliente, en este caso tener un salón de belleza móvil ofrecería comodidad no sólo al cliente sino también al estilista.

- Según la apreciación de los grupos, la zona dos tienen tres tipos o marcas de salones que tienen mayor participación en el mercado: Montalvo, Soho y los salones de belleza independientes que explotan la cercanía a los clientes y los horarios de disponibilidad. 
- El plan de negocio del salón de belleza móvil es aceptado al 100\% porque la muestra de los focus group llamarían para reservar una cita y realizarse los servicios de planchado, manicure, pedicure, depilación, tinte y corte dentro de la móvil. Las participantes consideran que los salones de belleza son de importancia para su cuidado personal, asisten por lo menos una vez al mes, la frecuencia depende de los servicios.

- Las variables más predominantes al momento de elegir un salón de belleza son: infraestructura, productos, atención, la tendencia y el estilista, pues según los Focus Group se ha determinado que estas variables son determinantes en decidir cambiar de salón de belleza. El tiempo de atención y traslado también se consideran importantes ya que llegan muy estresadas o no hay espacio en el momento que lo requieren y deben regresar.

- Con respecto a los hábitos de uso, la mayoría depende mucho de sus actividades diarias, trabajo o estudio.

- En cuanto a servicios adicionales para este salón de belleza móvil, los grupos indicaron que les gustaría tener a disposición: televisor, snacks, wifi, bebidas y tener una asesoría de imagen.

\subsection{Investigación Cuantitativa}

La investigación cuantitativa es el enfoque científico de la toma decisiones donde las subjetividades no son tomados por este enfoque y que por el contrario se basa en datos numéricos que luego son analizados para convertirlos en información (Render, Stair, \& Hanna, 2012). Las técnicas cuantitativas aprueban o rechazan una hipótesis establecida con porcentajes o estadísticas. (Benassini, 2014). 
A continuación, se necesita identificar los siguientes objetivos para la investigación cuantitativa:

- Determinar el porcentaje de personas dispuestas a ir al salón de belleza móvil o reservar una cita

- Determinar el porcentaje de los principales servicios a ofrecer

- Determinar el porcentaje de aceptación de precios en lanzamiento

- Determinar el porcentaje de medios de publicidad.

Para iniciar la investigación cuantitativa es necesario definir el alcance, según Hernández, Fernández, y Baptista (2010) mencionan que existen dos tipos de diseño para investigar; experimental y no experimental.

1. Experimental, Hernández et al. (2010) indican que se refiere a una situación de control en la cual se manipulan, de manera intencional, una o más variables independientes (causas) para analizar las consecuencias de tal manipulación sobre una o más variables dependientes (efectos).

2. No experimental, Hernández et al. (2010) indican que son los estudios que se realizan sin la manipulación deliberada de variables y en los que sólo se observan los fenómenos en su ambiente natural para después analizarlos.

A continuación, se muestra el siguiente cuadro donde se muestra la clasificación de la investigación no experimental (Ver Figura No. 15): 


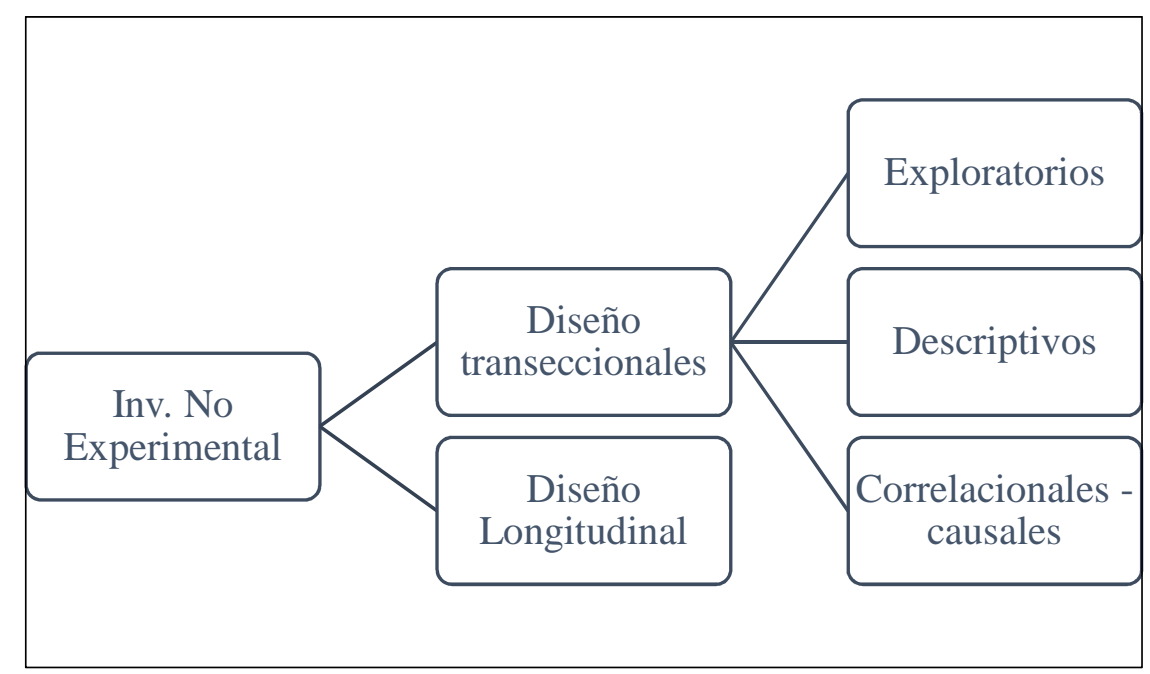

Figura 15. Clasificación de la investigación no experimental. Adaptado de Metodología de Investigación por Hernández, R., Fernández, C., \& Baptista, M., 2010, México: McGraw Hill Educación. Copyright 2010 por McGraw-Hill / Interamericana Editores, S.A. DE

a. Diseño longitudinal, estudios que recaban datos en diferentes puntos del tiempo.

b. Diseños transeccionales, son investigaciones que recopilan datos en un momento único, se clasifican en: (a) exploratorio, (b) descriptivo y (c) correlacionales.

Para definir las encuestas, Creswell (como se cita en Hernández et al., 2010) indica que son consideradas también como un diseño, basado en la clasificación detallada anteriormente, serían investigaciones no experimentales transversales o transeccionales descriptivas o correlacionales, ya que a veces tienen los propósitos de uno u otros diseños y a veces de ambos.

Según Hair et al. (2010) existen diferentes métodos de investigación mediante encuestas: (a) aplicada por personas, (b) aplicada por teléfono, (c) auto administrada y (d) asistida por computadora

Para la investigación cuantitativa se usó los métodos de encuestas por personas y encuestas asistidas por computadora (correo, Google forms) que actualmente es el método más rápido de llegar a más personas. 


\subsubsection{Proceso de muestreo.}

La muestra es un subconjunto de la población, se obtiene información de o acerca de una muestra y se le usa para hacer estimaciones sobre las diversas características de la población total. La muestra de la que se obtiene información es una sección transversal de la población total (Hair et al., 2010).

El muestreo, según McDaniel y Gates (2016), es el proceso de obtener un subconjunto de un grupo mayor (población), este subconjunto (muestra) posteriormente se podrá proyectar a la población.

Hair et al. (2010) indica que la investigación cuantitativa usa los métodos de muestreo probabilístico ya que cada unidad tiene probabilidad de ser elegida en la muestra, indicadas en la Tabla 28.

Tabla 28

Métodos de Investigación Cuantitativa

\begin{tabular}{ll}
\hline \multicolumn{1}{c}{ Método } & \multicolumn{1}{c}{ Definición } \\
\hline Muestreo Simple (MAS) & Unidad tiene igual oportunidad de ser seleccionada. \\
\hline $\begin{array}{l}\text { Muestreo sistemático } \\
\text { (MASI) }\end{array}$ & $\begin{array}{l}\text { Se ordenan unidades en una lista y se seleccionan de } \\
\text { acuerdo con su ubicación. }\end{array}$ \\
\hline $\begin{array}{l}\text { Muestreo estratificado } \\
\text { (MAE) }\end{array}$ & $\begin{array}{l}\text { Se divide a la población en grupos y se selecciona muestra } \\
\text { por cada grupo (estrato). }\end{array}$ \\
\hline $\begin{array}{l}\text { Muestreo por } \\
\text { conglomerado }\end{array}$ & Los estratos son mutuamente excluyentes \\
\hline
\end{tabular}

En la Figura 16 se muestra los pasos del desarrollo de un plan de muestreo. 


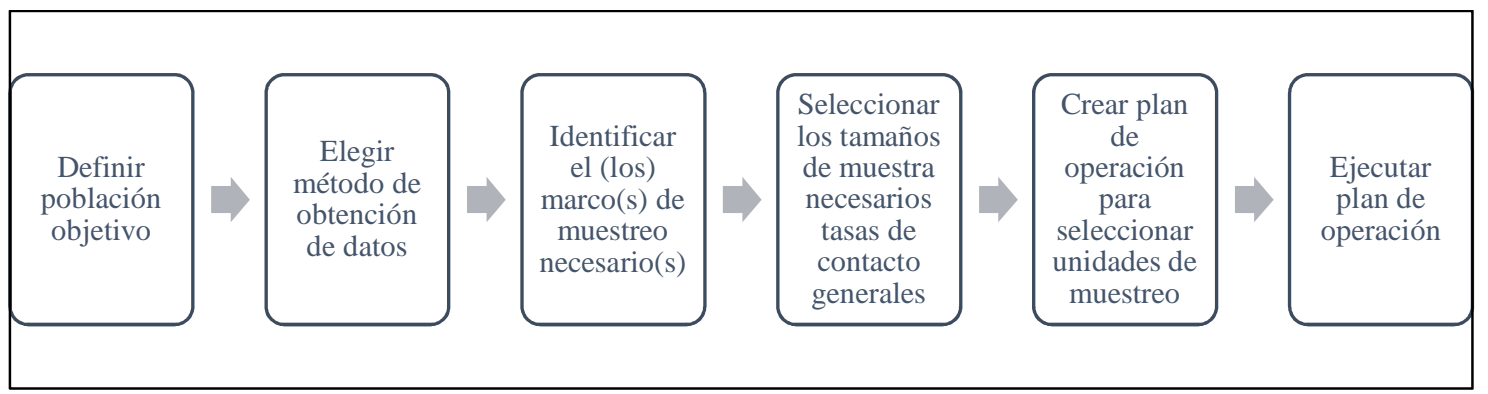

Figura 16. Pasos para desarrollar un plan de muestreo. Tomado de Investigación de Mercados En un ambiente de información digital por Hair, Robert y Otinau, 2010, México: Mc Graw Hill. Copyright 2010 por The McGraw-Hill Companies, Inc.

Definición de la población: De acuerdo a los parámetros utilizados en los criterios de segmentación la población es de 201,641 personas de la zona dos de Lima Metropolitana, Mujeres de 20 a 59 años de edad, NSE “C”, lo cual es una población infinita o desconocida (población mayor a 100 mil personas).

El tamaño de la muestra es estratificado, por lo tanto, se aplicó una cuota para poder determinar la cantidad de encuestas para cada distrito de la zona dos de Lima Metropolitana, aplicando primero la formula correspondiente.

De acuerdo a los resultados obtenidos, la población es infinita y el muestreo es estratificado, por lo tanto, se aplicará la siguiente formula:

$$
\mathrm{n}=\frac{\mathrm{Z}^{2} \mathrm{pq}}{\mathrm{E}^{2}}
$$

Donde:

$\mathrm{Z}=$ valor para un nivel de confianza

$\mathrm{p}=$ variabilidad positiva

$\mathrm{q}=$ variabilidad negativa $=1-\mathrm{p}$

$\mathrm{E}=$ porcentaje de error 
Considerando como información un nivel de confianza de $\mathrm{Z}=95 \%$ y un margen de error de $\mathrm{E}=5 \%$ se ha determinado que el tamaño de la muestra es 384 personas para encuestar.

En la Tabla No. 29 se elaboró el tamaño y elementos de la muestra de acuerdo con la población de mujeres de 20 a 59 años de edad, NSE “C”, indicando la cuota y el número de encuestas para cada distrito de la zona dos de Lima Metropolitana.

Tabla 29

Tamaño y elementos de la muestra

\begin{tabular}{lccrrrr}
\hline \multicolumn{1}{c}{ Distrito } & $\begin{array}{c}\text { Población } \\
\text { Total } \\
(2017)\end{array}$ & $\begin{array}{c}\text { Población } \\
\text { Por Edades } \\
(20-59 \\
\text { años })\end{array}$ & $\begin{array}{c}\text { Población } \\
\text { Mujeres } \\
(51.50 \%)\end{array}$ & $\begin{array}{c}\text { Población } \\
\text { por NSE } \\
\text { "C" } \\
(52.10 \%)\end{array}$ & No. Cuota & $\begin{array}{c}\text { No. } \\
\text { Encuestas } \\
(384)\end{array}$ \\
\hline Independencia & 216,938 & 120,582 & 62,100 & 32,354 & $16 \%$ & 62 \\
Los Olivos & 382,077 & 219,809 & 113,202 & 58,978 & $29 \%$ & 112 \\
San Martin de Porras & 727,923 & 411,117 & 211,725 & 110,309 & $55 \%$ & 210 \\
\hline & & & & & & \\
Total Zona Dos & $1,326,938$ & 751,509 & 387,027 & 201,641 & $100 \%$ & 384 \\
\hline
\end{tabular}

\subsubsection{Diseño de instrumento.}

Según Hair et al. (2010) un tema importante que se debe abordar durante el diseño de una encuentra es la medición que sería el proceso de determinar la cantidad o intensidad de información acerca de los constructos, conceptos y objetos.

Un constructo es una variable hipotética formada por un conjunto de respuestas o comportamientos a los que se considera relacionados entre sí.

El procedimiento de medición consiste en dos procesos de desarrollo claramente diferentes: (a) el desarrollo del constructo y (b) la escala de medición. 
Los niveles básicos de escala son: (a) nominales, (b) ordinales, (c) de intervalo y (d) proporciones.

Mediante una encuesta también se puede medir la actitud y comportamiento del encuestado ante una circunstancia, para medir las actitudes y comportamientos, se usan las escalas: (a) Likert, (b) diferencial semántico y (c) de intención conductual

Para las encuestas se usó más de una escala de medición ya que se midieron datos de segmentación, datos de preferencia y conductas hacia el uso del servicio ofrecido.

Se elaboró la ficha técnica de la encuesta que se detalla en la Tabla 30.

Se elaboraron los cuestionarios para encuesta detallados en el Anexo 3.

\section{Tabla 30}

Ficha técnica de la encuesta

\begin{tabular}{ll}
\multicolumn{1}{c}{ Naturaleza Metodológica } & \multicolumn{1}{c}{ Cuantitativa } \\
\hline Técnica metodológica & Encuesta por Internet y personal \\
\hline Tipo de cuestionario & Estructurado de 21 preguntas cerradas \\
\hline Universo & $\begin{array}{l}\text { Mujeres de Lima Metropolitana, zona dos, } \\
\text { NSE C, con edad entre 20-59 años }\end{array}$ \\
\hline Ámbito geográfico & Zona dos de Lima Metropolitana \\
\hline Elementos del muestreo & $\begin{array}{l}\text { Mujeres que asisten al menos una vez al mes a } \\
\text { salones de belleza }\end{array}$ \\
\hline Tipo de muestreo & Muestreo estratificado \\
\hline Tamaño muestral & 384 mujeres \\
\hline Nivel de confianza & $95 \%$ \\
\hline Margen de error & $5 \%$ (Universo >100,000) \\
\hline Tipo de preguntas & $\begin{array}{l}\text { Dicotómicas, de opción múltiple, con escala de } \\
\text { Likert, escala de importancia y escala de } \\
\text { intención de compra }\end{array}$ \\
\hline Fecha de recolección de datos & 12 de marzo de 2017 \\
\hline
\end{tabular}




\subsubsection{Análisis y procesamiento de datos.}

Según el tamaño de la muestra se realizó 384 encuestas en la zona dos de Lima Metropolitana, de los cuales 284 fueron por vía Google forms y 100 realizadas de forma personal en los centros comerciales; considerando la distribución de encuestas por distrito.

Se ha obtenido la siguiente información general de la muestra:

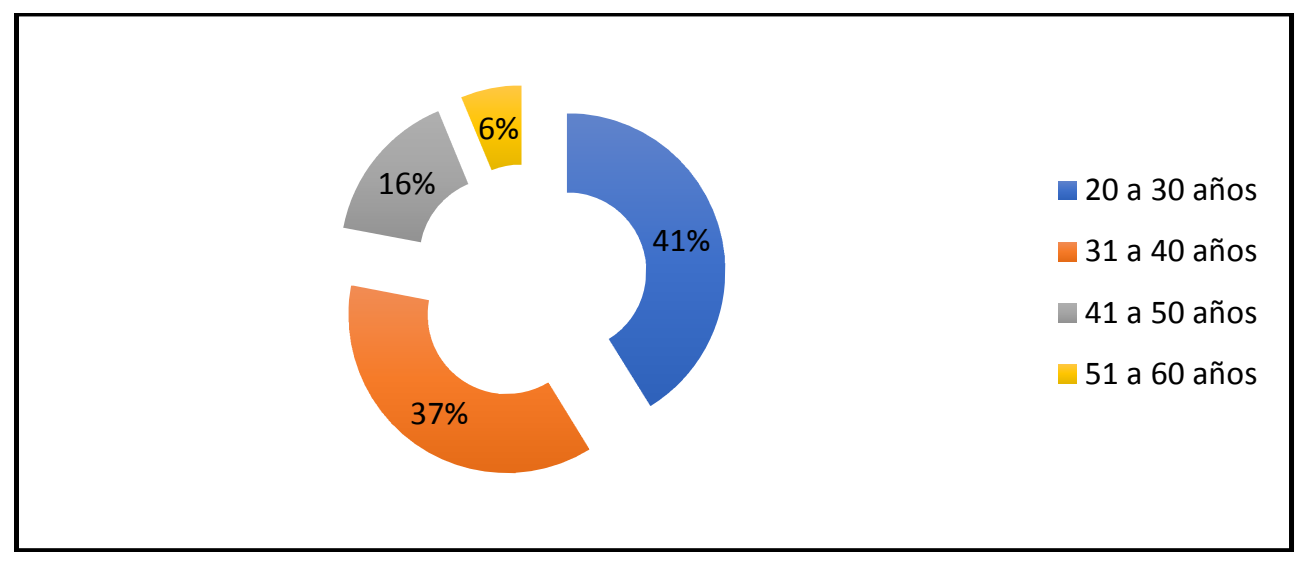

Figura 17. Rango de Edad de encuestadas

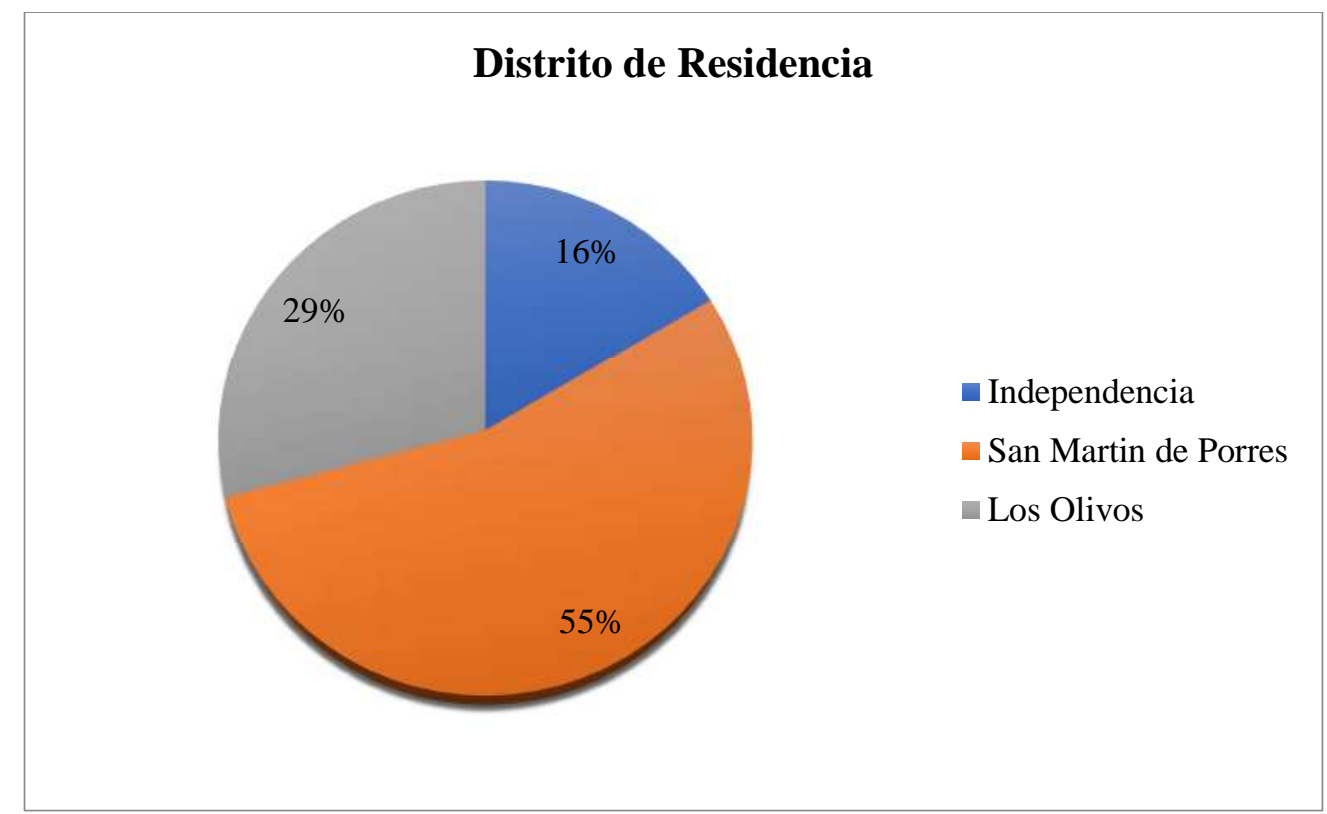


Figura 18. Distrito de residencia de encuestadas

Se realizó las encuestas al 100\% de las mujeres de la zona dos de Lima Metropolitana y según las Figuras 17 y 18 se obtiene como información importante de filtro, donde el $78 \%$ de las encuestadas tienen entre 20 y 40 años, lo que ayuda a poder estimar las costumbres, motivos y frecuencia de uso de los servicios de salones de belleza, asimismo, el 55\% de las encuestadas residen en San Martin de Porras, confirmando el desarrollo comercial y el distrito que tiene mayor población según las investigaciones realizadas anteriormente.

A continuación, se desarrollan las preguntas correspondientes a la encuesta realizada a la muestra seleccionada:

a. ¿Asiste al menos una vez al mes al salón de belleza?

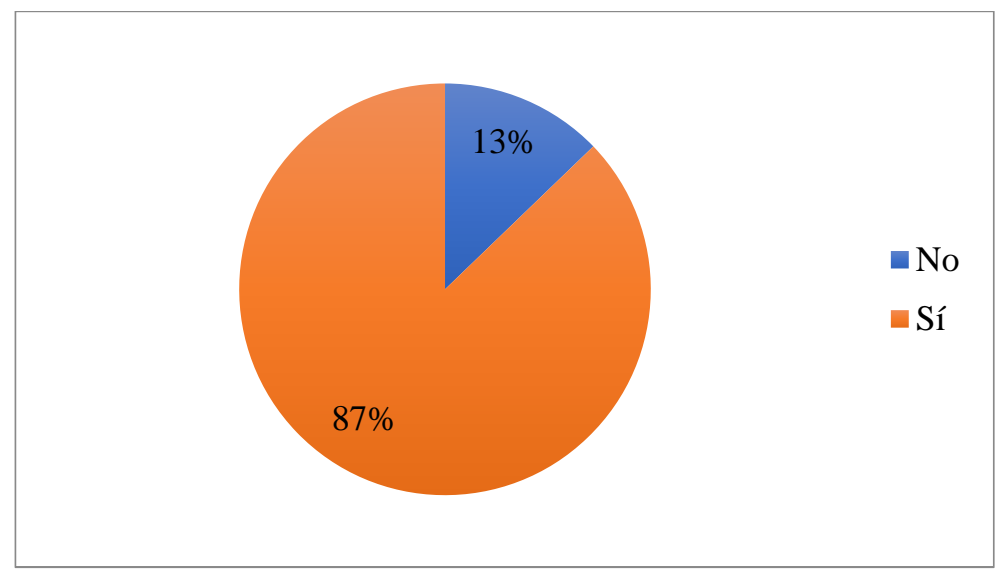

Figura 19. Asistencia a salones de belleza

\section{b. ¿Es un factor importante para usted asistir a un salón de belleza?}




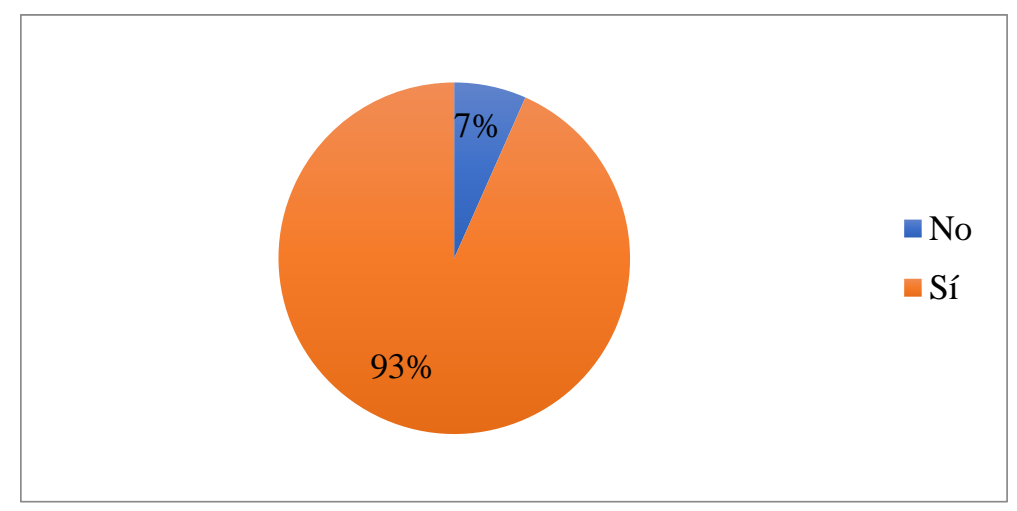

Figura 20. Importancia de asistir a un salón de belleza

Según las Figuras 19 y 20, de las 384 personas encuestadas, 334 personas afirmaron que asiste por lo menos un mes al salón de belleza y 357 afirmaron que es un factor importante asistir a un salón de belleza. En promedio de las dos preguntas principales son 346 personas que va una vez al mes al salón de belleza y es un factor importante, quiere decir, que existe algún tipo de necesidad que se deberá explotar en el plan de negocio.

Después de la aplicación de las preguntas filtro, ahora se continuó encuestando a las 346 personas, descartando a 38 personas las cuales no es de su interés ir a un salón de belleza. 
c. ¿Cuáles son las principales razones por las que asiste a un salón de belleza?

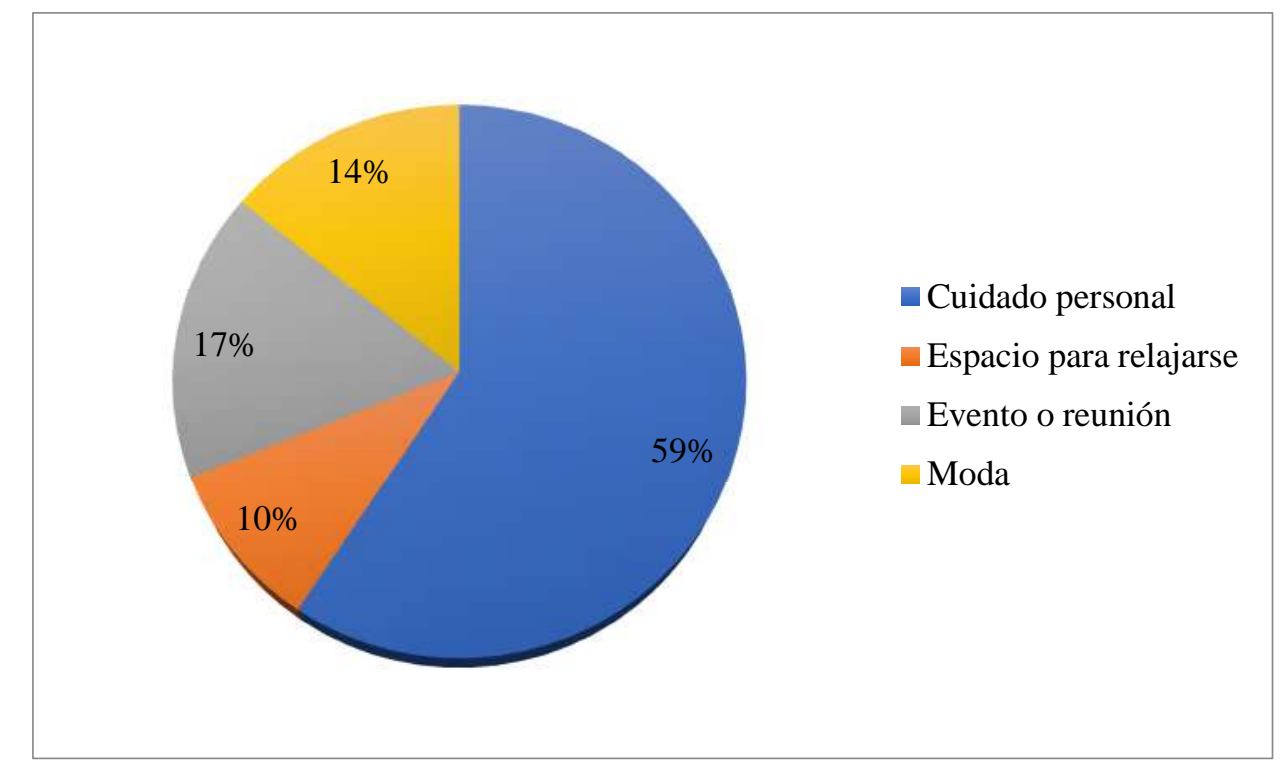

Figura 21. Razones de asistencia al salón de belleza

Según se muestra en la Figura 21, se encontró que un 59\% de la muestra asiste a los salones de belleza por cuidado personal, esto quiere decir que las personas pertenecientes al segmento toman los servicios de belleza para cubrir una necesidad de cuidado de imagen y/o salud, lo que hace suponer que se contará con una demanda constante en el mercado.

En menores proporciones se encuentra moda, eventos y espacio de relajación; se podrían explotar estas razones para crear una nueva necesidad y aumentar más aún la demanda. 


\section{d. De acuerdo con la pregunta anterior ¿con qué frecuencia solicita los siguientes servicios en el salón de belleza?}

Tabla 31

Frecuencia de solicitud de servicio de corte

\begin{tabular}{lrr}
\hline CORTE & CANTIDAD & \multicolumn{2}{c}{ PORCENTAJE } \\
\hline Una vez por semana & 17 & $5 \%$ \\
Cada 15 dias & 42 & $12 \%$ \\
Una vez al mes & 95 & $28 \%$ \\
Trimestral & 68 & $20 \%$ \\
No solicito & 69 & $20 \%$ \\
Ocasionalmente & 55 & $16 \%$ \\
\hline Total general & 346 & $100 \%$ \\
\hline
\end{tabular}

Según se muestra en la Tabla 31, la mayoría de personas solicitan el servicio de corte una vez al mes, esto hace considerar a este servicio como uno de los frecuentes dentro de la estimación de la demanda para el plan de negocio, asimismo, en la estimación del personal a contratar, se debe considerar tener un especialista en corte de cabello.

Tabla 32

Frecuencia de solicitud de servicio de peinado

\begin{tabular}{lrr}
\hline PEINADO & CANTIDAD & PORCENTAJE \\
\hline Una vez por semana & 41 & $10 \%$ \\
Cada 15 días & 47 & $12 \%$ \\
Una vez al mes & 96 & $24 \%$ \\
Trimestral & 17 & $4 \%$ \\
Ocasionalmente & 142 & $35 \%$ \\
No solicito & 64 & $16 \%$ \\
\hline Total general & 346 & $100 \%$ \\
\hline
\end{tabular}

Según Tabla 32, el servicio de peinado es solicitado ocasionalmente por los clientes, este comportamiento tiene concordancia con lo indicado en la pregunta anterior, en que sólo el $17 \%$ de personas asisten al salón de belleza por eventos especiales, se puede 
relacionar el tipo de servicio de peinado para eventos o reuniones, originando una estrategia de marketing para este tipo de casos.

Tabla 33

Frecuencia de solicitud de servicio de planchado

\begin{tabular}{lrr}
\hline PLANCHADO & CANTIDAD & PORCENTAJE \\
\hline Una vez por semana & 43 & $12 \%$ \\
Cada 15 dias & 57 & $16 \%$ \\
Una vez al mes & 84 & $24 \%$ \\
Trimestral & 39 & $11 \%$ \\
Ocasionalmente & 60 & $17 \%$ \\
No solicito & 64 & $18 \%$ \\
\hline Total general & 346 & $100 \%$ \\
\hline
\end{tabular}

Según Tabla 33, el servicio de planchado tiene un comportamiento constante para cada una de las frecuencias propuestas, esto brinda una primera estimación de que este servicio será constante para el plan de negocio, es decir, que se debe considerar la adquisición de recursos para ejecutar este servicio en la inversión inicial.

Tabla 34

Frecuencia de solicitud de servicio de alisado

\begin{tabular}{lrr}
\hline ALISADO & CANTIDAD & PORCENTAJE \\
\hline Una vez por semana & 35 & $10 \%$ \\
Cada 15 dias & 33 & $10 \%$ \\
Una vez al mes & 58 & $17 \%$ \\
Trimestral & 51 & $15 \%$ \\
Ocasionalmente & 82 & $24 \%$ \\
No solicito & 87 & $25 \%$ \\
\hline Total general & 346 & $100 \%$ \\
\hline
\end{tabular}

Según Tabla 34, el servicio de alisado es requerido ocasionalmente o no es usado, en este caso, se podría evaluar la posibilidad no incluir este servicio en el plan de negocio, 
esto se podrá validar más adelante con la pregunta dirigida al negocio de salón de belleza móvil.

Tabla 35

Frecuencia de solicitud de servicio de extensiones

\begin{tabular}{lrr}
\hline EXTENSIONES & CANTIDAD & \multicolumn{2}{c}{ PORCENTAJE } \\
\hline Una vez por semana & 31 & $9 \%$ \\
Cada 15 días & 26 & $8 \%$ \\
Una vez al mes & 47 & $14 \%$ \\
Trimestral & 26 & $7 \%$ \\
Ocasionalmente & 71 & $20 \%$ \\
No solicito & 145 & $42 \%$ \\
\hline Total general & 346 & $100 \%$ \\
\hline
\end{tabular}

Según Tabla 35, el servicio de extensiones no es solicitado por la mayoría en el sector encuestado (42\%), por lo tanto, se puede determinar no ofrecer el servicio, por lo menos en el inicio de la ejecución del plan de negocio, ya que involucra inversión en insumos para este servicio.

Tabla 36

Frecuencia de solicitud de servicio de coloración

\begin{tabular}{lrr}
\hline COLORACIÓN & CANTIDAD & \multicolumn{2}{c}{ PORCENTAJE } \\
\hline Una vez por semana & 27 & $8 \%$ \\
Cada 15 dias & 49 & $14 \%$ \\
Una vez al mes & 77 & $22 \%$ \\
Trimestral & 40 & $12 \%$ \\
Ocasionalmente & 68 & $20 \%$ \\
No solicito & 85 & $25 \%$ \\
\hline Total general & 346 & $100 \%$ \\
\hline
\end{tabular}

Según Tabla 36, el servicio de coloración es solicitado una vez al mes u ocasionalmente, pero no es tan solicitado en el sector encuestado, analizando esta 
información se puede determinar una atención especial para este tipo de servicios, con la finalidad de optimizar la adquisición de insumos sólo para una demanda confirmada.

Tabla 37

Frecuencia de solicitud de servicio de maquillaje

\begin{tabular}{lrr}
\hline MAQUILLAJE & CANTIDAD & \multicolumn{2}{c}{ PORCENTAJE } \\
\hline Una vez por semana & 35 & $10 \%$ \\
Cada 15 dias & 61 & $18 \%$ \\
Una vez al mes & 59 & $17 \%$ \\
Trimestral & 39 & $11 \%$ \\
Ocasionalmente & 88 & $25 \%$ \\
No solicito & 65 & $19 \%$ \\
\hline Total general & 346 & $100 \%$ \\
\hline
\end{tabular}

Según Tabla 37, para el servicio de maquillaje, el 25\% usan este servicio ocasionalmente, posiblemente para un evento o reunión ya que el maquillaje del día a día es ejecutado por ellas mismas en sus domicilios, pero si tiene una constante al mes, que ayuda a concluir que es importante planificar brindar este tipo de servicio en la proyección de la demanda e inversión inicial del plan de negocio.

Tabla 38

Frecuencia de solicitud de servicio de depilación

\begin{tabular}{lrr}
\hline DEPILACIONES & CANTIDAD & \multicolumn{2}{c}{ PORCENTAJE } \\
\hline Una vez por semana & 36 & $10 \%$ \\
Cada 15 dias & 106 & $31 \%$ \\
Una vez al mes & 79 & $23 \%$ \\
Trimestral & 26 & $7 \%$ \\
Ocasionalmente & 49 & $14 \%$ \\
No solicito & 50 & $14 \%$ \\
\hline Total general & 346 & $100 \%$ \\
\hline
\end{tabular}


Según Tabla 38, el 31\% indica que usan este servicio cada 15 días, este resultado ayuda a determinar que éste será un potencial servicio que se debe estimar en la proyección de demanda y proyección financiera del plan de negocio.

Tabla 39

Frecuencia de solicitud de servicio de pestañas postizas

\begin{tabular}{lrr}
\hline PESTAÑAS & CANTIDAD & \multicolumn{2}{c}{ PORCENTAJE } \\
\hline Una vez por semana & 38 & $11 \%$ \\
Cada 15 días & 54 & $16 \%$ \\
Una vez al mes & 55 & $16 \%$ \\
Trimestral & 26 & $7 \%$ \\
Ocasionalmente & 70 & $20 \%$ \\
No solicito & 103 & $30 \%$ \\
\hline Total general & 346 & $100 \%$ \\
\hline
\end{tabular}

Según Tabla 39, el 30\% indica que no solicitan este servicio, por lo accesible de los materiales para brindar este servicio se puede considerar como estrategia usar promociones para el incremento de uso de este servicio.

Tabla 40

Frecuencia de solicitud de servicio de manicure

\begin{tabular}{lrr}
\hline MANICURE & CANTIDAD & \multicolumn{2}{c}{ PORCENTAJE } \\
\hline Una vez por semana & 104 & $30 \%$ \\
Cada 15 dias & 99 & $29 \%$ \\
Una vez al mes & 70 & $20 \%$ \\
Trimestral & 20 & $6 \%$ \\
Ocasionalmente & 31 & $9 \%$ \\
No solicito & 22 & $6 \%$ \\
\hline Total general & 346 & $100 \%$ \\
\hline
\end{tabular}

Según la Tabla 40, el 30\% una vez por semana, esto ayuda a determinar que este servicio es uno de los principales del sector belleza, por lo tanto, dentro del plan de negocio se debe considerar la adquisición de los recursos sobre el promedio relacionado a 
este servicio, de manera que el cliente conozca la calidad del servicio y obtener fidelidad y recomendación.

Tabla 41

Frecuencia de solicitud de servicio de uñas acrigel

\begin{tabular}{lrr}
\hline ACRIGEL & CANTIDAD & \multicolumn{2}{c}{ PORCENTAJE } \\
\hline Una vez por semana & 25 & $7 \%$ \\
Cada 15 dias & 34 & $10 \%$ \\
Una vez al mes & 73 & $21 \%$ \\
Trimestral & 30 & $9 \%$ \\
Ocasionalmente & 77 & $22 \%$ \\
No solicito & 107 & $31 \%$ \\
\hline Total general & 346 & $100 \%$ \\
\hline
\end{tabular}

Según la Tabla 41, el $31 \%$ no solicita este servicio, pero se tiene un $43 \%$ que solicita el servicio una vez al mes u ocasionalmente, esto ayuda a determinar alguna estrategia de promociones para incrementar el uso de este tipo de servicio de manera más frecuente $u$ ofrecerlo junto con otros servicios que tienen la misma frecuencia de uso.

Tabla 42

Frecuencia de solicitud de servicio de pedicure

\begin{tabular}{lrr}
\hline PEDICURE & CANTIDAD & \multicolumn{2}{c}{ PORCENTAJE } \\
\hline Una vez por semana & 87 & $25 \%$ \\
Cada 15 dias & 118 & $34 \%$ \\
Una vez al mes & 73 & $21 \%$ \\
Trimestral & 17 & $5 \%$ \\
Ocasionalmente & 28 & $8 \%$ \\
No solicito & 24 & $7 \%$ \\
\hline Total general & 346 & $100 \%$ \\
\hline
\end{tabular}

Según Tabla 42, el 80\% solicita este servicio dentro del mes, con un 34\% cada quince días, al igual que el servicio de manicure, se determina que este servicio es primordial en un salón de belleza, por lo tanto, dentro del plan de negocio se debe 
considerar la adquisición de los recursos sobre el promedio relacionado a este servicio, de manera que el cliente conozca la calidad del servicio y obtener fidelidad y recomendación. Tabla 43

Cantidad y porcentaje de respuestas de frecuencia de solicitud de los servicios de salón de belleza

\begin{tabular}{lccc}
\hline \multirow{2}{*}{ Totalidad de servicios } & \multicolumn{2}{c}{ Respuestas } & Porcentaje de \\
\cline { 2 - 3 } & Frecuencia & Porcentaje & $14 \%$ \\
\hline Una vez por semana & 603 & $12 \%$ & $148 \%$ \\
Cada 15 días & 846 & $17 \%$ & $208 \%$ \\
Una vez al mes & 1001 & $20 \%$ & $246 \%$ \\
Trimestral & 464 & $10 \%$ & $114 \%$ \\
No solicito & 1031 & $21 \%$ & $253 \%$ \\
Ocasionalmente & 939 & $19 \%$ & $231 \%$ \\
\hline Total & 4884 & $100 \%$ & $1200 \%$ \\
\hline
\end{tabular}

Según Tabla 43, la mayoría de las respuestas obtenidas indican que usan los servicios del salón de belleza cada 15 días o una vez al mes, también se encontró porcentajes altos en las respuestas "No solicito" y "Ocasionalmente" esto se evidencia en algunos servicios de bajo requerimiento que luego se evaluará si se prestarán en el plan de negocio. 
e. De acuerdo con los servicios elegidos, ¿cuál es el tiempo promedio que permanece en el salón de belleza

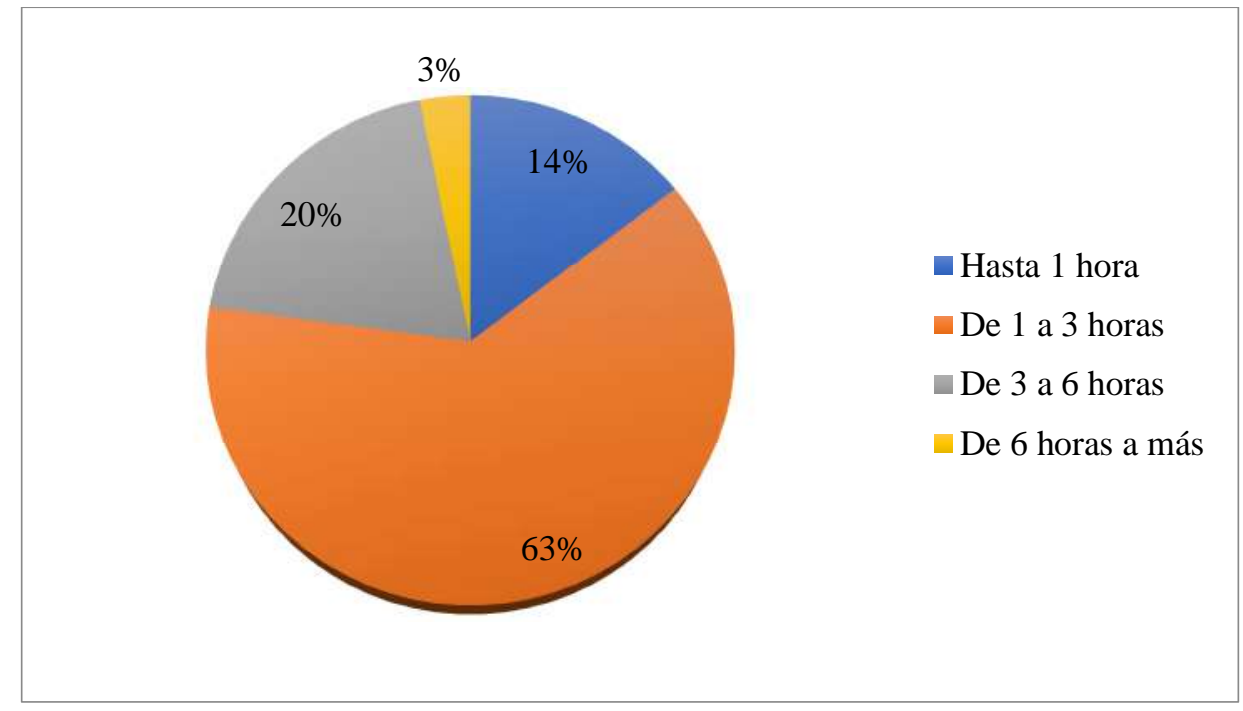

Figura 22. Tiempo promedio de permanencia en salones de belleza

Según la Figura 22, el 63\% de las encuestadas permanece de una a tres horas en el salón de belleza, con esta información se puede estimar las expectativas de los clientes y el número de atenciones que se podrán cubrir diariamente, de manera que se estime, según la rentabilidad planificada, la adquisición de recursos materiales y personal para la cobertura de las atenciones por planificar. 


\section{f. De acuerdo con la pregunta anterior ¿qué día de la semana y en qué horario suele visitar los salones de belleza?}

Tabla 44

Frecuencias correspondientes al horario de asistencia

\begin{tabular}{lrrrrrrr}
\hline Horario & Lunes & Martes & Miércoles & Jueves & Viernes & Sábado & Domingo \\
\hline Mañana (7 am a 12 pm) & 24 & 18 & 8 & 16 & 21 & 142 & 273 \\
Tarde (12 pm a 6 pm) & 28 & 29 & 35 & 35 & 41 & 139 & 54 \\
Noche (6 pm a 10pm) & 296 & 310 & 313 & 300 & 277 & 52 & 17 \\
No tengo horario fijo & 59 & 50 & 51 & 56 & 68 & 74 & 63 \\
\hline Total & 407 & 407 & 407 & 407 & 407 & 407 & 407 \\
\hline
\end{tabular}

Tabla 45

Porcentaje de horario de asistencia por día

\begin{tabular}{lrrrrrrr}
\hline Horario & Lunes & Martes & Miércoles & Jueves & Viernes & Sábado & Domingo \\
\hline Mañana (7 am a 12 pm) & $6 \%$ & $4 \%$ & $2 \%$ & $4 \%$ & $5 \%$ & $35 \%$ & $67 \%$ \\
Tarde (12 pm a 6 pm) & $7 \%$ & $7 \%$ & $9 \%$ & $9 \%$ & $10 \%$ & $34 \%$ & $13 \%$ \\
Noche (6 pm a 10pm) & $73 \%$ & $76 \%$ & $77 \%$ & $74 \%$ & $68 \%$ & $13 \%$ & $4 \%$ \\
No tengo horario fijo & $14 \%$ & $12 \%$ & $13 \%$ & $14 \%$ & $17 \%$ & $18 \%$ & $15 \%$ \\
\hline Total & $100 \%$ & $100 \%$ & $100 \%$ & $100 \%$ & $100 \%$ & $100 \%$ & $100 \%$ \\
\hline
\end{tabular}

Tabla 46

Porcentaje de respuestas correspondiente al horario de asistencia

\begin{tabular}{lccc}
\hline Preferencia horaria & \multicolumn{2}{c}{ Respuestas } & $\begin{array}{c}\text { Porcentaje } \\
\text { de casos }\end{array}$ \\
\cline { 2 - 3 } & Frecuencia & Porcentaje & $123 \%$ \\
Mañana & 502 & $18 \%$ & $89 \%$ \\
Tarde & 361 & $13 \%$ & $385 \%$ \\
Noche & 1565 & $55 \%$ & $103 \%$ \\
Sin horario fijo & 421 & $15 \%$ & $700 \%$ \\
\hline Total & 2849 & $100 \%$ & \\
\hline
\end{tabular}

Según la Tabla 44, 45 y 46, se determinó que de lunes a viernes la preferencia es asistir en la noche, se puede evaluar implementar un plan de marketing que logre aumentar la afluencia de público durante las mañanas y tardes (packs, promociones, etc.), asimismo, 
los días sábados y domingos aumenta la afluencia de público durante todo el día; esta información ayuda a establecer las pautas sobre dotación de personal; esto coincide con el análisis de las respuestas obtenidas, ya que se encuentra que el horario más elegido por las encuestadas fue la noche.

\section{g. ¿En qué mes del año acude más a los salones de belleza?}

Tabla 47

Frecuencia para visita mensual a salones de belleza

\begin{tabular}{lccc}
\hline \multirow{2}{*}{ Mes } & \multicolumn{2}{c}{ Respuestas } & Porcentaje de \\
\cline { 2 - 3 } & Frecuencia & Porcentaje & $40 \%$ \\
\hline Enero & 162 & $12 \%$ & $37 \%$ \\
Febrero & 150 & $11 \%$ & $28 \%$ \\
Marzo & 112 & $8 \%$ & $16 \%$ \\
Abril & 64 & $5 \%$ & $24 \%$ \\
Mayo & 98 & $7 \%$ & $25 \%$ \\
Junio & 103 & $7 \%$ & $41 \%$ \\
Julio & 168 & $12 \%$ & $16 \%$ \\
Agosto & 65 & $5 \%$ & $13 \%$ \\
Setiembre & 52 & $4 \%$ & $18 \%$ \\
Octubre & 73 & $5 \%$ & $28 \%$ \\
Noviembre & 114 & $8 \%$ & $58 \%$ \\
Diciembre & 237 & $17 \%$ & $343 \%$ \\
\hline Total & 1398 & $100 \%$ & \\
\hline
\end{tabular}

Según Tabla 47, se observa que los meses de enero, febrero, julio, noviembre y diciembre existe un incremento de la asistencia a los salones de belleza, si se quisiera determinar una estacionalidad de uso, se concluiría que en el sector encuestado la temporada de verano es donde se experimenta el incremento de demanda de los servicios.

Los meses de abril y setiembre son los meses más bajos en concurrencia de personas al salón de belleza, habría que usar alguna herramienta de marketing para incrementar la afluencia de público. 
h. ¿Con quién(es) suele asistir a los salones de belleza?

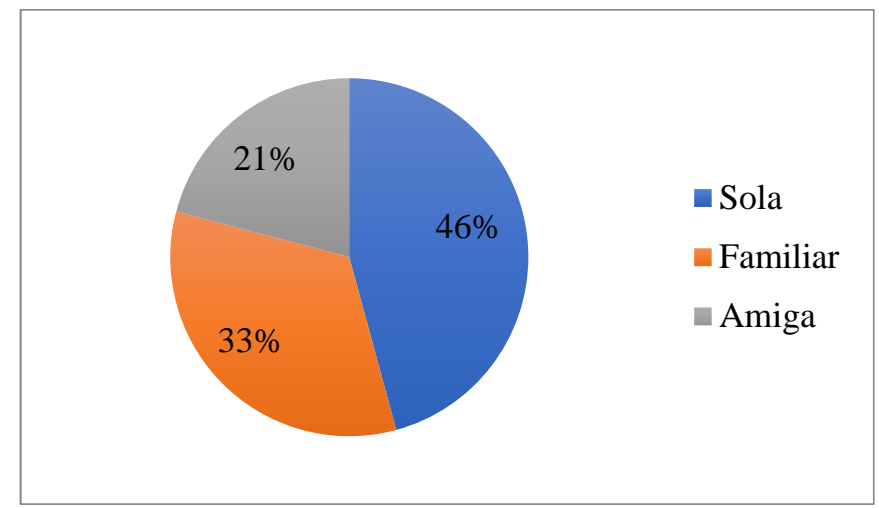

Figura 23. Con quién suelen asistir los clientes a salones de belleza

Según la respuesta de las encuestadas, el $46 \%$ asiste sola a los salones de belleza, con esta información se puede determinar establecer una estrategia de marketing para incentivar la atención por paquetes de personas, de manera que se incremente la demanda.

\section{i. ¿A qué salones de belleza de la ciudad de Lima Metropolitana suele asistir?}

Tabla 48

Frecuencia y porcentaje de asistencia a salones de belleza

\begin{tabular}{lccc}
\hline \multirow{2}{*}{ Salones de belleza } & \multicolumn{2}{c}{ Respuestas } & $\begin{array}{c}\text { Porcentaje } \\
\text { de casos }\end{array}$ \\
\cline { 2 - 3 } Amarige & Frecuencia & Porcentaje & $3 \%$ \\
Tomiko & 14 & $2 \%$ & $2 \%$ \\
Specchi & 10 & $2 \%$ & $5 \%$ \\
Montalvo & 21 & $3 \%$ & $39 \%$ \\
Marco Aldany & 159 & $24 \%$ & $17 \%$ \\
Aramis & 71 & $11 \%$ & $6 \%$ \\
Soho Color & 24 & $4 \%$ & $18 \%$ \\
Scarlet & 73 & $11 \%$ & $6 \%$ \\
Peluqueria Local & 24 & $4 \%$ & $55 \%$ \\
Servicio a Domicilio & 224 & $34 \%$ & $11 \%$ \\
\hline Total & 43 & $6 \%$ & $163 \%$ \\
\hline
\end{tabular}


Según Tabla 48, el 55\% de las respuestas obtenidas indican que prefieren asistir a la peluquería local y $39 \%$ indican que prefieren asistir a Montalvo, confirmando la información obtenida en la investigación cualitativa.

\section{j. De acuerdo con la pregunta anterior ¿reserva usted una cita?}

Se encontró que el $62 \%$ de personas encuestadas reservan cita para su atención, esto confirma que el plan de negocio podría priorizar su esquema de atención a domicilio, pero también hay un $38 \%$ que aún obtiene el servicio de manera convencional (cliente asiste al salón de belleza), es un mercado que no se puede desatender, es por eso que se debe estimar una estrategia de captación de demanda ubicando el negocio al alcance del cliente, sin la necesidad de reserva o cita (búsqueda de lugares con mayor afluencia de público).

k. Si su respuesta anterior fue afirmativa ¿Por qué medio realiza su reserva?

Tabla 49

Cantidad y porcentajes de medios de reserva de cita

\begin{tabular}{lccc}
\hline \multirow{2}{*}{ Medios para reservar cita } & \multicolumn{2}{c}{ Respuestas } & Porcentaje \\
\cline { 2 - 3 } & Frecuencia & Porcentaje & de casos \\
\hline Llamada Telefónica & 182 & $41 \%$ & $72 \%$ \\
Página Web & 24 & $5 \%$ & $9 \%$ \\
E-mail & 31 & $7 \%$ & $12 \%$ \\
Whatsapp & 71 & $16 \%$ & $28 \%$ \\
Facebook & 97 & $22 \%$ & $38 \%$ \\
Personalmente & 44 & $10 \%$ & $17 \%$ \\
\hline Total & 449 & $100 \%$ & $177 \%$ \\
\hline
\end{tabular}


Según Tabla 49, la reserva de citas es realizada en mayoría vía telefónica y Facebook, da a entender que estos medios se usan para las reservas en salones de belleza independientes, este resultado ayuda a que el plan de negocio pueda usar el medio de la reserva de cita como herramienta de diferenciación con respecto a la competencia que actualmente funciona en el mercado.

\section{1. ¿Qué tiempo suele tomarle a usted llegar al salón de belleza?}

Tabla 50

Frecuencia de tiempo de espera para atención en salones de belleza

\begin{tabular}{lcc}
\hline Respuesta & Frecuencia & Porcentaje \\
\hline 0 minutos (servicio a domicilio) & 26 & $6 \%$ \\
Hasta 30 minutos & 212 & $52 \%$ \\
De 30 minutos a 60 minutos & 127 & $31 \%$ \\
De 60 minutos a más & 42 & $10 \%$ \\
\hline Total & 407 & $100 \%$ \\
\hline
\end{tabular}

Según Tabla 50, a la mayoría de personas le toma hasta una hora movilizarse hacia el salón de belleza para atenderse, esto representa una oportunidad para el plan de negocio ya que un punto diferenciador es que el cliente no se movilizaría, sino la móvil irá donde se encuentre en cliente. 
m. ¿Cuánto tiempo está dispuesto a esperar para ser atendido?

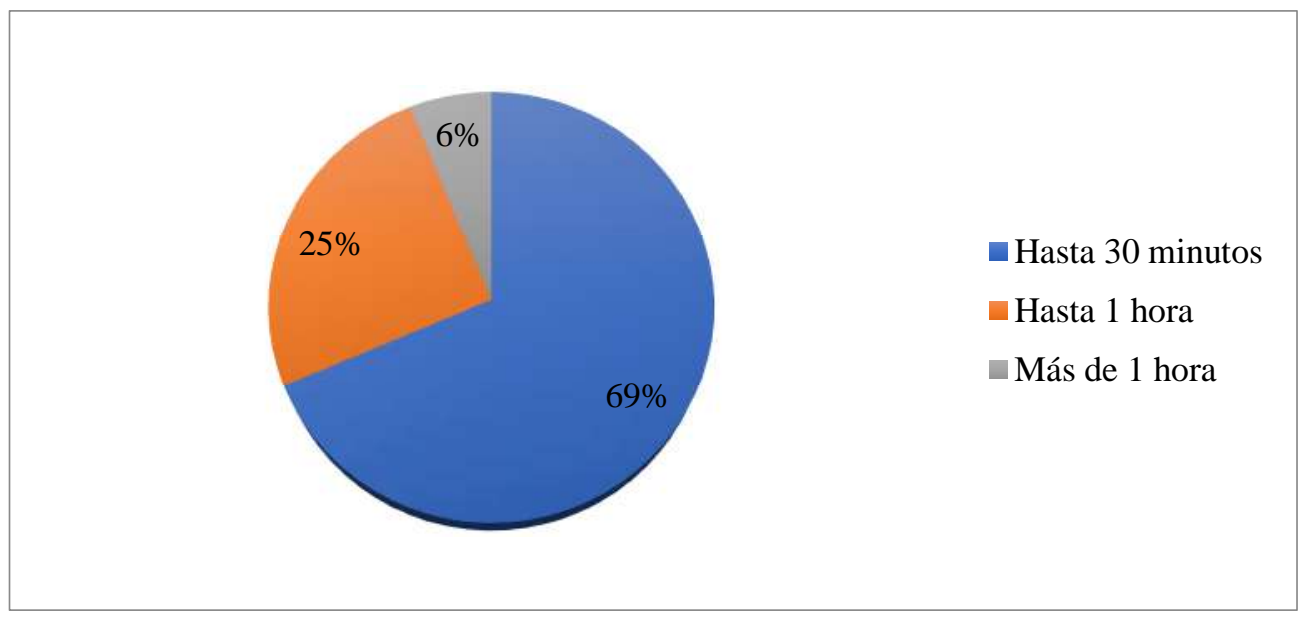

Figura 24. Disponibilidad de tiempo de espera

La información de la Figura 24 permite verificar las expectativas de los clientes con respecto al tiempo de espera, según los resultados, las expectativas del cliente se han ajustado a la oferta que existe actualmente en el sector de belleza, en este aspecto, el plan de negocio tiene una propuesta innovadora para reducir el tiempo de espera y cambiar las expectativas del cliente, obteniendo una ventaja con respecto a la competencia. 
n. Según su experiencia en el uso de estos servicios ¿Cuál es el tiempo promedio de atención?

Tabla 51

Frecuencia de tiempo de atención para cada servicio

\begin{tabular}{lccccc}
\hline Servicio & Hasta & De 30 a & De 1 a & De 3 hrs a & \\
\hline Corte & 30 min & 60 min & 3 hrs & más & Desconozco \\
Pestañas Postizas & 199 & 142 & 45 & 8 & 13 \\
Manicure & 114 & 123 & 73 & 10 & 87 \\
Pedicure & 95 & 234 & 60 & 5 & 13 \\
Depilaciones & 87 & 215 & 76 & 10 & 19 \\
Maquillaje & 84 & 174 & 81 & 28 & 40 \\
Peinado & 65 & 207 & 71 & 22 & 42 \\
Planchado & 61 & 222 & 99 & 8 & 17 \\
Uñas Acrigel & 48 & 211 & 110 & 10 & 28 \\
Extensiones de Cabello & 44 & 109 & 133 & 32 & 89 \\
Alisado & 41 & 81 & 112 & 37 & 136 \\
Coloración, mechas, & 33 & 99 & 143 & 60 & 72 \\
tintes & 33 & 90 & 152 & 45 & 87 \\
\hline
\end{tabular}

Tabla 52

Porcentaje de tiempo de atención para cada servicio

\begin{tabular}{lccccc}
\hline Servicio & $\begin{array}{c}\text { Hasta } \\
30 \mathrm{~min}\end{array}$ & $\begin{array}{c}\text { De 30 a } \\
60 \mathrm{~min}\end{array}$ & $\begin{array}{c}\text { De 1 a } \\
3 \mathrm{hrs}\end{array}$ & $\begin{array}{c}\text { De 3 hrs } \\
\text { a más }\end{array}$ & Desconozco \\
\hline Corte & $49 \%$ & $35 \%$ & $11 \%$ & $2 \%$ & $3 \%$ \\
Pestañas Postizas & $28 \%$ & $30 \%$ & $18 \%$ & $2 \%$ & $21 \%$ \\
Manicure & $23 \%$ & $57 \%$ & $15 \%$ & $1 \%$ & $3 \%$ \\
Pedicure & $21 \%$ & $53 \%$ & $19 \%$ & $2 \%$ & $5 \%$ \\
Depilaciones & $21 \%$ & $43 \%$ & $20 \%$ & $7 \%$ & $10 \%$ \\
Maquillaje & $16 \%$ & $51 \%$ & $17 \%$ & $5 \%$ & $10 \%$ \\
Peinado & $15 \%$ & $55 \%$ & $24 \%$ & $2 \%$ & $4 \%$ \\
Planchado & $12 \%$ & $52 \%$ & $27 \%$ & $2 \%$ & $7 \%$ \\
Uñas Acrigel & $11 \%$ & $27 \%$ & $33 \%$ & $8 \%$ & $22 \%$ \\
Extensiones de Cabello & $10 \%$ & $20 \%$ & $28 \%$ & $9 \%$ & $33 \%$ \\
Alisado & $8 \%$ & $24 \%$ & $35 \%$ & $15 \%$ & $18 \%$ \\
Coloración, mechas, tintes & $8 \%$ & $22 \%$ & $37 \%$ & $11 \%$ & $21 \%$ \\
\hline
\end{tabular}


Tabla 53

Frecuencia de respuestas obtenidas

\begin{tabular}{|c|c|c|c|}
\hline \multirow{2}{*}{ Tiempo de Servicios } & \multicolumn{2}{|c|}{ Respuestas } & \multirow{2}{*}{$\begin{array}{c}\text { Porcentaje de } \\
\text { casos }\end{array}$} \\
\hline & Frecuencia & Porcentaje & \\
\hline Hasta 30 minutos & 904 & $19 \%$ & $222 \%$ \\
\hline De 30 a 1 hora & 1907 & $39 \%$ & $469 \%$ \\
\hline De 1 a 3 horas & 1155 & $24 \%$ & $284 \%$ \\
\hline Más de 3 horas & 275 & $6 \%$ & $68 \%$ \\
\hline Desconozco & 643 & $13 \%$ & $158 \%$ \\
\hline Total & 4884 & $100 \%$ & $1200 \%$ \\
\hline
\end{tabular}

Según se muestras en las Tablas 51, 52 y 53, la mayoría de personas permanece hasta tres horas en el salón de belleza, los servicios de planchado, uñas acrigel, extensiones, alisado y coloración toman mayor tiempo en su ejecución, con esta información se estimó aplicar una estrategia de promociones para ofrecer packs de servicios adicionales que toman mayor tiempo, de manera que se pueda aumentar la demanda optimizando los tiempos de atención por parte de los estilistas prestadores del servicio.

Para los servicios que toman menor tiempo se podría planificar rutas de atención tomando en cuenta el tiempo de transporte hacia donde se ubican los clientes, asimismo, si se captan a los clientes en la vía pública se les puede brindar el tiempo estimado de atención basándose de información confiable. 
o. ¿Cuál es su promedio de gasto mensual en servicios de belleza?

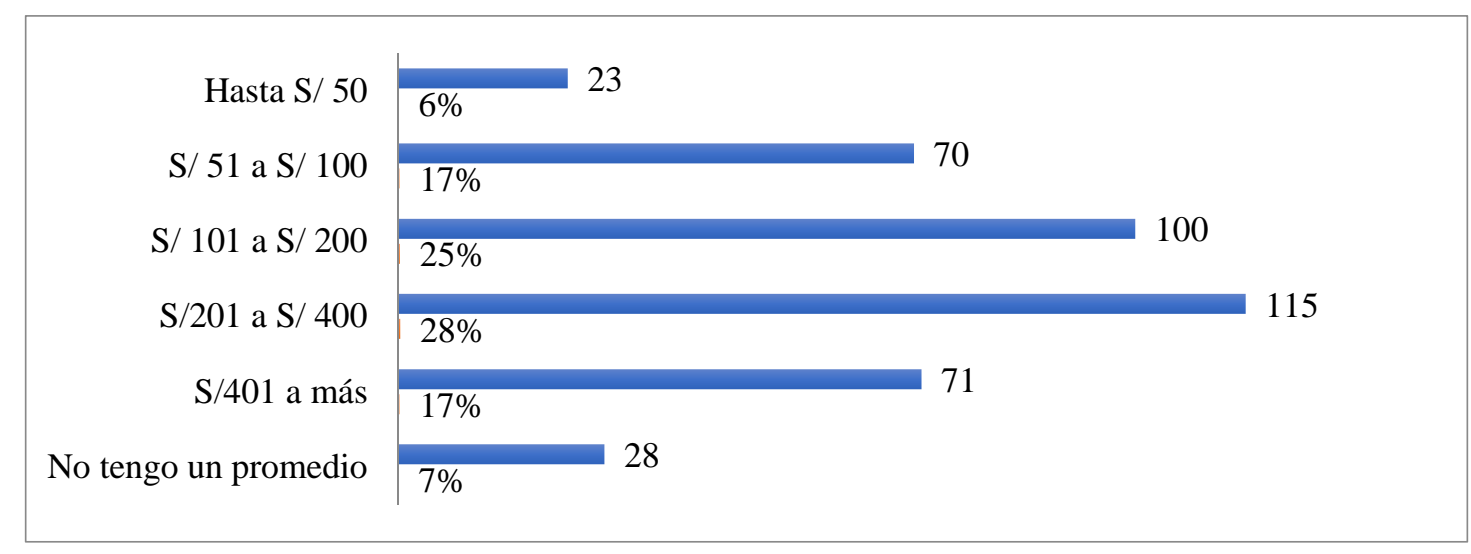

Figura 25. Promedio de gasto mensual en servicios de belleza

Según se muestra la Figura 25, el 93\% de las encuestadas destinan un presupuesto mensual a los servicios de belleza, además el 28\% destina hasta 400 soles para servicios de belleza, esto evidencia, que hay una cantidad elevada de personas que ya tienen como costumbre solicitar los servicios de belleza y que se han vuelto una necesidad para ellas. 
p. De acuerdo con su importancia seleccione los atributos que usted considera para elegir un salón de belleza

Tabla 54

Frecuencia por atributo

\begin{tabular}{lcccc}
\hline Atributo & $\begin{array}{l}\text { Muy } \\
\text { importante }\end{array}$ & $\begin{array}{l}\text { Poco } \\
\text { Importante }\end{array}$ & $\begin{array}{l}\text { Nada } \\
\text { importante } \\
\text { importante }\end{array}$ \\
\hline Calidad de productos & 334 & 68 & 5 & 0 \\
Personal calificado & 321 & 76 & 9 & 1 \\
Limpieza & 315 & 79 & 13 & 0 \\
Precios/Promociones & 292 & 104 & 11 & 0 \\
Relación cliente / estilista & 291 & 95 & 18 & 3 \\
Flexibilidad de horarios & 282 & 107 & 14 & 4 \\
Tiempo de espera & 271 & 123 & 13 & 0 \\
Local & 210 & 143 & 36 & 18 \\
Referencias & 200 & 153 & 50 & 4 \\
Ubicación & 186 & 159 & 42 & 20 \\
\hline
\end{tabular}

Tabla 55

Porcentaje por atributo

\begin{tabular}{lcccc}
\hline & $\begin{array}{l}\text { Muy } \\
\text { important } \\
\text { Atributo }\end{array}$ & $\begin{array}{l}\text { Important } \\
\text { e }\end{array}$ & $\begin{array}{l}\text { Poco } \\
\text { important } \\
\text { e }\end{array}$ & $\begin{array}{l}\text { Nada } \\
\text { important } \\
\text { e }\end{array}$ \\
\hline Calidad de productos & $82 \%$ & $17 \%$ & $1 \%$ & $0 \%$ \\
Personal calificado & $79 \%$ & $19 \%$ & $2 \%$ & $0 \%$ \\
Limpieza & $77 \%$ & $19 \%$ & $3 \%$ & $0 \%$ \\
Precios/Promociones & $72 \%$ & $26 \%$ & $3 \%$ & $0 \%$ \\
Relación cliente / estilista & $71 \%$ & $23 \%$ & $4 \%$ & $1 \%$ \\
Flexibilidad de horarios & $69 \%$ & $26 \%$ & $3 \%$ & $1 \%$ \\
Tiempo de espera & $67 \%$ & $30 \%$ & $3 \%$ & $0 \%$ \\
Local & $52 \%$ & $35 \%$ & $9 \%$ & $4 \%$ \\
Referencias & $49 \%$ & $38 \%$ & $12 \%$ & $1 \%$ \\
Ubicación & $46 \%$ & $39 \%$ & $10 \%$ & $5 \%$ \\
\hline
\end{tabular}


Según se muestra en las tablas 54 y 55, se identifican que los atributos más importantes son la calidad de los productos, el personal calificado y la limpieza; es decir, que en la planeación de la ingeniería del proyecto y la planificación financiera se deberá tener en cuenta la inversión necesaria para obtener productos de calidad para la ejecución de los servicios, contratar a personal con el debido grado de especialización para ejecutar las tareas de manera efectiva y se debe considerar los mecanismos necesarios para mantener la limpieza dentro del móvil.

\section{q. En su experiencia como cliente ¿qué tipo de inconveniente ha tenido en los servicios de belleza?}

Tabla 56

Frecuencia y porcentaje de respuestas obtenidas para atributos propuestos

\begin{tabular}{lccc}
\hline \multirow{2}{*}{ Incidencias } & \multicolumn{2}{c}{ Respuestas } & Porcentaje \\
\cline { 2 - 4 } & Frecuencia & Porcentaje & de casos \\
\hline Ninguno & 78 & $13 \%$ & $19 \%$ \\
Poca disponibilidad de horarios & 79 & $13 \%$ & $19 \%$ \\
Ausencia de especialista & 140 & $23 \%$ & $34 \%$ \\
Tiempo excesivo de espera & 131 & $22 \%$ & $32 \%$ \\
Atención deficiente de personal & 114 & $19 \%$ & $28 \%$ \\
Infraestructura inadecuada & 56 & $9 \%$ & $14 \%$ \\
\hline Total & 598 & $100 \%$ & $147 \%$ \\
\hline
\end{tabular}

Según se muestra en la Tabla 56, se tiene mayor dificultad en la ausencia del especialista, lo que hace muy importante la relación entre el cliente y el especialista, dentro del plan de negocio se debe considerar la dinámica de la dotación para que coincida con los clientes que deseen un determinado estilista 
El tiempo de espera se ha planificado que esté cubierto con la modalidad de atención del salón de belleza móvil, que considera que el salón se dirige hacia el cliente.

\section{r. De salir nuestro servicio al mercado ¿Usted solicitaría una cita para un servicio de} salón de belleza móvil?

Según la respuesta de las encuestadas, un 78\% tomaría el servicio del salón de belleza móvil a través de reserva de cita para atención, ya que después de una breve descripción del servicio planteado, el plan de negocio se ajusta a las necesidades que tienen actualmente.

\section{S. Si usted solicita el servicio de salón de belleza a domicilio, ¿Cuenta con estacionamiento para que la móvil lo pueda atender?}

Según la respuesta de las encuestadas, 64\% garantizarían estacionamiento para que la móvil pueda ubicarse y prestar los servicios solicitados, esto coincide con el estudio del sector, ya que en la zona dos la mayoría de personas viven en lugares en los que pueden disponer de estacionamiento ya que, a comparación de otras zonas de Lima, aun no se encuentra abarrotado de condominios donde estos espacios son más pequeños. 


\section{t. ¿Qué servicios solicitaría en el salón de belleza móvil?}

Tabla 57

Frecuencias y porcentajes de encuestados y respuestas recogidas para servicios que solicitarían en el salón de belleza móvil

\begin{tabular}{lccc}
\hline \multirow{2}{*}{ Servicios } & \multicolumn{2}{c}{ Respuestas } & $\begin{array}{c}\text { Porcentaje } \\
\text { de casos }\end{array}$ \\
\cline { 2 - 4 } & Frecuencia & Porcentaje & $43 \%$ \\
Corte & 160 & $10 \%$ & $31 \%$ \\
Peinado & 118 & $7 \%$ & $33 \%$ \\
Cepillado & 125 & $8 \%$ & $44 \%$ \\
Planchado & 167 & $10 \%$ & $14 \%$ \\
Alisado & 51 & $3 \%$ & $10 \%$ \\
Extensiones de cabello & 38 & $2 \%$ & $20 \%$ \\
Coloración, mecha, tinte & 75 & $5 \%$ & $18 \%$ \\
Tratamiento capilar & 66 & $4 \%$ & $43 \%$ \\
Maquillaje & 162 & $10 \%$ & $31 \%$ \\
Depilación & 115 & $7 \%$ & $24 \%$ \\
Pestañas postizas & 92 & $6 \%$ & $63 \%$ \\
Manicure & 237 & $14 \%$ & $14 \%$ \\
Uñas Acrigel & 52 & $3 \%$ & $54 \%$ \\
Pedicure & 202 & $12 \%$ & $441 \%$ \\
\hline Total & 1660 & $100 \%$ & \\
\hline
\end{tabular}

Según se muestra la Tabla 57, el resultado de esta pregunta para las encuestas ayuda a poder determinar los servicios que se pueden ofrecer en el lanzamiento del salón de belleza móvil; los servicios de manicure, pedicure, planchado, maquillaje, corte, cepillado y peinado se pueden considerar como los principales servicios del negocio, los otros servicios se pueden ofrecer bajo citas para los clientes, asegurando que la inversión en la compra de los materiales para estos servicios sea retornada en el menor tiempo. 


\section{u. ¿Estaría dispuesto a pagar los siguientes precios para estos servicios?}

Tabla 58

Tabla de precios propuestos para el salón de belleza móvil

\begin{tabular}{lrr}
\hline Servicio & \multicolumn{2}{c}{ Costo } \\
\hline Corte & S/ & 25.00 \\
Peinado & S/ & 40.00 \\
Cepillado & S/ & 30.00 \\
Planchado & S/ & 30.00 \\
Alisado & S/ & 250.00 \\
Extensiones de cabello (por mecha) & S/ & 2.50 \\
Tratamientos capilares & S/ & 60.00 \\
Maquillaje & S/ & 60.00 \\
Depilación rostro & S/ & 50.00 \\
Pestañas postizas & S/ & 20.00 \\
Manicure & S/ & 25.00 \\
Uñas acrigel & S/ & 75.00 \\
Pedicure & S/ & 35.00
\end{tabular}

Tabla 59

Frecuencia de preferencias de precios

\begin{tabular}{lccc}
\hline \multirow{2}{*}{ Aceptación Precios } & \multicolumn{2}{c}{ Respuestas } & Porcentaje de \\
\cline { 2 - 3 } & Frecuencia & Porcentaje & casos \\
\hline No & 626 & $12 \%$ & $154 \%$ \\
Tal vez & 1011 & $19 \%$ & $248 \%$ \\
Si & 3654 & $69 \%$ & $898 \%$ \\
\hline Total & 5291 & $100 \%$ & $1300 \%$ \\
\hline
\end{tabular}

Según se muestra Tablas 58 y 59 se determina que los clientes tienen la disponibilidad de pagar los precios propuestos, un bajo porcentaje de los precios deberían ser evaluados y revisar la posibilidad de lanzarlo con promociones especiales como paquetes con otros servicios de los cuales tienen disponibilidad de pago. 


\section{v. ¿Cómo le gustaría a Ud. informarse sobre el salón de belleza móvil?}

Tabla 60

Frecuencia y porcentaje sobre los medios de contacto

\begin{tabular}{lccc}
\hline \multirow{2}{*}{ Medio } & \multicolumn{2}{c}{ Respuestas } & Porcentaje \\
& Frecuencia & Porcentaje & $\begin{array}{c}\text { de casos } \\
\text { TV/Cable }\end{array}$ \\
Periódico, catálogo, encarte & 43 & $8 \%$ & $13 \%$ \\
Redes Sociales & 256 & $7 \%$ & $11 \%$ \\
Página Web & 114 & $40 \%$ & $63 \%$ \\
Correo Electrónico & 124 & $18 \%$ & $28 \%$ \\
Familiar/Amigos & 57 & $19 \%$ & $30 \%$ \\
Total & 646 & $9 \%$ & $14 \%$ \\
\hline
\end{tabular}

Según se muestra Tabla 60, la tendencia actual es usar las redes sociales a través de computadoras o smartphone, esto orienta a poder tener una estrategia de publicidad en redes sociales.

De acuerdo a toda la información de las encuestas tenemos las siguientes conclusiones de la investigación cuantitativa, de acuerdo a cada objetivo:

- Determinar el porcentaje de personas dispuestas a ir al salón de belleza móvil o reservar una cita.

De salir el salón de belleza móvil, el 78\% de encuestados tomaría el servicio en subir al salón de belleza móvil y de realizar una reserva una cita.

Hay un 64\% que aseguran el estacionamiento para poder atenderse en el salón de belleza móvil.

- Determinar el porcentaje de los principales servicios a ofrecer.

De acuerdo a los resultados de la encuesta, los siguientes servicios son los más frecuentes: Manicure 14\%, Pedicure 12\%, Corte, Peinado y Maquillase 10\% 
respectivamente. Por lo tanto, son los servicios más rápidos y se pueden realizar en menos de una hora.

- Determinar el porcentaje de aceptación de precios en lanzamiento.

Los encuestados indicaron con un $69 \%$ que si estarían dispuestos a pagar los precios de lanzamiento que se va a ofrecer durante el primero semestre.

- Determinar el porcentaje de medios de publicidad.

El 40\% de los encuestados desea que le llegue la información del salón de belleza móvil por redes sociales, es muy poca la demando que llegue a su correo, Televisión, periódico, entre otros.

\subsection{Conclusiones y recomendaciones del estudio cualitativo y cuantitativo}

Luego de realizar el estudio cualitativo y cuantitativo se puede extraer las siguientes conclusiones:

- El sector de belleza tiene un crecimiento constante durante los últimos años, muestra de ello son la cantidad de salones corporativos y salones independientes que va incrementando en la zona dos.

- Actualmente, la asistencia a los salones de belleza se ha vuelto una necesidad ya que es un factor predominante para el cuidado personal, y se considera una necesidad ya que la mayoría de personas destinan un presupuesto mensual para la adquisición de los servicios ofrecidos por los salones de belleza.

- Los factores que más predominan en los clientes para la selección de un salón de belleza son los productos usados, la calidad de profesionales, precios y la infraestructura; es decir, que en la estimación financiera se tendrá que priorizar la inversión en obtener los recursos de calidad 
superior al estándar, asimismo, se debe considerar un presupuesto para la capacitación constante del personal; también se debe considerar el acondicionamiento al móvil, ya que la apariencia tiene mucho impacto en la percepción de los clientes.

- Los meses de alta demanda son enero, mayo por campaña del día de la madre y diciembre que es el mes en que más eventos se presentan, el plan de marketing es muy importante para poder aumentar la demanda en los meses que tienen indicadores bajos; asimismo, los días de alta demanda son los fines de semana, hay que aplicar también planes de marketing para incrementar el número de atenciones los días de semana.

- Los servicios que se deben considerar para el lanzamiento son: corte, planchado, manicure y pedicure ya que son los servicios más usados según el estudio.

- Existe predisposición de los clientes potenciales de poder garantizar estacionamiento para que la móvil pueda prestar el servicio, no lo ven como una limitante del servicio, sino como una comodidad.

- En un promedio, el 78\% de las personas tienen la percepción de que el plan de negocio es innovador y lo consumirían, pero se hace hincapié en cumplir con todos los estándares de un salón de belleza convencional ofreciendo el valor agregado de servicios adicionales como snack, TV, Wifi, etc.

\subsection{Perfil del consumidor tipo y sus variantes}

A continuación, se detallará el perfil del consumidor como resultado de los estudios cuantitativos y cualitativos.

- Los usuarios del servicio son mujeres entre 20 y 59 años que residen en la zona dos de Lima Metropolitana y pertenecen al NSE C. 
- Una de las características principales del consumidor es que asiste por lo menos una vez al mes al salón de belleza para solicitar algún servicio.

- Son mujeres que trabajan y reservan una parte de su presupuesto mensual para utilizar los servicios de belleza ya que usan el servicio como parte de su cuidado personal, es por eso que muchas veces se ajustan a las ofertas del mercado.

- Siempre buscan obtener un valor agregado a los servicios que se tienen actualmente, dispuestas a elegir nuevas alternativas que puedan brindarles un mayor beneficio.

En este perfil se puede presentar algunas variantes como las siguientes:

- Los consumidores puedan usar el servicio junto con familiares que se encuentran dentro de otro NSE y edad.

- Algún cliente decida acceder al servicio por curiosidad y luego convertirse en asistente asidua del servicio. 


\section{Capítulo IV. Proyección del Mercado Objetivo.}

\subsection{El ámbito de la proyección}

Una vez que se ha finalizado la investigación de mercado y se ha identificado que existe una oportunidad del negocio, es necesario que la empresa pronostique el comportamiento futuro de sus variables de mercado, esto permitirá identificar la inversión necesaria, capacidad futura, materias primas y capital humano que se necesitará.

Para poder realizar una correcta proyección los especialistas en marketing deben seguir los siguientes pasos: (a) Métodos rigurosos para recopilar la información (b) Tiempo que deben pasar con los clientes, observando a los competidores y otros grupos externos. Es importante mencionar que se debe considerar detalles minuciosos sobre los deseos, las preferencias, y comportamiento de los compradores. (Kotler \& Keller, 2016)

En este capítulo se determinó la proyección de la demanda que tendrá el salón de belleza móvil, así como el pronóstico de ventas para los próximos cinco años que dura el Plan de Negocios.

\subsection{Selección del método de proyección}

Sapag (2011) divide los métodos de proyección en dos grandes grupos: métodos cuantitativos y métodos cualitativos. Los métodos cuantitativos se expresan matemáticamente por lo cual son más precisos, sin embargo, los métodos cualitativos complementan a los métodos cuantitativos ya que expresan la incertidumbre del comportamiento de las variables estudiadas. 
En la Tabla 61 se observa las técnicas mencionadas por Sapag (2011).

Tabla 61

\begin{tabular}{ll}
\hline Grupos de métodos & Tipos de métodos \\
\hline Métodos cuantitativos & - Modelos Causales \\
& - Modelos de series de tiempo \\
\hline Métodos cualitativos & - Método Delphi \\
& - Investigación de mercados \\
& - Predicción tecnológica \\
\hline
\end{tabular}

Técnicas de predicción

A continuación, se describirá los métodos más utilizados para la investigación de mercados:

- Modelos Causales. También llamado enfoque de análisis causal, este modelo trata de establecer las variables que impactan la demanda, de qué manera y cuánto influyen sobre ella. Para ello el modelo hace uso de antecedentes cuantitativos e históricos y confían que la relación variable-demanda no variará con el tiempo. Usualmente la proyección causal usa la regresión simple para una variable o regresión múltiple para varias variables.

- Modelo de series de tiempo. Este modelo proyecta el valor futuro de la demanda por medio de la extrapolación de los valores históricos de la misma, asumiendo que la única variable que explica el comportamiento es el tiempo. Este enfoque no considera cambios en preferencias del consumidor.

- Método Delphi. Este modelo se realiza a través de un enfoque subjetivo, el cual consiste en hallar una predicción a través de la respuesta anónima de expertos a unos cuestionarios que luego son procesados por un coordinador, hallando así una predicción a través de la convergencia de respuestas individuales. 
- Investigación de Mercado. Este enfoque está abocado a recopilar la opinión de los clientes para demostrar una hipótesis planteada sobre el producto o servicio ofertado. Esta recopilación se realiza a través de varias formas como encuestas, experimentos, test de concepto, test de mercados, intenciones de compra.

Sapag (2011) menciona que las técnicas cuantitativas son usadas cuando existe una gran cantidad de datos históricos, si este no fuera el caso para el proyecto de negocio se sugiere usar las técnicas cualitativas.

Para el plan de negocios se considera como clientes, a las mujeres cuyas edades son entre 20 a 59 años, de NSE C y que residan en la zona dos de Lima Metropolitana, durante el desarrollo del focus group y encuestas se pudo constatar que las mujeres de esta zona se preocupan por su cuidado personal y por lo menos van una vez al mes al salón de belleza.

La proyección de la demanda está relacionada con los resultados obtenidos del estudio de mercado, específicamente de las encuestas y de la información de la competencia. Como es un negocio nuevo no se pudo contar con datos históricos.

\subsubsection{Mercado Potencial.}

Es el conjunto de consumidores que presenta un nivel interés elevado por la oferta de mercado. Este tiene que ser definido por las siguientes características: (a) ingreso y (b) acceso al producto. (Kotler \& Keller, 2016)

Para el plan de negocios se estimó como primer lugar la tasa de crecimiento anual promedio del año 2017 al 2021 por el (INEI, 2017d), y se obtiene la siguiente información (Ver Tabla No. 62 ) 
Tabla 62

Tasa de crecimiento media de la población total

\begin{tabular}{lrr}
\hline \multirow{2}{*}{ Años } & & Tasa de crecimiento media de la población total \\
& & \\
\hline 2017 & $1.49 \%$ \\
2018 & $1.50 \%$ \\
2019 & $1.50 \%$ \\
2020 & $1.51 \%$ \\
2021 & $1.51 \%$ \\
\hline
\end{tabular}

Esta proyección de la demanda total para los próximos cinco años fue distribuida para la zona dos de Lima Metropolitana. (Ver Tabla No.63)

Tabla 63

Proyección Población Total Zona dos de Lima Metropolitana

\begin{tabular}{lccccc}
\hline \multicolumn{1}{c}{ Zona } & 2017 & 2018 & 2019 & 2020 & 2021 \\
\hline $\begin{array}{l}\text { Total Población Zona } 2 \\
\text { Lima Metropolitana }\end{array}$ & $1,326,938$ & $1,346,822$ & $1,367,066$ & $1,387,677$ & $1,408,662$ \\
\hline
\end{tabular}

Luego para poder determinar la demanda por edad, se identificó por edades de 20 a 59 años del (INEI, 2017d) y se estimó con la tasa de crecimiento anual, ya anteriormente mencionada, y tenemos la siguiente información (Ver Tabla No.64)

Tabla 64

Proyección Población por edades de Zona dos de Lima Metropolitana

\begin{tabular}{lrrrrc}
\hline \multicolumn{1}{c}{ Zona } & 2017 & 2018 & 2019 & 2020 & 2021 \\
\hline $\begin{array}{l}\text { Total Población Zona } 2 \\
\text { Lima Metropolitana }\end{array}$ & 751,509 & 765,691 & 780,178 & 794,976 & 810,091 \\
\hline
\end{tabular}

Para terminar se estimó el mercado potencial extrayendo de la siguiente manera (a) información de la población por edades de los años 2011 al 2015 (INEI, 2017d), (b) 
proyección según crecimiento por cada año del 2016 hasta el 2021, (c) selección de porcentaje de población femenina (limacomovamos.org, 2015), (d) selección de porcentaje de población pertenecientes al NSE C (apeim.com.pe, 2016)

El mercado potencial se obtuvo de la siguiente fórmula: Población total de Lima Metropolitana por edades por el porcentaje de mujeres de Lima Metropolitana (51.50\%) y por el nivel socio económico C (52.10\%). (ver Tabla 65)

Tabla 65

\begin{tabular}{lrrrrr}
\hline \multicolumn{1}{c}{ Zona } & Año 1 & Año 2 & Año 3 & Año 4 & Año 5 \\
\hline $\begin{array}{l}\text { Total zona dos de Lima } \\
\text { Metropolitana }\end{array}$ & 201,641 & 205,446 & 209,333 & 213,304 & 217,360 \\
\hline \multicolumn{2}{l}{ Mercado Potencial Zona dos de Lima Metropolitana } & & & \\
\hline
\end{tabular}

\subsubsection{Mercado Disponible.}

Es el conjunto de consumidores que tienen interés e ingresos y están calificados para comprar la oferta del mercado. (Kotler \& Keller, 2016)

Para el plan de negocios se estimó el mercado disponible aplicando las siguientes preguntas de la encuesta, considerando como base el mercado potencial:

Pregunta filtro No 4: ¿Asiste a un salón de belleza?, respuesta si $=87 \%$

Pregunta filtro No. 5: De acuerdo a la pregunta anterior ¿Asiste al menos una vez al mes?, respuesta $\mathrm{si}=93 \%$

Por lo tanto, se aplicó el mercado disponible por el porcentaje de la pregunta filtro No. 4 y por la pregunta filtro No. 5. (Ver Tabla No. 66) 
Tabla 66

Mercado Disponible Zona dos de Lima Metropolitana

\begin{tabular}{crrrrr}
\hline Zona & Año 1 & Año 2 & Año 3 & Año 4 & Año 5 \\
\hline Total zona dos & 163,148 & 166,227 & 169,372 & 172,584 & 175,866 \\
\hline
\end{tabular}

\subsubsection{Mercado Efectivo.}

El mercado efectivo se obtiene del mercado disponible y se define como los consumidores que aceptarían el producto o servicio ofertado. (Kotler \& Keller, 2016)

Para el plan de negocios se estimó el mercado efectivo después de aplicar las siguientes preguntas de la encuesta tomando como base el mercado disponible:

Pregunta No. 21: De salir nuestro servicio al mercado ¿Usted solicitaría una cita para el servicio de salón de belleza?, repuesta si $=78 \%$

Pregunta No. 22: Si usted solicita el servicio de salón de belleza a domicilio, ¿Cuenta con estacionamiento para que la móvil lo pueda atender?, repuesta si $=64 \%$

Por lo tanto, se aplicó el mercado efectivo por el porcentaje de la pregunta No. 21 y por la pregunta No. 22 (ver Tabla 67).

\section{Tabla 67}

Mercado Efectivo zona dos de Lima Metropolitana

\begin{tabular}{ccrrrc}
\hline Zona & Año 1 & Año 2 & Año 3 & Año 4 & Año 5 \\
\hline Total zona dos & 81,443 & 82,980 & 84,550 & 86,154 & 87,792 \\
\hline
\end{tabular}




\subsubsection{Mercado Objetivo.}

Es el conjunto de consumidores que adquieren el producto de la empresa. (Kotler \& Keller, 2016)

Para el plan de negocio se estimó el mercado objetivo en función del mercado efectivo tomando en cuenta lo siguiente: (a) se consideró obtener una participación de mercado de $0.65 \%$ para el quinto año del presente plan (b) se tiene en conocimiento que el sector belleza tiene un crecimiento anual del 10\%. (elcomercio.pe, 2016)

Según Tabla 68 se muestra el porcentaje del mercado objetivo

Tabla 68

Porcentaje de mercado objetivo de zona dos de Lima Metropolitana

\begin{tabular}{rlllll}
\hline Zona & Año 1 & Año 2 & Año 3 & Año 4 & Año 5 \\
\hline Total zona dos & $0.46 \%$ & $0.50 \%$ & $0.55 \%$ & $0.59 \%$ & $0.65 \%$ \\
\hline
\end{tabular}

Según Tabla 69 se muestra el número de personas que pertenecen al mercado objetivo

Tabla 69

Mercado objetivo de zona dos de Lima Metropolitana

\begin{tabular}{cccccc}
\hline Zona & Año 1 & Año 2 & Año 3 & Año 4 & Año 5 \\
\hline Total zona dos & 377 & 418 & 462 & 512 & 567 \\
\hline
\end{tabular}


En la Tabla 70 se consolidan el número de población de acuerdo con los tipos de mercado obtenidos:

Tabla 70

Resumen de Mercados de Zona dos de Lima Metropolitana

\begin{tabular}{lrrrrr}
\hline \multicolumn{1}{c}{ Mercados / Años } & \multicolumn{1}{c}{2017} & 2018 & 2019 & \multicolumn{1}{c}{2020} & 2021 \\
\hline Mercado Potencial & 201,641 & 205,446 & 209,333 & 213,304 & 217,360 \\
Mercado Disponible & 163,148 & 166,227 & 169,372 & 172,584 & 175,866 \\
Mercado Efectivo & 81,443 & 82,980 & 84,550 & 86,154 & 87,792 \\
Mercado Objetivo & 377 & 418 & 462 & 512 & 567 \\
\hline
\end{tabular}

\subsection{Pronóstico de Ventas}

El pronóstico de ventas es la base para el presupuesto y para planear las diferentes operaciones a corto plazo. (Kotler \& Keller, 2016)

Para el plan de negocio se estimó la frecuencia de asistencia a salones de belleza obtenidos de la encuesta, se procedió a calcular el consumo de servicios por año:

Pregunta aplicada $\mathrm{N}^{\circ} 7$ : de acuerdo a la pregunta anterior ¿con que frecuencia solicita lo siguientes servicios en el salón de belleza?

Para el presente cálculo, sólo se ha considerado los servicios que tienen los valores más altos de frecuencia de consumo: (a) corte de cabello (ver Tabla 68), (b) planchado (ver Tabla 69), (c) manicure (ver Tabla 70) y (d) pedicure (ver Tabla 71). 
Tabla 71

Frecuencia de Consumo para Corte de Cabello

\begin{tabular}{lrrrr}
\hline \multicolumn{1}{c}{ Frecuencia Consumo } & $\begin{array}{c}\text { Factor al } \\
\text { año }\end{array}$ & Encuestados & $\%$ & Ponderado \\
\cline { 1 - 2 } Una vez por semana & 52 & 17 & $5 \%$ & 3 \\
(Semanal) & 26 & 42 & $12 \%$ & 3 \\
Cada 15 días (Quincenal) & 12 & 95 & $28 \%$ & 3 \\
Una vez al mes (Mensual) & 4 & 68 & $20 \%$ & 1 \\
Trimestral & 0 & 69 & $20 \%$ & - \\
No solicito & 6 & 55 & $16 \%$ & 1 \\
Ocasionalmente (Bimestral) & & 346 & $100 \%$ & 11 \\
Total & & & & \\
\hline
\end{tabular}

Tabla 72

Frecuencia de Consumo para Planchado

\begin{tabular}{lrrrr}
\hline \multicolumn{1}{c}{ Frecuencia Consumo } & Al año & Encuestados & $\%$ & Ponderado \\
\cline { 1 - 3 } Una vez por semana & 52 & 43 & $12 \%$ & 6 \\
(Semanal) & 26 & 57 & $16 \%$ & 4 \\
Cada 15 días (Quincenal) & 12 & 84 & $24 \%$ & 3 \\
Una vez al mes (Mensual) & 4 & 39 & $11 \%$ & 0 \\
Trimestral & 0 & 60 & $17 \%$ & - \\
No solicito & 6 & 64 & $18 \%$ & 1 \\
Ocasionalmente (Bimestral) & & 346 & $100 \%$ & 15 \\
\cline { 1 - 2 } Total & & & &
\end{tabular}


Tabla 73

Frecuencia de Consumo para Manicure

\begin{tabular}{lrrrr}
\hline \multicolumn{1}{c}{ Frecuencia Consumo } & $\mathrm{Al}$ año & Encuestados & \multicolumn{2}{c}{$\begin{array}{c}\text { Veces al } \\
\text { año }\end{array}$} \\
\cline { 1 - 2 } Una vez por semana & 52 & 104 & $30 \%$ & 16 \\
(Semanal) & 26 & 99 & $29 \%$ & 7 \\
Cada 15 días (Quincenal) & 12 & 70 & $20 \%$ & 2 \\
Una vez al mes (Mensual) & 4 & 20 & $6 \%$ & 0 \\
Trimestral & 0 & 31 & $9 \%$ & - \\
No solicito & 6 & 22 & $6 \%$ & 0 \\
Ocasionalmente (Bimestral) & & 346 & $100 \%$ & 26 \\
Total & & & &
\end{tabular}

Tabla 74

Frecuencia de Consumo para Pedicure

\begin{tabular}{lrrrr}
\hline \multicolumn{1}{c}{ Frecuencia Consumo } & $\mathrm{Al}$ año & Encuestados & \multicolumn{2}{c}{$\begin{array}{c}\text { Veces al } \\
\text { año }\end{array}$} \\
\hline Una vez por semana & 52 & 87 & $25 \%$ & 13 \\
(Semanal) & 26 & 118 & $34 \%$ & 9 \\
Cada 15 dias (Quincenal) & 12 & 73 & $21 \%$ & 3 \\
Una vez al mes (Mensual) & 4 & 17 & $5 \%$ & 0 \\
Trimestral & 0 & 28 & $8 \%$ & - \\
No solicito & 6 & 24 & $7 \%$ & 0 \\
Ocasionalmente (Bimestral) & & 346 & $100 \%$ & 25 \\
Total veces al año
\end{tabular}


Según Tabla 75 se muestra que los servicios con mayor frecuencia de consumo son manicure y pedicure

Tabla 75

Resumen de Frecuencia de Consumo por servicios

\begin{tabular}{lcc}
\hline Frecuencia de Consumo & \multicolumn{2}{l}{ Una vez al mes } \\
\hline Servicio de Corte de Cabello & 11 & veces al año \\
Servicio de Planchado & 15 & veces al año \\
Servicio de Manicure & 26 & veces al año \\
Servicio de Pedicure & 25 & veces al año \\
\hline
\end{tabular}

La proyección de demanda se desarrolla a partir de estas tres fuentes de información: (a) lo que la gente dice, análisis de los futuros compradores, análisis de expertos y competencia, (b) lo que la gente hace, realizar pruebas con el producto colocado en el mercado y (c) lo que la gente ha hecho, analizar los registros de antiguas conductas de compras, series estadísticos de demanda. (Kotler \& Keller, 2016)

Para el plan de negocio se estimó la demanda con la determinación del mercado objetivo y la frecuencia de uso para cada horizonte de servicio, con la finalidad de poder estimar servicios por cada año (ver Tabla 76).

Tabla 76

Resumen proyección de demanda por cantidad de servicio al año

\begin{tabular}{|c|c|c|c|c|c|}
\hline & 2017 & 2018 & 2019 & 2020 & 2021 \\
\hline Mercado Objetivo & 377 & 418 & 462 & 512 & 567 \\
\hline Demanda Corte de Cabello & 4,047 & 4,481 & 4,962 & 5,496 & 6,086 \\
\hline Demanda Planchado & 5,710 & 6,324 & 7,003 & 7,755 & 8,589 \\
\hline Demanda Manicure & 9,816 & 10,870 & 12,038 & 13,331 & 14,764 \\
\hline Demangla Pedicure & 9,419 & 10,430 & 11,550 & 12,791 & 14,166 \\
\hline Total & 28,992 & 32,105 & 35,553 & 39,374 & 43,606 \\
\hline
\end{tabular}


gún la Tabla 77 se muestra los precios de venta obtenidos en el estudio del mercado, el cual servirá para realizar la proyección de ventas anual:

Tabla 77

Precios de Venta Sugeridos

\begin{tabular}{lr}
\hline Servicios & Precio Sugerido \\
\hline Corte de Cabello & S/ 15.00 \\
Planchado & S/ 30.00 \\
Manicure & S/ 15.00 \\
Pedicure & S/ 20.00 \\
\hline
\end{tabular}

Según Tabla 78 muestra el resumen de programación de ventas anual por servicio, tomando como base el resumen de la proyección de demanda en Tabla 76 y los precios de venta sugerido en Tabla 77.

Tabla 78

Resumen de Programación de ventas anual por servicio

\begin{tabular}{lrrrrr}
\hline & \multicolumn{1}{c}{2017} & \multicolumn{1}{c}{2018} & \multicolumn{1}{c}{2019} & \multicolumn{1}{c}{2020} & \multicolumn{1}{c}{2021} \\
\hline Ventas Servicio Corte Cabello & $\mathrm{S} / .60,699$ & $\mathrm{~S} / .67,216$ & $\mathrm{~S} / .74,436$ & $\mathrm{~S} / .82,434$ & $\mathrm{~S} / .91,294$ \\
Ventas Servicio Planchado & $\mathrm{S} / .171,314$ & $\mathrm{~S} / .189,708$ & $\mathrm{~S} / .210,084$ & $\mathrm{~S} / .232,657$ & $\mathrm{~S} / .257,664$ \\
Ventas Servicio Manicure & $\mathrm{S} / .147,246$ & $\mathrm{~S} / .163,055$ & $\mathrm{~S} / .180,569$ & $\mathrm{~S} / .199,970$ & $\mathrm{~S} / .221,464$ \\
Ventas Servicio Pedicure & $\mathrm{S} / .188,377$ & $\mathrm{~S} / .208,602$ & $\mathrm{~S} / .231,007$ & $\mathrm{~S} / .255,828$ & $\mathrm{~S} / .283,326$ \\
\hline Total Ventas Anual & $\mathrm{S} / .567,636$ & $\mathrm{~S} / .628,582$ & $\mathrm{~S} / .696,096$ & $\mathrm{~S} / .770,889$ & $\mathrm{~S} / .853,749$ \\
\hline
\end{tabular}

Para el plan de negocio se estimó que para el primer año se tendrá una estacionalidad conservadora debido a ser un negocio nuevo ingresando al mercado, para los siguientes años se consideró la estacionalidad obtenida en el estudio de mercado aplicando la siguiente pregunta de la encuesta:

Pregunta encuesta No. 10: ¿En qué mes del año acude más a los salones de belleza?

Estacionalidad año uno: Por temporadas 
Estacionalidad siguientes años: Por temporadas (Ver Tablas No. 79 y No. 80)

Tabla 79

Estacionalidad por meses enero - junio

\begin{tabular}{lcccccc}
\hline & Enero & Feb & Marzo & Abril & Mayo & Junio \\
\hline Primer Año & $4 \%$ & $5 \%$ & $6 \%$ & $7 \%$ & $9 \%$ & $8 \%$ \\
\hline 2do al 5to año & $12 \%$ & $11 \%$ & $8 \%$ & $5 \%$ & $7 \%$ & $7 \%$ \\
\hline
\end{tabular}

Tabla 80

Estacionalidad por meses julio - diciembre

Julio Agosto Setiembre Octubre Noviembre Diciembre

\begin{tabular}{lllllll}
\hline Primer Año & $10 \%$ & $8 \%$ & $8 \%$ & $8 \%$ & $10 \%$ & $17 \%$ \\
\hline 2do al 5to año & $12 \%$ & $5 \%$ & $4 \%$ & $5 \%$ & $8 \%$ & $17 \%$ \\
\hline
\end{tabular}

Según Tablas $81,82,83,84,85,86,87,88,89$ y 90 se detalla la programación de ventas mensuales por cantidad de servicio, importe de venta y cada año para la zona dos de Lima Metropolitana. 
Tabla 81

Programación Mensual de Ventas para el Año 1 (Expresado en servicios)

\begin{tabular}{lcccccccccrrrrr}
\hline Servicios & Ene & Feb & Mar & Abr & May & Jun & Jul & Ago & Set & Oct & Nov & Dic & Totales \\
\hline Corte de & & & & & & & & & & & & & & \\
Cabello & 162 & 202 & 243 & 283 & 364 & 324 & 405 & 324 & 324 & 324 & 405 & 688 & 4,047 \\
Planchado & 228 & 286 & 343 & 400 & 514 & 457 & 571 & 457 & 457 & 457 & 571 & 971 & 5,710 \\
Manicure & 393 & 491 & 589 & 687 & 883 & 785 & 982 & 785 & 785 & 785 & 982 & 1,669 & 9,816 \\
Pedicure & 377 & 471 & 565 & 659 & 848 & 754 & 942 & 754 & 754 & 754 & 942 & 1,601 & 9,419 \\
\hline Totales & 1,160 & 1,450 & 1,740 & 2,029 & 2,609 & 2,319 & 2,899 & 2,319 & 2,319 & 2,319 & 2,899 & 4,929 & 28,992 \\
\hline
\end{tabular}

Tabla 82

Programación Mensual de Ventas para el Año 1 (Expresado en soles)

\begin{tabular}{lrrrrrrrrrrrrr}
\hline Servicios & \multicolumn{1}{c}{ Ene } & \multicolumn{1}{c}{ Feb } & \multicolumn{1}{c}{ Mar } & \multicolumn{1}{c}{ Abr } & May & \multicolumn{1}{c}{ Jun } & Jul & \multicolumn{1}{c}{ Ago } & Set & Oct & Nov & Dic & Totales \\
\hline Corte de & & & & & & & & & & & & \\
Cabello & $\mathrm{S} / .7,034$ & $\mathrm{~S} / .6,513$ & $\mathrm{~S} / .4,863$ & $\mathrm{~S} / .2,779$ & $\mathrm{~S} / .4,255$ & $\mathrm{~S} / .4,472$ & $\mathrm{~S} / .7,294$ & $\mathrm{~S} / .2,822$ & $\mathrm{~S} / 2,258$ & $\mathrm{~S} / .3,170$ & $\mathrm{~S} / .4,950$ & $\mathrm{~S} / .10,290$ & $\mathrm{~S} / .60,699$ \\
Planchado & $\mathrm{S} / .19,852$ & $\mathrm{~S} / .18,381$ & $\mathrm{~S} / .13,725$ & $\mathrm{~S} / .7,843$ & $\mathrm{~S} / .12,009$ & $\mathrm{~S} / .12,622$ & $\mathrm{~S} / .20,587$ & $\mathrm{~S} / .7,965$ & $\mathrm{~S} / .6,372$ & $\mathrm{~S} / .8,946$ & $\mathrm{~S} / .13,970$ & $\mathrm{~S} / .29,043$ & $\mathrm{~S} / .171,314$ \\
Manicure & $\mathrm{S} / .17,063$ & $\mathrm{~S} / .15,799$ & $\mathrm{~S} / 11,797$ & $\mathrm{~S} / .6,741$ & $\mathrm{~S} / .10,322$ & $\mathrm{~S} / .10,849$ & $\mathrm{~S} / .17,695$ & $\mathrm{~S} / .6,846$ & $\mathrm{~S} / .5,477$ & $\mathrm{~S} / .7,689$ & $\mathrm{~S} / .12,007$ & $\mathrm{~S} / .24,962$ & $\mathrm{~S} / .147,246$ \\
Pedicure & $\mathrm{S} / 21,829$ & $\mathrm{~S} / .20,212$ & $\mathrm{~S} / .15,092$ & $\mathrm{~S} / .8,624$ & $\mathrm{~S} / .13,205$ & $\mathrm{~S} / .13,879$ & $\mathrm{~S} / .22,638$ & $\mathrm{~S} / .8,759$ & $\mathrm{~S} / .7,007$ & $\mathrm{~S} / .9,837$ & $\mathrm{~S} / .15,361$ & $\mathrm{~S} / .31,935$ & $\mathrm{~S} / .188,377$ \\
\hline Totales & $\mathrm{S} / .65,778$ & $\mathrm{~S} / .60,905$ & $\mathrm{~S} / .45,476$ & $\mathrm{~S} / .25,986$ & $\mathrm{~S} / .39,791$ & $\mathrm{~S} / .41,822$ & $\mathrm{~S} / .68,214$ & $\mathrm{~S} / .26,392$ & $\mathrm{~S} / .21,114$ & $\mathrm{~S} / .29,641$ & $\mathrm{~S} / .46,288$ & $\mathrm{~S} / .96,230$ & $\mathrm{~S} / .567,636$ \\
\hline
\end{tabular}


Tabla 83

Programación Mensual de Ventas para el Año 2 (Expresado en servicios)

\begin{tabular}{lcccccccccrrrrrr}
\hline Servicios & Ene & Feb & Mar & Abr & May & Jun & Jul & Ago & Set & Oct & Nov & Dic & Totales \\
\hline Corte de & & & & & & & & & & & & & & & \\
Cabello & 519 & 481 & 359 & 205 & 314 & 330 & 539 & 208 & 167 & 234 & 365 & 760 & 4,481 \\
Planchado & 733 & 678 & 507 & 289 & 443 & 466 & 760 & 294 & 235 & 330 & 516 & 1,072 & 6,324 \\
Manicure & 1,260 & 1,166 & 871 & 498 & 762 & 801 & 1,306 & 505 & 404 & 568 & 886 & 1,843 & 10,870 \\
Pedicure & 1,209 & 1,119 & 836 & 477 & 731 & 768 & 1,253 & 485 & 388 & 545 & 851 & 1,768 & 10,430 \\
\hline Totales & 3,720 & 3,445 & 2,572 & 1,470 & 2,251 & 2,365 & 3,858 & 1,493 & 1,194 & 1,676 & 2,618 & 5,443 & 32,105 \\
\hline
\end{tabular}

Tabla 84

Programación Mensual de Ventas para el Año 2 (Expresado en soles)

\begin{tabular}{|c|c|c|c|c|c|c|c|c|c|c|c|c|c|}
\hline Servicios & Ene & Feb & Mar & Abr & May & Jun & Jul & Ago & Set & Oct & Nov & Dic & Totales \\
\hline $\begin{array}{l}\text { Corte de } \\
\text { Cabello }\end{array}$ & $\mathrm{S} / .7,789$ & $\mathrm{~S} / .7,212$ & S/.5,385 & S/.3,077 & S/.4,712 & S/.4,952 & S/.8,078 & $\mathrm{S} / 3,125$ & $\mathrm{~S} / .2,500$ & $\mathrm{~S} / 3,310$ & S/.5,481 & S/.11,395 & S/.67,216 \\
\hline Planchado & S/.21,983 & S/.20,355 & S/.15,198 & S/.8,685 & S/.13,299 & S/.13,977 & S/.22,798 & $\mathrm{S} / .8,820$ & S/.7,056 & S/.9,906 & S/.15,470 & $\mathrm{S} / .32,161$ & S/.189,708 \\
\hline Manicure & S/.18,895 & S/.17,495 & $\mathrm{S} / .13,063$ & S/.7,465 & $\mathrm{S} / .11,430$ & $\mathrm{~S} / .12,013$ & S/.19,595 & $\mathrm{S} / .7,581$ & S/.6,065 & S/.8,514 & $\mathrm{S} / .13,296$ & S/.27,642 & S/.163,055 \\
\hline Pedicure & $\mathrm{S} / .24,173$ & $\mathrm{~S} / .22,382$ & S/.16,712 & $\mathrm{S} / .9,550$ & S/.14,623 & S/.15,369 & S/.25,068 & S/.9,699 & S/.7,759 & S/.10,893 & S/.17,010 & S/.35,364 & $\mathrm{S} / .208,602$ \\
\hline Totales & $\mathrm{S} / .72,840$ & S/.67,444 & S/.50,358 & $\mathrm{S} / .28,776$ & S/.44,064 & $\mathrm{S} / .46,312$ & S/.75,538 & $\mathrm{S} / .29,226$ & $\mathrm{~S} / .23,381$ & $\mathrm{~S} / .32,823$ & S/.51,258 & S/.106,562 & S/.628,582 \\
\hline
\end{tabular}


Tabla 85

Programación Mensual de Ventas para el Año 3 (Expresado en servicios)

\begin{tabular}{lcccccccrrrrrr}
\hline Servicios & Ene & Feb & Mar & Abr & May & Jun & Jul & Ago & Set & Oct & Nov & Dic & Totales \\
\hline Corte de & & & & & & & & & & & & & \\
Cabello & 575 & 532 & 398 & 227 & 348 & 366 & 596 & 231 & 185 & 259 & 405 & 841 & 4,962 \\
Planchado & 811 & 751 & 561 & 321 & 491 & 516 & 842 & 326 & 260 & 366 & 571 & 1,187 & 7,003 \\
Manicure & 1,395 & 1,292 & 964 & 551 & 844 & 887 & 1,447 & 560 & 448 & 629 & 982 & 2,041 & 12,038 \\
Pedicure & 1,338 & 1,239 & 925 & 529 & 810 & 851 & 1,388 & 537 & 430 & 603 & 942 & 1,958 & 11,550 \\
\hline Totales & 4,120 & 3,815 & 2,848 & 1,628 & 2,492 & 2,619 & 4,273 & 1,653 & 1,322 & 1,857 & 2,899 & 6,027 & 35,553 \\
\hline
\end{tabular}

Tabla 86

Programación Mensual de Ventas para el Año 3 (Expresado en soles)

\begin{tabular}{|c|c|c|c|c|c|c|c|c|c|c|c|c|c|}
\hline Servicios & Ene & Feb & Mar & Abr & May & Jun & Jul & Ago & Set & Oct & Nov & Dic & Totales \\
\hline $\begin{array}{l}\text { Corte de } \\
\text { Cabello }\end{array}$ & $S / .8,626$ & S/.7,987 & S/.5,963 & $\mathrm{S} / .3,408$ & $\mathrm{~S} / .5,218$ & S/.5,484 & S/.8,945 & $\mathrm{S} / .3,461$ & $\mathrm{~S} / .2,769$ & S/.3,887 & S/.6,070 & S/.12,619 & S/.74,436 \\
\hline Planchado & $\mathrm{S} / .24,344$ & $\mathrm{~S} / .22,541$ & S/.16,831 & S/.9,618 & S/.14,727 & S/.15,478 & $\mathrm{S} / .25,246$ & S/.9,768 & S/.7,814 & S/.10,970 & S/.17,131 & S/.35,615 & $\mathrm{S} / .210,084$ \\
\hline Manicure & S/.20,924 & S/.19,374 & S/.14,466 & $\mathrm{S} / .8,266$ & S/.12,658 & S/.13,304 & $\mathrm{S} / .21,699$ & $\mathrm{~S} / .8,396$ & S/.6,716 & S/.9,429 & S/.14,724 & S/.30,611 & S/.180,569 \\
\hline Pedicure & S/.26,769 & $\mathrm{S} / .24,786$ & S/.18,507 & S/.10,575 & S/.16,194 & S/.17,020 & S/.27,761 & S/.10,741 & S/.8,593 & S/.12,063 & S/.18,838 & S/.39,162 & S/.231,007 \\
\hline otales & $\mathrm{S} / .80,663$ & S/.74,688 & $\mathrm{S} / .55,767$ & $\mathrm{~S} / .31,867$ & $\mathrm{~S} / .48,796$ & S/.51,286 & S/.83,651 & S/.32,365 & $\mathrm{S} / .25,892$ & S/.36,348 & S/.56,763 & S/.118,008 & S/.696,096 \\
\hline
\end{tabular}


Tabla 87

Programación Mensual de Ventas para el Año 4 (Expresado en servicios)

\begin{tabular}{lccccccrrrrrrr}
\hline Servicios & Ene & Feb & Mar & Abr & May & Jun & Jul & Ago & Set & Oct & Nov & Dic & Totales \\
\hline Corte de & & & & & & & & & & & & & \\
Cabello & 637 & 590 & 440 & 252 & 385 & 405 & 660 & 256 & 204 & 287 & 448 & 932 & 5,496 \\
Planchado & 899 & 832 & 621 & 355 & 544 & 571 & 932 & 361 & 288 & 405 & 632 & 1,315 & 7,755 \\
Manicure & 1,545 & 1,430 & 1,068 & 610 & 935 & 982 & 1,602 & 620 & 496 & 696 & 1,087 & 2,260 & 13,331 \\
Pedicure & 1,482 & 1,372 & 1,025 & 586 & 897 & 942 & 1,537 & 595 & 476 & 668 & 1,043 & 2,169 & 12,791 \\
\hline Totales & 4,563 & 4,225 & 3,154 & 1,803 & 2,760 & 2,901 & 4,732 & 1,831 & 1,465 & 2,056 & 3,211 & 6,675 & 39,374 \\
\hline
\end{tabular}

Tabla 88

Programación Mensual de Ventas para el Año 4 (Expresado en soles)

\begin{tabular}{|c|c|c|c|c|c|c|c|c|c|c|c|c|c|}
\hline Servicios & Ene & Feb & Mar & Abr & May & Jun & Jul & Ago & Set & Oct & Nov & Dic & Totales \\
\hline $\begin{array}{l}\text { Corte de } \\
\text { Cabello }\end{array}$ & S/.9,552 & $\mathrm{S} / .8,845$ & S/.6,604 & S/.3,774 & S/.5,779 & S/.6,073 & S/.9,906 & $S / .3,833$ & S/.3,066 & S/.4,304 & S/.6,722 & S/.13,975 & S/.82,434 \\
\hline Planchado & $\mathrm{S} / .26,960$ & S/.24,963 & S/.18,639 & S/.10,651 & S/.16,309 & S/.17,141 & S/.27,959 & S/.10,817 & $\mathrm{S} / .8,654$ & S/.12,149 & S/.18,972 & S/.39,442 & S/.232,657 \\
\hline Manicure & S/.23,172 & $\mathrm{S} / .21,456$ & S/.16,020 & S/.9,155 & S/.14,018 & S/.14,733 & $\mathrm{S} / .24,031$ & S/.9,298 & $\mathrm{S} / .7,438$ & S/.10,442 & S/.16,307 & S/.33,901 & S/.199,970 \\
\hline Pedicure & S/.29,645 & S/.27,449 & S/.20,496 & S/.11,712 & S/.17,934 & S/.18,849 & S/.30,743 & S/.11,895 & S/.9,516 & S/.13,359 & $S / .20,862$ & S/.43,370 & $\mathrm{S} / .255,828$ \\
\hline Totales & $\mathrm{S} / .89,330$ & $\mathrm{~S} / .82,713$ & S/.61,759 & S/.35,291 & $\mathrm{S} / .54,039$ & S/.56,797 & $\mathrm{S} / .92,639$ & $\mathrm{~S} / .35,842$ & $\mathrm{~S} / .28,674$ & S/.40,254 & S/.62,862 & S/.130,687 & $\mathrm{S} / .770,889$ \\
\hline
\end{tabular}


Tabla 89

Programación Mensual de Ventas para el Año 5 (Expresado en servicios)

\begin{tabular}{lcccccccccrrrr}
\hline Servicios & Ene & Feb & Mar & Abr & May & Jun & Jul & Ago & Set & Oct & Nov & Dic & Totales \\
\hline Corte de & & & & & & & & & & & & & \\
Cabello & 705 & 653 & 488 & 279 & 427 & 448 & 731 & 283 & 226 & 318 & 496 & 1,032 & 6,086 \\
Planchado & 995 & 922 & 688 & 393 & 602 & 633 & 1,032 & 399 & 319 & 448 & 700 & 1,456 & 8,589 \\
Manicure & 1,711 & 1,584 & 1,183 & 676 & 1,035 & 1,088 & 1,774 & 686 & 549 & 771 & 1,204 & 2,503 & 14,764 \\
Pedicure & 1,642 & 1,520 & 1,135 & 649 & 993 & 1,044 & 1,702 & 659 & 527 & 740 & 1,155 & 2,402 & 14,166 \\
\hline Totales & 5,053 & 4,679 & 3,493 & 1,996 & 3,057 & 3,213 & 5,240 & 2,027 & 1,622 & 2,277 & 3,556 & 7,392 & 43,606 \\
\hline
\end{tabular}

Tabla 90

Programación Mensual de Ventas para el Año 5 (Expresado en soles)

\begin{tabular}{|c|c|c|c|c|c|c|c|c|c|c|c|c|c|}
\hline Servicios & Ene & Feb & Mar & Abr & May & Jun & Jul & Ago & Set & Oct & Nov & Dic & Totales \\
\hline $\begin{array}{l}\text { Corte de } \\
\text { Cabello }\end{array}$ & S/.10,579 & S/.9,796 & S/.7,314 & S/.4,179 & S/.6,400 & S/.6,726 & S/.10,971 & S/.4,245 & $\mathrm{S} / .3,396$ & S/.4,767 & S/.7,445 & S/.15,477 & S/.91,294 \\
\hline Planchado & $\mathrm{S} / .29,858$ & $S / .27,646$ & S/.20,643 & S/.11,796 & S/.18,062 & S/.18,984 & S/.30,964 & S/.11,980 & S/.9,584 & S/.13,455 & $\mathrm{S} / .21,011$ & $\mathrm{~S} / .43,681$ & $\mathrm{~S} / .257,664$ \\
\hline Manicure & S/.25,663 & $\mathrm{S} / .23,762$ & S/.17,742 & S/.10,139 & S/.15,525 & S/.16,317 & S/.26,614 & S/.10,297 & $\mathrm{S} / .8,238$ & S/.11,564 & S/.18,059 & S/.37,544 & $\mathrm{S} / .221,464$ \\
\hline Pedicure & S/.32,832 & S/.30,400 & S/.22,699 & S/.12,971 & $\mathrm{S} / .19,861$ & S/.20,875 & S/.34,048 & S/.13,173 & S/.10,539 & S/.14,795 & $S / .23,104$ & S/.48,032 & $\mathrm{S} / .283,326$ \\
\hline otales & $\mathrm{S} / .98,932$ & S/.91,604 & S/.68,398 & S/.39,084 & $\mathrm{S} / .59,848$ & $\mathrm{~S} / .62,901$ & \#\#\#\#\#\#\# & $\mathrm{S} / .39,695$ & $\mathrm{~S} / .31,756$ & S/.44,581 & S/.69,619 & S/.144,734 & $\mathrm{S} / .853,749$ \\
\hline
\end{tabular}




\subsection{Aspectos críticos que impactan el pronóstico de ventas}

Para el pronóstico de ventas hay factores que puedan afectar la programación mencionada, los cuales pueden corresponder a factores no controlables (externos) y controlables por la empresa (internos).

Los aspectos críticos que puedan impactar el pronóstico de ventas se detallan a continuación:

- La desaceleración económica que afecta el poder adquisitivo de la mujer limeña, ello podría ocasionar que el ingreso destinado a su cuidado personal disminuya para destinarlo a la canasta básica del hogar.

- Si la demanda incrementa y no se tiene los productos y especialistas que necesitan los clientes, se puede tener problemas en la atención al cliente.

- El incremento de los costos de los productos profesionales de belleza puede afectar seriamente al precio de venta sugerido al mercado y esto disminuirá la demanda proyectada.

- Restricciones legales y el incremento de la fiscalización, debido al gran nivel de informalidad en las empresas competidoras y que no cumplen con la ley.

- Crecimiento de competencia, al ser un salón de belleza móvil la competencia puede imitar el plan de negocio y puede originar descuentos o guerra de precios, lo cual esto puede afectar a los resultados de la empresa.

- Mala atención de los servicios profesionales de belleza puede originar disminución a las ventas proyectados debido a que existe una conexión entre el cliente y el estilista. 


\section{Capítulo V. Ingeniería del Proyecto}

\subsection{Estudio de ingeniería}

El estudio de ingeniería permite identificar el mejor proceso productivo para alcanzar un producto final de calidad, identificando los equipos y maquinarias, el layout del servicio, el personal necesario y otros requerimientos básicos como mantenimiento e insumos para emplearlos de manera eficiente y eficaz. Se identificará variables externas que podrían afectar como aspectos legales, económicos financieros, tecnológicos y los que afecten en forma directa como la característica del servicio, la demanda, ventas, abastecimiento de material directo y tipos de comercialización. (Sapag \& Sapag, 2008)

\subsubsection{Modelamiento y selección de procesos productivos.}

Krajewski, Ritzman, \& Malhotra (2013) mencionan que la estructura de los procesos en los servicios depende del tipo y cantidad de contacto con el cliente, donde el cliente evalúa la calidad del servicio que recibe identificando el valor agregado que busca para poder ser parte de la fidelización de los clientes que busca la organización.

En la Figura 26, se puede observar la matriz cliente - contacto, donde se define como se identifica al tipo de cliente y el nivel de interacción que se tiene en las diferentes partes de los procesos de servicios: 


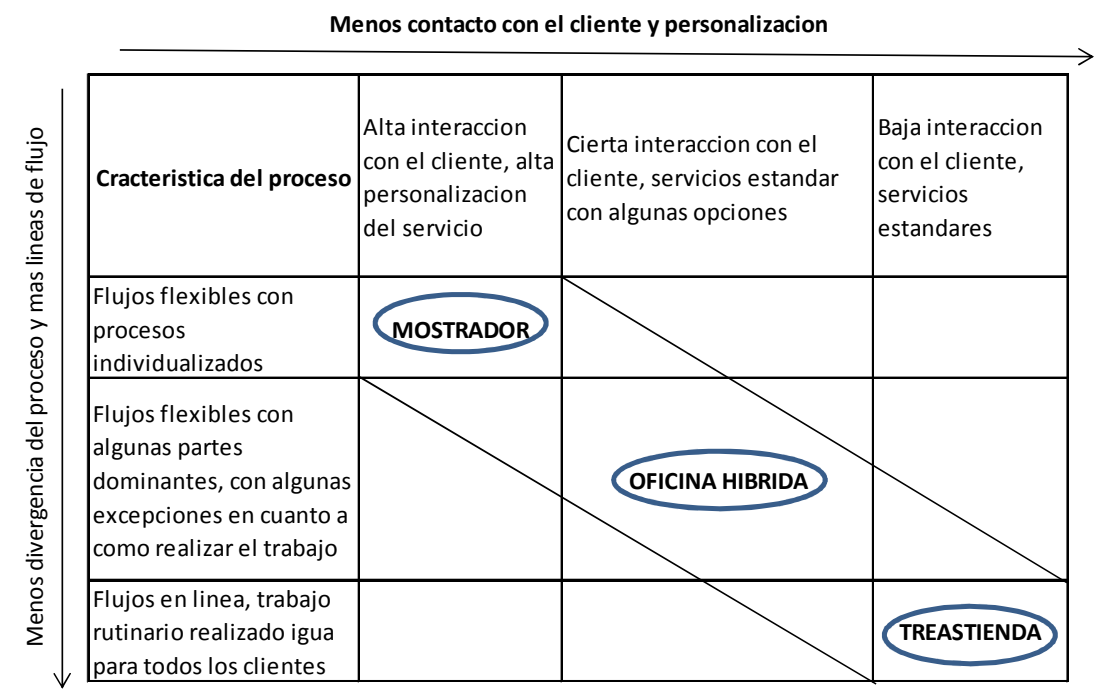

Figura 26. Matriz cliente - contacto para proceso de servicio. Tomado de Administración de operaciones (p. 93), por L. Krajewski et al., 2013, México: Pearson Educación. Copyright 2013 por Pearson Educación.

De acuerdo con la matriz cliente - contacto, definido por Krajewski et al., el servicio a domicilio que brindará el salón de belleza móvil para las mujeres de la zona dos de Lima Metropolitana, se posiciona dentro de la estructura del proceso de servicio de mostrador, teniendo una alta interacción y personalización con el cliente, debido a la poca divergencia y flexibilidad de los servicios con la finalidad de brindar comodidad y satisfacción.

Habiéndose explicado la estructura de los procesos de los servicios que se va a implementar, como se muestra en la Figura 27, se ha desarrollado el flujograma del proceso de reserva de cita a domicilio y en la Figura 28, el flujograma del proceso del servicio de atención del salón de belleza móvil: 


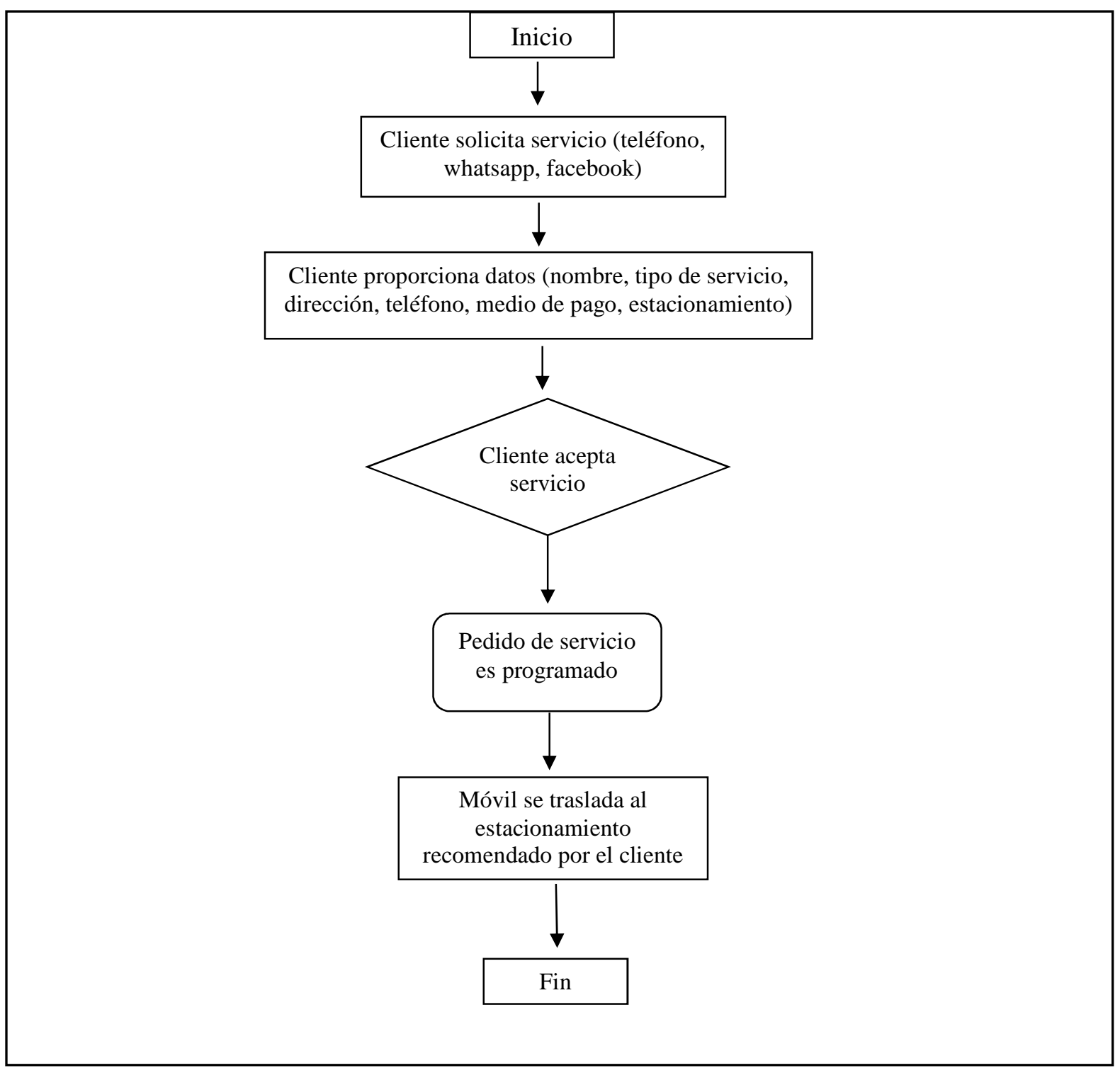

Figura 27. Flujograma del proceso de reserva de cita a domicilio. Se considera con 24 horas de anticipación para la programación de reserva 


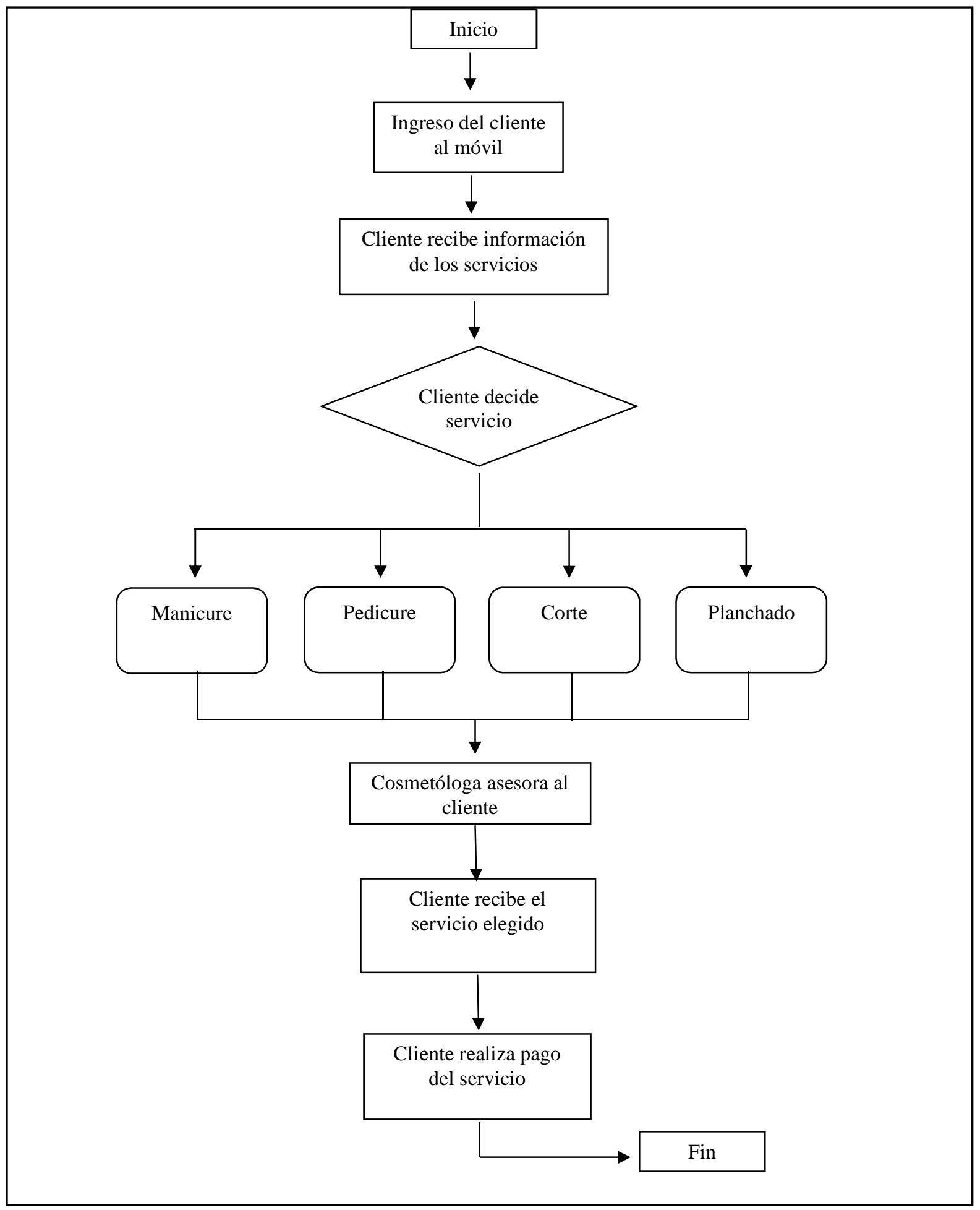

Figura 28. Flujograma del proceso del servicio de atención. Se considera cuando al cliente se encuentra frente a la unidad móvil 
Definición de las etapas del proceso:

1. Cliente solicita el servicio: el cliente realiza la reserva del servicio por medio de redes sociales como facebook, whatsapp, correos y línea telefónica.

2. Cliente proporciona datos: el cliente que solicita el servicio y realiza una reserva o cita tiene que inscribir o proporcionar: nombre, dirección, tipo de servicio, teléfono, correo, medio de pago y confirmación de lugar de estacionamiento.

3. Programación de reservas

4. La unidad móvil se traslada al estacionamiento: la unidad móvil recibe la orden del servicio y se desplaza al estacionamiento.

5. Ingreso a la unidad móvil: el cliente decide ingresar a la móvil para recibir los servicios del salón de belleza móvil.

6. Recibe información de los servicios: los especialistas de la cosmetología ofrecen los servicios y productos al cliente.

7. Cliente decide servicio(s): el cliente de acuerdo con su necesidad elige el servicio de manicure, pedicure, corte y/o planchado.

8. Cosmetóloga asesora al cliente: la cosmetóloga brindará asesoría de los modelos y tendencias que el cliente tiene para el servicio a brindarse a fin de que el cliente pueda elegir.

9. Cliente es atendido por cosmetóloga: el cliente recibe el servicio escogido a cargo de la cosmetóloga.

10. Cancelación del servicio: cliente realiza pago del servicio: efectivo, tarjeta bancaria.

11. Salida del móvil: cliente se retira de la unidad móvil. 
Servicios que brinda el salón de belleza móvil:

a) Manicure: tratamiento de belleza dedicado al mejoramiento y cuidado de las manos y uñas, con tratamiento de hidratación de manos y pintado de uñas. Consiste en la limpieza, exfoliación, eliminación de cutícula, limado y esmaltado de uñas.

b) Pedicure: tratamiento de belleza dedicado al mejoramiento y cuidado de los pies y uñas, consiste en una desinfección, exfoliación, tratamiento de cutícula y uñas, con masajes desde los pies hasta más arriba del tobillo permitiendo la estimulación de la circulación de la sangre.

c) Corte: realizar un cambio de aspecto del cabello acortándolo, modificándolo o adornándolos más o menos sofisticadas que dependen de las últimas tendencias de la moda.

d) Planchado: consiste en modelar el cabello rizado, ondulado o encrespado que alisa el pelo de manera temporal aportando una textura y un brillo con la aplicación de shampoo, acondicionador, sprays y otros productos anti-frizz.

\subsubsection{Selección del equipamiento.}

Sapag \& Sapag (2008) menciona que la selección del equipamiento (maquinaria, equipo, mobiliario, vehículos, etc), depende del proceso productivo y la tecnología que se pueda utilizar para poder cuantificar los costos, inversiones, e ingresos al proyecto.

Se tomará como base el proceso de atención de los servicios detallados anteriormente para establecer los requerimientos del equipamiento, maquinarias e insumos necesarios para satisfacer la demanda estimada y proyectada en el capítulo anterior según como se muestra a continuación: 
a) Adquisición de unidades móviles tipo furgón según como se muestra las Figuras 29 y 30 , con las capacidades para brindar los servicios de corte, manicure, pedicure y planchado.

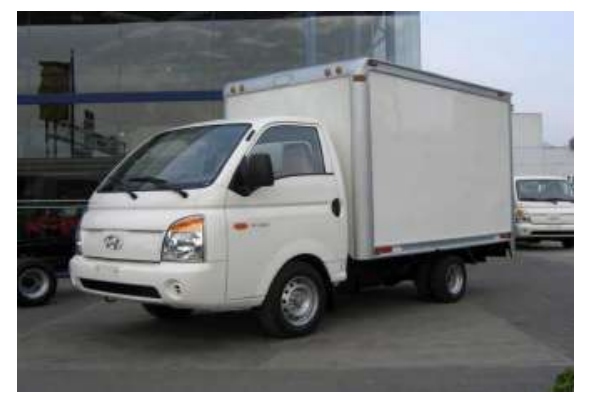

Figura 29. Unidad móvil tipo furgón, acondicionada para brindar los servicios del salón de belleza móvil

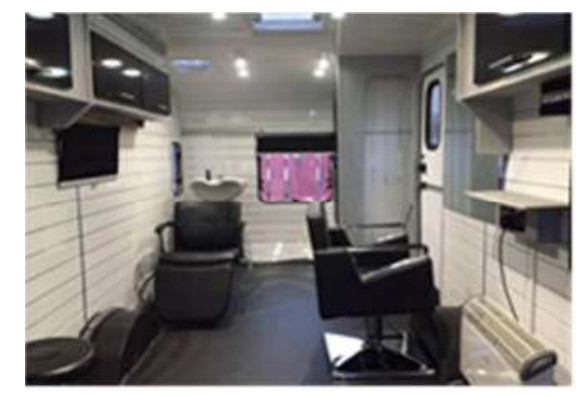

Figura 30. Interior de la unidad móvil tipo furgón, acondicionada para brindar los servicios del salón de belleza móvil

b) Adquisición del equipamiento e instrumentos que se muestran en la Tabla 91 y 92, necesarios para brindar los servicios dentro de la móvil. La compra del equipamiento se considera dentro de la inversión inicial y la compra de los instrumentos se hará de forma anual. 
Tabla 91

Equipamiento para el acondicionamiento del salón de belleza móvil

\begin{tabular}{cll}
\hline Nro. & \multicolumn{1}{c}{ Equipamiento } & \multicolumn{1}{c}{ Descripción } \\
\hline 1 & Muebles & Silla para corte y planchado \\
\hline & & Espejo con mostrador \\
\hline & Lavadero \\
\hline & Kit manicure y pedicure \\
\hline 2 & $\begin{array}{l}\text { Equipos eléctricos y } \\
\text { electrónicos }\end{array}$ & Auxiliar de manos y pies \\
\hline & Computadora \\
\hline & Tablet \\
\hline & Televisor 32" \\
\hline 3 & Cámaras de vigilancia \\
\hline & Aire acondicionado \\
\hline & Extintor \\
\hline & Botiquín de primeros auxilios \\
\hline & Tanque de agua \\
\hline & Accesorios para tanque de agua \\
\hline
\end{tabular}

Nota: Se considera el equipamiento para poder implementar las cuatro estaciones de servicio dentro del furgón 
Tabla 92

Instrumentos para los servicios del salón de belleza móvil

\begin{tabular}{lc}
\hline \multicolumn{1}{c}{ Descripción } & Unidad \\
\hline Peines & Unidad \\
\hline Cepillo para cabello & Unidad \\
\hline Tijeras para corte & Unidad \\
\hline Tijera para entresacado & Unidad \\
\hline Atomizador para agua & Unidad \\
\hline Secadora baby blush & Unidad \\
\hline Plancha de cabello & Unidad \\
\hline Ganchos para separar cabello & Unidad \\
\hline Tijera de uñas & Unidad \\
\hline Corta uñas para pies & Unidad \\
\hline Corta cutículas en forma de alicate & Unidad \\
\hline Corta cutícula & Unidad \\
\hline Lima de uñas cuadrada blanca & Unidad \\
\hline Palito de naranjo & Unidad \\
\hline Cepillo de uñas & Unidad \\
\hline Limpia cayos & Unidad \\
\hline Esterilizador & Unidad \\
\hline Toallas & Unidad \\
\hline Capas & Unidad \\
\hline Aromatizadores & Unidad
\end{tabular}

Nota: La adquisición de los instrumentos es de acuerdo con el plan de compras anual que se ha proyectado.

c) La adquisición de los productos e insumos que se muestran en la Figura 31, se han considerado con una frecuencia de compra mensual para la realización de los servicios de atención del salón de belleza móvil: 


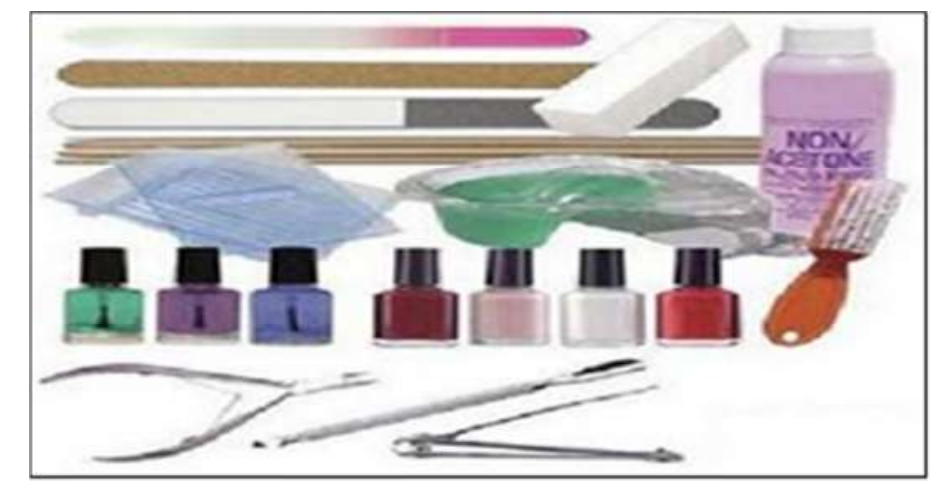

Figura 31. Productos e insumos

La adquisición de los insumos se ha proyectado de acuerdo a la cantidad de servicios de corte, servicios de planchado, servicios de manicure, y servicios de pedicure que se realicen en forma mensual para una mejor rotación de productos según preferencia del cliente por la marca a utilizar como se puede apreciar en las Tablas 93, 94, 95 y 96. Tabla 93

Insumos necesarios para el servicio de corte

\begin{tabular}{ll}
\hline \multicolumn{1}{c}{ Producto } & Unidad \\
\hline Shampoo Reflex 1 Lt. & Unidad \\
\hline Acondicionador Reflex 1 Lt. & Unidad \\
\hline Alcohol 200 ml. & Unidad \\
\hline Talco Baby Johnson 500 mg. & Unidad \\
\hline Gillette & Unidad \\
\hline Brillo Reflex 500 ml. & Unidad \\
\hline
\end{tabular}


Tabla 94

Insumos necesarios para el servicio de planchado

\begin{tabular}{lc}
\hline \multicolumn{1}{c}{ Producto } & Unidad \\
\hline Thermo Protector Ialotherm & Unidad \\
\hline Silicona líquida Salone 400ml & Unidad \\
\hline Shampoo Reflex & Litro \\
\hline Acondicionador Reflex & Litro \\
\hline
\end{tabular}

Tabla 95

Insumos necesarios para el servicio de manicure

\begin{tabular}{lc}
\hline \multicolumn{1}{c}{ Producto } & Unidad \\
\hline Shampoo Reflex & Litro \\
\hline Algodón & Unidad \\
\hline Alcohol & Litro \\
\hline Acetona Cutex & Unidad \\
\hline Brillo Vogue & Unidad \\
\hline Base de esmalte Vogue & Unidad \\
\hline Brillo secante Vogue & Unidad \\
\hline Lima para manos & Unidad \\
\hline Papel toalla Elite & Caja \\
\hline Crema de manos Acuarin $400 \mathrm{ml}$ & Unidad \\
\hline
\end{tabular}


Tabla 96

Insumos necesarios para el servicio de pedicure

\begin{tabular}{lc}
\hline \multicolumn{1}{c}{ Producto } & Unidad \\
\hline Shampoo Reflex & Litro \\
\hline Algodón & Unidad \\
\hline Alcohol & Litro \\
\hline Acetona Cutex & Unidad \\
\hline Brillo Vogue & Unidad \\
\hline Base de esmalte Vogue & Unidad \\
\hline Brillo secante Vogue & Unidad \\
\hline Separadores de dedos & Unidad \\
\hline Lima para pies & Unidad \\
\hline Papel toalla Elite & Caja \\
\hline Crema de manos Acuarin $400 \mathrm{ml}$ & Unidad \\
\hline
\end{tabular}

d) Se necesitará una oficina para la ejecución de trabajos administrativos con servicios básicos de agua, luz, internet, línea telefónica.

e) Adquisición de equipamiento básico para la oficina administrativa del salón de belleza móvil como: un escritorio, un computador, un teléfono y tres sillas (ver Figura 32)

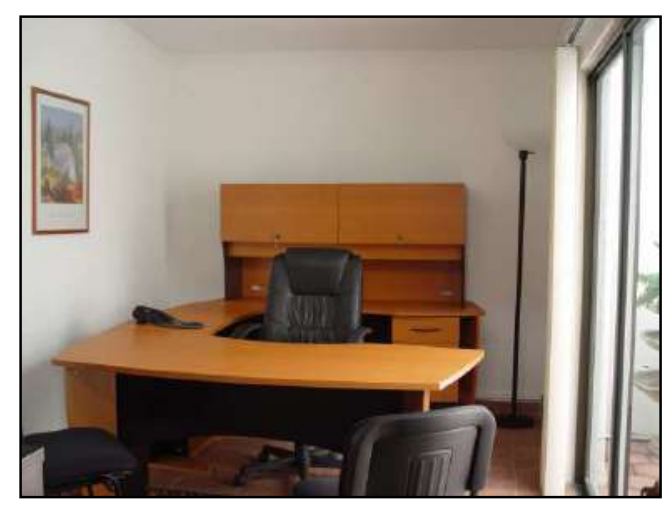

Figura 32. Equipamiento básico para la oficina administrativa 


\subsubsection{Lay out.}

Según Krajewski et al. (2013), la ubicación de los procesos productivos se plasma dentro de un área física para demostrar que son tangibles de acuerdo al flujograma de procesos.

Para el plan de negocio del salón de belleza móvil se ha considerado los siguientes ambientes:

a) Móvil tipo furgón equipada y acondicionada de acuerdo al proceso de atención al cliente mostrado en el flujograma de procesos de la Figuras 27 y 28 antes mostradas, los cuales sirvieron para desarrollar el esquema de distribución de cuatro estaciones, considerando dimensiones del equipamiento e instrumentos. Además, en la Figura 33, se puede apreciar la distribuirán de los espacios respectivos para cada servicio, de acuerdo al Reglamento Nacional de Edificaciones RNE A080, oficinas artículo seis según se muestra:

- Dos estaciones para servicio de manicure y pedicure

- Una estación para servicio de corte y planchado

- Lavadero para cabello

- Un armario para almacenamiento de insumos y materiales 


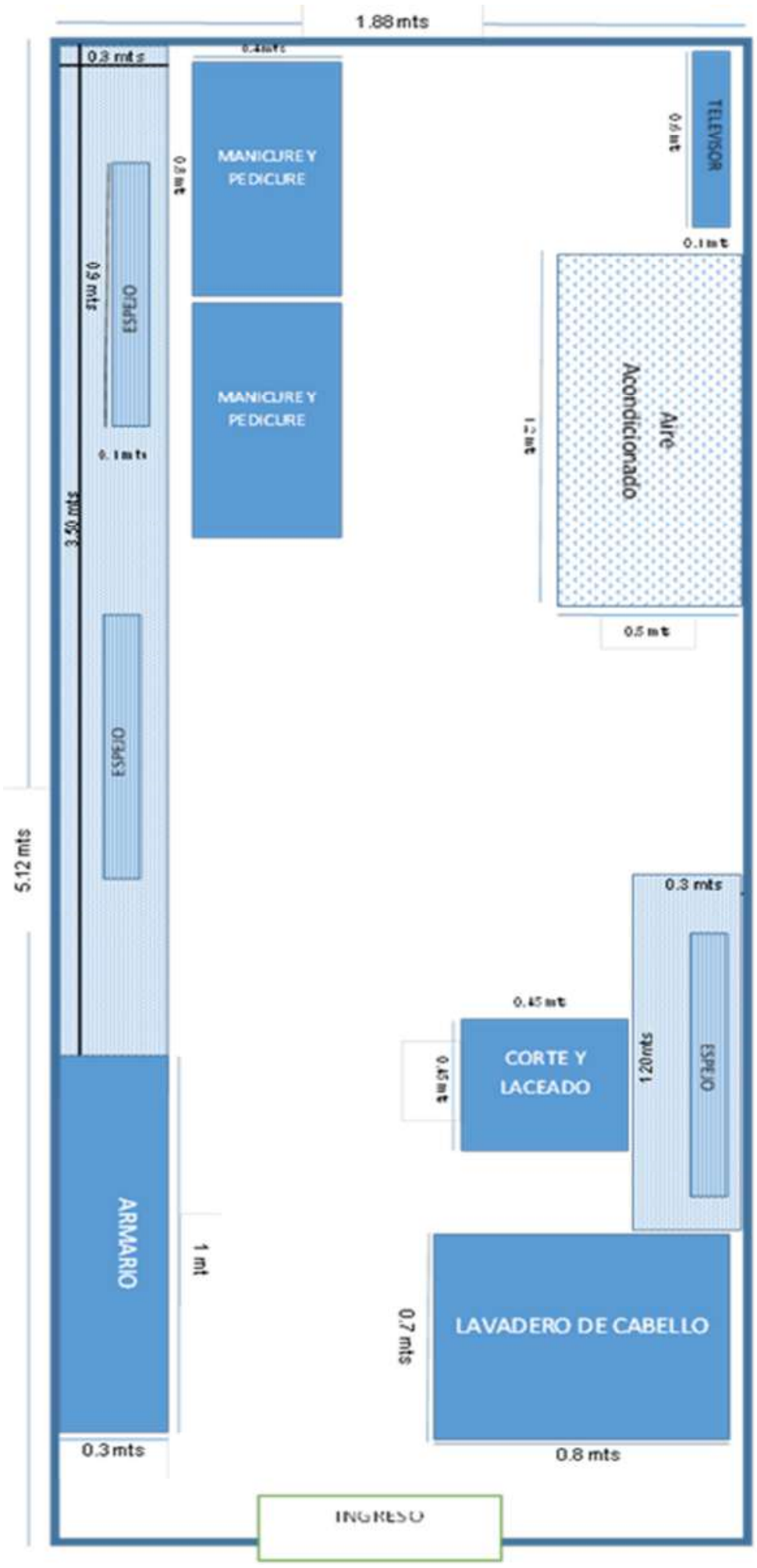

Figura 33. Layout de móvil (esquema de distribución para la atención de los servicios del salón de belleza móvil) 
b) Oficina administrativa como se muestra en la Figura 34, con la distribución de los ambientes para realizar trabajos de marketing, contabilidad, programación de reserva de cita, horarios de trabajo de los colaboradores, programa de mantenimiento de la móvil, kardex y requerimientos de los materiales y equipos para reposición.

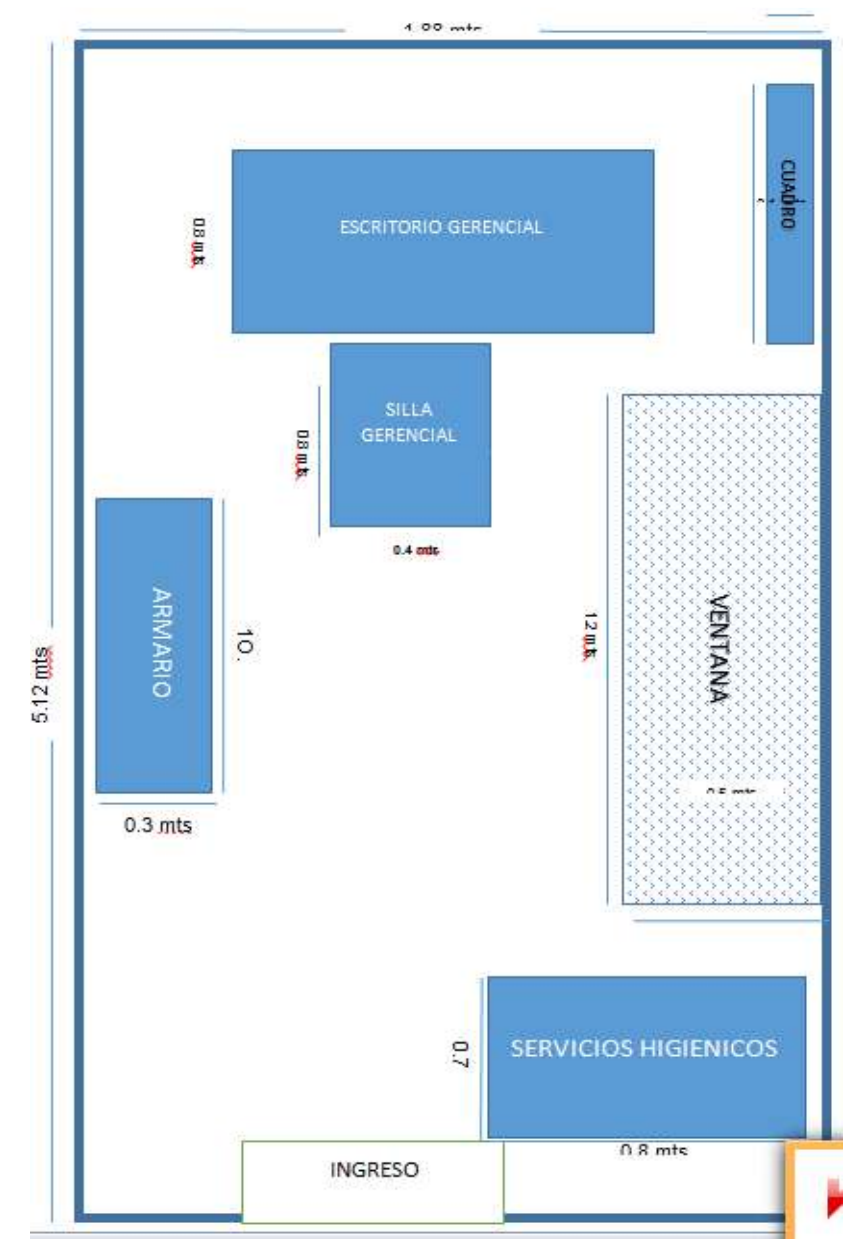

Figura 34. Layout de oficina (esquema de distribución oficina administrativa) 


\subsubsection{Distribución de equipos y maquinarias.}

Según Krajewsji (2013), la distribución de los equipos y maquinarias serán ubicados de acuerdo al factor de importancia y de acercamiento al proceso de servicio solicitado por el cliente.

La distribución del equipamiento y maquinaria (ver Figura 35) está de acuerdo con las estaciones que se utilizarán en los procesos que se mostraron en el diagrama de layout.

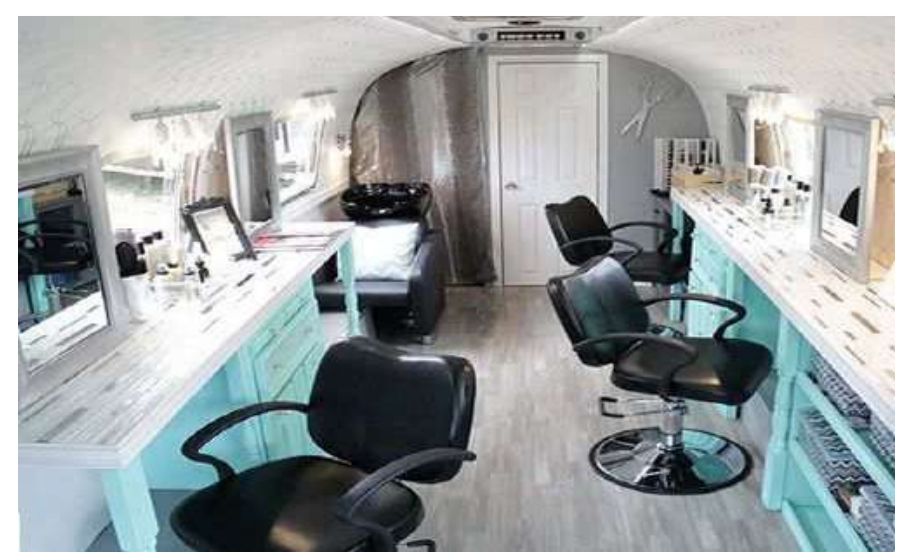

Figura 35. Distribución de estaciones, equipos y maquinaria

A continuación, se detallan los equipos y maquinarias que serán distribuidos según sus dimensiones y estaciones de servicio, necesarios para brindar una mejor comodidad en el salón de belleza móvil (ver Tabla 97 y 98): 
Tabla 97

Requerimiento necesario de equipos y maquinarias para salón de belleza móvil

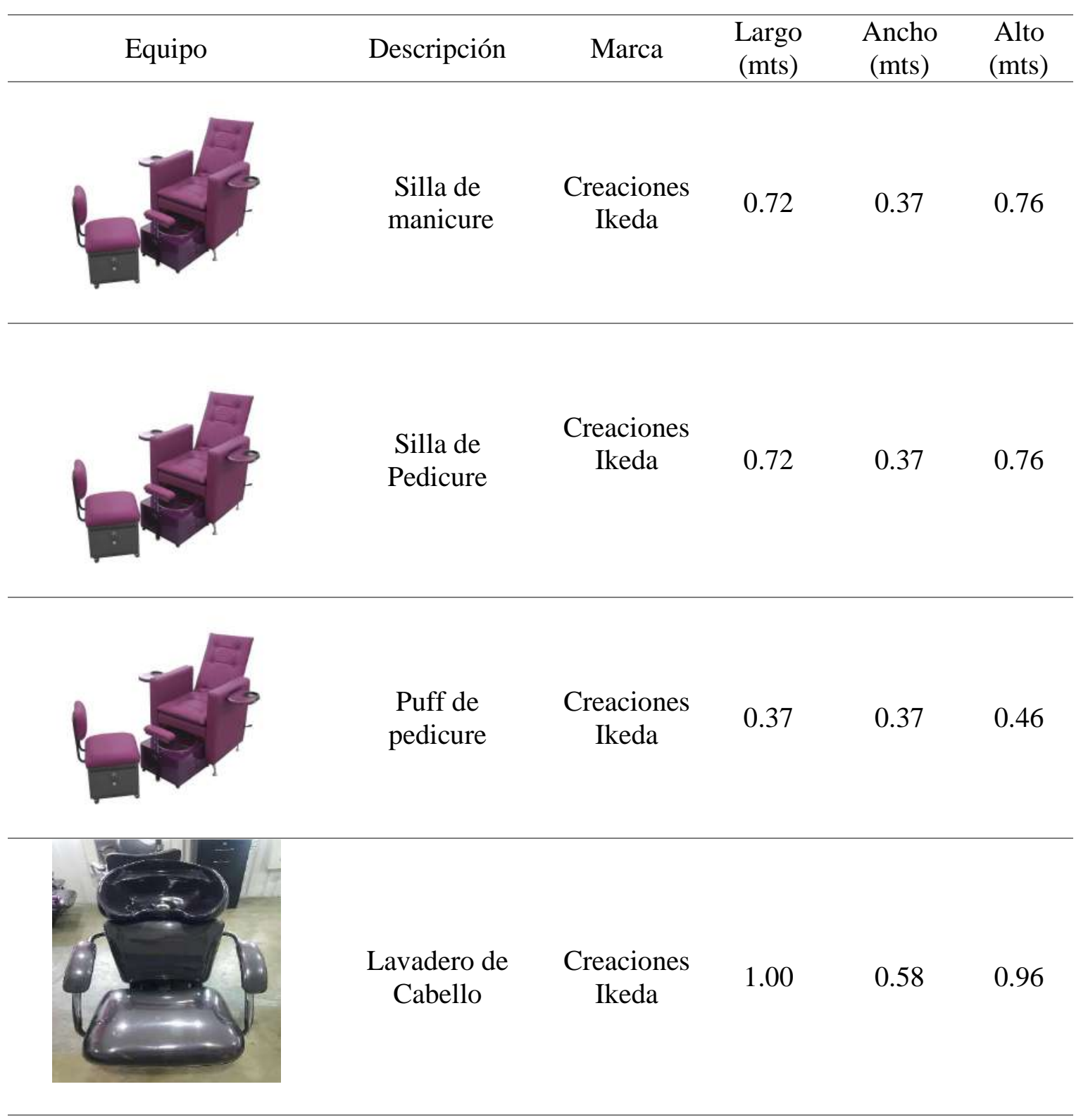

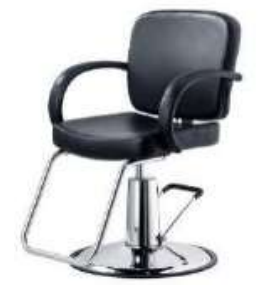

Silla para corte Creaciones pelo Ikeda

0.50

0.63

0.89 
Tabla 98 "Continuación”

Requerimiento necesario de equipos y maquinarias para salón de belleza móvil

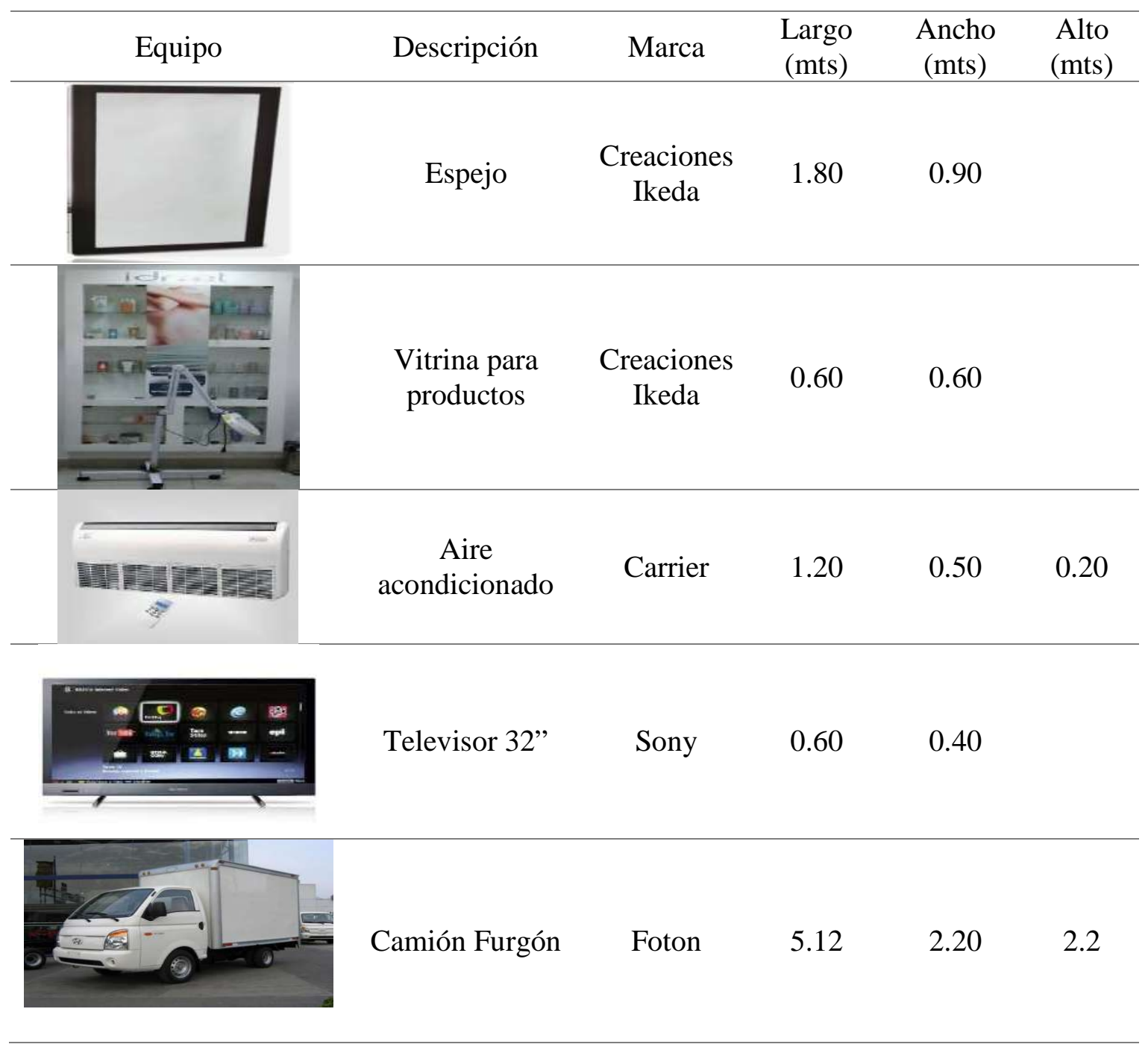




\subsection{Determinación del Tamaño}

Sapag \& Sapag (2008) menciona que la determinación del tamaño depende de la información que se tenga de las variables del proyecto como factor humano, materiales, necesidad del servicio y la cantidad de servicios de acuerdo a la estrategia comercial que se pueda brindar de acuerdo a la política de la organización.

Para el plan de negocio del salón de belleza móvil se ha determinado el tamaño del negocio de acuerdo al análisis de la demanda, cantidad de servicios anuales, tiempo promedio de cada servicio y la cantidad de horas de trabajo diario por cada colaborador.

\subsubsection{Proyección de crecimiento.}

De acuerdo con la investigación realizada se consideró el crecimiento anual del sector, el cual corresponde el 10\%, por lo cual, la proyección de los cinco años que se ha estimado (ver Tabla 99), es la cantidad de los servicios demandados que se tendrá cada año por cada servicio, para poder estimar los requerimientos de los productos necesarios. Tabla 99

Cantidad de servicios proyectados por año

\begin{tabular}{lrrrrr}
\hline Ventas (Servicios) & \multicolumn{1}{c}{2017} & \multicolumn{1}{c}{2018} & \multicolumn{1}{c}{2019} & \multicolumn{1}{c}{2020} & \multicolumn{1}{c}{2021} \\
\hline Corte de Cabello & 4,047 & 4,481 & 4,962 & 5,496 & 6,086 \\
Planchado & 5,710 & 6,324 & 7,003 & 7,755 & 8,589 \\
Manicure & 9,816 & 10,870 & 12,038 & 13,331 & 14,764 \\
Pedicure & 9,419 & 10,430 & 11,550 & 12,791 & 14,166 \\
\hline Total & 28,992 & 32,105 & 35,553 & 39,374 & 43,606 \\
\hline
\end{tabular}

\subsubsection{Recursos.}

D’Alessio (2013) menciona que una adecuada selección de los recursos permite realizar las estrategias de la organización en los objetivos a corto plazo, generando 
relaciones entre los recursos, las capacidades y las ventajas competitivas de la organización.

El proceso de acondicionamiento debe considerar la selección de recursos financieros, físicos, humanos, y tecnológicos, los que fortalecerán las competencias de la organización tomando en cuenta materiales, mano de obra y maquinarias.

a) Materiales

La cantidad de materiales necesarios para realizar los servicios de corte, planchado, manicure y pedicure, se muestran en las Tablas 100, 101, 102 y 103 respectivamente, donde se muestra el costo de los productos necesarios por cada servicio realizado, tomando en consideración la cantidad de servicios proyectados de forma anual según lo indicado en la Tabla 102, lo que nos permitirá tener un kardex de consumo por cada producto en forma mensual como se muestra a continuación:

Tabla 100

Productos necesarios para servicio de corte

\begin{tabular}{lcrcc}
\hline \multicolumn{1}{c}{ Producto } & Unid. Medida & Precio (S/) & $\begin{array}{c}\text { Cantidad de } \\
\text { servicios x } \\
\text { Producto }\end{array}$ & $\begin{array}{c}\text { Costo x } \\
\text { Servicio }\end{array}$ \\
\hline Shampoo & $1 \mathrm{Lt}$. & $\mathrm{S} / 8.00$ & 20 & $\mathrm{~S} / 0.40$ \\
\hline Acondicionador & $1 \mathrm{Lt}$. & $\mathrm{S} / 12.00$ & 20 & $\mathrm{~S} / 0.60$ \\
\hline Alcohol & $200 \mathrm{mml}$ & $\mathrm{S} / 4.50$ & 10 & $\mathrm{~S} / 0.45$ \\
\hline Talco & $500 \mathrm{mml}$ & $\mathrm{S} / 20.00$ & 20 & $\mathrm{~S} / 1.00$ \\
\hline Gillette & Unid & $\mathrm{S} / 1.00$ & 2 & $\mathrm{~S} / 0.50$ \\
\hline Brillo & $500 \mathrm{mml}$ & $\mathrm{S} / 15.00$ & 15 & $\mathrm{~S} / 1.00$ \\
\hline
\end{tabular}


Tabla 101

Productos necesarios para servicio de planchado

\begin{tabular}{lcrcc}
\hline \multicolumn{1}{c}{ Producto } & Unid. Medida & Precio (S/) & $\begin{array}{c}\text { Cantidad de } \\
\text { servicios x } \\
\text { Producto }\end{array}$ & $\begin{array}{c}\text { Costo x } \\
\text { Servicio }\end{array}$ \\
\hline ThermoProtector & Unid & S/ 12.00 & 15 & S/ 0.80 \\
\hline Silicona liquida & $400 \mathrm{ml}$ & $\mathrm{S} / 20.00$ & 20 & $\mathrm{~S} / 1.00$ \\
\hline Shampoo & $1 \mathrm{Lt}$. & $\mathrm{S} / 8.00$ & 20 & $\mathrm{~S} / 0.40$ \\
\hline Acondicionador & $1 \mathrm{Lt}$. & $\mathrm{S} / 12.00$ & 20 & $\mathrm{~S} / 0.60$ \\
\hline
\end{tabular}

Tabla 102

Productos necesarios para servicio de manicure

\begin{tabular}{lcrrr}
\hline \multicolumn{1}{c}{ Producto } & $\begin{array}{c}\text { Unid. } \\
\text { Medida }\end{array}$ & $\begin{array}{c}\text { Precio } \\
(\mathrm{S} /)\end{array}$ & $\begin{array}{c}\text { Cantidad de } \\
\text { servicios x } \\
\text { Producto }\end{array}$ & $\begin{array}{c}\text { Costo x } \\
\text { Servicio }\end{array}$ \\
\hline Shampoo & $\mathrm{Lt}$ & $\mathrm{S} / 8.00$ & 100 & $\mathrm{~S} / 0.08$ \\
\hline Algodón & Unid & $\mathrm{S} / 4.00$ & 30 & $\mathrm{~S} / 0.13$ \\
\hline Alcohol & $\mathrm{Lt}$ & $\mathrm{S} / 4.50$ & 30 & $\mathrm{~S} / 0.15$ \\
\hline Acetona & Unid & $\mathrm{S} / 6.00$ & 35 & $\mathrm{~S} / 0.17$ \\
\hline Brillo & Unid & $\mathrm{S} / 8.00$ & 25 & $\mathrm{~S} / 0.32$ \\
\hline Base de esmalte & Unid & $\mathrm{S} / 8.00$ & 25 & $\mathrm{~S} / 0.32$ \\
\hline Brillo secante & Unid & $\mathrm{S} / 8.00$ & 25 & $\mathrm{~S} / 0.32$ \\
\hline Lima para manos & Unid & $\mathrm{S} / 2.50$ & 1 & $\mathrm{~S} / 2.50$ \\
\hline Papel toalla & Caja & $\mathrm{S} / 24.00$ & 50 & $\mathrm{~S} / 0.48$ \\
\hline Crema de manos & $400 \mathrm{ml}$ & $\mathrm{S} / 8.00$ & 20 & $\mathrm{~S} / 0.40$ \\
\hline
\end{tabular}


Tabla 103

Productos necesarios para servicio de pedicure

\begin{tabular}{lcrrr}
\hline Producto & $\begin{array}{c}\text { Unid. } \\
\text { Medida }\end{array}$ & $\begin{array}{c}\text { Precio } \\
(\mathrm{S} /)\end{array}$ & $\begin{array}{c}\text { Cantidad de } \\
\text { servicios x } \\
\text { Producto }\end{array}$ & $\begin{array}{c}\text { Costo } \\
\text { Servicio }\end{array}$ \\
\hline Shampoo & Lt & $\mathrm{S} / 8.00$ & 50 & $\mathrm{~S} / 0.16$ \\
\hline Algodón & Unid & $\mathrm{S} / 4.00$ & 30 & $\mathrm{~S} / 0.13$ \\
\hline Alcohol & $\mathrm{Lt}$ & $\mathrm{S} / 4.50$ & 30 & $\mathrm{~S} / 0.15$ \\
\hline Acetona & Unid & $\mathrm{S} / 6.00$ & 35 & $\mathrm{~S} / 0.17$ \\
\hline Brillo & Unid & $\mathrm{S} / 8.00$ & 25 & $\mathrm{~S} / 0.32$ \\
\hline Base de esmalte & Unid & $\mathrm{S} / 8.00$ & 25 & $\mathrm{~S} / 0.32$ \\
\hline Brillo secante & Unid & $\mathrm{S} / 8.00$ & 25 & $\mathrm{~S} / 0.32$ \\
\hline Separadores de dedos & Unid & $\mathrm{S} / 1.00$ & 1 & $\mathrm{~S} / 1.00$ \\
\hline Lima para pies & Unid & $\mathrm{S} / 3.50$ & 1 & $\mathrm{~S} / 3.50$ \\
\hline Papel toalla & Caja & $\mathrm{S} / 24.00$ & 50 & $\mathrm{~S} / 0.48$ \\
\hline Crema de manos & $400 \mathrm{mml}$ & $\mathrm{S} / 8.00$ & 20 & $\mathrm{~S} / 0.40$ \\
\hline
\end{tabular}

b) Mano de obra

Los servicios laborales que se requieren en cuanto a personas y horas de trabajo para poder satisfacer la demanda de los servicios que se ofrecen en el salón de belleza móvil son:

- Supervisora Cosmetóloga: Horario de trabajo de martes a domingo y 48 horas semanales.

- Cosmetólogas: Horario de trabajo de martes a domingo y 48 horas semanales

En la Tabla 104 se muestra la cantidad de horas de trabajo en forma mensual, semanal y anual requerida por el personal de supervisora y cosmetóloga para poder realizar los servicios del salón de belleza móvil. 
Tabla 104

Datos para cálculo de mano de obra

\begin{tabular}{lrl}
\hline \multicolumn{1}{c}{ Variable } & \multicolumn{2}{c}{ Valor } \\
\hline Tiempo promedio de servicios $=$ & 31.25 & Minutos \\
\hline Número de horas semanales por cosmetóloga $=$ & 48 & Horas \\
\hline Número de horas mensuales por cosmetóloga $=$ & 192 & Horas \\
\hline Número de horas anuales por cosmetóloga $=$ & 2208 & Horas \\
\hline
\end{tabular}

Nota: Dentro del tiempo promedio de servicios se ha considerado 26.25 por servicio +5 minutos de transporte $=31.25$ minutos $(15$ minutos por cada tres servicios).

Tabla 105

Datos para el cálculo de mano de obra directa requerida

\begin{tabular}{lccccc}
\hline \multicolumn{1}{c}{ Variable } & Año 1 & Año 2 & Año 3 & Año 4 & Año 5 \\
\hline $\begin{array}{l}\text { Número de horas MOD } \\
\text { requeridas }\end{array}$ & 15,100 & 16,721 & 18.517 & 20,507 & 22,711 \\
\hline Numero de cosmetólogas & 7 & 8 & 9 & 10 & 11 \\
\hline
\end{tabular}

Tabla 106

Requerimiento de mano de obra proyectado

\begin{tabular}{llllll}
\hline & Año 1 & Año 2 & Año 3 & Año 4 & Año 5 \\
\hline Sup. Cosmetóloga & 3 & 4 & 4 & 4 & 4 \\
\hline Cosmetóloga & 4 & 4 & 5 & 6 & 7 \\
\hline
\end{tabular}

Por lo tanto, de acuerdo a la Tabla 105 y 106, se puede observar que la mano de obra directa requerida se incrementa a partir del tercer año según la demanda de servicios proyectada siendo en el primer y segundo año de siete cosmetólogas y al término del proyecto se requerirá once cosmetólogas 
En el salón de belleza móvil se empleará turnos de trabajos rotativos con la finalidad de brindar un horario flexible para poder atender la demanda en la zona dos según se muestra en las Tablas 107 y 108.

Tabla 107

Horario de trabajo de supervisora y cosmetóloga móvil uno

\begin{tabular}{|c|c|c|c|c|c|c|c|c|c|c|c|c|}
\hline \multicolumn{13}{|l|}{ Móvil 1} \\
\hline & \multicolumn{2}{|c|}{ Martes } & \multicolumn{2}{|c|}{ Miércoles } & \multicolumn{2}{|c|}{ Jueves } & \multicolumn{2}{|c|}{ Viernes } & \multicolumn{2}{|c|}{ Sábado } & \multicolumn{2}{|c|}{ Domingo } \\
\hline Colaborador & 07:00 & $14: 00$ & 07:00 & $14: 00$ & 07:00 & $14: 00$ & 07:00 & $14: 00$ & 07:00 & $14: 00$ & 07:00 & $14: 00$ \\
\hline & 15:00 & 22:00 & $15: 00$ & $22: 00$ & $15: 00$ & 22:00 & $15: 00$ & 22:00 & $15: 00$ & $22: 00$ & 15:00 & $22: 00$ \\
\hline $\begin{array}{l}\text { Supervisora } \\
1\end{array}$ & 8 & & 8 & & 8 & & 8 & & 8 & & 8 & \\
\hline $\begin{array}{l}\text { Supervisora } \\
3\end{array}$ & & 8 & & 8 & & 8 & & 8 & & 8 & & 8 \\
\hline $\begin{array}{l}\text { Cosmetóloga } \\
1\end{array}$ & 8 & & 8 & & 8 & & 8 & & 8 & & 8 & \\
\hline $\begin{array}{l}\text { Cosmetóloga } \\
2\end{array}$ & & 8 & & 8 & & 8 & & 8 & & 8 & & 8 \\
\hline
\end{tabular}

Tabla 108

Horario de trabajo de supervisora y cosmetóloga móvil dos

\begin{tabular}{|c|c|c|c|c|c|c|c|c|c|c|c|c|}
\hline \multicolumn{13}{|l|}{ Móvil 2} \\
\hline \multirow[b]{2}{*}{ Colaborador } & \multicolumn{2}{|c|}{ Martes } & \multicolumn{2}{|c|}{ Miércoles } & \multicolumn{2}{|c|}{ Jueves } & \multicolumn{2}{|c|}{ Viernes } & \multicolumn{2}{|c|}{ Sábado } & \multicolumn{2}{|c|}{ Domingo } \\
\hline & $\begin{array}{l}\text { 07:00 } \\
15: 00\end{array}$ & $\begin{array}{l}14: 00 \\
22: 00\end{array}$ & $\begin{array}{l}07: 00 \\
15: 00\end{array}$ & $\begin{array}{l}14: 00 \\
22: 00\end{array}$ & $\begin{array}{l}07: 00 \\
15: 00\end{array}$ & $\begin{array}{l}14: 00 \\
22: 00\end{array}$ & $\begin{array}{l}07: 00 \\
15: 00\end{array}$ & $\begin{array}{l}14: 00 \\
22: 00\end{array}$ & $\begin{array}{l}07: 00 \\
15: 00\end{array}$ & $\begin{array}{l}14: 00 \\
22: 00\end{array}$ & $\begin{array}{l}07: 00 \\
15: 00\end{array}$ & $\begin{array}{l}14: 00 \\
22: 00\end{array}$ \\
\hline $\begin{array}{l}\text { Supervisora } \\
2\end{array}$ & & 8 & & 8 & & 8 & & 8 & & 8 & & 8 \\
\hline $\begin{array}{l}\text { Cosmetóloga } \\
3\end{array}$ & & 8 & & 8 & & 8 & & 8 & & 8 & & 8 \\
\hline $\begin{array}{l}\text { Cosmetóloga } \\
4\end{array}$ & & 8 & & 8 & & 8 & & 8 & & 8 & & 8 \\
\hline
\end{tabular}


b) Maquinaria y equipo

De acuerdo con el tipo de servicio y cantidad de la demanda se proyecta un requerimiento de equipamiento que será necesario para la implementación de la unidad móvil tipo furgón (ver Tabla 109).

Tabla 109

$R$

\begin{tabular}{|c|c|c|}
\hline$e$ & Descripción & Cantidad \\
\hline Muebles & Silla para corte y planchado & 2 \\
\hline Muebles & Espejo con mostrador & 2 \\
\hline Muebles & Lavadero & 2 \\
\hline Muebles & Kit manicure y pedicure & 4 \\
\hline$\stackrel{e}{\text { Muebles }}$ & Vitrina para pared & 2 \\
\hline Muebles & Auxiliar de manos y pies & 4 \\
\hline Equipos eléctricos y electrónicos & Tablet & 2 \\
\hline Équipos eléctricos y electrónicos & Televisor 32" & 2 \\
\hline Equipos eléctricos y electrónicos & Cámaras de vigilancia & 2 \\
\hline Equipos eléctricos y electrónicos & Aire acondicionado & 2 \\
\hline Materiales & Extintor & 2 \\
\hline Materiales & Botiquín de primeros auxilios & 2 \\
\hline Materiales & Tanque de agua & 2 \\
\hline Materiales & Accesorios para tanque de agua & 2 \\
\hline Materiales & Grupo electrógeno portátil & 2 \\
\hline Maquinaria & Vehículo Furgón & 2 \\
\hline Muebles & $\begin{array}{l}\text { Armario de melamina de } \\
1.8 * 0.9 \text { (con puerta) }\end{array}$ & 2 \\
\hline Muebles & Escritorio (silla) & 1 \\
\hline Equipos eléctricos y electrónicos & Laptop & 1 \\
\hline Muebles & Modular de oficina (con sillas) & 1 \\
\hline
\end{tabular}

$e$

equipamiento 


\subsubsection{Tecnología.}

Dobar (2015) menciona que la tecnología crece cada día y con ella trae la modernidad en equipos, maquinarias y nuevos servicios, las cuales ayudarán a dar un mejor servicio de calidad.

El presente plan de negocio se hará uso de tecnología en:

a. Creación y diseño de página web para el negocio

b. Redes sociales para captación y acercamiento a los clientes.

c. Ofertar promociones o paquetes a través de redes sociales.

d. Uso de POS para pagos electrónicos de los servicios.

e. Uso de tablets en los móviles para el registro de ventas.

f. Instalación de una laptop para la oficina administrativa

g. Obtención de bases de datos de los clientes

h. Encuestas de satisfacción de los clientes

i. Facilitar a los clientes tipo de cortes y diseños de uñas mediante links de internet

j. Reservas y pagos en línea de los servicios

\subsubsection{Flexibilidad.}

Según Krajewsji et al. (2013), la flexibilidad de los recursos, los cuales se debe tomar en consideración para tener una fuerza de trabajo flexible y eficiente en los procesos productivos que desarrolla la organización con el fin de poder satisfacer la demanda del público objetivo. 
Para el servicio de salón de belleza móvil esta flexibilidad se refleja en:

a) Los horarios del personal que labora en la móvil tipo furgón,

b) La facilidad de solicitar el servicio a domicilio en horarios que disponga el cliente.

c) Ahorro de tiempo para los clientes (espera- traslado - tiempo para uno mismo).

d) La facilidad de poder llegar a diferentes lugares de la zona dos.

e) Infraestructura y equipamiento para realizar los servicios

\subsubsection{Selección del tamaño ideal.}

El salón de belleza móvil ha calculado el tamaño ideal del negocio considerando ventas proyectadas y capacidad máxima de servicios por móvil para poder determinar la cantidad necesaria de unidades móviles tipo furgón que se necesitarían para cubrir la demanda. Para el cálculo de la capacidad máxima se considera las variables mencionadas (ver Tabla 110).

Tabla 110

\begin{tabular}{lrll}
\hline \multicolumn{1}{c}{ Variables } & Valor & \\
\hline Duración promedio por servicio & 31.25 & Minutos \\
\hline Horas de atención al día & 15 & Horas \\
\hline Número de servicios máximos al día & 29 & \\
\hline Número de estaciones por móvil & 3 & \\
\hline
\end{tabular}

Variables para cálculo de capacidad máxima

Nota $:$ Número de servicios al día = Duración promedio x Horas al día 
Tabla 111

Capacidad máxima de servicios

\begin{tabular}{lr}
\hline \multicolumn{1}{c}{ Capacidad máxima } & \# de servicios \\
\hline Capacidad de servicios diario por móvil & 86 \\
\hline Capacidad de servicios mensual por móvil & 2,074 \\
\hline Capacidad de servicios anual por móvil & 24,883
\end{tabular}

Nota: Capacidad de servicios diario por móvil = Número de servicios máximos al día $\mathrm{x}$ Número de estaciones por móvil

Según la Tabla 111, se puede observar la capacidad máxima de atención de una unidad móvil es de 24,883 servicios, para calcular la cantidad de unidades móviles requeridas se considera la cantidad de servicios proyectados para el proyecto (ver Tabla 112).

Tabla 112

C

á

Número de servicios

Año 1 Año 2 Año 3 Año 4 Año 5

$l$ Número de 28,992 $32,105 \quad 35,553$ $39,374 \quad 43,606$ móviles requeridos

c Capacidad máxima (servicios) 2

$\begin{array}{llll}2 & 2 & 2 & 2\end{array}$

\% utilización 49,776 $49,776 \quad 49,776$ 49,776 49,776 $u$ $58 \%$ $65 \%$ $71 \%$ $79 \%$ $88 \%$

lo de unidades móviles requeridas

Por lo tanto, el plan de negocio necesita contar con dos unidades móviles tipo furgón para cubrir la demanda, realizando los servicios a domicilio en la zona dos. 
Debido al incremento de los servicios en los cinco años proyectados se puede observar que solo se utilizaría el $88 \%$ de la capacidad máxima de atención según se muestra en la tabla anterior, lo cual, se consideraría que en la zona dos no es necesario el incremento de otra móvil, debiendo considerarse como crecimiento otros distritos que demanden el servicio de salón de belleza móvil a domicilio, siendo a la vez una estrategia de expansión de la marca.

\subsection{Estudio de localización}

Según Sapag (2008), al estudiar la localización del proyecto se puede dar varias soluciones factibles de acuerdo a los criterios económicos, estratégicos, institucionales y emociones que guíen a una decisión que maximice la rentabilidad del proyecto. Dentro de este estudio de localización es necesario realizar la selección de la macro localización y dentro de esta se debe realizar la de micro localización.

En el plan de negocio del salón de belleza móvil, el estudio de localización tiene como estrategia competitiva el poder desplazarse al lugar donde el cliente solicite el servicio y así cubrir la demanda de los servicios de belleza para las personas que requieran de ahorro de tiempo, comodidad y relajo sin tener que movilizarse desde la localidad de donde se encuentren al salón de belleza.

\subsubsection{Definición de factores locacionales.}

Según Sapag (2011), los factores generales que son determinantes en la decisión de la localización para el plan de negocio son: localización de clientes, localización de 
proveedores, tamaño del proyecto, proximidad de los mercados, importe de operación, importe de distribución, recursos humanos, factores físicos y climatológicos.

Para el plan de negocio del salón de belleza móvil, se ha considerado factores que reúnan características importantes que ubiquen el local para trabajos administrativos (ver Tabla 110).

Definición de factores locacionales empleados para oficina administrativa:

- Zona céntrica para las rutas: Mejor ubicación para controlar las rutas establecidas o cualquier desperfecto que pueda tener la móvil.

- Costo reducido de alquiler: Dentro de los tres distritos es la que mejor opción económica presenta por el alquiler de la oficina.

- Facilidad de acceso: Facilidad de ubicación para clientes y proveedores.

- Dimensión: Dimensión necesaria según el plan que no genere mayor costo.

- Cercanía de proveedores: Contacto directo con proveedores de la zona para un abastecimiento inmediato.

- Tráfico en el distrito: Se evalúa el tráfico para no tener retrasos en los horarios de trabajo.

- Cercanía a centros financieros: Se tiene mayor facilidad para hacer trámites bancarios y administrativos sin la necesidad de utilizar mucho tiempo por la distancia.

Tabla 113

Matriz de Localización de oficina administrativa

\begin{tabular}{ccccccccc}
\hline & $\%$ & Los Olivos & $\begin{array}{c}\text { Independenc } \\
\text { ia }\end{array}$ & $\begin{array}{c}\text { San Martin de } \\
\text { Porres }\end{array}$ \\
\hline Factores & $\begin{array}{c}\text { Ponderado } \\
\text { expertos }\end{array}$ & CA & PT & CA & PT & CA & PT \\
\hline
\end{tabular}




\begin{tabular}{lrrrrrrr}
\hline Zona céntrica para las rutas & 0.15 & 4 & 0.6 & 2 & 0.3 & 3 & 0.45 \\
\hline Costo reducido de alquiler & 0.2 & 5 & 1 & 1 & 0.2 & 2 & 0.4 \\
\hline Facilidad de acceso & 0.1 & 2 & 0.2 & 5 & 0.5 & 4 & 0.4 \\
\hline Dimensión & 0.05 & 1 & 0.05 & 2 & 0.1 & 1 & 0.05 \\
\hline Cercanía de proveedores & 0.2 & 3 & 0.6 & 3 & 0.6 & 1 & 0.2 \\
\hline Tráfico en el distrito & 0.15 & 2 & 0.3 & 4 & 0.6 & 5 & 0.75 \\
$\begin{array}{l}\text { Cercanía a centros } \\
\text { financieros }\end{array}$ & 0.15 & 3 & 0.45 & 3 & 0.45 & 2 & 0.3 \\
\hline & 1 & & 3.2 & & 2.75 & & 2.55 \\
\hline
\end{tabular}

Nota: CA: Criterio de Aplicación, PT: Puntaje Total

De acuerdo con el resultado de la matriz de la Tabla 113, se define que el mejor distrito para la ubicación de la oficina administrativa es Los Olivos, debido al bajo costo de alquiler y a la ubicación céntrica que tendría en el distrito.

Con respecto a la localización de la móvil tipo furgón para realizar los servicios del salón de belleza se ha definido que por ser el servicio a domicilio, dependerá de la ubicación que designe el cliente al momento de solicitar la reserva considerando un lugar seguro y sin causar molestia a los residentes de la zona de la zona dos.

\subsubsection{Consideraciones legales.}

Según Sapag (2011), cada país de acuerdo al tipo de actividad laboral que realiza sea producto o servicio cuenta con legislaciones, reglamentos, decretos, y costumbres de acuerdo a su constitución política las cuales se vuelven prohibitivas o permisivas, pudiendo afectar en un principio a las inversiones o capital de trabajo del proyecto de la organización.

Los objetivos del marco legal de un proyecto de inversión es formar parte de la sociedad económica y tributaria las que sirven para conocer las normas y regulaciones existentes las cuales harán viable el proyecto de inversión. 


\subsubsection{Identificación del marco legal.}

Según Sapag (2011), en la etapa de implementación y posterior operación todo proyecto se desarrolla en un marco legal donde se prohíbe o permite lo que el estado ha aceptado.

Debido al producto o servicio que brinda se rige en base a normas para la constitución e incorporación a la actividad comercial, la cual deberá considerar las contrataciones y remuneraciones del personal de acuerdo con la modalidad de trabajo establecido por el ministerio de trabajo. De igual forma deberá cumplir con las normas sanitarias, ambientales, seguridad laboral, y normas de calidad y certificaciones que afecten el desarrollo del servicio de calidad según se muestra en la Figura 36.

El salón de belleza móvil cumplirá las normas vigentes en lo que respecta a la constitución de la empresa, se realizará la contratación del personal especializado en el rubro de la belleza de acuerdo con las normas de contrataciones y remuneraciones, cumplirá con las reglamentaciones vigentes de salubridad para los equipos y artefactos que norma el ministerio de salud, y certificaciones de calidad para los procesos de los servicios que se brindará. 


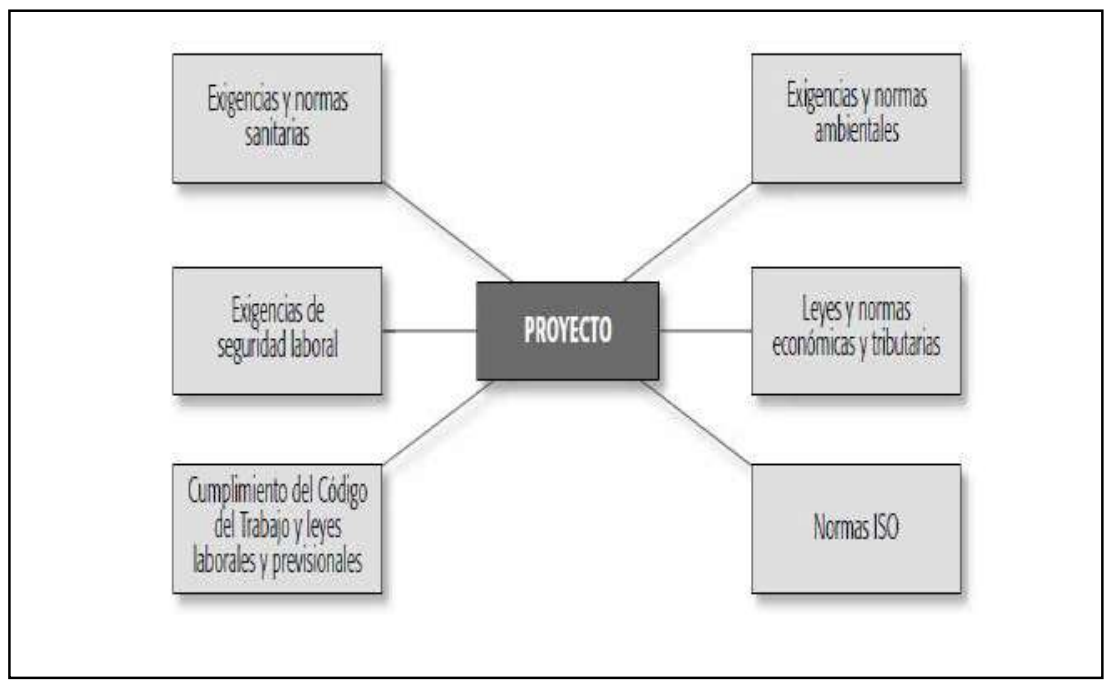

Figura 36. Consideraciones del proyecto. Tomado de Preparación y Evaluación de Proyectos 5ta Edición: Efectos económicos del estudio legal, por Nassir Sapag Chain (pág. 249) 


\section{Licencias y Autorizaciones:}

Los requisitos generales para que la empresa esté inscrita en el registro de personas jurídicas de los registros públicos de Los Olivos, según ley 28976, articulo siete sobre licencia de funcionamiento (comercial, industrial y/o de servicios).

1. Solicitud de licencia de funcionamiento, con carácter de declaración jurada, según formato.

1.1 Persona natural:

- Presentación de número de RUC.

- DNI o carne de extranjería.

1.2 Persona jurídica:

- Vigencia de poder.

- DNI o Carne de Extranjería del representante legal.

- En caso de representación de persona natural: Carta poder legalizada.

2. Declaración Jurada de la Observancia de condiciones de Seguridad en Defensa Civil o inspección técnica de Seguridad en Defensa Civil de Detalle o Multidisciplinaria según corresponda.

En la Tabla 114 se muestra los pagos por derecho de trámite, incluyendo el plazo por concepto de Licencia de Funcionamiento en el distrito de Los Olivos. 
Tabla 114

Requisitos y pagos para la licencia de funcionamiento

\begin{tabular}{|c|c|c|}
\hline Requisitos Especifico & Plazo & $\begin{array}{l}\text { Derecho } \\
\text { de trámite }\end{array}$ \\
\hline $\begin{array}{l}\text { Establecimiento con área menor de } 100 \mathrm{~m} 2 \text { y capacidad de } \\
\text { almacenamiento no mayor de } 30 \% \text { del área total. Evaluación Ex } \\
\text { Post. Declaración Jurada de Observancia de seguridad. }\end{array}$ & 1 día & $\mathrm{S} / 72.00$ \\
\hline
\end{tabular}

Establecimiento con área mayor a 100m2. Evaluación ex ante por 1 día $\quad$ S/ 103.00 parte de la municipalidad.

Establecimiento con área mayor a $500 \mathrm{~m} 2$ evaluación ex ante. 3 días $\quad$ S/ 62.00 Certificado de Inspección Técnica de Seguridad en Defensa Civil de detalle o multidisciplinaria

Documentos solicitados:

- Copia del DNI: de ser empresa del representante legal.

- Copia del RUC: ficha de la SUNAT, en caso se trate de RUS, copia de los últimos recibos de pago al banco.

- Carta Poder: persona jurídica con firma legalizada, vigencia del poder del representante legal.

- Contrato del alquiler: en caso de ser alquilado.

- Estado de cuenta y resumen de autoevaluó: solicitarlo en el área de informática.

- De ser empresa: constitución o testimonio de la empresa.

- Copia de certificado de defensa civil vigente: si no se cuenta con el certificado se llenará un formulario de declaración jurada de observancia de defensa civil que lo otorga la sub gerencia de comercialización y mercado gratuitamente. De 
tratarse de un área mayor a $501 \mathrm{~m} 2$ se deberá adjuntar copia del certificado de defensa civil vigente dado por el INDECI.

- Verificados estos requisitos se procederá al pago de la tasa para la obtención de la licencia de funcionamiento.

Lo que respecta a Defensa Civil es la inspección técnica de seguridad en defensa civil básica.

- Hasta $100 \mathrm{~m}^{2}$ y capacidad de almacenamiento no mayor al $30 \%$ del área total del local - $2 \%$ UIT

- Desde 101 a $500 m^{2}-6.3 \%$ UIT

- $\quad$ Costo de UIT $=\mathrm{S} / 4,050$

\section{a. Legislación Laboral}

La empresa se establecerá dentro del Régimen Laboral Especial (Decreto Supremo $N^{o}$ 007-2008-TR), debido al total de ventas anual, cantidad de trabajadores, considerando los derechos y beneficios de ley que les corresponde (ver Tabla 116 y 116). 
Tabla 115

Cuadro comparativo Régimen Laboral Especial de la MYPE

\begin{tabular}{|c|c|c|}
\hline Derecho & Microempresa & Pequeña empresa \\
\hline Remuneración & $\begin{array}{l}\text { RMV (S/850). } \\
\text { Con acuerdo del CNT podrá ser } \\
\text { menor. }\end{array}$ & RMV (S/850). \\
\hline Jornada de Trabajo & 8 horas. & 8 horas. \\
\hline Horario de Trabajo & $\begin{array}{l}\text { Normativa RLC. } \\
\text { Horario nocturno: No se aplicará la } \\
\text { sobretasa del } 35 \% \text {. }\end{array}$ & $\begin{array}{l}\text { Normativa RLC. } \\
\text { Horario nocturno: No se } \\
\text { aplicará la sobretasa del } 35 \% \text {. }\end{array}$ \\
\hline $\begin{array}{l}\text { Trabajo en } \\
\text { Sobretiempo }\end{array}$ & Normativa RLC. & Normativa RLC. \\
\hline Descanso Semanal & Normativa RLC. & Normativa RLC. \\
\hline $\begin{array}{l}\text { Descanso } \\
\text { Vacacional }\end{array}$ & $\begin{array}{l}15 \text { días calendario de descanso por } \\
\text { cada año completo de servicios. } \\
\text { Puede reducirse a siete días, recibiendo } \\
\text { la respectiva compensación } \\
\text { económica. }\end{array}$ & $\begin{array}{l}15 \text { días calendario de } \\
\text { descanso por cada año } \\
\text { completo de servicios. } \\
\text { Puede reducirse a siete días, } \\
\text { recibiendo la respectiva } \\
\text { compensación económica. }\end{array}$ \\
\hline $\begin{array}{l}\text { Descanso en Días } \\
\text { Feriados }\end{array}$ & Normativa RLC. & Normativa RLC. \\
\hline $\begin{array}{l}\text { Indemnización por } \\
\text { Despido } \\
\text { Injustificado }\end{array}$ & $\begin{array}{l}10 \text { remuneraciones diarias por cada } \\
\text { año completo de servicios con un } \\
\text { máximo de } 90 \text { remuneraciones diarias. }\end{array}$ & $\begin{array}{l}20 \text { remuneraciones diarias por } \\
\text { cada año completo de } \\
\text { servicios con un máximo de } \\
120 \text { remuneraciones diarias. }\end{array}$ \\
\hline S.C.T.R. & No les corresponde. & $\begin{array}{l}\text { De acuerdo a lo dispuesto en } \\
\text { la Ley } N^{\circ} 26790 \text {. }\end{array}$ \\
\hline Seguro de Vida & No les corresponde. & $\begin{array}{l}\text { De acuerdo a lo dispuesto en } \\
\text { el Decreto Legislativo } N^{\circ} 688 .\end{array}$ \\
\hline Derechos Colectivos & No les corresponde & Normativa RLC. \\
\hline $\begin{array}{l}\text { Participación en las } \\
\text { Utilidades }\end{array}$ & No les corresponde. & $\begin{array}{l}\text { De acuerdo a lo dispuesto en } \\
\text { el Decreto Legislativo } N^{\circ} 892 .\end{array}$ \\
\hline C.T.S. & No les corresponde. & $\begin{array}{l}15 \text { remuneraciones diarias por } \\
\text { año completo de servicios, } \\
\text { hasta alcanzar un máximo de } \\
90 \text { remuneraciones diarias. }\end{array}$ \\
\hline $\begin{array}{l}\text { Gratificaciones de } \\
\text { Fiestas Patrias y } \\
\text { Navidad }\end{array}$ & No les corresponde. & $\begin{array}{l}\text { El monto de las } \\
\text { gratificaciones es equivalente } \\
\text { a media remuneración cada } \\
\text { una. }\end{array}$ \\
\hline $\begin{array}{l}\text { Aseguramiento en } \\
\text { Salud }\end{array}$ & $\begin{array}{l}\text { Los trabajadores y conductores serán } \\
\text { (carácter obligatorio) afiliados al } \\
\text { Régimen Semi contributivo del SIS } \\
\text { (SIS Microempresa). }\end{array}$ & 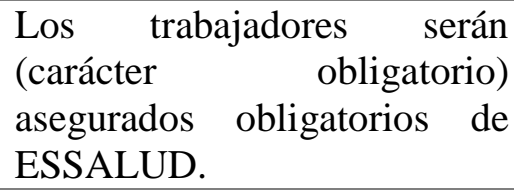 \\
\hline
\end{tabular}


Tabla 116 "Continuación”

$\begin{array}{ll}\begin{array}{l}\text { Sistema de } \\ \text { Pensiones }\end{array} & \begin{array}{l}\text { Los trabajadores y conductores podrán } \\ \text { (carácter voluntario) afiliarse al SNP } \\ \text { (carácter obligatorio) afiliarse }\end{array} \\ & \text { Aquellos que al SPP (AFP). no se encuentran (AFP). } \\ & \text { afiliados o sean beneficiarios de algún } \\ & \text { régimen previsional, podrán optar por } \\ & \text { el Sistema de Pensiones Sociales } \\ & \text { (SPS). } \\ & \text { El SPS es de carácter obligatorio para } \\ & \text { los trabajadores y conductores de la } \\ & \text { microempresa que no superen los } \\ & \text { cuarenta (40) años de edad y es de } \\ & \text { carácter facultativo para aquellos que } \\ & \text { tengan más de cuarenta (40) años de } \\ & \text { edad. }\end{array}$

PONTE DIVA S.A.C., elaborará con contratos de tipo indefinido y contrato renovable a seis meses, considerando los puestos que conformen la organización se definirá el contrato por colaborador, según se detalla a continuación (Ver Tabla 117):

Tabla 117

Tipos de contrato

\begin{tabular}{cc}
\hline Puesto & Tipo de contrato \\
\hline Administrador & Contrato indefinido \\
\hline Supervisora & Contrato temporal (renovable cada seis \\
& meses) \\
\hline Cosmetólogas & Contrato temporal (renovable cada seis \\
meses)
\end{tabular}

b. Legislación Tributaria 
La empresa pertenecerá al Régimen Especial de la MYPE, debido a que se ubica dentro de los regímenes de venta que se muestra:

- Microempresa: ventas anuales hasta el monto máximo de 150 UIT

- Pequeña Empresa: ventas anuales superiores a 150 UIT y hasta el monto máximo de 1700 UIT.

- Mediana Empresa: ventas anuales superiores a 1700 UIT y hasta el monto máximo de 2300 UIT

Comprobantes de pago que la empresa debe exigir:

- Facturas

Cuando se adquiera bienes y/o se reciba la prestación de servicios necesarios para generar sus rentas, se debe exigir que le otorguen.

- Tickets

Que den derecho al crédito fiscal y/o que permitan sustentar gasto o costo para efectos tributarios, pudiendo emitir liquidaciones de compra. También están considerados los recibos de luz, agua, teléfono, y recibos de arrendamiento.

Comprobante que la empresa debe emitir por la venta de su producto

- Factura

Si el cliente tiene RUC debe extenderse una factura.

Persona Jurídica:

Se debe llevar contabilidad completa en todos los casos. Asimismo, se debe llevar adicionalmente cualquier otro libro especial al que estuviera obligada debido al tipo de organización o a otras circunstancias particulares, como se menciona:

- Registro de Compras 
- Registro de Ventas

- Libro diario Simplificado

\subsubsection{Ordenamiento jurídico de la empresa.}

Según Sapag (2011), de acuerdo a la localización del proyecto existen normas, leyes regionales, sectoriales y municipales que no estén dentro de un marco normativo general, teniendo que considerar variables distintas de acuerdo a su modalidad de trabajo, así como su forma de tributar, el régimen laboral que deberán tener sus trabajadores con beneficios y seguros distintos a otras empresas.

De las formas empresariales formales se tiene las mostradas en la Tabla 118 de acuerdo con el tipo de empresa. 
Tabla 118

Formas empresariales formales

\section{Tipo de empresa}

Empresa Unipersonal

\begin{tabular}{cc}
\hline & Empresa Unipersonal \\
& \\
\hline $\begin{array}{c}\text { Empresa } \\
\text { persona }\end{array}$ & Sociedades Anónima \\
Jurídica & (S.A.)
\end{tabular}

\section{Definición}

\section{Persona natural con negocio que tiene} una actividad que aporta capital, trabajo, esfuerzo y cuya responsabilidad es limitada, (empresa a título personal) No existe un capital mínimo para constituirse, se constituye como mínimo con dos personas y puede llegar a tener 749 socios, los socios no responden con su patrimonio personal, capital social se divide en acciones, conformada por junta general de accionistas, directorio y gerencia

Sociedad Anónima Cerrada Se constituye como mínimo con dos personas (S.A.C.) y puede llegar a tener como máximo 20 socios, los socios no responden con su patrimonio personal, conformada por junta general de accionistas, directorio y gerencia.

\section{Sociedad de Responsabilidad Limitada \\ (S.RL.)
Se constituye como mínimo con dos personas y puede llegar a tener 20 socios, conformada por junta general de socios y gerencia, capital social se divide en participaciones, la responsabilidad de los socios está limitada a sus aportaciones.

\section{Empresa Independiente de Responsabilidad limitada (E.I.R.L.)
Conformada por una sola persona, titular y gerencia, el titular es el órgano máximo de la empresa tiene la decisión de los bienes y actividades, las decisiones se pueden asentar en un mismo libro de actas.

a. Forma Societaria

La empresa será constituida bajo la forma de sociedad anónima cerrada, la razón social será: PONTE DIVA S.A.C. 
Por ello, toda obligación frente a terceros será asumida por la nueva persona Jurídica.

- Se prescindirá del Directorio.

- Existe derecho de preferencia para la transferencia de las acciones.

- Se puede limitar la transferencia de acciones por acuerdo entre accionistas o con terceros.

- Posibilidad de realización de juntas de accionistas sin que estos deban estar físicamente presentes en el domicilio de la sociedad.

Este tipo de sociedad requiere una cantidad de accionistas no menor a dos, ni mayor a 20 .

En la Tabla 119 se muestra el aporte de participación de los cuatro socios de PONTE DIVA S.A.C.

Tabla 119

Aporte societario de PONTE DIVA S.A.C.

\begin{tabular}{lcr}
\hline \multicolumn{3}{c}{ Aporte de cada socio } \\
\hline Paola Rodríguez & S/ & 32,877 \\
Claudio Aramburu & S/ & 32,877 \\
Milagros Morales & S/ & 32,877 \\
Jurgens Dávila & S/ & 32,877 \\
\hline Total S/ & S/ & 131,507 \\
\hline
\end{tabular}

- No se podrá inscribir las acciones en el Registro Público de Mercado de Valores, por lo que no se podrá cotizar en la Bolsa de Valores de Lima.

- No se afecta el patrimonio personal, la responsabilidad de los socios se encuentra limitada por el aporte efectuado, por lo que no responden personalmente con su patrimonio por las deudas u obligaciones de la empresa. 
- Las titularidades de las acciones no son de carácter público, por lo que ante cualquier modificación y/o transferencia de acciones, no se debe inscribir en Registros Públicos (RRPP), con lo que se ahorrará recursos (tiempo y dinero al no tener que incurrir en gastos registrales adicionales)

Los órganos de la empresa son:

- Junta General de Accionistas (JGA): Será el órgano supremo de la sociedad, estará integrado por el total de socios que conforma la sociedad, se encargarán de aprobar y desaprobar las decisiones e inversiones importantes que se decida implementar en el negocio a través del Administrador.

- Gerente General / Administrador: Será el representante legal de la sociedad frente a terceros. Así también, será el ejecutor de las disposiciones de la JGA.

Para la formalización como persona jurídica, se debe seguir los siguientes pasos:

1. Búsqueda y reserva: Se verifica si existe otra empresa con la misma denominación a través de Superintendencia Nacional de los Registros Públicos - SUNARP, de no existir se procede a reservar el nombre.

2. Elaboración de la minuta por abogado: Se presentará en la Oficina de Asesoramiento, dos juegos del proyecto de minuta en originales, adjuntando el certificado de búsqueda mercantil y copia simple del DNI de los socios y/o accionistas titulares y cónyuges en el caso de ser casados.

Si el aporte de capital es en bienes, los cónyuges de los socios y/o accionistas deberán firmar el proyecto de minuta. En el caso de que el aporte 
sea en efectivo, este monto se depositará en una cuenta corriente a nombre de la empresa.

3. Escritura pública ante notario: Una vez redactada la minuta, se llevará a una notaría para que un notario público la revise y la eleve a escritura pública.

4. Inscripción de registro de Personas Jurídicas: Para inscribirse en el Registro de Sociedades se debe contar con los siguientes documentos:

- Formato de solicitud de inscripción debidamente llenado y suscrito.

- Copia del documento de identidad del representante, con la constancia de haber sufragado en las últimas elecciones o haber solicitado la dispensa respectiva.

- Escritura pública que contenga el Pacto Social y el Estatuto.

- Comprobante de depósito por el pago de derechos registrales (tasas).

5. Obtención del número de RUC: El Registro Único de Contribuyentes (RUC) es lo que identificará a nuestra empresa ante la Superintendencia Nacional de Administración Tributaria (SUNAT) para el pago de los impuestos. El trámite inicia con la presentación de la escritura, copia simple del DNI del representante legal y recibo de agua y luz del local donde va a funcionar la empresa ante la SUNAT.

Así también se deberá definir el régimen tributario mediante el cual declararemos nuestras ventas. Se eligió el Régimen general de Renta. A su vez esta elección de régimen nos permite identificar los comprobantes de pago que podremos emitir, siendo los siguientes:

- Boleta de Ventas. 
- Factura Comercial.

Finalmente, se comprará y legalizará libros contables con la finalidad de registrar las operaciones de la empresa. Esto estará legalizado por un notario público.

Base Legal: Artículos $15^{\circ}, 17^{\circ}$ y $176^{\circ}$ del Reglamento General de los Registros Públicos, aprobado por Resolución № 195-2001-SUNARP/SN (23/07/2001); $5^{\circ}, 54^{\circ}$ y $55^{\circ}$ de la Ley General de Sociedades - Ley $N^{\circ} 26887$ (09/12/1997); Reglamento del Registro de Sociedades, aprobado por Resolución N²00-2001-SUNARP/SN (27/07/2001); Decreto Supremo N ${ }^{\circ}$ 37-94-JUS (07/07/1994).

b. Registro de Marca:

- Registro que otorga seguridad jurídica para poder desenvolverse en el mercado.

- El registro de marcas está a cargo de la dirección de signos distintivos de INDECOPI.

- Se va a tener la posibilidad de impedir que terceros registren o utilicen en el mercado signos confundibles con el nuestro.

- Vigencia de diez años a partir de la fecha en que se expide la resolución que otorga el registro, con tiempo de renovación de seis meses anteriores o seis meses posteriores a la fecha de vencimiento del registro.

Búsqueda de Antecedentes: fonética y figurativa. 
Ambos servicios de búsquedas tienen un costo establecido en el TUPA del INDECOPI.

Antes de presentar una solicitud de registro es recomendable averiguar si existe un signo registrado o solicitado con anterioridad, que pudiera ser confundible con la marca que se pretende registrar.

Para ello, se tiene los servicios de búsquedas fonéticas y búsquedas figurativas, los cuales son opcionales y sus resultados son referenciales, toda vez que el otorgamiento o la denegatoria del registro solicitado, dependerá de la evaluación que en cada caso realice la Dirección, conforme a las normas vigentes.

- Búsqueda fonética: Obteniendo información respecto de signos que se pronuncien de manera idéntica o semejante, aun cuando difieran en su escritura.

- Búsqueda figurativa: Obteniendo información respecto de signos que incluyan elementos figurativos idénticos o similares, aun cuando el elemento denominativo sea distinto uno del otro.

Para solicitar el registro de la marca que se muestra en la Figura 37, se deberá definir qué producto se desea distinguir, y ubicar en qué clase de la clasificación Internacional se encuentra dicho producto, a través de la web de INDECOPI se encontrará un resumen de la referida clasificación. 


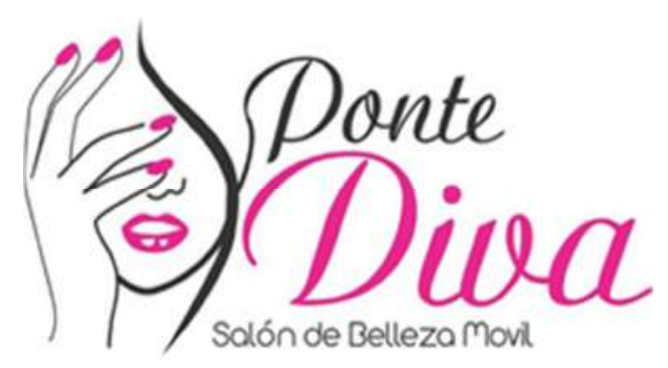

Figura 37. Logo a registrar

1. Requisitos de la solicitud:

La solicitud se presenta en formato (03 ejemplares), en el cual se consignará:

- Datos de identificación del solicitante (incluyendo domicilio para notificaciones)

- Debemos adjuntar el poder en instrumento privado, copia de la escritura pública, partida registral, u otro documento análogo, en el que consten las facultades con las que actúa el representante, de ser necesario presentar poderes correspondientes.

- Indicación expresa del producto para el cual se solicita el registro de la marca.

- El comprobante de pago de las tasas respectivas (se deberá pagar una tasa por cada clase en la que se solicite el registro)

2. Examen de los requisitos de forma

Dentro de los 15 días útiles de recibida la solicitud, la dirección examinará si la misma cumple con los requisitos formales señalados.

3. Publicación de la solicitud 
Cumplidos los requisitos formales de la solicitud, la dirección ordenará la publicación de la misma. La publicación de la solicitud de registro se realizará por una sola vez en el diario oficial El Peruano, costo asumido por el solicitante.

\subsection{Determinación de la localización óptima}

Según Sapag (2011), para determinar la localización óptima del proyecto se debe considerar los factores que influyen en la decisión de tener cerca a clientes, estar en una zona con demanda de acuerdo a la segmentación realizada para obtener la mayor cantidad de usuarios que soliciten el servicio, el tener proveedores estratégicos con respecto a los productos, materiales o insumos que se debe tener en forma oportuna y de calidad, disponibilidad de servicios básicos para la comodidad del público objetivo, y sobre todo un recurso humano especializado, todos estos factores llevan a tomar una decisión de donde sería la mejor localización del servicio.

En la Tabla 113 se analizó que la mejor alternativa de localización para la oficina administrativa del salón de belleza móvil es en el distrito de Los Olivos, calle Carlos de los Heros 160 Urbanización Antares (ver Figura 38 y 39). 


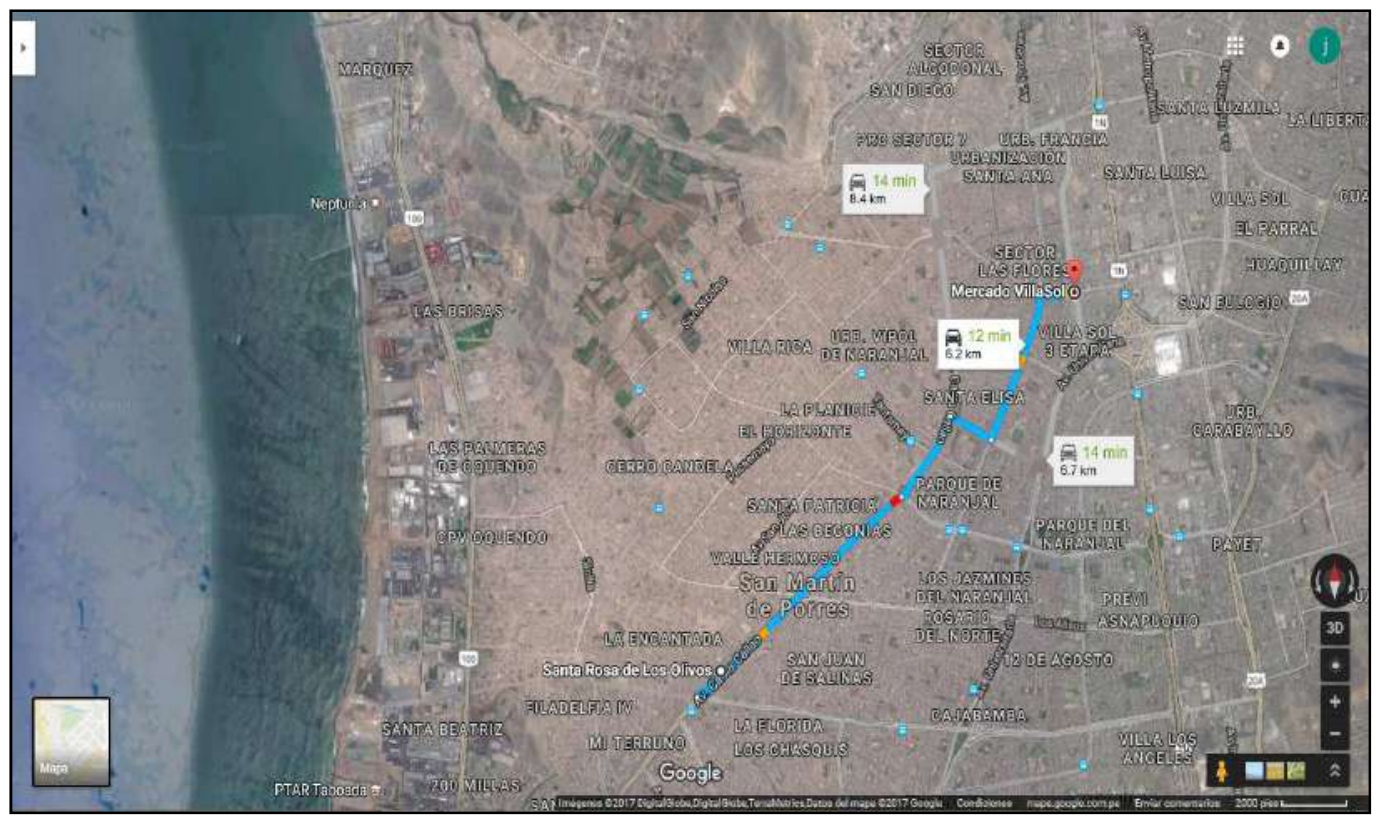

Figura 38. Macro localización distrito de Los Olivos

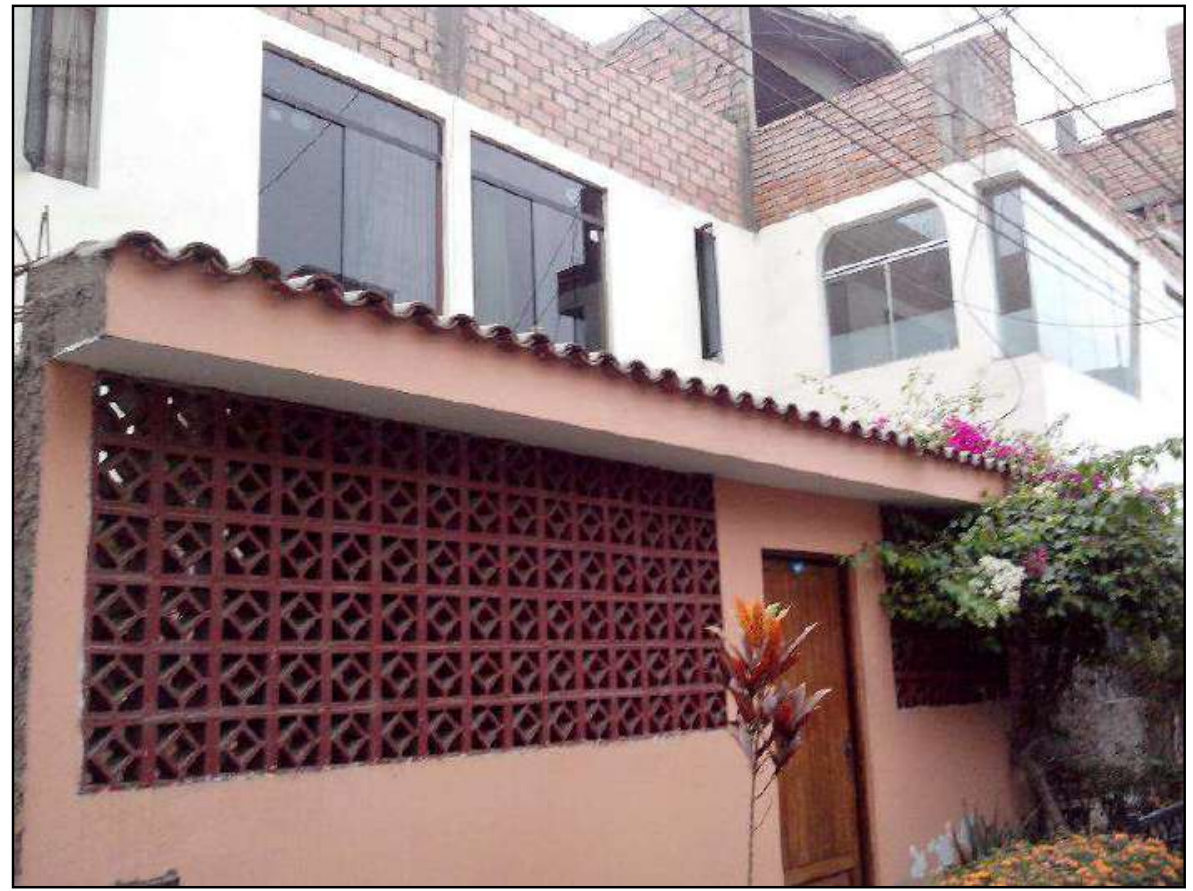

Figura 39. Micro localización Calle Carlos de los Heros 160 Urbanización Antares Los Olivos 


\section{Capítulo VI. Aspectos Organizacionales}

\subsection{Caracterización de la cultura organizacional deseada}

Según D'Alessio (2013) la cultura organizacional que se planea estratégicamente y se proyecta en el futuro es el que tiene altas posibilidades de sobrevivir. Esta organización debe tener cuatro componentes fundamentales como: (a) visión, (b) misión (c) valores (d) código de ética. Es así que en las organizaciones se preocupan que los gerentes y colaboradores tengan pleno conocimiento de la visión, que sea clara y que tengan un sentido, dando un valor agregado para que pueda permanecer en el tiempo brindando sus productos o servicios.

\subsubsection{Visión.}

D'Alessio (2013) menciona que la visión es lo que una organización busca ser en el futuro, haciendo un análisis del estado actual y futuro de la organización, entendiendo la razón de ser del negocio, identificando dónde se desenvuelve y estableciendo un reto a futuro. Una visión debe cumplir las siguientes características: (a) ser clara, (b) ambiciosa, (c) temporal, (d) de alcance geográfico, (e) comprendida por los colaboradores, (f) promueve el sentido de urgencia y $(\mathrm{g})$ permitir visualizar el futuro

Se plantea la visión del negocio respondiendo a la pregunta planteada según D’Alessio ¿Qué queremos llegar a ser?, es así que la visión del salón de belleza móvil es:

Ser una empresa líder de salones de belleza móviles llevando servicios de cuidado personal a las mujeres de la zona dos de Lima Metropolitana para el 2021.

\subsubsection{Misión.}

La misión es lo que la organización debe hacer ahora para poder llegar a lo planificado haciendo todo bien para tener éxito, además sirve de límite entre lo que se debe hacer y no se debe hacer para tomar buenas decisiones. (D'Alessio, 2013) 
Para D’Alessio (2013) la misión debe contener lo siguiente: (a) definición de la organización (b) diferenciación de la organización (c) permite evaluar las actividades ejecutadas (d) ser entendible para todos (e) brinda confianza en la organización.

Se plantea la misión del negocio respondiendo a la pregunta planteada según D’Alessio ¿Cuál es nuestro negocio?, por lo tanto, la misión del salón de belleza móvil es:

Proveer servicios de manicure, pedicure, corte y planchado dentro del salón de belleza móvil brindando un ambiente cómodo, seguro y acogedor para satisfacer las necesidades de cuidado personal de las mujeres de la zona dos de Lima Metropolitana ofreciendo personal especializado y productos de calidad.

\subsubsection{Principios.}

Según D’Alessio (2013) los valores o principios son los que van a determinar el comportamiento de la organización para resultados deseables o indeseables, es por eso que son considerados como los pilares que dirigen el comportamiento de sus funcionarios, gerentes y colaboradores los cuales servirán para la toma de decisiones.

Para el presente plan de negocio se considera los siguientes principios:

1.- Vocación de servicio

2.- Amabilidad y respeto

3.- Profesionalismo

4.- Confianza 


\subsection{Formulación de Estrategias del Negocio}

Para poder formular la estrategia del negocio, primero se debe identificar los objetivos principales del negocio:

- $\quad$ Incrementar las ventas cada año un $10 \%$

- $\quad$ Tener la participación del $0.65 \%$ del sector belleza

Para poder logar los objetivos planteados para el negocio se realizó un análisis con estrategia de Océano Azul, el cual plantea dejar de lado la competencia entre las empresas existentes a través de la innovación. (Chan \& Mauborgne, 2005)

En la tabla 120 se observa la aplicación de la Matriz de las Cuatro Acciones para la creación de un océano azul y que responden a las preguntas planteadas por los autores:

- ¿Cuáles variables que la industria da por sentadas se deben eliminar?

- $\quad$ ¿Cuáles variables se deben reducir muy por debajo de la norma de la industria?

- ¿Cuáles variables se deben incrementar muy por encima de la norma de la industria?

- ¿ ¿Cuáles variables se deben crear porque la industria nunca las ha ofrecido? 
Tabla 120.

Matriz de las Cuatro Acciones

\begin{tabular}{llcc}
\hline Acciones & Variables & $\begin{array}{c}\text { Salón de } \\
\text { belleza actual }\end{array}$ & $\begin{array}{c}\text { Salón de } \\
\text { belleza móvil }\end{array}$ \\
\hline Eliminar & - Local fijo & 10 & 0 \\
& - Desplazamiento de clientes a local & 10 & 0 \\
\hline Reducir & - Tiempos de espera para el cliente & 8 & 2 \\
& - Costos fijos para el negocio & 7 & 4 \\
\hline Incrementar & - Personal calificado & & 5 \\
& - Relación de confianza & 5 & 5 \\
& - Reserva de citas & 5 & 8 \\
& - Servicios a domicilio & 4 & 9 \\
& - Ahorro de tiempo en espera y traslado & 0 & 9 \\
\hline Crear & - Salón de belleza móvil & & 10 \\
& - Servicios de streaming & 0 & 10
\end{tabular}




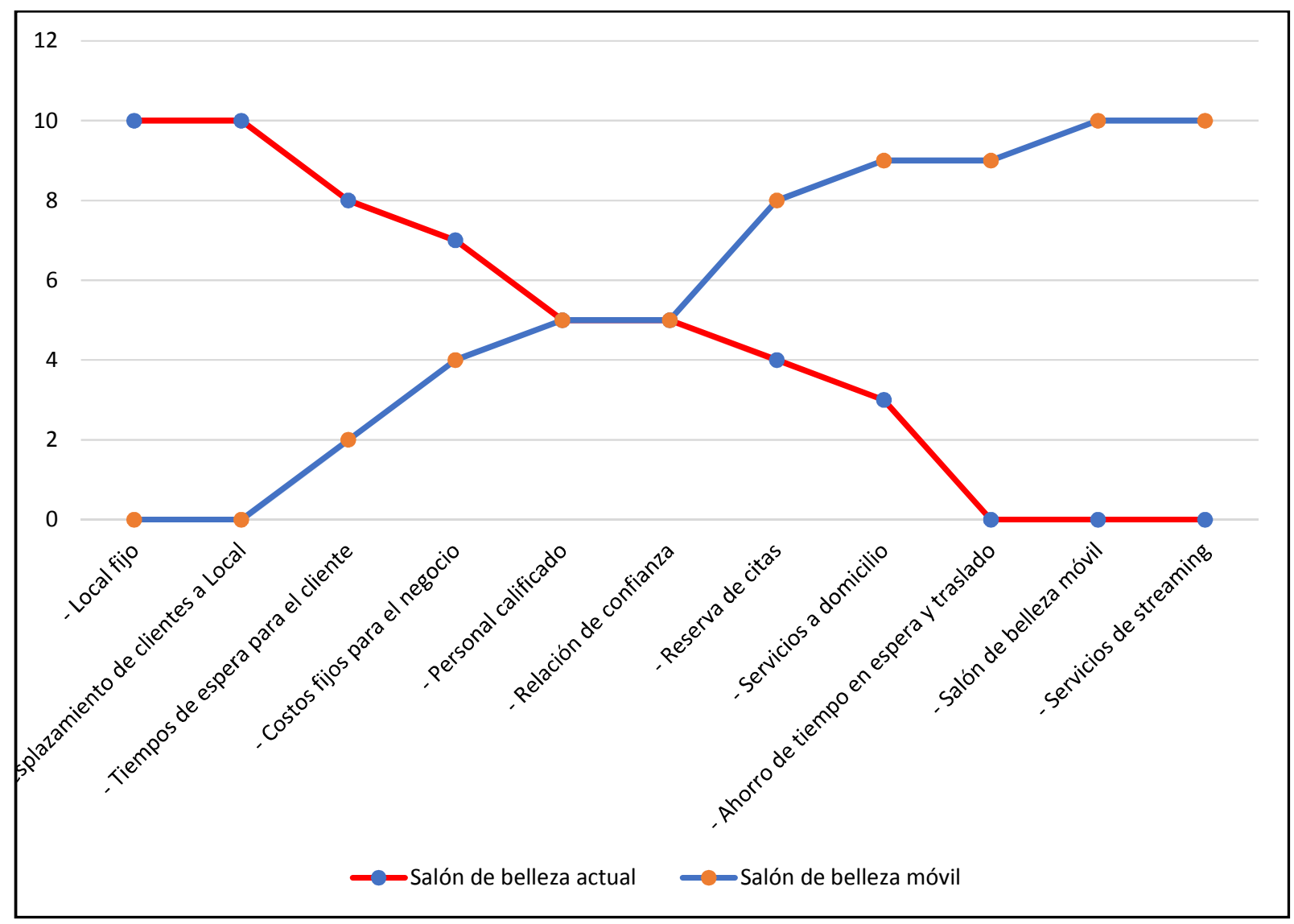

Figura 40. Cuadro estratégico del Océano azul para el salón de belleza móvil

En la Figura 40 se observa las áreas de divergencia, donde el Océano Azul se contrapone a la corriente del mercado de la industria de salones de belleza convencionales con locales fijos. Es así que el foco se centra en brindar servicios a través del salón de belleza móvil a domicilio incrementando el ahorro de tiempos en espera y traslado y servicios a través de reservas. Por tal motivo, nuestra estrategia del océano azul es "la innovación del valor", el cual permite crear nuevas opciones de servicio y atención fuera de lo convencional o tradicional de los salones de belleza. 


\subsection{Determinación de las ventajas competitivas críticas}

Según David (2013), el término de ventaja competitiva se define como algo que el negocio realice de una manera mejor que la competencia, esto representa que el negocio realiza algo que su rival no puede o que desean.

Para determinar las ventajas competitivas del salón de belleza móvil se realizará un análisis según el modelo VRIO de Barney (1997) basado en recursos y capacidades de la organización (ver Tabla 121), identificándolos con las siguientes características (a) ¿es valioso? (b) ¿es raro? (c) ¿es inimitable? y (d) ¿está la organización preparada para explotar el recurso/capacidad? 
Tabla 121

Análisis VRIO

\begin{tabular}{|c|c|c|c|c|c|c|}
\hline Recursos y Capacidades & Posee & Valioso & Raro & Inimitable & $\begin{array}{l}\text { Organi- } \\
\text { zacional }\end{array}$ & $\begin{array}{l}\text { Implicancia } \\
\text { competitiva }\end{array}$ \\
\hline $\begin{array}{l}\text { Primer salón de belleza } \\
\text { móvil en Lima }\end{array}$ & $\mathrm{Si}$ & $\mathrm{Si}$ & $\mathrm{Si}$ & $\mathrm{Si}$ & $\mathrm{Si}$ & $\begin{array}{l}\text { Ventaja } \\
\text { competitiva } \\
\text { sostenible }\end{array}$ \\
\hline $\begin{array}{l}\text { Ubicación cerca del } \\
\text { cliente }\end{array}$ & $\mathrm{Si}$ & $\mathrm{Si}$ & No & No & $\mathrm{Si}$ & $\begin{array}{l}\text { Paridad } \\
\text { competitiva }\end{array}$ \\
\hline $\begin{array}{l}\text { Atención inmediata sin } \\
\text { espera }\end{array}$ & $\mathrm{Si}$ & $\mathrm{Si}$ & No & No & $\mathrm{Si}$ & $\begin{array}{l}\text { Paridad } \\
\text { competitiva }\end{array}$ \\
\hline $\begin{array}{l}\text { Infraestructura agradable y } \\
\text { moderna en una móvil }\end{array}$ & $\mathrm{Si}$ & $\mathrm{Si}$ & $\mathrm{Si}$ & No & $\mathrm{Si}$ & $\begin{array}{l}\text { Ventaja } \\
\text { competitiva } \\
\text { temporal }\end{array}$ \\
\hline $\begin{array}{l}\text { Flexibilidad de moverse a } \\
\text { cualquier ubicación }\end{array}$ & $\mathrm{Si}$ & $\mathrm{Si}$ & $\mathrm{Si}$ & No & $\mathrm{Si}$ & $\begin{array}{l}\text { Ventaja } \\
\text { competitiva } \\
\text { temporal }\end{array}$ \\
\hline $\begin{array}{l}\text { Precios accesibles al } \\
\text { mercado }\end{array}$ & $\mathrm{Si}$ & $\mathrm{Si}$ & No & No & $\mathrm{Si}$ & $\begin{array}{l}\text { Paridad } \\
\text { competitiva }\end{array}$ \\
\hline $\begin{array}{l}\text { Ofertar servicios más } \\
\text { solicitados }\end{array}$ & $\mathrm{Si}$ & $\mathrm{Si}$ & No & No & $\mathrm{Si}$ & $\begin{array}{l}\text { Paridad } \\
\text { competitiva }\end{array}$ \\
\hline $\begin{array}{l}\text { Contar con un horario de } \\
\text { atención extendido }\end{array}$ & $\mathrm{Si}$ & $\mathrm{Si}$ & No & No & $\mathrm{Si}$ & $\begin{array}{l}\text { Paridad } \\
\text { competitiva }\end{array}$ \\
\hline $\begin{array}{l}\text { Personal calificado en } \\
\text { servicios ofrecidos }\end{array}$ & $\mathrm{Si}$ & $\mathrm{Si}$ & No & No & $\mathrm{Si}$ & $\begin{array}{l}\text { Paridad } \\
\text { competitiva }\end{array}$ \\
\hline $\begin{array}{l}\text { Personal capacitado } \\
\text { constantemente }\end{array}$ & $\mathrm{Si}$ & $\mathrm{Si}$ & No & No & $\mathrm{Si}$ & $\begin{array}{l}\text { Paridad } \\
\text { competitiva }\end{array}$ \\
\hline $\begin{array}{l}\text { Investigación de nuevas } \\
\text { tendencias sobre negocios } \\
\text { móviles }\end{array}$ & $\mathrm{Si}$ & $\mathrm{Si}$ & $\mathrm{Si}$ & No & $\mathrm{Si}$ & $\begin{array}{l}\text { Ventaja } \\
\text { competitiva } \\
\text { temporal }\end{array}$ \\
\hline Fidelización de clientes & $\mathrm{Si}$ & $\mathrm{Si}$ & No & No & $\mathrm{Si}$ & $\begin{array}{l}\text { Paridad } \\
\text { competitiva }\end{array}$ \\
\hline $\begin{array}{l}\text { Gerenciar centrado en el } \\
\text { perfil del cliente }\end{array}$ & $\mathrm{Si}$ & $\mathrm{Si}$ & No & No & $\mathrm{Si}$ & $\begin{array}{l}\text { Paridad } \\
\text { competitiva }\end{array}$ \\
\hline
\end{tabular}

Del análisis VRIO se concluye que las ventajas competitivas para el salón de belleza móvil es:

Ventaja competitiva sostenible:

- Ser el primer salón de belleza móvil en Lima 
Ventaja competitiva temporal:

- Infraestructura agradable y moderna en un móvil

- Flexibilidad de moverse a cualquier ubicación

- Investigación de nuevas tendencias sobre negocios móviles

\subsection{Diseño de la estructura organizacional deseada}

Según D'Alessio (2013), la estructura organizacional es el sostén de la organización, es la que direccionará a la organización para proveer las estrategias por medio de las políticas formuladas.

Las clasificaciones por diseños tradicionales son: simple, funcional y de divisiones, y por diseños contemporáneos son: equipo, proyecto, sin límites y organización que aprende, según Robbins y Coulter (como se cita en D'Alessio, 2013).

Para el presente plan de negocio el diseño de la estructura organizacional que se empleará es estructura funcional.

\subsubsection{Organigrama Funcional.}

El salón de belleza móvil contará con la siguiente estructura funcional (ver Figura 41). 


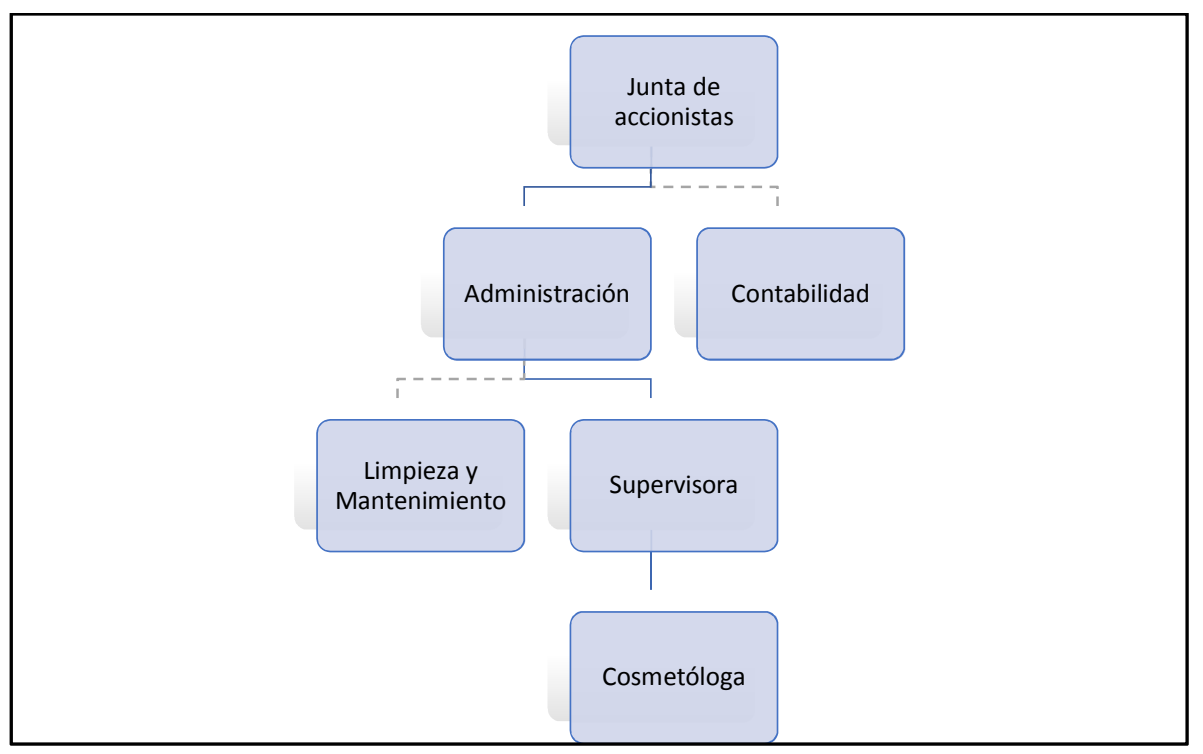

Figura 41. Estructura de la empresa

Teniendo en cuenta el tipo de negocio la organización se conformará de los siguientes puestos:

a. Junta de accionistas: socios inversionistas y dueños de la empresa, los cuales se encargan de constituir la empresa y posteriormente tomar decisiones estratégicas de la organización para su desarrollo.

b. Administración: se encargará de las decisiones diarias de la organización, realizar el monitoreo de las ventas, distribución de rutas y turnos para las móviles, además de las actividades administrativas y comerciales de la empresa.

c. Supervisora: se encargará de la supervisión directa y constante de todas las actividades diarias realizadas en cada móvil, garantizar la correcta atención del servicio, velar por la satisfacción de los clientes que se atienden en la móvil, además la supervisora se encargará de conducir el móvil hasta los lugares de destino.

d. Cosmetóloga: conformada por el personal calificado en cosmetología para realizar el servicio requerido por el cliente. 
Además, la organización contará con los siguientes servicios tercerizados:

a. Contabilidad: encargado de llevar los registros contables de la empresa, declaración de impuestos y otras actividades relacionadas al área de contabilidad.

b. Limpieza: encargado de realizar los servicios de limpieza diarios de las móviles.

\subsection{Diseño de los perfiles de puestos clave}

El plan de negocio de salón de belleza móvil tendrá los siguientes puestos claves descritos a continuación jefe administrativo (ver Tabla 122), supervisora (ver Tabla 123), cosmetóloga (ver Tabla 124). Además, se contará con servicios profesionales outsourcing de contabilidad y mantenimiento los cuales no se describen como puestos claves. 
Tabla 122

Perfil de puesto de jefe administrativo

\begin{tabular}{|c|c|}
\hline Puesto & Administrador \\
\hline Objetivo del puesto & $\begin{array}{l}\text { Administrar los recursos humanos, materiales (logística) y financieros } \\
\text { relacionados con los procesos de negocio, diseñando las políticas y } \\
\text { procedimientos a seguir en materia presupuestal, flujos de efectivo, } \\
\text { análisis financiero, movilidad del personal y control del gasto } \\
\text { administrativo; garantizando el suministro oportuno de los recursos } \\
\text { necesariamente requeridos para brindar un servicio de calidad. }\end{array}$ \\
\hline Responsabilidades & $\begin{array}{l}\text { a) Planificar y dirigir las políticas estratégicas, llevando a cabo el } \\
\text { control y seguimiento de la planificación, presupuesto y resultados } \\
\text { de los proyectos correspondientes. } \\
\text { b) Liderará reuniones de lanzamiento, toma de datos, seguimiento y } \\
\text { mejora de procesos en la organización. } \\
\text { c) Proporcionará soluciones a las necesidades planteadas por los } \\
\text { clientes y realizará propuestas de colaboración profesional que } \\
\text { satisfagan dichas necesidades. } \\
\text { d) Controlará la calidad de los trabajos, realizando un seguimiento de } \\
\text { los resultados de los proyectos, garantizando la satisfacción del } \\
\text { cliente con los mismos. } \\
\text { e) Resolverá dificultades que puedan surgir durante la ejecución de los } \\
\text { trabajos. } \\
\text { f) Velará por el cumplimiento de los objetivos y del desarrollo de la } \\
\text { cartera de negocio ya existente y de nueva creación sea el caso. } \\
\text { g) Ejecutará los objetivos estratégicos de la compañía de acuerdo a las } \\
\text { políticas básicas de actuación a corto, medio y largo plazo, de } \\
\text { acuerdo con las directrices aprobadas. } \\
\text { h) Asegurará y garantizará la consecución de los resultados y } \\
\text { rentabilidades esperadas, acordes con los presupuestos anuales y el } \\
\text { Plan Estratégico definido. } \\
\text { i) Establecerá y mantendrá las relaciones oportunas con los agentes } \\
\text { intervinientes en las empresas en su ámbito geográfico de actuación } \\
\text { (organismo e instituciones, clientes, socios, etc.). }\end{array}$ \\
\hline Requisitos & $\begin{array}{l}\text { - Titulación Universitaria Superior en Economía, Administración y } \\
\text { Dirección de Empresas, Derecho y/o afines o inclusive técnica. } \\
\text { - Experiencia contrastada de al menos cinco años en puestos de } \\
\text { dirección y desarrollo de negocio. } \\
\text { - Conocimientos básicos en marketing } \\
\text { - Nivel básico de inglés. }\end{array}$ \\
\hline
\end{tabular}


Tabla 123

Perfil de puesto de supervisora cosmetóloga

\begin{tabular}{|c|c|}
\hline Puesto & Supervisora \\
\hline Objetivo del puesto & $\begin{array}{l}\text { Brindar un servicio de asesoramiento especializado de belleza y } \\
\text { presentación personal al cliente, brindando un servicio de calidad en un } \\
\text { ambiente cómodo, cálido y acogedor para satisfacer la necesidad de los } \\
\text { clientes y se pueda alcanzar a fidelización del servicio. }\end{array}$ \\
\hline Responsabilidades & $\begin{array}{l}\text { a) Supervisar el trabajo de las cosmetólogas para realizar un trabajo de } \\
\text { calidad a los clientes de acuerdo al servicio solicitado, } \\
\text { b) Supervisará y aplicará de forma correcta los productos requeridos } \\
\text { con la marca, modelo y color. } \\
\text { c) Llevará el kardex semanal de los materiales e insumos para solicitar } \\
\text { los requerimientos de material para mantener en stock productos de } \\
\text { alta rotación, } \\
\text { d) Supervisará y conservará los usos y costumbres de acuerdo a la } \\
\text { política de higiene y salubridad para el mejor servicio al cliente. } \\
\text { e) Supervisará el cumplimiento de las rutas a seguir durante la semana } \\
\text { para cubrir con la demanda. }\end{array}$ \\
\hline Requisitos & $\begin{array}{l}\text { - Cosmetóloga con experiencia más de un año en corte, laceado, uñas } \\
\text { manos y pies } \\
\text { - } \\
\text { Servicios de estilismo en general que se brinde en un salón de } \\
\text { - Preferencia que viva en sector zona dos y alrededores } \\
\text { - } \quad \text { Años de experiencia: Uno } \\
\text { - } \quad \text { Que tenga brevete y experiencia en manejo más de un año }\end{array}$ \\
\hline
\end{tabular}


Tabla 124

Perfil de puesto de cosmetóloga

\begin{tabular}{|c|c|}
\hline Puesto & Cosmetóloga \\
\hline Objetivo del puesto & $\begin{array}{l}\text { Brindar un servicio de belleza y de presentación personal al cliente, } \\
\text { dándole una atención personalizada en un ambiente cómodo, cálido y } \\
\text { acogedor para satisfacer la necesidad de los clientes. }\end{array}$ \\
\hline Responsabilidades & $\begin{array}{l}\text { a) Utilizar los equipos e insumos necesarios para realizar un trabajo } \\
\text { de calidad a los clientes de acuerdo al servicio solicitado. } \\
\text { b) Aplicará de forma correcta los productos requeridos con la marca, } \\
\text { modelo y color. } \\
\text { c) Informará el consumo semanal de los materiales e insumos para } \\
\text { solicitar los requerimientos de material para mantener en stock } \\
\text { productos de alta rotación, } \\
\text { d) Realizar los servicios de acuerdo a la política de higiene y } \\
\text { salubridad. }\end{array}$ \\
\hline Requisitos & 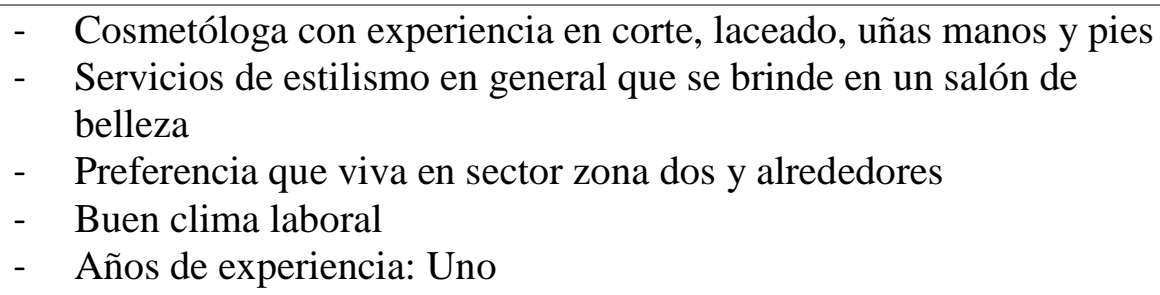 \\
\hline
\end{tabular}

\subsection{Remuneraciones, compensaciones e incentivos}

Los colaboradores para el plan de negocio celebrarán un contrato de Régimen Laboral Especial dirigido a fomentar la formalización y desarrollo de las Micro y Pequeña Empresa (Decreto Legislativo $\mathrm{N}^{\circ}$ 1086).

Los colaboradores que trabajen en la organización serán remunerados de acuerdo a los cargos que desempeñen, habilidades técnicas y específicas que puedan dar valor agregado a la fidelización de los clientes.

Los derechos de los colaboradores serán según Tabla 125. 
Tabla 125

Derechos de los colaboradores

\begin{tabular}{|c|c|}
\hline Concepto & Descripción \\
\hline \multirow[t]{3}{*}{ Remuneración } & Cosmetóloga (S/1200) \\
\hline & Cosmetóloga Supervisora (S/ 1800) \\
\hline & Jefe de Administración (S/ 2500) \\
\hline Jornada de trabajo & 48 horas semanales \\
\hline Sobretiempo & Remuneración por trabajo en sobretiempo \\
\hline Descanso & Semanal y en días feriados \\
\hline Descanso vacacional & 15 días calendarios \\
\hline $\begin{array}{l}\text { Cobertura de seguridad social en } \\
\text { salud }\end{array}$ & ESSALUD 9\% \\
\hline Indemnización & $\begin{array}{l}\text { Por despido de } 10 \text { días de remuneración por año de servicios } \\
\text { (con un tope de } 90 \text { días de remuneración) }\end{array}$ \\
\hline Cobertura de Seguro de Vida & No tiene \\
\hline Gratificaciones & Un sueldo al año pagado en julio y diciembre \\
\hline Utilidades & No tiene \\
\hline CTS & Mitad de un sueldo al año \\
\hline Derechos colectivos & No tiene \\
\hline
\end{tabular}

En base a los derechos establecidos para los colaboradores se establece la planilla anual de mano de obra directa y gastos operativos anuales (ver Tabla 126, 127, 128, 129, 130 y 131).

Tabla 126

Planilla Anual de mano de obra directa para el Año 1 (Soles)

\begin{tabular}{lccccccccc}
\hline $\begin{array}{l}\text { Mano de } \\
\text { obra directa }\end{array}$ & Cant. & $\begin{array}{c}\text { Remun. } \\
\text { Base }\end{array}$ & $\begin{array}{c}\text { Remun. } \\
\text { Anual }\end{array}$ & $\begin{array}{c}\text { Gratif. } \\
\text { (jul- } \\
\text { dic) }\end{array}$ & $\begin{array}{c}\text { Sub- } \\
\text { Total }\end{array}$ & $\begin{array}{c}\text { ESSALUD } \\
(9 \%)\end{array}$ & $\begin{array}{c}\text { CTS } \\
(8.33 \%)\end{array}$ & $\begin{array}{c}\text { Total Gasto } \\
\text { Remuneración } \\
\text { Anual por } \\
\text { trabajador }\end{array}$ & $\begin{array}{c}\text { Total } \\
\text { Mano Obra } \\
\text { Directa }\end{array}$ \\
\hline $\begin{array}{l}\text { Cosmetóloga } \\
\begin{array}{l}\text { Comestóloga } \\
\text { Supervisora }\end{array}\end{array}$ & 5 & 1,200 & 14,400 & 1,200 & 15,600 & 1,296 & 600 & 17,496 & 87,480 \\
\hline Total & 2 & 1,800 & 21,600 & 1,800 & 23,400 & 1,944 & 900 & 26,244 & 52,488 \\
\hline
\end{tabular}


Tabla 127

Planilla Anual de mano de obra directa para el Año 2 (Soles)

\begin{tabular}{|c|c|c|c|c|c|c|c|c|c|}
\hline $\begin{array}{l}\text { Mano de obra } \\
\text { directa }\end{array}$ & Cant. & $\begin{array}{l}\text { Remun. } \\
\text { Base }\end{array}$ & $\begin{array}{l}\text { Remun. } \\
\text { Anual }\end{array}$ & $\begin{array}{c}\text { Gratif. } \\
\text { (jul- } \\
\text { dic) }\end{array}$ & $\begin{array}{l}\text { Sub- } \\
\text { Total }\end{array}$ & $\begin{array}{l}\text { ESSALUD } \\
(9 \%)\end{array}$ & $\begin{array}{c}\text { CTS } \\
(8.33 \%)\end{array}$ & $\begin{array}{c}\text { Total Gasto } \\
\text { Remuneración } \\
\text { Anual por } \\
\text { trabajador }\end{array}$ & $\begin{array}{c}\text { Total } \\
\text { Mano } \\
\text { de Obra } \\
\text { Directa }\end{array}$ \\
\hline Cosmetóloga & 5 & 1,200 & 14,400 & 1,200 & 15,600 & 1,296 & 600 & 17,496 & 87,480 \\
\hline $\begin{array}{l}\text { Comestóloga } \\
\text { Supervisora }\end{array}$ & 2 & 1,800 & 21,600 & 1,800 & 23,400 & 1,944 & 900 & 26,244 & 52,488 \\
\hline Total & & & & & & & & & 139,968 \\
\hline
\end{tabular}

Tabla 128

Planilla Anual de mano de obra directa para el Año 3 (Soles)

\begin{tabular}{lrrrrrrrrr}
\hline $\begin{array}{l}\text { Mano de } \\
\text { obra directa }\end{array}$ & Cant. & $\begin{array}{c}\text { Remun. } \\
\text { Base }\end{array}$ & $\begin{array}{c}\text { Remun. } \\
\text { Anual }\end{array}$ & $\begin{array}{c}\text { Gratif. } \\
\text { (jul- } \\
\text { dic) }\end{array}$ & $\begin{array}{c}\text { Sub- } \\
\text { Total }\end{array}$ & $\begin{array}{c}\text { ESSALUD } \\
(9 \%)\end{array}$ & $\begin{array}{c}\text { CTS } \\
(8.33 \%)\end{array}$ & $\begin{array}{c}\text { Total Gasto } \\
\text { Remuneración } \\
\text { Anual por } \\
\text { trabajador }\end{array}$ & $\begin{array}{c}\text { Total } \\
\text { Mano Obra } \\
\text { Directa }\end{array}$ \\
\hline $\begin{array}{l}\text { Cosmetóloga } \\
\begin{array}{l}\text { Comestóloga } \\
\text { Supervisora }\end{array}\end{array}$ & 6 & 1,200 & 14,400 & 1,200 & 15,600 & 1,296 & 600 & 17,496 & 104,976 \\
\hline & 1,800 & 21,600 & 1,800 & 23,400 & 1,944 & 900 & 26,244 & 52,488 \\
\hline
\end{tabular}

Tabla 129

Planilla Anual de mano de obra directa para el Año 4 (Soles)

\begin{tabular}{lrrrrrrrrr}
\hline $\begin{array}{l}\text { Mano de } \\
\text { obra directa }\end{array}$ & Cant. & $\begin{array}{c}\text { Remun. } \\
\text { Base }\end{array}$ & $\begin{array}{c}\text { Remun. } \\
\text { Anual }\end{array}$ & $\begin{array}{c}\text { Gratif. } \\
\text { jul- } \\
\text { dic) }\end{array}$ & $\begin{array}{c}\text { Sub- } \\
\text { Total }\end{array}$ & $\begin{array}{c}\text { ESSALUD } \\
(9 \%)\end{array}$ & $\begin{array}{c}\text { CTS } \\
(8.33 \%)\end{array}$ & $\begin{array}{c}\text { Total Gasto } \\
\text { Remuneración } \\
\text { Anual por } \\
\text { trabajador }\end{array}$ & $\begin{array}{c}\text { Total } \\
\text { de Obra } \\
\text { Directa }\end{array}$ \\
\hline $\begin{array}{l}\text { Cosmetóloga } \\
\begin{array}{l}\text { Comestóloga } \\
\text { Supervisora }\end{array}\end{array}$ & 7 & 1,200 & 14,400 & 1,200 & 15,600 & 1,296 & 600 & 17,496 & 122,472 \\
\hline Total & 2 & 1,800 & 21,600 & 1,800 & 23,400 & 1,944 & 900 & 26,244 & 52,488 \\
\hline
\end{tabular}


Tabla 130

Planilla Anual de mano de obra directa para el Año 5 (Soles)

\begin{tabular}{lrrrrrrrrr}
\hline $\begin{array}{l}\text { Mano de } \\
\text { obra directa }\end{array}$ & Cant. & $\begin{array}{c}\text { Remun. } \\
\text { Base }\end{array}$ & $\begin{array}{c}\text { Remun. } \\
\text { Anual }\end{array}$ & $\begin{array}{c}\text { Gratif. } \\
\text { jul- } \\
\text { dic) }\end{array}$ & $\begin{array}{c}\text { Sub- } \\
\text { Total }\end{array}$ & ESSALUD (9\%) & $\begin{array}{c}\text { CTS } \\
(8.33 \%)\end{array}$ & $\begin{array}{c}\text { Total Gasto } \\
\text { Remuneración } \\
\text { Anual por } \\
\text { trabajador }\end{array}$ & $\begin{array}{c}\text { Total } \\
\text { de Obra } \\
\text { Directa }\end{array}$ \\
\hline $\begin{array}{l}\text { Cosmetóloga } \\
\text { Comestóloga }\end{array}$ & 8 & 1,200 & 14,400 & 1,200 & 15,600 & 1,296 & 600 & 17,496 & 139,968 \\
Supervisora & 2 & 1,800 & 21,600 & 1,800 & 23,400 & 1,944 & 900 & 26,244 & 52,488 \\
\hline Total & & & & & & & & & 192,456 \\
\hline
\end{tabular}

Tabla 131

Gastos operativos de personal (Soles)

\begin{tabular}{|c|c|c|c|c|c|c|c|c|c|}
\hline $\begin{array}{l}\text { Mano de } \\
\text { obra directa }\end{array}$ & Cant. & $\begin{array}{l}\text { Remun. } \\
\text { Base }\end{array}$ & $\begin{array}{l}\text { Remun. } \\
\text { Anual }\end{array}$ & $\begin{array}{c}\text { Gratif. } \\
\text { (jul- } \\
\text { dic) }\end{array}$ & $\begin{array}{l}\text { Sub- } \\
\text { Total }\end{array}$ & $\begin{array}{c}\text { ESSALUD } \\
(9 \%)\end{array}$ & $\begin{array}{c}\text { CTS } \\
(8.33 \%)\end{array}$ & $\begin{array}{c}\text { Total Gasto } \\
\text { Remuneración } \\
\text { Anual por } \\
\text { trabajador }\end{array}$ & $\begin{array}{c}\text { Total } \\
\text { Mano de } \\
\text { Obra } \\
\text { Directa }\end{array}$ \\
\hline $\begin{array}{l}\text { Jefe de } \\
\text { Administra- } \\
\text { ción y } \\
\text { Finanzas }\end{array}$ & 1 & 2,500 & 30,000 & 2,500 & 32,500 & 2,700 & 1,250 & 36,450 & 36,450 \\
\hline Contador & 1 & 1,000 & 12,000 & 0 & 0 & 0 & 0 & 12,000 & 12,000 \\
\hline Total & & & & & & & & & 48,450 \\
\hline
\end{tabular}

\subsection{Política de recursos humanos}

D'Alessio (2013) menciona que todos los colaboradores desde gerentes hasta operarios forman parte importante de la estructura organizacional, la cual debido a sus competencias y responsabilidades son necesarias para poder cumplir las estrategias trazadas.

Los líderes de las organizaciones deben considerar que los cambios tienen un proceso de transición, los cuales ciertas personas se resistirán a ese cambio y deberán afrontar la realidad.

Para el plan de negocio se emplearán las siguientes políticas de recursos humanos: 
a. Reclutamiento y selección: se reclutará y seleccionará al personal con altas capacidades profesionales y personales que tengan concordancia con las exigencias del negocio para brindar un servicio de calidad.

b. Evaluación de desempeño: se evaluará anualmente a los colaboradores para fomentar la superación y excelencia en la calidad del servicio

c. Formación y desarrollo: se capacitará al personal cada tres meses con el fin de mantener una actualización de las nuevas tendencias para el cuidado de la belleza y la imagen personal.

d. Remuneración: las remuneraciones serán según las responsabilidades, estos estarán acorde al mercado buscando la motivación y desarrollo profesional.

e. Salud ocupacional: se facilitará acciones que promuevan un clima organizacional armónico y condiciones seguras de trabajo. 


\section{Capítulo VII. Plan de Marketing}

\subsection{Estrategias de marketing}

Para formular la estrategia de marketing para el salón de belleza móvil se usó la matriz de producto y mercado propuesta por Ansoff (1957) el cual permite definir las alternativas estratégicas con las que cuenta la organización y de esta manera incrementar sus ventas, elegir el momento de crecer corporativamente, o a nivel de producto, o de ser necesario aclarar la dirección a seguir de la empresa. La Matriz de Ansoff relaciona los productos con los mercados en base al criterio de novedad o actualidad. En la Figura 42 se muestra la matriz que establece cuatro alternativas estratégicas: estrategia de penetración de mercados, estrategia de desarrollo de nuevos productos, estrategia de desarrollo de nuevos mercados o estrategia de diversificación.

(Ebooks, 2013)

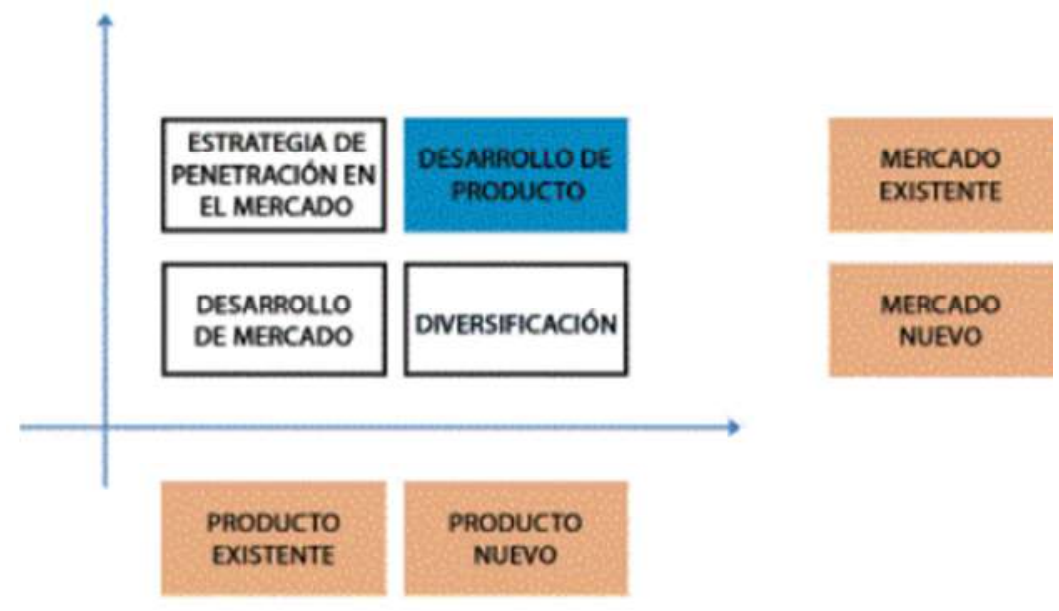

Figura 42. Matriz de Ansoff. Tomado de "Matrix Ansoff. Strategy skills." Por Free Management Ebooks, 2013. Recuperado de: http://www.free-management-ebooks.com/dldebk-pdf/fmeansoff-matrix.pdf

Para el salón de belleza móvil la estrategia de "desarrollo de productos", la cual refiere que la empresa desarrolla nuevos productos, los modifica o actualiza para los mercados en los 
que opera actualmente. En la actualidad los salones de belleza operan de manera tradicional ofreciendo sus servicios en un local fijo y esperando que los clientes se acerquen a sus locales, a diferencia el salón de belleza móvil cambia el concepto no usando un local fijo sino un móvil que irá hasta el domicilio de los clientes según su necesidad.

\subsubsection{Estrategia de Producto.}

Considerando como referencia la Matriz de Ansoff (1957), matriz productomercado. Ponte Diva Salón de belleza móvil escogió la estrategia de desarrollo de producto puesto que este negocio se está innovando en un nuevo formato, siendo el rubro de belleza un sector maduro. Se detallan a continuación las innovaciones y propuestas del salón de belleza móvil:

- Brindar capacitaciones a todos los profesionales de belleza de la organización, integrando al equipo de trabajo a un especialista en el sector belleza.

- El staff de profesionales de belleza o el especialista aconsejará las últimas tendencias de la moda a nivel internacional.

- Reserva de atención, los clientes podrán solicitar los servicios de acuerdo a su disponibilidad de horario.

- El diseño móvil y temático de belleza, con sillas y tocadores cómodos donde los clientes pueden atenderse.

- Visualizar el recorrido de la móvil a través de redes sociales para poder tomar los servicios ofrecidos de manicure, pedicure, corte y planchado.

- Pagos por medio de tarjetas bancarias

- Servicio de snacks bar, bebidas, música, películas, televisión a gusto del cliente dentro de la móvil. 
- Servicio de Reservas Recurrentes, el cliente podrá acceder a la programación recurrente de su próxima visita.

Tomando en cuenta las propuesta e innovaciones se establece lo siguiente:

Objetivo: posicionar en la mente del consumidor y colaboradores el nuevo formato de salón de belleza móvil y la marca para crear conciencia sobre el cuidado personal en las mujeres.

Táctica: publicar por redes sociales o e-mailing a los clientes sobre reservas, rutas y horarios de la móvil, nuevas tendencias internacionales, y ofertas.

Costo de Actividad: capacitaciones del experto en belleza para los colaboradores (4 horas al mes) y publicaciones de marketing durante todo el mes. El costo se encuentra incluido dentro del presupuesto de marketing.

Para poder ilustrar el presente plan de negocio se utilizará las Figuras 43 y 44 de negocios similares del extranjero (México y Estados Unidos), ya que en el Perú no existe.

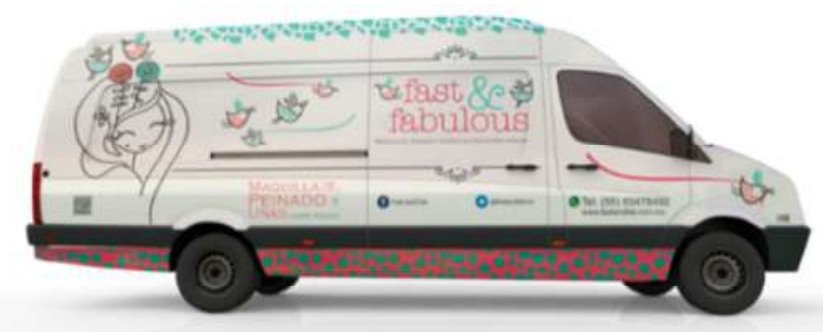

Figura 43. Salón de Belleza móvil cerrado. Tomado de "Fast and Fabulous", 2016. Recuperado de http://fastandfab.com.mx 


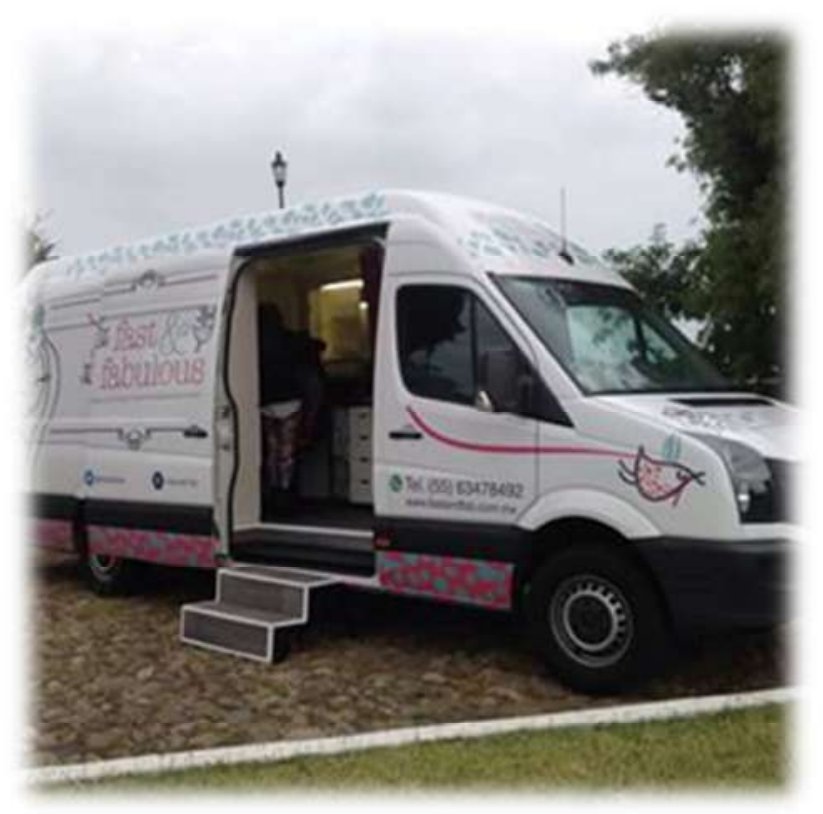

Figura 44. Salón de belleza móvil abierto. Tomado de " Fast and Fabulous", 2016. Recuperado https://scontent.cdninstagram.com/t51.288515/s320x320/e15/1389448_1476271202648391_1285610541_n.jpg

a. Servicios básicos:

Los servicios básicos que ofrecerá "Ponte Diva Salón” dentro de la móvil son los siguientes:

- Servicio de Corte de Cabello

- Servicio de Planchado

- Servicio de Manicure

- Servicio de Pedicure

El horario de atención será de martes a domingo de 07:00 am a 10:00pm

A continuación, se observa en la Figura 45 y 46 ilustrando los servicios que se ofrecerán dentro de la móvil. 


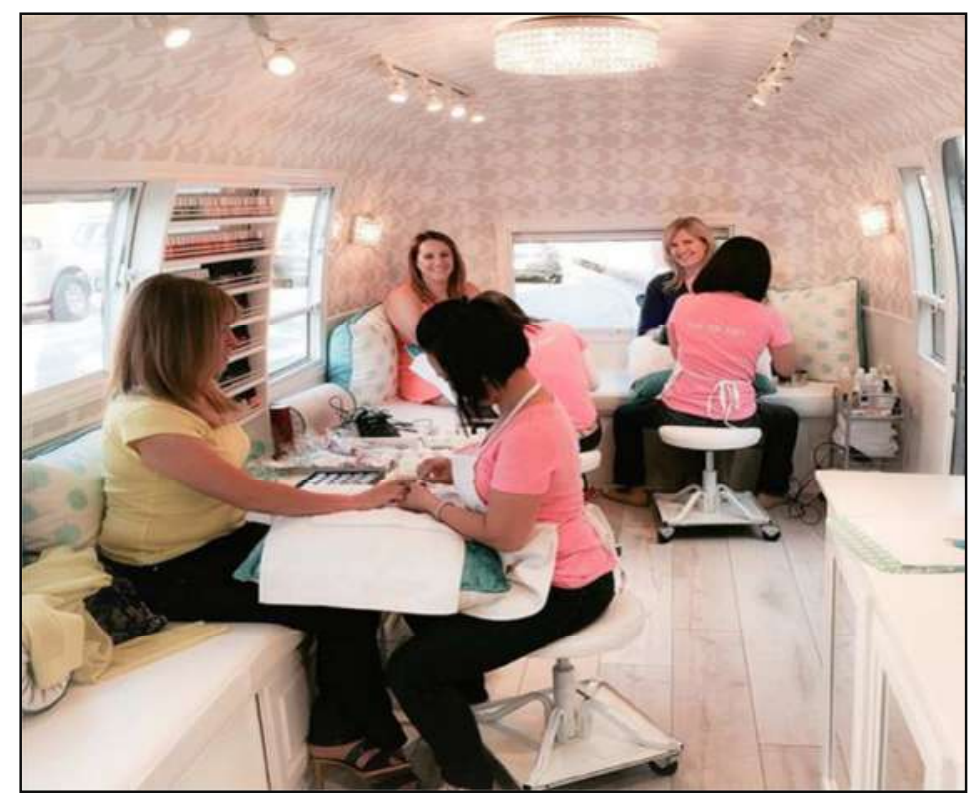

Figura 45. Servicio de Manicure y Pedicure dentro de la móvil. Tomado por "La Lacquiere Mobile nail salón", 2016. Recuperado de https://i.pinimg.com/236x/19/fc/4c/19fc4c2b31598781b20c366185f79170--mobile-salonmobile-nail-salon-ideas.jpg

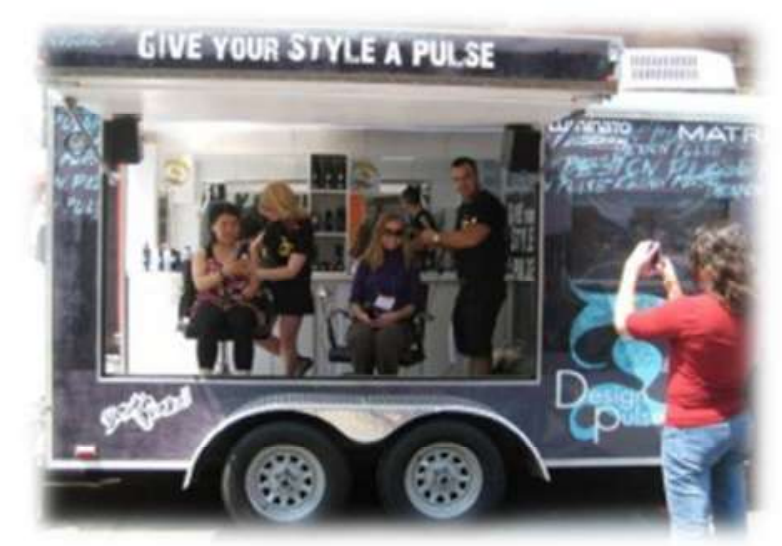

Figura 46. Servicio de Corte de Cabello y Planchado dentro de la móvíl. Recuperado de http://apefoodt.com/wp-content/uploads/2016/08/salon-movil-01-300x215.jpg

\section{b. Empaque}

Se utilizará una móvil tipo furgón (ver Figura 47), la cual contará con propaganda adherida a los costados de ambas puertas de la cabina, así como, el costado de cada cara 
de la cajonada del furgón, la cual mostrará el logo de la marca dando una sensación de comodidad, calidad y placer de sentirse bella. El ingreso será por la puerta posterior de la móvil por medio de una escalera de plancha estriada de tres peldaños forrada con jebe antideslizante, en el interior del furgón se encontrará un ambiente debidamente acondicionado, con paredes laterales forradas de colomural con diseño propio de color rosa, tendrá un piso laminado tipo parquet desde el inicio hasta el final del ambiente, contará con sistema de led para una mejor iluminación, tendrá agua fría y caliente, aire acondicionado para la aclimatación del ambiente, televisor y equipo de sonido para la relajación o distracción, además de un snack bar, lo que facilitará el desarrollo de un servicio de calidad.

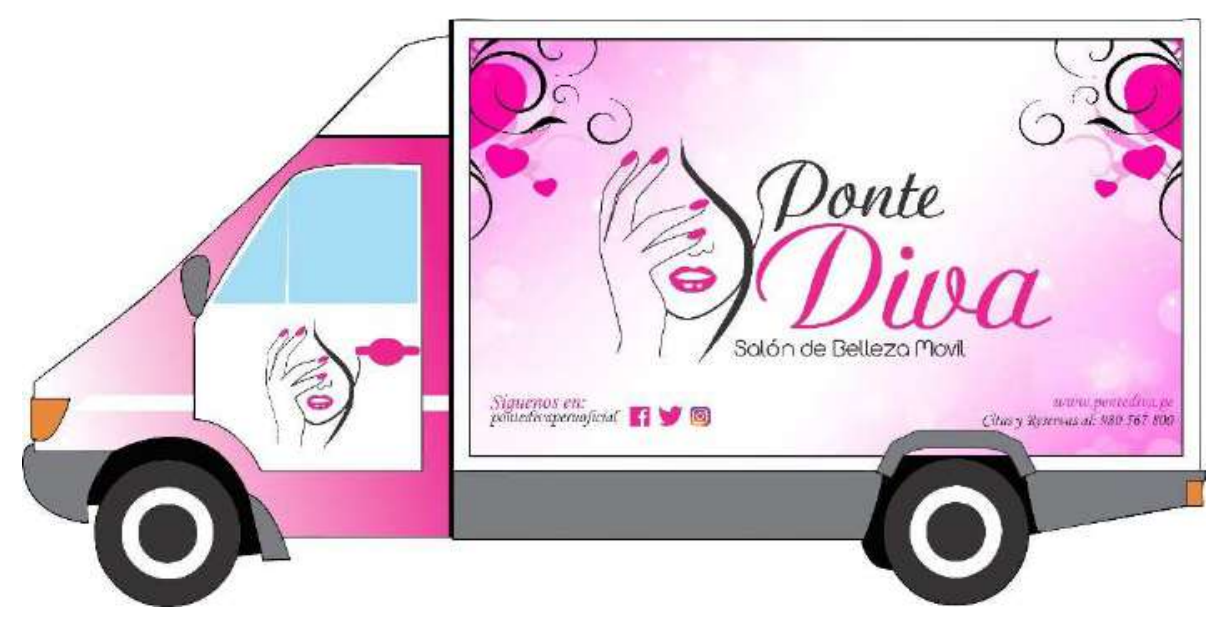

Figura 47. Unidad móvil Ponte Diva Salón

c. Marca

El servicio saldrá al mercado con el nombre de "Ponte Diva", debido al estudio de mercado y focus group realizados donde se intercambió una lluvia de ideas y mezcla de opiniones de las participantes, siendo este un nombre fácil de pronunciar y de recordar, la 
cual involucra palabras sencillas que se relacionan mucho con el tema de belleza, rapidez, y efectivo a domicilio.

d. Logotipo

A continuación, se muestra el logotipo de "Ponte Diva Salón” (ver Figura 48).

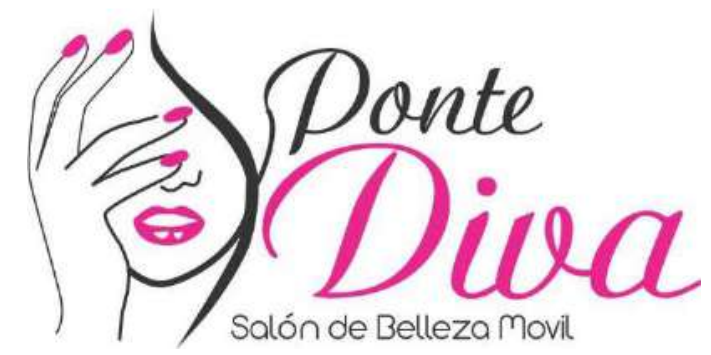

Figura 48. Logotipo de Ponte Diva

Imagen:

Muestra los servicios que ofrecemos como corte de cabello, uñas, planchado y peinado, siendo estos los que van a resaltar la belleza femenina.

Texto:

Color rosado: es femenino, sexy, influye en los sentimientos, demuestra amor, energía sin agitación, temperatura agradable, de la vida joven, atractiva, pasional, apreciada a los ojos del hombre.

Ponte: Invita e incentiva a las mujeres a tomar la decisión de probar con rapidez el servicio que se brinda, para obtener resultados maravillosos.

Diva: Hacer que las clientas se sientan únicas, lindas, que sobre salgan sobre otras, que sean especiales y atractivas. 


\subsubsection{Estrategia de Precio.}

Según Santesmases (2012), indica los siguientes puntos a considerar para las estrategias de precios:

a. Costes, márgenes, y descuentos

b. Fijación de precio a un solo producto. Existen tres criterios: competencia o sensibilidad demanda según segmentos de mercado.

c. Fijación de precios a una línea de productos como elasticidad cruzada.

El precio de los productos de Ponte Diva se determinó tomando en cuenta los siguiente:

- Costos de producción/servicio y los gastos operacionales

- Percepción de los consumidores, según investigación de mercado

- Estudio de mercado, analizando los precios de la competencia.

La estrategia que se usó para asignar precios fue la de fijación de precios, debido a que el salón de belleza móvil ofrecerá un servicio rápido, con productos de calidad y una infraestructura innovadora. Es por ellos, que los precios son ligeramente acorde al mercado. El objetivo de esta estrategia de precios es la rápida recuperación de la inversión.

Ponte Diva, ofrecerá los precios mostrados en la Tabla 132 la cual está relacionada a los tiempos estimados de atención, productos, materiales y profesionales de belleza: 
Tabla 132

Lista de precios de Ponte Diva

\begin{tabular}{lll}
\hline Servicio & Precio & Tiempo estimado \\
Corte de Cabello & S/ 15.00 & 20 minutos \\
Planchado o Peinado & S/ 30.00 & 40 minutos \\
Manicure & S/ 15.00 & 15 minutos \\
Pedicure & S/ 20.00 & 30 minutos \\
\hline
\end{tabular}

\subsubsection{Estrategia de distribución.}

La distribución del producto está directamente relacionada con la demanda del mercado, es por eso, que se busca las mejores opciones en cuanto a presentación y calidad para estimular la adquisición del cliente. Los canales de distribución son los que van a satisfacer al cliente la necesidad de obtener el producto que está deseando.

(Santesmases, 2012).

Ponte Diva utilizará una estrategia de distribución exclusiva y directa para la prestación de servicios por medio de la móvil, quien llevará el salón de belleza en hora oportuna hasta el domicilio especificado por el cliente dentro de Lima Norte, zona dos.

Asimismo, cada móvil deberá estar en óptimas condiciones de limpieza, material, insumos, entre otros para garantizar la calidad de cada servicio supervisado por cada encargada.

El objetivo principal es aprovechar la afluencia comercial y digital del público en la zona dos de Lima Norte.

\subsubsection{Estrategia de promoción y publicidad.}

La promoción de un producto es el conjunto de actividades que tratan de comunicar los beneficios que reporta el producto y de persuadir al mercado objetivo de que lo compre a quien lo ofrece. Es una combinación de las siguientes actividades: ventas 
personales, publicidad, propaganda, relaciones públicas, promoción de ventas, marketing directo.

La estrategia de promoción y publicidad contemplará las siguientes herramientas: Promoción para consumidores

Se utilizarán mecanismos o instrumentos para aumentar la participación de los clientes a corto plazo, o mejorar las relaciones a largo plazo con los mismos mediante:

Los cupones: en el primer mes, en la etapa de lanzamiento se contará con una decoración especial de belleza en la móvil, se lanzarán Packs de Ofertas con precios de introducción, como ofrecer los servicios de Manicure y Pedicure a S/ 35.00 (ver Figura 49).

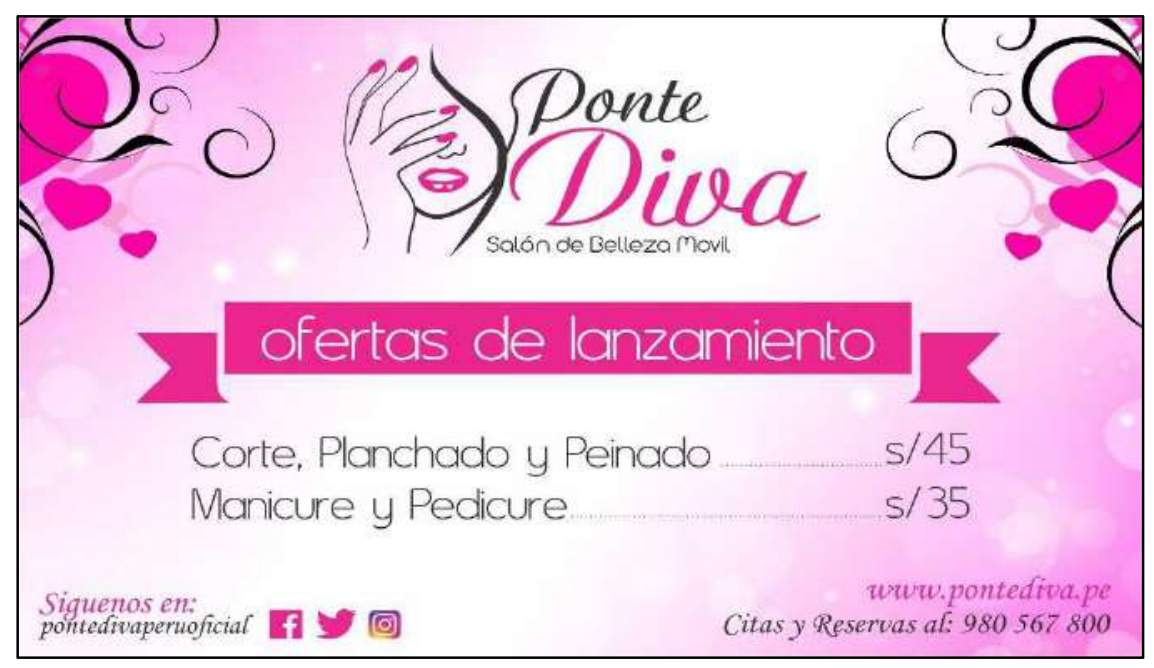

Figura 49. Ofertas de Lanzamiento de Ponte Diva

Para la difusión de nuestros servicios a domicilio y promociones de la móvil "Ponte Diva", se utilizará redes sociales como Facebook, WhatsApp y web (responsive). Durante los meses que se calendarice alguna festividad como día de la madre, fiestas patrias, fiestas de fin de año para empresas y año nuevo, se otorgarán a los clientes 
por medio de las redes sociales cupones con descuento en servicios específicos, así como bonificaciones por acumulación de servicios, los cuales podrán ser usados a requerimiento del cliente.
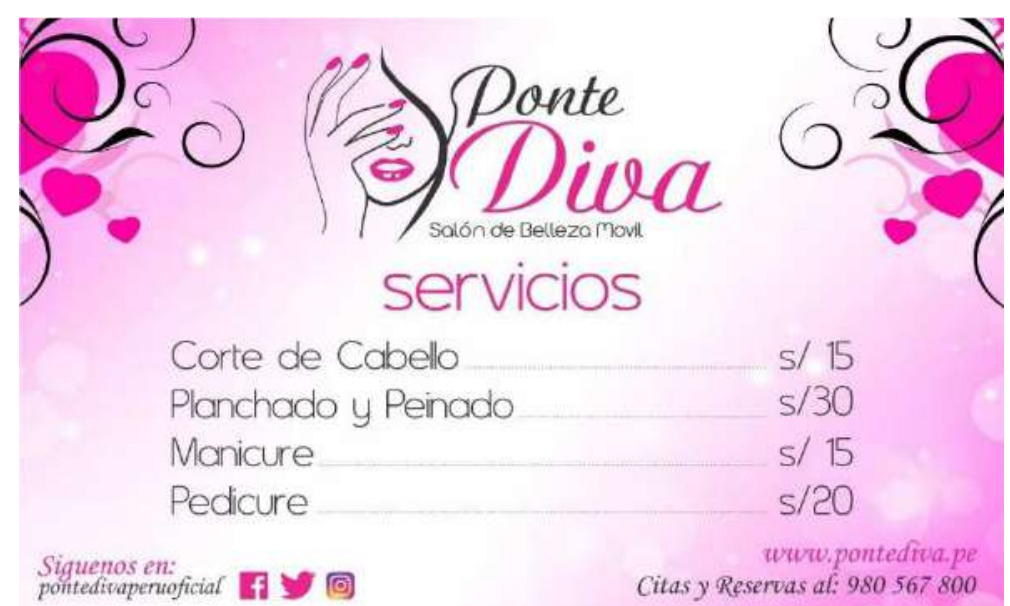

Figura 50. Precios de los servicios de Ponte Diva

Promociones comerciales: las promociones comerciales estarán acorde a nuestros precios de servicios (ver Figura 50).

Se utilizarán herramientas para promocionar marcas específicas las cuales tengan mayor demanda en el sector para aumentar la participación de los clientes y tener socios estratégicos para la realización de posicionamiento de la marca mediante: 
Exhibiciones: se realizará eventos de lanzamiento de productos y nuevas tendencias, con personal especializado representante de marcas participando en centros comerciales, universidades, desfiles de modas y eventos de imagen para hacer conocida la marca y promocionar la compra del servicio en forma corporativa por empresas, otorgando cupones de gratis de servicios en "Ponte Diva Salón".

Promoción para negocios: se utilizarán estrategias de marketing cruzada con empresas fabricantes o distribuidores de marcas, con el fin de promocionarlas y aumentar el consumo de sus productos, así como tener socios estratégicos para la realización del posicionamiento de la marca mediante:

Exposiciones o Simposio: convenios con empresas de las marcas más conocidas para formar parte de sus presentaciones en eventos, lanzamientos a fin con la belleza y cuidado corporal, con la finalidad de ser un medio donde ellos promocionen sus productos y a la vez hacer conocido al negocio posicionando la marca como idea innovadora.

\subsection{Estrategia de ventas}

Según (Lambini, 2009), la creación y proyección de una estrategia de ventas, se necesita ver a largo plazo las metas de ventas y análisis del ciclo de negocios, la primera etapa es la fase inductoria, segunda etapa es la fase de crecimiento, la tercera fase es la estacionaria, la cuarta fase es la maduración y la quinta fase es declive.

\section{Fase Introductoria.}

Los elementos que pueden perjudicar en esta etapa inicial son: 
- El consumidor potencial, debido a que solo los consumidores más motivados por la curiosidad serán las primeras personas en subir al salón de belleza móvil y probar los servicios ofrecidos.

- La competencia en el mercado actual y los futuros competidores.

Se realizó las siguientes estrategias en esta etapa:

Estrategia No. 1: Crear concurso entre los clientes por redes sociales, a base de quien se ganará un paquete promocional de lanzamiento.

Objetivo: Recodar el nombre del salón de belleza móvil entre el nuevo mercado potencial.

Acción 1: Realizar la campaña pagada de intriga en redes sociales, lanzando el salón de belleza móvil, con los servicios básicos y promocionales para aumentar los leads de ingreso.

Acción 2: Realizar interacción y concurso en redes sociales, los premios son los paquetes promocionales de lanzamiento.

Estrategia No. 2: Realizar un recorrido durante el primer mes de lanzamiento por todos los centros comerciales de la zona dos de Lima Metropolitana.

Objetivo: Atraer mayor cantidad de consumidores potenciales para el salón de belleza móvil.

Acción 1: Los salones de belleza móvil van a recorrer los centros comerciales más concurrentes de la zona dos de Lima Metropolitana, entregando flyer o volantes con las nuevas promociones de lanzamiento.

Acción 2: Se realizará concurso de manera presencial en cada centro comercial para que puedan probar los servicios del salón de belleza móvil. 
Fase de crecimiento.

En esta etapa el salón de belleza móvil deberá contar con consumidores finales satisfechos que regresen nuevamente a realizarse los servicios de belleza e influyan en otros clientes por recomendación, de manera que las ventas aumenten, de igual modo se debe tener en cuenta que esta fase debe ingresar nuevos competidores, quienes ya copiaron el presente plan de negocios.

Por lo tanto, debemos seguir las siguientes estrategias:

Estrategia No. 1: Adicionar nuevos servicios de belleza, nuevas tendencias de moda.

Objetivo: Extender el tamaño del mercado local.

Acción 1: Se debe aprovechar las capacitaciones de los estilistas o profesionales para brindar otro tipo de servicios de belleza, incluyendo las nuevas tendencias de la moda en fecha.

Acción 2: Obtener información de los mismos consumidores finales, quienes pueden aconsejarnos o indicarnos que productos debemos traer o que servicios debemos adicionar a nuestra lista para poder satisfacer esa necesidad.

Estrategia No. 2: Aumentar la promoción por redes sociales nuestra página web, Facebook, Instagram, twitter.

Objetivo: Generar nuevas visitas o ingresos al salón de belleza móvil.

Acción 1: Realizar campañas pagadas agresivas de tal manera que la interacción con el consumidor final sea más dinámica

Acción 2: Incrementar las promociones en los servicios de belleza, por el día de la madre, secretaria, fiestas patrias, fiestas navideñas o eventos especiales que pueden tener en cualquier momento. 


\section{Fase estacionaria.}

En esta etapa la competencia estará más agresivo y el indicador clave de desempeño es la participación de mercado, por tal motivo, los objetivos que tendrá el salón de belleza móvil será posicionar la marca en la mente de los consumidores finales, si como mantener la lealtad de la marca.

\section{Fase madurez.}

En esta etapa de madurez el objetivo prioritario del salón de belleza móvil será proteger y de ser posible aumentar la participación de mercado, así como ganar una ventaja competitiva sustentable sobre los competidores directos.

Fase declive.

Se debe contemplar esta etapa de declive debido a que puede verse cambios con el tiempo de las costumbres de ir al salón de belleza móvil, así como cambios en su entorno social o económico. El salón de belleza móvil de llegar a esta etapa deberá tomar la decisión de dirigirse a otro mercado, traspasar el negocio o cambiar de rubro.

\subsubsection{Plan de ventas.}

Al iniciar operaciones, se tendrá el primer de salón móvil en los centros comerciales, durante el primer mes y los otros dos móviles estarán en las avenidas más concurridas donde se encuentre los salones de belleza tradicionales (local fijo). En un plazo de 5 años se estima llegar a vender S/ 853,479 netos, en todos los servicios que se ofrecerá como lanzamiento, tal como se describe en el programa de ventas del capítulo IV. 
Se detalla a continuación el resumen de las ventas en soles por año por servicio

(Ver Tabla 133):

Tabla 133

Plan de Ventas Anual en Soles

\begin{tabular}{lrrrrr}
\hline & \multicolumn{1}{c}{2017} & \multicolumn{1}{c}{2018} & \multicolumn{1}{c}{2019} & \multicolumn{1}{c}{2020} & \multicolumn{1}{c}{2021} \\
\hline Ventas Servicio Corte Cabello & $\mathrm{S} / .60,699$ & $\mathrm{~S} / .67,216$ & $\mathrm{~S} / .74,436$ & $\mathrm{~S} / .82,434$ & $\mathrm{~S} / .91,294$ \\
Ventas Servicio Planchado & $\mathrm{S} / .171,314$ & $\mathrm{~S} / .189,708$ & $\mathrm{~S} / .210,084$ & $\mathrm{~S} / .232,657$ & $\mathrm{~S} / .257,664$ \\
Ventas Servicio Manicure & $\mathrm{S} / .147,246$ & $\mathrm{~S} / .163,055$ & $\mathrm{~S} / .180,569$ & $\mathrm{~S} / .199,970$ & $\mathrm{~S} / .221,464$ \\
Ventas Servicio Pedicure & $\mathrm{S} / .188,377$ & $\mathrm{~S} / .208,602$ & $\mathrm{~S} / .231,007$ & $\mathrm{~S} / .255,828$ & $\mathrm{~S} / .283,326$ \\
\hline Total Ventas Anual & $\mathrm{S} / .567,636$ & $\mathrm{~S} / .628,582$ & $\mathrm{~S} / .696,096$ & $\mathrm{~S} / .770,889$ & $\mathrm{~S} / .853,749$ \\
\hline
\end{tabular}

\subsubsection{Políticas de servicios y garantías.}

Dentro de las políticas de servicio y garantías que ofrecerá "Ponte Diva Salón", para las mujeres 20 a 59 años de la zona norte dos se ha establecido lo siguiente:

- Políticas de Producto

- Los servicios que se brindan son los de mayor demanda solicitados por los clientes.

- La empresa deberá implementar las técnicas de moda (tendencias)

- Deberá brindar un servicio de calidad y vender una experiencia divina

- Utilizar productos de calidad

- Evaluar en forma mensual el servicio que otorgan nuestros colaboradores

- Políticas de Precios

- Evaluar la variación de precios en el mercado.

- Beneficiar a las clientas con descuentos por paquete u ofrecer algún servicio adicional sin cargo.

- Establecer unas metas de ventas mensuales para evaluar el punto de equilibrio. 
- Políticas de Publicidad y Promoción

- Realizar promociones especiales de acuerdo a las estaciones del año

- Hacer evaluaciones a los clientes para saber por qué medio se enteraron de nuestra idea innovadora.

- Rediseñar las piezas gráficas exhibidas en el exterior del local

- Entrega de merchandising u obsequios para ocasiones especiales

Programas de acción para los primeros seis meses:

- Mes uno: Se lanzará una campaña una promoción de ventas y se montará exhibidores en las principales avenidas de las zonas dos de Lima Norte, con el fin de posicionar la marca y el nuevo formato de salón de belleza móvil. Asimismo, apoyar y fomentar el lanzamiento del producto en el mes siguiente. Además, se creará especulaciones de lo que se viene en redes sociales, con expertos de belleza, bloggers, influencers. El personal estará atento a las reservas y chats en línea para poder explicar los servicios y características de este nuevo salón de belleza móvil.

- Mes dos: Se iniciará una campaña impresa, radio e internet integrada, dirigida a nuestros consumidores, la población de Lima Norte, zona dos. La campaña mostrará todas las ofertas, beneficios y tendencias internacionales de la belleza. Esta campaña multimedia estará apoyada por anuncios en Google adwords y videos exclusivos para redes sociales. - Mes tres: Conforme la campaña publicitaria multimedia se lleva a cabo, se va añadir las promociones, ofertas, tips de belleza y que puede hacer sus pagos con tarjetas bancarias para los consumidores, como también un concurso de packs integrales de belleza 
gratuitos. Por medio de la móvil que estará recorriendo los tres distritos de la zona dos de Lima Norte se podrá ir posicionando en la mente del consumidor la marca y los servicios. - Mes cuatro: Se realizará un concurso entre las unidades móviles que tenga mayor venta para poder premiar a la unidad móvil que llegue a su cuota de venta o pase el $50 \%$ ó el $100 \%$ de las ventas estimadas, también se puede hacer el concurso por distritos, el que tenga mayor ventas y mejor atención al cliente, y será publicado en redes sociales para que puedan apreciar la calidad de servicios y estilista que se tiene en este salón de belleza móvil.

- Mes cinco: En ese mes se planteará relanzar las nuevas tendencias de belleza en el mercado, considerando que cada cuatro meses varía la moda, según los expertos. Cambio de imágenes y tendencias en la página web, redes sociales, nuevas ofertas y tips de belleza.

- Mes seis: La campaña de radio agregará una nueva frase publicitaria que promoverá las nuevas ofertas y tendencias de belleza, generando concurso, el selfie de belleza. Además, se revisará y analizará los resultados de las encuestas de satisfacción de los clientes para usarlos en promociones futuras, y como retroalimentación para las actividades de producto y marketing. 


\section{Capítulo VIII. Planificación Financiera.}

\subsection{La Inversión}

La inversión es la entrega de dinero que realiza una empresa o persona con el fin de generar beneficios en un periodo mayor de un año (Gitman \& Zutter, 2012).

\subsubsection{Inversión pre-operativa}

Son todos los desembolsos que se realicen antes de que el negocio empiece a funcionar, forma parte del llamado calendario de inversiones previas a la puesta en marcha (Sapag, 2011).

Estas inversiones tratan de cubrir los rubros de (a) activos fijos, que son fácilmente identificables porque son objetos físicos utilizados para las actividades de la empresa y tienen una vida útil relativamente larga; y (b) activos intangibles, que no tienen representación física, pero generan beneficios futuros como concesiones, derechos, patentes y marcas (Stickney, Weill, Schipper, Francis, \& Avolio, 2011).

\section{Activo Fijo}

Para el plan de negocio la inversión de activos tangibles es de S/ 143,200 (con IGV) y se distribuirán para los rubros de servicios (S/ 136,680) y operativa $(\mathrm{S} / 6,540)$, el detalle se aprecia a continuación: 
Tabla 134

Activos tangibles para servicios y operaciones

\begin{tabular}{|c|c|c|c|c|}
\hline \multicolumn{5}{|c|}{ Servicios } \\
\hline Descripción & Cantidad & $\begin{array}{c}\text { Costo } \\
\text { unitario } \mathrm{S} /\end{array}$ & $\begin{array}{l}\text { S/ Sin } \\
\text { IGV }\end{array}$ & $\begin{array}{c}\text { S/ Con } \\
\text { IGV }\end{array}$ \\
\hline Silla para corte y planchado & 2 & 127 & 254 & 300 \\
\hline Espejo con mostrador & 2 & 364 & 729 & 860 \\
\hline Lavadero & 2 & 186 & 373 & 440 \\
\hline Kit manicure y pedicure & 4 & 271 & 1,085 & 1,280 \\
\hline Vitrina para pared & 2 & 407 & 814 & 960 \\
\hline Auxiliar de manos y pies & 4 & 195 & 780 & 920 \\
\hline Tablet & 2 & 339 & 678 & 800 \\
\hline Televisor 32" & 2 & 1,271 & 2,542 & 3,000 \\
\hline Cámaras de vigilancia & 2 & 847 & 1,695 & 2,000 \\
\hline Aire acondicionado & 2 & 1,271 & 2,542 & 3,000 \\
\hline Extintor & 2 & 68 & 136 & 160 \\
\hline Botiquín de primeros auxilios & 2 & 25 & 51 & 60 \\
\hline Tanque de agua & 2 & 169 & 339 & 400 \\
\hline Accesorios para tanque de agua & 2 & 42 & 85 & 100 \\
\hline Grupo electrógeno portátil & 2 & 1,017 & 2,034 & 2,400 \\
\hline Vehículo furgón & 2 & 50,847 & 101,695 & 120,000 \\
\hline Total activos fijos - servicio & & & 115,831 & 136,680 \\
\hline \multicolumn{5}{|c|}{ Operaciones } \\
\hline Armario de melamina de $1.8^{*} 0.9$ (con puerta) & 2 & 950 & 1,900 & 2,242 \\
\hline Escritorio (silla) & 1 & 1,100 & 1,100 & 1,298 \\
\hline Laptop & 1 & 1,271 & 1,271 & 1,500 \\
\hline Modular de oficina (con sillas) & 1 & 1,271 & 1,271 & 1,500 \\
\hline Total activos fijos - operativos & & & 5,542 & 6,540 \\
\hline
\end{tabular}

Como se puede ver en la Tabla 134 la inversión para activos tangibles para servicios es de S/ 136,680 siendo la inversión más alta la de los furgones que de acuerdo a la definición del tamaño del negocio se determinó comprar dos furgones nuevos que cuestan S/ 60,000 cada uno, el monto restante consiste en los accesorios para la modificación de los furgones. 
Además, en la inversión para activos tangibles (S/ 6,540) para operaciones se consideran los accesorios para la oficina del administrador del negocio.

\section{Activo Intangible}

La inversión en activos intangibles para el plan de negocio está formada por los gastos de constitución de la empresa y los gastos pre-operativos que se conforman del acondicionamiento del local, acondicionamiento de los furgones, campaña de marketing para el lanzamiento y la selección de personal inicial. 
Tabla 135

Inversión intangible

\begin{tabular}{lrrrr}
\hline \multicolumn{1}{c}{ Constitución de la empresa } & & & \\
\hline \multicolumn{1}{c}{ Descripción } & Cant. & $\begin{array}{c}\text { Costo } \\
\text { unitario S/ }\end{array}$ & $\begin{array}{c}\text { S/ Sin } \\
\text { IGV }\end{array}$ & $\begin{array}{c}\text { Son } \\
\text { IGV }\end{array}$ \\
\hline Constitución de empresa & 1 & 8 & 8 & 8 \\
Reserva de nombre SUNARP & 1 & 16 & 16 & 16 \\
Reserva de marca - INDECOPI & 1 & 631 & 631 & 633 \\
Elaboración de minuta de constitución & 1 & 392 & 392 & 395 \\
Inscripción den registros públicos & 1 & 30 & 30 & 30 \\
Escritura pública & 1 & 165 & 165 & 165 \\
Legalización de libros contables & 1 & 235 & 235 & 235 \\
Libros (planilla, compras, ventas) & 1 & 25 & 25 & 30 \\
Emisión de facturas y boletas & 1 & 641 & 641 & 641 \\
Compra de seguro SOAT & 1 & 2,034 & 2,034 & 2,034 \\
Diseño página web / redes sociales & 1 & 2,119 & 2,119 & 2,500 \\
Licencia Windows & 1 & 1,542 & 1,542 & 1,820 \\
Antivirus & 1 & 153 & 153 & 180 \\
\hline Total inversión intangible & & 7,991 & 7,991 & 8,687 \\
\hline
\end{tabular}

Gastos pre-operativos

Acondicionamiento local principal

\begin{tabular}{lllll}
\hline Acondicionamiento de oficina & 1 & 1,271 & 1,271 & 1,500 \\
\hline
\end{tabular}

Acondicionamiento de furgones

\begin{tabular}{|c|c|c|c|c|}
\hline Acondicionamiento interior & 2 & 12,712 & 25,424 & 30,000 \\
\hline \multicolumn{5}{|c|}{ Alquiler y garantía de cochera pre operativo } \\
\hline Alquiler & 2 & 254 & 508 & 600 \\
\hline \multicolumn{5}{|c|}{ Marketing de lanzamiento } \\
\hline Evento de lanzamiento de marca & 1 & 2,542 & 2,542 & 3,000 \\
\hline \multicolumn{5}{|c|}{$\begin{array}{l}\text { Selección de personal inicial } \\
\end{array}$} \\
\hline Empresa de recursos humanos & 1 & 2,500 & 2,500 & 2,950 \\
\hline Uniforme de personal & 3 & 68 & 203 & 240 \\
\hline Total gastos pre-operativos & & & 32,449 & 38,290 \\
\hline
\end{tabular}

Como se puede ver en la Tabla 135 la inversión para activos intangibles asciende a S/ 8,687 incluido IGV siendo la inversión más alta la compra de SOAT para los furgones y el diseño de la página web, los gastos pre-operativos ascienden a $S / 38,290$ 
incluido IGV siendo la inversión más alta el servicio de acondicionamiento de los furgones para que contenga toda la infraestructura de un salón de belleza convencional.

\subsubsection{Inversión en capital de trabajo}

El capital de trabajo es conocido comúnmente como activo corriente y hace referencia a la parte de la inversión que pasa a formar parte de la operación habitual del negocio, representa al financiamiento a corto plazo de la empresa (inventarios, cuentas por cobrar y efectivo) (Gitman \& Zutter, 2012).

Según el tipo de negocio y servicios ofrecidos las ventas se realizarán al contado y los gastos de personal, servicios y alquileres se registran mensualmente.

También se incluye el impuesto a la renta (1.5\%), las capacitaciones se consideran trimestrales, las campañas de marketing en los meses de mayor afluencia de público y se considera el recargo por comisión de ventas procesadas con pago electrónico (ver Tabla 136). 
Tabla 136

Capital de Trabajo

\begin{tabular}{|c|c|c|c|c|c|c|c|c|c|c|c|c|}
\hline $\begin{array}{c}\text { INGRESOS } \\
\text { EFECTIVO (Contado) } \\
\end{array}$ & Mes 1 & Mes 2 & Mes 3 & Mes 4 & Mes 5 & Mes 6 & Mes 7 & Mes 8 & Mes 9 & Mes 10 & Mes 11 & Mes 12 \\
\hline Estacionalidad & $4 \%$ & $5 \%$ & $6 \%$ & $7 \%$ & $9 \%$ & $8 \%$ & $10 \%$ & $8 \%$ & $8 \%$ & $8 \%$ & $10 \%$ & $17 \%$ \\
\hline Corte de Cabello & 7,034 & 6,513 & 4,863 & 2,779 & 4,255 & 4,472 & 7,294 & 2,822 & 2,258 & 3,170 & 4,950 & 10,290 \\
\hline Planchado & 19,852 & 18,381 & 13,725 & 7,843 & 12,009 & 12,622 & 20,587 & 7,965 & 6,372 & 8,946 & 13,970 & 29,043 \\
\hline Manicure & 17,063 & 15,799 & 11,797 & 6,741 & 10,322 & 10,849 & 17,695 & 6,846 & 5,477 & 7,689 & 12,007 & 24,962 \\
\hline Pedicure & 21,829 & 20,212 & 15,092 & 8,624 & 13,205 & 13,879 & 22,638 & 8,759 & 7,007 & 9,837 & 15,361 & 31,935 \\
\hline Ventas mensuales & 19,242 & 24,052 & 28,863 & 33,673 & 43,294 & 38,484 & 48,105 & 38,484 & 38,484 & 38,484 & 48,105 & 81,778 \\
\hline IGV Ventas & 3,464 & 4,329 & 5,195 & 6,061 & 7,793 & 6,927 & 8,659 & 6,927 & 6,927 & 6,927 & 8,659 & 14,720 \\
\hline Total Ventas & 22,705 & 28,382 & 34,058 & 39,735 & 51,087 & 45,411 & 56,764 & 45,411 & 45,411 & 45,411 & 56,764 & 96,498 \\
\hline $\begin{array}{l}\text { TOTAL INGRESOS } \\
\text { EFECTIVO }\end{array}$ & 22,705 & 28,382 & 34,058 & 39,735 & 51,087 & 45,411 & 56,764 & 45,411 & 45,411 & 45,411 & 56,764 & 96,498 \\
\hline $\begin{array}{l}\text { EGRESOS } \\
\text { EFECTIVO }\end{array}$ & Mes 1 & Mes 2 & Mes 3 & Mes 4 & Mes 5 & Mes 6 & Mes 7 & Mes 8 & Mes 9 & Mes 10 & Mes 11 & Mes 12 \\
\hline Material directo & 4,927 & 6,158 & 7,390 & 8,621 & 11,085 & 9,853 & 12,316 & 9,853 & 9,853 & 9,853 & 12,316 & 20,938 \\
\hline IGV Material directo & 887 & 1,108 & 1,330 & 1,552 & 1,995 & 1,774 & 2,217 & 1,774 & 1,774 & 1,774 & 2,217 & 3,769 \\
\hline $\begin{array}{l}\text { Gastos de personal } \\
\text { (Sueldos) }\end{array}$ & 13,100 & 13,100 & 13,100 & 13,100 & 13,100 & 13,100 & 13,100 & 13,100 & 13,100 & 13,100 & 13,100 & 13,100 \\
\hline Gratificación & & & & & & & 6,050 & & & & & 6,050 \\
\hline CTS & & & & & 3,025 & & & & & & 3,025 & \\
\hline ESSALUD & 1,089 & 1,089 & 1,089 & 1,089 & 1,089 & 1,089 & 1,089 & 1,089 & 1,089 & 1,089 & 1,089 & 1,089 \\
\hline Material indirecto & 3,970 & & & & & & & & & & & \\
\hline IGV Material indirecto & 715 & 0 & 0 & 0 & 0 & 0 & 0 & 0 & 0 & 0 & 0 & 0 \\
\hline Gastos Generales & 2,310 & 2,310 & 2,310 & 2,310 & 2,310 & 2,310 & 2,310 & 2,310 & 2,310 & 2,310 & 2,310 & 2,310 \\
\hline IGV Gastos Generales & 236 & 236 & 236 & 236 & 236 & 236 & 236 & 236 & 236 & 236 & 236 & 236 \\
\hline Capacitación personal & 5,085 & & & 5,085 & & & 5,085 & & & 5,085 & & \\
\hline IGV Capacitación & 915 & & & 915 & & & 915 & & & 915 & & \\
\hline Promoción y & 6,667 & & & & & 6,667 & & & & & 6,667 & \\
\hline
\end{tabular}


Publicidad

IGV Promoción y

Publicidad

Comisión POS

IGV Comisión POS

Pago IGV (al estado) -

Del módulo de IGV

PAGO A CUENTA

IMPUESTO RENTA

(1.5\%)

\begin{tabular}{|c|c|c|c|c|c|c|c|c|c|c|c|}
\hline 1,200 & 0 & 0 & 0 & 0 & 1,200 & 0 & 0 & 0 & 0 & 1,200 & 0 \\
\hline 356 & 445 & 534 & 623 & 801 & 712 & 890 & 712 & 712 & 712 & 890 & 1,513 \\
\hline 64 & 80 & 96 & 112 & 144 & 128 & 160 & 128 & 128 & 128 & 160 & 272 \\
\hline 0 & 0 & 0 & 0 & 0 & 0 & 0 & 0 & 0 & 4,465 & 3,874 & 4,846 \\
\hline & 289 & 361 & 433 & 505 & 649 & 577 & 722 & 577 & 577 & 577 & 722 \\
\hline 2,224 & 2,224 & 2,224 & 2,224 & 2,224 & 2,224 & 2,224 & 2,224 & 2,224 & 2,224 & 2,224 & 2,224 \\
\hline 43,744 & 27,039 & 28,669 & 36,300 & 36,514 & 39,941 & 47,169 & 32,147 & 32,002 & 42,467 & 49,885 & 57,068 \\
\hline$-21,038$ & 1,343 & 5,389 & 3,435 & 14,574 & 5,470 & 9,594 & 13,264 & 13,408 & 2,944 & 6,878 & 39,430 \\
\hline$-21,038$ & $-19,695$ & $-14,306$ & $-10,872$ & 3,702 & 9,172 & 18,766 & 32,030 & 45,439 & 48,382 & 55,261 & 94,691 \\
\hline
\end{tabular}

\begin{tabular}{|c|c|c|c|c|c|c|c|c|c|c|c|}
\hline MODULO DE IGV & Año 0 & Mes 1 & Mes 2 & Mes 3 & Mes 4 & Mes 5 & Mes 6 & Mes 7 & Mes 8 & Mes 9 & Mes \\
\hline IGV Ventas & & 3,464 & 4,329 & 5,195 & 6,061 & 7,793 & 6,927 & 8,659 & 6,927 & 6,927 & 6,9 \\
\hline IGV Material directo & & -887 & $-1,108$ & $-1,330$ & $-1,552$ & $-1,995$ & $-1,774$ & $-2,217$ & $-1,774$ & $-1,774$ & \\
\hline IGV Material Indirecto & & -715 & 0 & 0 & 0 & 0 & 0 & 0 & 0 & 0 & \\
\hline IGV Gastos generales & & -236 & -236 & -236 & -236 & -236 & -236 & -236 & -236 & -236 & \\
\hline IGV Capacitacion & & -915 & 0 & 0 & -915 & 0 & 0 & -915 & 0 & 0 & \\
\hline IGV Promocion y Publicidad & & $-1,200$ & 0 & 0 & 0 & 0 & $-1,200$ & 0 & 0 & 0 & \\
\hline IGV Comision POS & & -64 & -80 & -96 & -112 & -144 & -128 & -160 & -128 & -128 & \\
\hline IGV Activos tangibles & $-21,847$ & & & & & & & & & & \\
\hline IGV Activos intangibles & -696 & & & & & & & & & & \\
\hline IGV Gastos pre-operativos & $-5,841$ & & & & & & & & & & \\
\hline IGV Neto & $-28,384$ & -553 & 2,905 & 3,533 & 3,246 & 5,418 & 3,590 & 5,131 & 4,790 & 4,790 & \\
\hline Credito fiscal & $-28,384$ & $-28,937$ & $-26,032$ & $-22,499$ & $-19,252$ & $-13,835$ & $-10,245$ & $-5,114$ & -325 & 0 & \\
\hline Pago de IGV & 0 & 0 & 0 & 0 & 0 & 0 & 0 & 0 & 0 & 4,465 & \\
\hline
\end{tabular}


Además, se considera el siguiente capital de trabajo anual (ver Tabla 137).

Tabla 137

\begin{tabular}{lrrrrrr}
\hline & Año 0 & Año 1 & \multicolumn{1}{c}{ Año 2 } & Año 3 & Año 4 & Año 5 \\
\hline Ventas & & 481,048 & 532,696 & 589,912 & 653,296 & 723,516 \\
Capital de trabajo necesario & & 21,038 & 23,297 & 25,799 & 28,571 & 31,642 \\
Inversion capital de trabajo & $-21,038$ & $-2,259$ & $-2,502$ & $-2,772$ & $-3,071$ & \\
\hline Recuperacion de capital de trabajo & & & & & & 31,642 \\
\hline \multicolumn{1}{l}{ Capital de Trabajo Anual $(S /)$} & & & & & &
\end{tabular}

Se puede verificar que al quinto año se recupera el S/ 31,642 en capital de trabajo.

\subsubsection{Costo del proyecto}

Se considera el costo total del proyecto, considerando la inversión pre-operativa y la inversión por capital de trabajo.

Tabla 138

$C$

\begin{tabular}{lrrrr}
\hline \multicolumn{5}{c}{ INVERSIÓN ANO 0 (S/) } \\
\multicolumn{1}{c}{ Inversión } & $\begin{array}{c}\text { Inversión sin } \\
\text { IGV }\end{array}$ & \multicolumn{1}{c}{ IGV } & \multicolumn{1}{l}{$\begin{array}{l}\text { Inversión } \\
\text { con IGV }\end{array}$} & \multicolumn{1}{c}{$\%$} \\
\hline Activo Fijo Tangible & 121,373 & 21,847 & 143,220 & $68 \%$ \\
Activo Intangible & 7,991 & 696 & 8,687 & $4 \%$ \\
Capital de Trabajo & 21,038 & & 21,038 & $10 \%$ \\
Gastos pre-operativos & 32,449 & 5,841 & 38,290 & $18 \%$ \\
\hline Total & 182,851 & 28,384 & 211,235 & $100 \%$ \\
\hline$t$
\end{tabular}

otal proyecto 
Se puede observar en la Tabla 138 que la inversión inicial total es de S/ 211,235 incluido IGV, la más relevante es el activo fijo tangible que incluye la compra de los furgones, siendo éstos la adquisición más valiosa de la empresa.

\subsubsection{Inversiones futuras}

Según el estudio de mercado ejecutado para la estimación de la demanda, en los próximos cinco años, que es la duración del plan, se considera que la inversión inicial es suficiente para cubrir la demanda estimada y lograr los objetivos planteados.

\subsection{Financiamiento}

\subsubsection{Endeudamiento y condiciones}

El endeudamiento de una empresa hace referencia al monto de dinero de otras empresas o personas que usa para generar utilidades, los compromisos para el pago de deudas son acordados mediante contratos donde se establece el plazo y monto de pagos, se dice que cuando mayor es la deuda, mayor es el riesgo de que la empresa no cumpla con los pagos de sus activos. Existen dos tipos de medidas de endeudamiento: (a) grado de endeudamiento y (b) capacidad de pago de deudas (Gitman \& Zutter, 2012).

Adicionalmente al aporte de capital de cada uno de los accionistas, el plan de negocio será financiado por un préstamo del Banco de Crédito del Perú, por una suma de S/ 80,000 que representa el 37.48\% de la inversión inicial (ver Tabla 139). 
Tabla 139

Estructura de financiamiento

\begin{tabular}{|c|c|c|c|}
\hline Inversión & $\begin{array}{c}\text { Inversión con } \\
\text { IGV }\end{array}$ & Capital propio & Deuda \\
\hline Activo Fijo Tangible & S/. 143,220 & 63,220 & S/. 80,000 \\
\hline Activo Intangible & S/. $\quad 8,687$ & 8,687 & $\mathrm{~S} /$. \\
\hline Capital de Trabajo & 21,038 & 21,038 & S/. \\
\hline Gastos pre-operativos & 38,290 & 38,290 & $\mathrm{~S} /$. \\
\hline \multirow[t]{2}{*}{ TOTAL } & S/. 211,235 & 131,235 & $\mathrm{~S} / .80,000$ \\
\hline & & $62.13 \%$ & $37.87 \%$ \\
\hline
\end{tabular}

El préstamo bancario se amortizará a un periodo de cuatro años con cuotas fijas (ver Tabla 140).

Tabla 140

Condiciones de préstamo

Condiciones de Préstamo

\begin{tabular}{lr}
\hline Importe & 80,000 \\
TEA & $16 \%$ BCP \\
TEM & $1.24 \%$ \\
Plazo & 4 años \\
\hline Cuota mensual & 2,224
\end{tabular}

Con estas condiciones se procede a calcular el cronograma de pago anual. 
Tabla 141

Financiamiento anual

\begin{tabular}{lcccc}
\hline Descripción & Deuda $(\mathrm{S} /)$ & Interés $(\mathrm{S} /)$ & Amortización $(\mathrm{S} /)$ & Cuota $(\mathrm{S} /)$ \\
\hline Año 1 & 80,000 & 10,895 & 15,790 & 26,685 \\
Año 2 & 64,210 & 8,369 & 18,316 & 26,685 \\
Año 3 & 45,894 & 5,438 & 21,247 & 26,685 \\
Año 4 & 24,647 & 2,039 & 24,647 & 26,685 \\
\hline Total & & 26,742 & 80,000 & 106,742 \\
\hline
\end{tabular}

Como se puede observar en la Tabla 141, el monto del préstamo es S/ 80,000 y los intereses ascienden a S/ 26,742, esto resulta que al final del periodo del préstamo se haya hecho un pago de S/ 106,742 en total.

\subsubsection{Capital y costo de oportunidad}

El costo de oportunidad se define como la rentabilidad a la que el inversionista renuncia por invertir en un negocio. El costo de oportunidad se calcula con el modelo CAPM:

$$
K e=R f+\beta *(R m-R f)+R p
$$

Donde:

Ke: Costo de oportunidad

Rm: Rendimiento esperado del mercado

Rf: Tasa de libre riesgo

$\beta$ : Beta del sector

Rp: Riesgo país 
El rendimiento esperado del mercado se obtiene en base al promedio aritmético de las acciones del mercado de Estados Unidos, considerando el periodo de 2007 a 2016 (nueve años).

La tasa de libre riesgo se obtiene usando como base el promedio de rendimiento de la tasa de los bonos del tesoro de Estados Unidos, considerando el periodo de 2007 a 2016 (nueve años), similar al rendimiento esperando del mercado (ver Tabla 142).

Tabla 142

Información de rendimiento esperado y tasa de libre riesgo

\begin{tabular}{ccc}
\hline Años & S\&P 500 & 10-year T. Bond \\
\hline $1928-2016$ & $11.42 \%$ & $5.18 \%$ \\
$1967-2016$ & $11.45 \%$ & $7.08 \%$ \\
$2007-2016$ & $8.64 \%$ & $5.03 \%$ \\
\hline
\end{tabular}

Nota: Tomado de Damodaran online, http://www.damodaran.com, 2017

Para el riesgo del sector se ha considerado la beta desapalancada del sector Business \& Consumer Services a enero del 2017, la beta para este sector es de 0.82, el cual se apalancará usando el porcentaje de endeudamiento y la razón de capital que se encuentran detalladas en la estructura de financiamiento (ver Tabla 143).

Tabla 143

\section{Beta apalancada}

\begin{tabular}{lr}
\hline \multicolumn{2}{c}{ Cálculo de Beta Apalancada $=(1+(1-\mathrm{t}) *(\mathrm{D}+\mathrm{B} 40 / \mathrm{C}))$} \\
\hline Beta desapalancada & 0.82 \\
Porcentaje de endeudamiento $(\% \mathrm{D})$ & $37 \%$ \\
Razón de capital $(\% \mathrm{E})$ & $63 \%$ \\
Impuesto a la renta $(\mathrm{t})$ & $29.5 \%$ \\
\hline Beta Apalancado & 1.17
\end{tabular}


El riesgo país a abril 2017 es de 1.46\%. (ambito.com, 2017)

Con la información extraída y calculada anteriormente se realiza el cálculo del COK apalancado usando la fórmula CAPM (ver Tabla 144).

Tabla 144

\section{COK apalancado}

\begin{tabular}{lr}
\hline Cálculo del COK apalancado & \\
\hline Rendimiento del mercado USA (S\&P 500) & $8.64 \%$ \\
Tasa libre de riesgo USA (T-Bonds) & $5.03 \%$ \\
Beta desapalancada & 0.82 \\
$\% \mathrm{D}$ & $37 \%$ \\
\%E & $63 \%$ \\
Riesgo país & $1.46 \%$ \\
Impuesto a la renta & $29.5 \%$ \\
\hline Beta Apalancado & 1.17 \\
COK Real Perú (COK) & $10.7 \%$ \\
Riesgo del Proyecto (50 \% más) & $5.4 \%$ \\
\hline COK apalancado del proyecto & $16.1 \%$ \\
\hline
\end{tabular}

Adicionalmente a aplicar el riesgo país queda un COK Real Perú de 10.7\%, para efectos de proyectos y considerando diversos factores de riesgo como el mercado y competidores se ha sumado un 50\% al COK Real Perú, obteniendo un COK final de $16.1 \%$.

\subsubsection{Costo de capital promedio ponderado}

Refleja el costo futuro promedio esperado del costo de capital a largo plazo, se calcula ponderando el costo de cada tipo de capital con su proporción en la estructura del capital de la empresa esta es la fórmula (Gitman \& Zutter, 2012): 


$$
\mathrm{WACC}=\mathrm{Ke}^{*} \mathrm{C}+\mathrm{Kd}^{*}(1-\mathrm{IR}) * \mathrm{D}
$$

Donde:

Ke: Costo de oportunidad (COK apalancado)

C: Razón de capital

D: Razón de endeudamiento deflactado

Kd: Tasa de financiamiento real

IR: Impuesto a la renta

Tabla 145

C

\begin{tabular}{llrrr}
\cline { 2 - 4 } & \multicolumn{1}{c}{ Capital } & \multicolumn{1}{c}{ Monto } & \multicolumn{1}{c}{$\%$} & Costo de capital \\
\cline { 2 - 5 }$l$ & Deuda Activos Fijos & 80,000 & $38 \%$ & $16.00 \%$ \\
& Capital propio & 131,235 & $62 \%$ & $16.09 \%$ \\
\cline { 3 - 5 } & & 211,235 & $100 \%$ & \\
\cline { 3 - 5 } & Costo promedio ponderado capital (WACC) & & & $14.27 \%$ \\
\hline
\end{tabular}

ulo del WACC

Aplicando la fórmula detallada líneas arriba se obtiene el valor del WACC en $14.27 \%$ (ver Tabla 145).

\subsection{Presupuestos Base}

\subsubsection{Presupuesto de ventas.}

Muestra los ingresos que serán obtenidos por los servicios del salón de belleza móvil.

El precio de cada uno de los servicios ofrecidos por el salón de belleza móvil se detalla en la Tabla 146. 
Tabla 146

Precio de servicios al público

\begin{tabular}{lcc}
\hline \multicolumn{1}{c}{ Servicios } & $\begin{array}{c}\text { Precio venta público sugerido } \\
\text { (Soles) }\end{array}$ & $\begin{array}{c}\text { Valor venta público (sin } \\
\text { IGV) - Soles }\end{array}$ \\
\hline Corte de Cabello & 15 & 13 \\
Planchado & 30 & 25 \\
Manicure & 15 & 13 \\
Pedicure & 20 & 17
\end{tabular}

Según la proyección de demanda realizada en el capítulo cuatro se calcula el ingreso multiplicando esta demanda por el precio de cada servicio, se ha considerado castigar el primer año por ser un negocio nuevo e innovador (ver Tabla 147).

Tabla 147

Presupuesto por ventas

\begin{tabular}{lrrrrr}
\hline Ventas (soles) sin IGV & \multicolumn{1}{c}{ Año 1 } & \multicolumn{1}{c}{ Año 2 } & \multicolumn{1}{c}{ Año 3 } & \multicolumn{1}{c}{ Año 4 } & \multicolumn{1}{c}{ Año 5 } \\
\hline Corte de cabello & 46,419 & 51,771 & 57,740 & 64,398 & 71,824 \\
Planchado & 131,010 & 146,116 & 162,964 & 181,754 & 202,711 \\
Manicure & 112,604 & 125,587 & 140,068 & 156,219 & 174,232 \\
Pedicure & 144,981 & 161,698 & 180,342 & 201,136 & 224,328 \\
\hline Total ventas anuales (sin & & & & & \\
IGV) & 435,013 & 485,172 & 541,114 & 603,507 & 673,095 \\
IGV & 78,302 & 87,331 & 97,401 & 108,631 & 121,157 \\
Total ventas anuales & & & & & \\
(con IGV) & 513,315 & 572,503 & 638,515 & 712,139 & 794,252 \\
\hline
\end{tabular}

\subsubsection{Presupuesto de costos de producción (de servicio).}

Los costos de producción que se asumirán para la prestación de los servicios están formados por la mano de obra, el material directo y los costos indirectos del servicio. 
De acuerdo a la proyección de la demanda de cada uno de los servicios se realizó la asignación de horas hombre, material directo y costo indirecto del servicio obteniendo la siguiente información (ver Tabla 148, 149, 150 y 151).

Tabla 148

Costo de producción de servicio de corte de cabello

\begin{tabular}{lccccc}
\hline Corte de Cabello & Año 1 & Año 2 & Año 3 & Año 4 & Año 5 \\
\hline Concepto & 3,652 & 4,073 & 4,542 & 5,066 & 5,650 \\
\hline Servicios & 1,217 & 1,358 & 1,514 & 1,689 & 1,883 \\
Horas hombre & & & & & \\
\hline Costos producción (S/) & 12,224 & 13,633 & 15,205 & 16,958 & 18,914 \\
\hline Material directo & 15,253 & 15,253 & 17,160 & 19,067 & 20,973 \\
Mano de obra directa & 6,342 & 6,440 & 6,549 & 6,671 & 6,789 \\
CIS & 33,819 & 35,326 & 38,914 & 42,696 & 46,676 \\
\hline Total costo producción (S/) & & & & & \\
\hline \multicolumn{7}{c}{ Costo producción unitario (S/) } & 9.26 & 8.67 & 8.57 & 8.43 & 8.26 \\
\hline Costo total unitario (S/) & & & & & \\
\hline Servicios & Año 1 & Año 2 & Año 3 & Año 4 & Año 4 \\
\hline Costos totales (S/) & 3,652 & 4,073 & 4,542 & 5,066 & 5,650 \\
\hline Material directo & & & & & \\
Mano de obra directa & 12,224 & 13,633 & 15,205 & 16,958 & 18,914 \\
CIS & 15,253 & 15,253 & 17,160 & 19,067 & 20,973 \\
Gastos operativos & 6,342 & 6,440 & 6,549 & 6,671 & 6,789 \\
\hline Total costos (S/) & 9,694 & 9,260 & 8,922 & 8,821 & 8,924 \\
\hline Costo total unitario (S/) & 43,513 & 44,586 & 47,836 & 51,517 & 55,600 \\
\hline & 11.92 & 10.95 & 10.53 & 10.17 & 9.84 \\
\hline
\end{tabular}


Tabla 149

Costo de producción de servicio planchado

\begin{tabular}{|c|c|c|c|c|c|}
\hline Planchado & & & & & \\
\hline Concepto & Año 1 & Año 2 & Año 3 & Año 4 & Año 5 \\
\hline Servicios & 5,153 & 5,747 & 6,410 & 7,149 & 7,973 \\
\hline Horas hombre & 3,435 & 3,831 & 4,273 & 4,766 & 5,316 \\
\hline \multicolumn{6}{|l|}{ Costos producción (S/) } \\
\hline Material directo & 12,228 & 13,637 & 15,210 & 16,964 & 18,920 \\
\hline Mano de obra directa & 43,050 & 43,050 & 48,431 & 53,812 & 59,194 \\
\hline CIS & 17,899 & 18,176 & 18,484 & 18,829 & 19,160 \\
\hline Total costo producción (S/) & 73,177 & 74,863 & 82,125 & 89,605 & 97,273 \\
\hline Costo producción unitario (S/) & 14.20 & 13.03 & 12.81 & 12.53 & 12.20 \\
\hline Costo total unitario (S/) & Año 1 & Año 2 & Año 3 & Año 4 & Año 4 \\
\hline Servicios & 5,153 & 5,747 & 6,410 & 7,149 & 7,973 \\
\hline \multicolumn{6}{|l|}{ Costos totales (S/) } \\
\hline Material directo & 12,228 & 13,637 & 15,210 & 16,964 & 18,920 \\
\hline Mano de obra directa & 43,050 & 43,050 & 48,431 & 53,812 & 59,194 \\
\hline CIS & 17,899 & 18,176 & 18,484 & 18,829 & 19,160 \\
\hline Gastos operativos & 27,360 & 26,134 & 25,181 & 24,896 & 25,188 \\
\hline Total costos $(\mathrm{S} /)$ & 100,537 & 100,997 & 107,306 & 114,500 & 122,461 \\
\hline Costo total unitario (S/) & 19.51 & 17.57 & 16.74 & 16.02 & 15.36 \\
\hline
\end{tabular}


Tabla 150

Costo de producción de servicio de manicure

\begin{tabular}{lccccc}
\hline Manicure & & & & & \\
\hline Concepto & Año 1 & Año 2 & Año 3 & Año 4 & Año 5 \\
\hline Servicios & 8,858 & 9,880 & 11,019 & 12,289 & 13,706 \\
Horas hombre & 2,953 & 3,293 & 3,673 & 4,096 & 4,569 \\
\hline Costos producción (S/) & & & & & \\
\hline Material directo & 36,594 & 40,814 & 45,520 & 50,769 & 56,622 \\
Mano de obra directa & 37,002 & 37,002 & 41,627 & 46,252 & 50,877 \\
CIS & 15,385 & 15,622 & 15,888 & 16,183 & 16,468 \\
\hline Total costo producción (S/) & 88,981 & 93,438 & 103,034 & 113,204 & 123,968 \\
\hline & & & & & \\
\hline Costo producción unitario (S/) & 10.05 & 9.46 & 9.35 & 9.21 & 9.04 \\
\hline & & & & & \\
\hline Costo total unitario (S/) & Año 1 & Año 2 & Año 3 & Año 4 & Año 4 \\
\hline Servicios & 8,858 & 9,880 & 11,019 & 12,289 & 13,706 \\
& & & & & \\
\hline Costos totales (S/) & & & & & \\
\hline Material directo & 36,594 & 40,814 & 45,520 & 50,769 & 56,622 \\
Mano de obra directa & 37,002 & 37,002 & 41,627 & 46,252 & 50,877 \\
CIS & 15,385 & 15,622 & 15,888 & 16,183 & 16,468 \\
Gastos operativos & 23,516 & 22,462 & 21,643 & 21,398 & 21,649 \\
\hline Total costos (S/) & 112,497 & 115,900 & 124,677 & 134,602 & 145,617 \\
\hline
\end{tabular}


Tabla 151

Costo de producción de servicio de pedicure

\begin{tabular}{|c|c|c|c|c|c|}
\hline Pedicure & & & & & \\
\hline Concepto & Año 1 & Año 2 & Año 3 & Año 4 & Año 5 \\
\hline Servicios & 8,554 & 9,540 & 10,640 & 11,867 & 13,235 \\
\hline Horas hombre & 3,564 & 3,975 & 4,433 & 4,945 & 5,515 \\
\hline \multicolumn{6}{|l|}{ Costos producción (S/) } \\
\hline Material directo & 50,415 & 56,228 & 62,712 & 69,943 & 78,008 \\
\hline Mano de obra directa & 44,663 & 44,663 & 50,246 & 55,829 & 61,412 \\
\hline CIS & 18,570 & 18,857 & 19,177 & 19,534 & 19,878 \\
\hline Total costo producción (S/) & 113,649 & 119,749 & 132,135 & 145,306 & 159,298 \\
\hline Costo producción unitario (S/) & 13.29 & 12.55 & 12.42 & 12.24 & 12.04 \\
\hline Costo total unitario (S/) & Año 1 & Año 2 & Año 3 & Año 4 & Año 4 \\
\hline Servicios & 8,554 & 9,540 & 10,640 & 11,867 & 13,235 \\
\hline \multicolumn{6}{|l|}{ Costos totales $(\mathrm{S} /)$} \\
\hline Material directo & 50,415 & 56,228 & 62,712 & 69,943 & 78,008 \\
\hline Mano de obra directa & 44,663 & 44,663 & 50,246 & 55,829 & 61,412 \\
\hline CIS & 18,570 & 18,857 & 19,177 & 19,534 & 19,878 \\
\hline Gastos operativos & 30,278 & 28,921 & 27,866 & 27,551 & 27,874 \\
\hline Total costos $(\mathrm{S} /)$ & 143,927 & 148,670 & 160,001 & 172,857 & 187,172 \\
\hline
\end{tabular}


Luego de realizar el costo por cada servicio se consolida para generar el presupuesto de costos de servicio final (ver Tabla 152).

Tabla 152

Presupuesto de costo de producción de los servicios

\begin{tabular}{|c|c|c|c|c|c|}
\hline \multicolumn{6}{|c|}{ Costo de Servicios } \\
\hline Costo de Servicio Unitario & Año 1 & Año 2 & Año 3 & Año 4 & Año 5 \\
\hline Servicios & 26,217 & 29,240 & 32,611 & 36,371 & 40,565 \\
\hline Horas hombre & 11,169 & 12,457 & 13,894 & 15,496 & 17,282 \\
\hline \multicolumn{6}{|l|}{ Costos producción $(\mathrm{S} /)$} \\
\hline Material directo & 111,461 & 124,313 & 138,647 & 154,633 & 172,463 \\
\hline Mano de obra directa & 139,968 & 139,968 & 157,464 & 174,960 & 192,456 \\
\hline CIS & 58,196 & 59,095 & 60,098 & 61,217 & 62,295 \\
\hline Total costo producción $(\mathrm{S} /)$ & 309,625 & 323,376 & 356,209 & 390,811 & 427,215 \\
\hline Costo producción unitario promedio (S/) & 11.81 & 11.06 & 10.92 & 10.75 & 10.53 \\
\hline Costo total unitario (S/) & Año 1 & Año 2 & Año 3 & Año 4 & Año 4 \\
\hline Servicios & 26,217 & 29,240 & 32,611 & 36,371 & 40,565 \\
\hline \multicolumn{6}{|l|}{ Costos totales $(\mathrm{S} /)$} \\
\hline Material directo & 111,461 & 124,313 & 138,647 & 154,633 & 172,463 \\
\hline Mano de obra directa & 139,968 & 139,968 & 157,464 & 174,960 & 192,456 \\
\hline CIS & 58,196 & 59,095 & 60,098 & 61,217 & 62,295 \\
\hline Gastos operativos & 90,849 & 86,777 & 83,612 & 82,666 & 83,635 \\
\hline Total costos $(\mathrm{S} /)$ & 400,474 & 410,153 & 439,821 & 473,476 & 510,850 \\
\hline Costo total unitario promedio (S/) & 15.28 & 14.03 & 13.49 & 13.02 & 12.59 \\
\hline
\end{tabular}




\subsubsection{Presupuesto de compras.}

Para el presupuesto de compras se han considerado los costos fijos y variables (detallados en el capítulo cinco) por cada servicio en proporción a la demanda proyectada (ver Tabla 153).

Tabla 153

Presupuesto de compras anual

\begin{tabular}{lrrrrrr}
\hline Compras (S/) & Año 1 & \multicolumn{1}{c}{ Año 2 } & \multicolumn{1}{c}{ Año 3 } & \multicolumn{1}{c}{ Año 4 } & \multicolumn{1}{c}{ Año 5 } & \multicolumn{1}{c}{ Totales } \\
\hline Corte de Cabello & 12,224 & 13,633 & 15,205 & 16,958 & 18,914 & 76,933 \\
Planchado & 12,228 & 13,637 & 15,210 & 16,964 & 18,920 & 76,958 \\
Manicure & 36,594 & 40,814 & 45,520 & 50,769 & 56,622 & 230,319 \\
Pedicure & 50,415 & 56,228 & 62,712 & 69,943 & 78,008 & 317,306 \\
\hline Totales & 111,461 & 124,313 & 138,647 & 154,633 & 172,463 & 701,517 \\
\hline
\end{tabular}

\subsubsection{Presupuesto de costo de ventas.}

El costo de ventas se conforma por los costos directos que fueron considerados dentro de los costos de producción (de servicio) y presupuesto de compras. Se debe detallar los costos indirectos del servicio (ver Tabla 154).

Tabla 154

Equipamiento necesario para los servicios (utensilios)

\begin{tabular}{lrrrrr}
\hline Concepto & Año 1 & \multicolumn{1}{c}{ Año 2 } & \multicolumn{1}{c}{ Año 3 } & Año 4 & \multicolumn{1}{c}{ Año 5 } \\
\hline Otros suministros & 3,970 & 3,970 & 3,970 & 3,970 & 3,970 \\
\hline Material indirecto (sin IGV) & 3,970 & 3,970 & 3,970 & 3,970 & 3,970 \\
IGV & 715 & 715 & 715 & 715 & 715 \\
Material indirecto (con IGV) & 4,685 & 4,685 & 4,685 & 4,685 & 4,685 \\
\hline
\end{tabular}

Costos y gastos varios relacionados con los servicios que se brindarán, en este rubro resaltan el combustible y mantenimiento de los furgones (ver Tabla 155). 
Tabla 155

Gastos Varios

\begin{tabular}{lrrrr}
\hline \multicolumn{1}{c}{ Conceptos } & $\begin{array}{c}\text { Costo } \\
\text { mensual } \\
(\text { sin IGV) }\end{array}$ & $\begin{array}{c}\text { Costo } \\
\text { anual (sin } \\
\text { IGV) }\end{array}$ & $\begin{array}{c}\text { IGV } \\
\text { Costo } \\
\text { anual con } \\
\text { IGV }\end{array}$ \\
\hline Servicio de teléfono - internet & 130 & 1,560 & 281 & 1,841 \\
Servicios de mantenimiento móvil & 250 & 3,000 & 540 & 3,540 \\
Servicios de cochera & 300 & 3,600 & & 3,600 \\
Alquiler oficinas (incluye agua y luz) & 700 & 8,400 & & 8,400 \\
Útiles de oficina & 80 & 960 & 173 & 1,133 \\
Imprevistos & 200 & 2,400 & 432 & 2,832 \\
Combustible & 650 & 7,800 & 1,404 & 9,204 \\
\hline & 2,310 & 27,720 & 2,830 & 30,550
\end{tabular}

Adicionalmente, se consideran los costos por capacitación al personal, según la práctica del mercado, se deben capacitar por lo menos tres veces al año (ver Tabla 156).

Tabla 156

Gastos de capacitación

\begin{tabular}{lcccc}
\hline Conceptos & $\begin{array}{c}\text { Costo } \\
\text { trimestral } \\
(\text { sin IGV) }\end{array}$ & $\begin{array}{c}\text { Costo } \\
\text { anual (sin } \\
\text { IGV) }\end{array}$ & IGV & $\begin{array}{c}\text { Costo anual } \\
\text { (con IGV) }\end{array}$ \\
\hline Capacitación de personal & 5,085 & 20,339 & 3,661 & 24,000
\end{tabular}

\subsubsection{Presupuesto de gastos administrativos.}

Están compuestos por los sueldos administrativos, los gastos de oficina, alquileres, servicios, además la depreciación de equipos y mobiliario de la oficina (ver Tabla 157 y 158). 
Tabla 157

Planilla de personal administrativo

\begin{tabular}{lcccc}
\hline $\begin{array}{l}\text { Gastos } \\
\text { Administrativos } \\
\text { (Soles) }\end{array}$ & Cantidad & $\begin{array}{c}\text { Remuneración } \\
\text { Base }\end{array}$ & $\begin{array}{c}\text { Remuneración } \\
\text { Anual }\end{array}$ & $\begin{array}{c}\text { Total Gasto } \\
\text { Remuneración } \\
\text { Anual por } \\
\text { trabajador }\end{array}$ \\
\hline $\begin{array}{l}\text { Jefe de } \\
\text { Administración y }\end{array}$ & 1 & 2,500 & 30,000 & 36,450 \\
$\begin{array}{l}\text { Finanzas } \\
\text { Contador }\end{array}$ & 1 & 1,000 & 12,000 & 12,000 \\
\hline
\end{tabular}

Tabla 158

Otros gastos administrativos

\begin{tabular}{lr}
\hline \multicolumn{1}{c}{ Otros gastos operativos (Soles) } & $\begin{array}{c}\text { Costo anual } \\
(\text { sin IGV) }\end{array}$ \\
\hline Servicio de teléfono - internet & 1,092 \\
Alquiler oficinas (incluye agua y luz) & 8,400 \\
Útiles de oficina & 960 \\
Imprevistos & 1,200 \\
\hline Total otros gastos operativos (sin IGV) & 11,652 \\
IGV & 585 \\
Total otros gastos operativos (con IGV) & 12,237 \\
\hline
\end{tabular}

\subsubsection{Presupuesto de marketing y ventas.}

El presupuesto de marketing está conformado por las actividades de publicidad: uso de las redes sociales (Facebook, Twitter, Instagram), la elaboración y entrega de flyers para dar a conocer las rutas, los servicios e información adicional sobre cuidados de belleza a los clientes que se atenderá en la zona dos de Lima Metropolitana, como se detalla en Tabla 159. 
Tabla 159

\begin{tabular}{lrrrrr}
\hline \multicolumn{1}{c}{ Campañas } & \multicolumn{1}{c}{ Año 1 } & \multicolumn{1}{c}{ Año 2 } & Año 3 & Año 4 & Año 5 \\
\hline Redes Sociales & 10,000 & 15,000 & 5,000 & 5,000 & 5,000 \\
Banners & 5,000 & 5,000 & 4,000 & 2,700 & 2,700 \\
Volantes & 5,000 & 5,000 & 1,800 & 1,000 & 1,000 \\
\hline Total Gasto Anual & 20,000 & 15,000 & 10,800 & 8,700 & 8,700 \\
\hline
\end{tabular}

Gastos anuales en marketing

\subsubsection{Presupuesto de gastos financieros.}

Conformado por los costos del valor del dinero en el tiempo que genera el préstamo solicitado al BCP del S/ 80,000 (ver Tabla 160).

Tabla 160

Gastos financieros

\begin{tabular}{lcccccc}
\hline Descripción & Año 1 & Año 2 & Año 3 & Año 4 & Total \\
\hline Deuda & $\mathrm{S} / 80,000$ & $\mathrm{~S} / 64,210$ & $\mathrm{~S} / 45,894$ & $\mathrm{~S} / 24,647$ & & \\
Interés & $\mathrm{S} / 10,895$ & $\mathrm{~S} / 8,369$ & $\mathrm{~S} / 5,438$ & $\mathrm{~S} / 2,039$ & $\mathrm{~S} /$ & 26,742 \\
Amortización & $\mathrm{S} / 15,790$ & $\mathrm{~S} / 18,316$ & $\mathrm{~S} / 21,247$ & $\mathrm{~S} / 24,647$ & $\mathrm{~S} /$ & 80,000 \\
\hline Total Cuota & $\mathrm{S} / 26,685$ & $\mathrm{~S} / 26,685$ & $\mathrm{~S} / 26,685$ & $\mathrm{~S} / 26,685$ & $\mathrm{~S} / 106,742$ \\
\hline
\end{tabular}

\subsection{Presupuestos de Resultados}

\subsubsection{Estado de ganancias y pérdidas proyectado}

También llamado estado de resultados muestra un resumen de la situación financiera correspondiente a la operación de la empresa durante un periodo establecido, el periodo puede ser mensual para la administración, como anual o trimestral para los dueños. 
En este estado se comienza considerando los ingresos por ventas y se va reduciendo los gastos realizados: (a) ventas, (b) operativos, (c) administrativos, (d) financieros, (e) impuestos y (f) dividendos, se va obteniendo las utilidades (a) bruta, (b) operativa, (c) neta sin impuestos, (d) neta sin impuestos; para obtener finalmente las (e) ganancias disponibles (Gitman \& Zutter, 2012).

En la Tabla 161 y 162 se observa que la utilidad en todos los periodos se muestra positivo, a pesar de que el primer año se castigó la proyección de la demanda por ser un negocio nuevo, además se puede visualizar que los gastos operativos son mayores el primer año de operación, el potencial crecimiento de los negocios del sector belleza hace que siempre se obtenga utilidades. 
Tabla 161

Estado de ganancias y pérdidas proyectado (sin incluir gastos financieros)

\begin{tabular}{lccccc}
\hline \multicolumn{5}{c}{ Estado De Ganancias y Pérdidas (Sin Incluir Gastos Financieros) } \\
\hline Año 1 & Año 2 & Año 3 & Año 4 & Año 5 \\
\hline Ventas & 435,013 & 485,172 & 541,114 & 603,507 & 673,095 \\
Costo de ventas & $(309,625)$ & $(323,376)$ & $(356,209)$ & $(390,811)$ & $(427,215)$ \\
$\quad$ (-) Material directo & $(111,461)$ & $(124,313)$ & $(138,647)$ & $(154,633)$ & $(172,463)$ \\
$\quad$ (-) Mano de obra directa & $(139,968)$ & $(139,968)$ & $(157,464)$ & $(174,960)$ & $(192,456)$ \\
(-) CIS & $(58,196)$ & $(59,095)$ & $(60,098)$ & $(61,217)$ & $(62,295)$ \\
\hline Utilidad bruta & 125,388 & 161,796 & 184,905 & 212,697 & 245,880 \\
\hline Gastos operativos & $(90,849)$ & $(86,777)$ & $(83,612)$ & $(82,666)$ & $(83,635)$ \\
\hline Ebit o utilidad operativa & 34,539 & 75,019 & 101,294 & 130,031 & 162,245 \\
\hline (-) Impuestos & $(3,454)$ & $(10,284)$ & $(18,035)$ & $(26,513)$ & $(36,016)$ \\
\hline Utilidad neta & 31,085 & 64,735 & 83,258 & 103,518 & 126,229 \\
\hline
\end{tabular}

Tabla 162

Estado de ganancias y pérdidas proyectado (incluir gastos financieros)

\begin{tabular}{lccccc}
\hline \multicolumn{6}{c}{ Estado de Ganancias y Pérdidas (Incluir gastos financieros) } \\
\hline & Año 1 & Año 2 & Año 3 & Año 4 & Año 5 \\
\hline Ventas & 435,013 & 485,172 & 541,114 & 603,507 & 673,095 \\
Costo de ventas & $(309,625)$ & $(323,376)$ & $(356,209)$ & $(390,811)$ & $(427,215)$ \\
(-) Material directo & $(111,461)$ & $(124,313)$ & $(138,647)$ & $(154,633)$ & $(172,463)$ \\
$\quad$ (-) Mano de obra directa & $(139,968)$ & $(139,968)$ & $(157,464)$ & $(174,960)$ & $(192,456)$ \\
(-) CIS & $(58,196)$ & $(59,095)$ & $(60,098)$ & $(61,217)$ & $(62,295)$ \\
\hline Utilidad bruta & 125,388 & 161,796 & 184,905 & 212,697 & 245,880 \\
\hline Gastos operativos & $(90,849)$ & $(86,777)$ & $(83,612)$ & $(82,666)$ & $(83,635)$ \\
\hline Ebit o utilidad operativa & 34,539 & 75,019 & 101,294 & 130,031 & 162,245 \\
\hline Gastos financieros & $(10,895)$ & $(8,369)$ & $(5,438)$ & $(2,039)$ \\
\hline Utilidad antes impuestos & 23,644 & 66,650 & 95,855 & 127,992 & 162,245 \\
\hline Impuestos & $(2,364)$ & $(7,815)$ & $(16,431)$ & $(25,911)$ & $(36,016)$ \\
\hline Utilidad neta & 21,279 & 58,834 & 79,424 & 102,081 & 126,229 \\
\hline \multicolumn{5}{c}{} \\
\hline Escudo fiscal & 1,090 & 2,469 & 1,604 & 601 \\
\hline
\end{tabular}




\subsubsection{Balance proyectado.}

El balance general representa un resumen de la situación financiera en un momento específico. Hace una amortización entre los activos (corrientes y no corrientes) de la empresa contra el financiamiento (deuda) que puede resultar en deuda o patrimonio (aporte de dueños) (Gitman \& Zutter, 2012).

En la Tabla 163 se puede observar el crecimiento del activo corriente ocasionado en mayoría por la caja que se genera ya que todos los servicios que se brindarán serán al contado. 
Tabla 163

Balance proyectado

\begin{tabular}{|c|c|c|c|c|c|c|}
\hline \multicolumn{7}{|c|}{ Balance General Proyectado } \\
\hline & Año 0 & Año 1 & Año 2 & Año 3 & Año 4 & Año 5 \\
\hline \multicolumn{7}{|l|}{ Activo corriente } \\
\hline Caja & & 51,713 & 109,762 & 185,126 & 279,363 & 519,957 \\
\hline Capital de trabajo & 23,223 & 25,901 & 28,888 & 32,218 & 35,933 & \\
\hline Crédito fiscal (IGV) & 28,384 & 0 & 0 & & & \\
\hline Total activo corriente & 51,607 & 77,614 & 138,650 & 217,344 & 315,296 & 519,957 \\
\hline \multicolumn{7}{|l|}{ Activo no corriente } \\
\hline $\begin{array}{l}\text { Activo tangible } \\
\text { (-) Depreciación }\end{array}$ & 121,373 & 121,373 & 121,373 & 121,373 & 121,373 & \\
\hline acumulada & & 12,430 & 24,859 & 37,289 & 49,719 & \\
\hline $\begin{array}{l}\text { Activo intangible y pre- } \\
\text { operativos } \\
\text { (-) Amortización }\end{array}$ & 40,440 & 40,440 & 40,440 & 40,440 & 40,440 & 40,440 \\
\hline $\begin{array}{l}\text { (-) Amortizacion } \\
\text { acumulada }\end{array}$ & & 8,088 & 16,176 & 24,264 & 32,352 & 40,440 \\
\hline Total activo no corriente & 161,813 & 141,295 & 120,777 & 100,260 & 79,742 & 0 \\
\hline Total activos & 213,420 & 218,909 & 259,427 & 317,604 & 395,038 & 519,957 \\
\hline \multicolumn{7}{|l|}{ Pasivos } \\
\hline Deuda & 80,000 & 64,210 & 45,894 & 24,647 & 0 & \\
\hline Total pasivos & 80,000 & 64,210 & 45,894 & 24,647 & 0 & 0 \\
\hline \multicolumn{7}{|l|}{ Patrimonio } \\
\hline Capital & 133,420 & 133,420 & 133,420 & 133,420 & 133,420 & 133,420 \\
\hline Utilidad acumulada & & & 21,279 & 80,114 & 159,538 & 261,619 \\
\hline $\begin{array}{l}\text { Utilidad del ejercicio } \\
\text { Pérdida neta por activos }\end{array}$ & & 21,279 & 58,834 & 79,424 & 102,081 & 126,229 \\
\hline fijos & & & & & & $-1,310$ \\
\hline Total patrimonio & 133,420 & 154,699 & 213,534 & 292,958 & 395,038 & 519,957 \\
\hline Total pasivos y patrimonio & 213,420 & 218,909 & 259,427 & 317,604 & 395,038 & 519,957 \\
\hline
\end{tabular}

\subsubsection{Flujo de caja proyectado.}

El estado de flujo de caja muestra un resumen de todos los flujos de efectivo durante un periodo de tiempo determinado y hace una diferenciación entre los flujos operativos, de inversión y financieros de la empresa (Gitman \& Zutter, 2012) 


\section{Flujo de caja Operativo}

Es un cuadro consolidado que detalla los ingresos y egresos del plan de negocio en un periodo determinado y se muestran las variaciones.

En la Tabla 164 se puede verificar los ingresos por ventas versus todos los egresos, como se puede ver, el flujo operativo siempre es positivo en todos los años. Tabla 164

Flujo de caja operativo

\begin{tabular}{|c|c|c|c|c|c|c|}
\hline \multicolumn{7}{|c|}{ Flujo de Caja Operativo Proyectado } \\
\hline & $\begin{array}{c}\text { Año } \\
0\end{array}$ & Año 1 & Año 2 & Año 3 & Año 4 & Año 5 \\
\hline Ventas & & 513,315 & 572,503 & 638,515 & 712,139 & 794,252 \\
\hline (-) Material directo & & $(131,524)$ & $(146,689)$ & $(163,603)$ & $(182,467)$ & $(203,507)$ \\
\hline (-) Mano de obra directa & & $(139,968)$ & $(139,968)$ & $(157,464)$ & $(174,960)$ & $(192,456)$ \\
\hline$(-)$ CIS & & $(46,997)$ & $(48,059)$ & $(49,242)$ & $(50,562)$ & $(52,035)$ \\
\hline (-) Gastos operativos & & $(93,784)$ & $(88,979)$ & $(85,244)$ & $(84,128)$ & $(85,647)$ \\
\hline (-) Impuesto renta & & $(3,454)$ & $(10,284)$ & $(18,035)$ & $(26,513)$ & $(36,016)$ \\
\hline Flujo de caja operativo & & 97,588 & 138,524 & 164,926 & 193,508 & 224,592 \\
\hline
\end{tabular}

\section{Flujo de Capital}

El flujo de capital o de inversión considera las inversiones que el proyecto necesita en activos tangibles, activos intangibles y capital de trabajo para el año cero y para el capital de trabajo incremental de los siguientes años (ver Tabla 165).

Estos montos se restan del flujo operativo para obtener el flujo económico. 
Tabla 165

Flujo de capital

Flujo De Capital o Inversión

\begin{tabular}{|c|c|c|c|c|c|c|}
\hline & Año 0 & Año 1 & Año 2 & Año 3 & Año 4 & Año 5 \\
\hline (-) Inversión activos fijos & $(143,220)$ & & & & & \\
\hline $\begin{array}{l}\text { (-) Inversión activos } \\
\text { intangibles }\end{array}$ & $(8,687)$ & & & & & \\
\hline $\begin{array}{l}\text { (-) Inversión gastos pre- } \\
\text { operativos }\end{array}$ & $(38,290)$ & & & & & \\
\hline $\begin{array}{l}\text { (-) Inversión capital de } \\
\text { trabajo }\end{array}$ & $(23,223)$ & $(2,678)$ & $(2,987)$ & $(3,331)$ & $(3,715)$ & \\
\hline $\begin{array}{l}\text { (+) Valor de desecho activos } \\
\text { fijos }\end{array}$ & & & & & & 68,816 \\
\hline (+) Valor de recupero kw & & & & & & 35,933 \\
\hline Flujo de capital o inversión & $(213,420)$ & $(2,678)$ & $(2,987)$ & $(3,331)$ & $(3,715)$ & 104,749 \\
\hline $\begin{array}{l}\text { Pago IGV (liquidación de } \\
\text { IGV) }\end{array}$ & 0 & $(17,602)$ & $(53,272)$ & $(61,151)$ & $(69,473)$ & $(88,746)$ \\
\hline Flujo de caja económico & $(213,420)$ & 77,309 & 82,266 & 100,445 & 120,321 & 240,594 \\
\hline
\end{tabular}

\section{Flujo de Servicio de la deuda}

Considera todo el detalle del monto financiero del proyecto, amortización, interés y escudo fiscal.

Luego se calcula con el flujo de caja económico y como resultado se obtiene el flujo de caja financiero (ver Tabla 166). 
Tabla 166

Flujo de servicio de la deuda

\begin{tabular}{lcrrrrr}
\hline \multicolumn{7}{c}{ Flujo De Servicio de la Deuda } \\
& Año 0 & Año 1 & Año 2 & Año 3 & Año 4 & Año 5 \\
\hline Préstamo & 80,000 & & & & & \\
(-) Cuotas & & $(26,685)$ & $(26,685)$ & $(26,685)$ & $(26,685)$ & \\
(+) Escudo fiscal & & 1,090 & 2,469 & 1,604 & 601 & \\
\hline Flujo de servicio de la deuda & 80,000 & $(25,596)$ & $(24,217)$ & $(25,081)$ & $(26,084)$ & 0 \\
\hline
\end{tabular}

$\begin{array}{llllll}\text { Flujo de caja financiero } \quad(133,420) & 51,713 & 58,049 & 75,364 & 94,237 & 240,594\end{array}$

\section{Liquidación del IGV}

A continuación, se muestra la Liquidación de IGV en la Tabla 167.

Tabla 167

Liquidación del IGV

\section{Liquidación IGV}

\begin{tabular}{lrrrrrr}
\hline & Año 0 & Año 1 & \multicolumn{1}{c}{ Año 2 } & Año 3 & Año 4 & \multicolumn{1}{c}{ Año 5 } \\
\hline IGV ingresos & & 78,302 & 87,331 & 97,401 & 108,631 & 121,157 \\
IGV valor desecho activos fijos & & & & & & 10,414 \\
(-) IGV material directo & & $(20,063)$ & $(22,376)$ & $(24,956)$ & $(27,834)$ & $(31,043)$ \\
(-) IGVCIS & & $(6,620)$ & $(6,782)$ & $(6,962)$ & $(7,164)$ & $(7,388)$ \\
(-) IGV gastos operativos & & $(5,634)$ & $(4,901)$ & $(4,331)$ & $(4,161)$ & $(4,393)$ \\
(-) IGV inversión activos fijos & $(21,847)$ & & & & & \\
(-) IGV inversión activos & $(696)$ & & & & & \\
intangibles & $(5,841)$ & & & & & \\
(-) IGV gastos pre-operativos & $(28,384)$ & 45,985 & 53,272 & 61,151 & 69,473 & 88,746 \\
\hline IGV neto & 0 & $(17,602)$ & $(53,272)$ & $(61,151)$ & $(69,473)$ & $(88,746)$ \\
Pago de IGV (estado) & & & & & & \\
\hline
\end{tabular}




\section{Capítulo IX. Evaluación Económico Financiera}

\subsection{Evaluación Financiera}

Según Sapag (2011), la inversión es lo poco que se usa en el presente, y la cantidad o porción que se toma de los flujos de caja en el transcurrir del tiempo es el retorno que considera dicha recompensa. La utilización de los flujos considera una tasa de interés que remplaza la equivalencia de dos sumas de dinero en dos periodos diferentes.

El propósito de rebajar los flujos de caja futuros en el tiempo es saber si la inversión hecha por los accionistas da mayor beneficio que los usos de alternativa de la misma suma de dinero requerida por el proyecto. Las principales formas que usan el concepto de flujo de caja descontado son el valor actual neto (VAN), y la tasa interna de retorno (TIR),

\subsubsection{TIR.}

Según Sapag (2011), evalúa el proyecto en base a una sola tasa de rendimiento por periodo, donde la rentabiidad actual es identico a los abonos expresados en moneda actual. Es la tasa de interés que ofrece una inversión, porcentaje de beneficio o pérdida que tendrá una inversión para las cantidades que no se han retirado del proyecto. 
Siendo la fórmula:

$$
\sum_{t=1}^{n} \frac{B N_{t}}{(1+r)^{t}}-I_{0}=0
$$

$\mathrm{BNt}=$ Flujos de dinero en cada periodo

Io = Inversión en momento inicial

n = Números de periodos de tiempo

$\mathrm{r}=$ Tasa interna de retorno

Para el presente plan de negocio se halló la Tasa Interna de Retorno Económico (TIRE), la cual no considera servicio de deuda, siendo el financiamiento sólo capital propio y también se halló la Tasa Interna de Retorno Financiero (TIRF) el pago por servicio de deuda.

A continuación, en la Tabla 168 y 169 se muestra los resultados:

Tabla 168

Tasa interna de retorno económico (TIRE)

\begin{tabular}{lrccccc}
\hline & \multicolumn{1}{c}{ Año 0 } & Año 1 & Año 2 & Año 3 & Año 4 & Año 5 \\
\hline Flujo de caja económico & $(213,420)$ & 77,309 & 82,266 & 100,445 & 120,321 & 240,594 \\
\hline WACC $=$ & $14.27 \%$ & & & & & \\
TIR Económica $=$ & $39.18 \%$ & & & & &
\end{tabular}

Tabla 169

Tasa interna de retorno financiero (TIRF)

\begin{tabular}{lrccccc}
\hline & Año 0 & Año 1 & Año 2 & Año 3 & Año 4 & Año 5 \\
\hline Flujo de caja económico & $(133,420)$ & 51,713 & 58,049 & 75,364 & 94,237 & 240,594 \\
\hline COK $=$ & $16.06 \%$ & & & & & \\
TIR Financiera $=$ & $49.80 \%$ & & & & &
\end{tabular}


Como se observa la TIRE (39.18\%) es mayor al WACC (14.27\%) y además la TIRF (49.80\%) es mayor al COK (16.06\%), entonces se infiere que el proyecto es viable y se debe aceptar.

\subsubsection{VAN.}

Según Sapag (2011), los proyectos deben aceptarse si el valor actual neto (VAN) es igual o superior a cero, siendo la diferencia entre todos sus ingresos y egresos expresados en moneda actual.

La fórmula para la obtención es:

$$
V A N=\sum_{t=1}^{n} \frac{B N_{t}}{(1+i)^{t}}-I_{0}
$$

Tabla 170

Valor Actual Neto Económico (VANE)

\begin{tabular}{lrrrrrr}
\hline & Año 0 & Año 1 & Año 2 & Año 3 & Año 4 & Año 5 \\
\hline $\begin{array}{l}\text { Flujo de caja } \\
\text { económico }\end{array}$ & $(213,420)$ & 77,309 & 82,266 & 100,445 & 120,321 & 240,594 \\
\hline WACC $=$ & $14.27 \%$ & & & & & \\
VAN Económico $=$ & $178,623.71$ & & & & &
\end{tabular}

\begin{tabular}{lrrrrrr}
\hline & Año 0 & Año 1 & Año 2 & Año 3 & Año 4 & Año 5 \\
\hline $\begin{array}{l}\text { Flujo de caja } \\
\text { financiero }\end{array}$ & $(133,420)$ & 51,713 & 58,049 & 75,364 & 94,237 & 240,594 \\
\hline COK $=$ & $16.06 \%$ & & & & & \\
VAN Financiero $=$ & $168,623.13$ & & & & &
\end{tabular}


Tabla 171

Valor Actual Neto Financiero (VANF)

Como se observa en las Tablas 170 y 171 tanto el indicador VANE como el VANF son mayor a 0 , entonces se infiere que el proyecto es viable y se debe aceptar.

\subsubsection{ROE.}

Es el indicador financiero más preciso para valorar la rentabilidad del capital, mide el rendimiento que obtienen los accionistas de los fondos invertidos en la sociedad, trata de medir la capacidad que tiene la empresa de remunerar a sus accionistas.

$$
\text { ROE }=\text { Utilidad Neta / Patrimonio }
$$

Tabla 172

$R O E$

\begin{tabular}{lcccccc}
\hline \multicolumn{1}{c}{ Indicador } & Año 0 & Año 1 & Año 2 & Año 3 & Año 4 & Año 5 \\
\hline Utilidad Neta & & 21,279 & 58,834 & 79,424 & 102,081 & 126,229 \\
Patrimonio & 133,420 & 154,699 & 213,534 & 292,958 & 395,038 & 519,957 \\
\hline ROE & & $16 \%$ & $38 \%$ & $37 \%$ & $35 \%$ & $32 \%$
\end{tabular}

En la Tabla 172 se observa que el proyecto retorna una rentabilidad sobre el patrimonio entregado por parte de los accionistas.

\subsubsection{Ratios.}

Es la relación entre dos números, resultado de relacionar dos cuentas del balance o del estado de ganancias y pérdidas. 
Los ratios entregan la información para tomar decisiones certeras a los interesados en la organización y son de importancia para determinar algun rumbo que tomará la empresa durante un periodo de tiempo. 
Tabla 173

Ratios

\begin{tabular}{llccccc}
\hline \multirow{1}{*}{ Ratios } & \multicolumn{1}{c}{ Fórmula } & Año & Año & Año & Año & Año \\
& & 1 & 2 & 3 & 4 & 5 \\
\hline Margen Bruto & Utilidad Bruta / Ventas & $29 \%$ & $33 \%$ & $34 \%$ & $35 \%$ & $37 \%$ \\
\hline Margen Operativo & Utilidad Operativa / Ventas & $8 \%$ & $15 \%$ & $19 \%$ & $22 \%$ & $24 \%$ \\
\hline Margen Neto & Utilidad Neta / ventas & $5 \%$ & $12 \%$ & $15 \%$ & $17 \%$ & $19 \%$ \\
\hline ROA & Utilidad Neta / Activos & $10 \%$ & $27 \%$ & $31 \%$ & $32 \%$ & $32 \%$ \\
\hline Endeudamiento total & Pasivos / Patrimonio & $60 \%$ & $42 \%$ & $21 \%$ & $8 \%$ & $0 \%$ \\
\hline Grado de Propiedad & Patrimonio / Activos & $63 \%$ & $71 \%$ & $82 \%$ & $92 \%$ & $100 \%$ \\
\hline Cobertura de Gastos & Utilidad Operativa / Gastos & & & & & \\
Financieros & Financieros & 3.2 & 9.0 & 18.6 & 63.8 & \\
\hline
\end{tabular}

De la Tabla 173, el proyecto presenta los siguientes resultados:

a. Margen Bruto, mide el margen de beneficio de las ventas antes de los gastos operativo, el proyecto presenta un beneficio positivo año a año, alcanzando un margen de $37 \%$ para el quinto año.

b. Margen Operativo, mide el margen de beneficio de las ventas antes de los impuestos, el proyecto presenta un beneficio positivo año a año, alcanzando un margen de $24 \%$ para el quinto año.

c. Margen Neto, mide el margen de beneficio de las ventas después del pago de impuestos y gastos financieros, el proyecto presenta un beneficio positivo año a año, alcanzando un margen de $19 \%$ para el quinto año.

d. ROA, mide el grado de utilidad con respecto a los activos adquiridos por la empresa, el proyecto presenta un ROA positivo alcanzando un retorno de $32 \%$ para el quinto año, lo cual indicaría que el proyecto tiene una capacidad de generar $31 \%$ de renta con respecto a sus activos. 
e. Endeudamiento total, indica la relación entre los aportados por los acreedores y los recursos aportados por la empresa, se observa que el proyecto presenta un $60 \%$ de deuda con respecto al patrimonio al primer año, pero llega a $0 \%$ al quinto año.

f. Grado de propiedad, mide la relación del patrimonio con respecto a los activos de la empresa, el proyecto inicia con un $63 \%$ de propiedad de la empresa con respecto a los activos de esta y al quinto año la empresa tiene el 100\% de propiedad de los activos ya que al quinto año no tendría deuda con acreedores.

g. Cobertura de Gastos Financieros, indica el grado en que la empresa puede cubrir sus gastos financieros sin verse en riesgo de incumplir pagos de intereses a los acreedores, el proyecto muestra que el primer año la empresa tiene obtiene tres veces los gastos financieros y al cuarto año la empresa obtendría 63 veces los gastos financieros que ya serían mínimos debido a que el financiamiento con acreedores es a cuatro años.

\subsection{Análisis de Riesgo}

Es la inhabilitación que puede llegar a presentar una empresa o individuo por no cumplir con sus obligaciones financieras en la medida que se endeuda, permite determinar el grado de riesgo que posee la empresa. 


\subsubsection{Análisis de punto de equilibrio.}

El costo total comienza a partir de los costos fijos y corresponde a la sumatoria de los costos fijos mas los costos variables por unidad producida. El cruce de los ingresos con los costos totales es el punto de equilibrio.

A continuación, en la Tabla 174 se presenta el análisis de punto de equilibrio:

Tabla 174

Punto de equilibrio

\begin{tabular}{|c|c|c|c|c|c|}
\hline \multicolumn{6}{|c|}{ Punto de Equilibrio } \\
\hline & Año 1 & Año 2 & Año 3 & Año 4 & Año 5 \\
\hline Ventas (en soles) & 435,013 & 485,172 & 541,114 & 603,507 & 673,095 \\
\hline Ventas (en cantidades) & 26,217 & 29,240 & 32,611 & 36,371 & 40,565 \\
\hline Precio de venta promedio & 16.59 & 16.59 & 16.59 & 16.59 & 16.59 \\
\hline Material directo & 111,461 & 124,313 & 138,647 & 154,633 & 172,463 \\
\hline Mano de obra directa & 139,968 & 139,968 & 157,464 & 174,960 & 192,456 \\
\hline CIS variables & 7,800 & 8,699 & 9,702 & 10,821 & 12,069 \\
\hline Gastos operativos variables & 8,048 & 8,976 & 10,011 & 11,165 & 12,452 \\
\hline Costos variables & 267,277 & 281,956 & 315,824 & 351,579 & 389,440 \\
\hline Costo variable unitario promedio & 10.19 & 9.64 & 9.68 & 9.67 & 9.60 \\
\hline CIS fijos & 50,396 & 50,396 & 50,396 & 50,396 & 50,226 \\
\hline Gastos operativos fijos & 82,801 & 77,801 & 73,601 & 71,501 & 71,183 \\
\hline Costos fijos & 133,197 & 128,197 & 123,997 & 121,897 & 121,410 \\
\hline Punto de equilibrio (en cantidades) & 20,818 & 18,446 & 17,949 & 17,598 & 17,363 \\
\hline Punto de equilibrio (en soles) & 345,438 & 306,066 & 297,822 & 292,011 & 288,098 \\
\hline Punto de equilibrio (cantidades) & Año 1 & Año 2 & Año 3 & Año 4 & Año 5 \\
\hline Corte de cabello & 2,900 & 2,569 & 2,500 & 2,451 & 2,418 \\
\hline Planchado & 4,092 & 3,626 & 3,528 & 3,459 & 3,413 \\
\hline Manicure & 7,034 & 6,232 & 6,065 & 5,946 & 5,867 \\
\hline Pedicure & 6,792 & 6,018 & 5,856 & 5,742 & 5,665 \\
\hline Punto de equilibrio (en cantidades) & 20,818 & 18,446 & 17,949 & 17,598 & 17,363 \\
\hline
\end{tabular}


Según el análisis realizado líneas arriba para obtener ganancia el negocio debe cubrir 20,818 servicios el primer año y 17,363 el quinto año.

\subsubsection{Análisis de sensibilidad.}

Es interrrelacionar variables para saber cual es el efecto de las combinaciones posibles, considera la sensibilidad del VAN con respecto a los cambios en las variables fundamentales del proyecto como el rango probable de valores variables.

Para el plan de negocio se ejecuto el análisis de sensibilidad considerando como variables de entrada al precio de los servicios, la cantidad de servicios, costo del material directo y costo del personal, las variables variarán $10 \%$, se interpretará la sensibilidad a través del VANE y TIRE.

Tabla 175

Análisis de sensibilidad unidimensional para la variable precio

\begin{tabular}{|c|c|c|}
\hline \multicolumn{3}{|c|}{ Variable de Entrada - Precios (Soles) } \\
\hline & Normal & $\mathrm{VANE}=0$ \\
\hline Disminución máxima de precios & & $-14.15 \%$ \\
\hline Corte de Cabello & 15.00 & 12.88 \\
\hline Planchado & 30.00 & 25.75 \\
\hline Manicure & 15.00 & 12.88 \\
\hline Pedicure & 20.00 & 17.17 \\
\hline \multicolumn{3}{|c|}{ Variables de salida } \\
\hline VANE & 176,088 & 0 \\
\hline TIRE & $43.55 \%$ & $17.58 \%$ \\
\hline WACC & $17.55 \%$ & $17.58 \%$ \\
\hline
\end{tabular}

De la Tabla 175, se determina que los precios al público pueden disminuir en un máximo de $14.15 \%$, manteniendo sin variaciones las demás variables. 
Tabla 176

Análisis de sensibilidad unidimensional para la variable demanda

\begin{tabular}{|c|c|c|}
\hline \multicolumn{3}{|c|}{ Variable de entrada - Demanda } \\
\hline & Normal & $\mathrm{VANE}=0$ \\
\hline Disminución máxima de la demanda & & $-28.05 \%$ \\
\hline Corte de Cabello & 22,983 & 16,536 \\
\hline Planchado & 32,432 & 23,335 \\
\hline Manicure & 55,752 & 40,113 \\
\hline Pedicure & 53,837 & 38,735 \\
\hline \multicolumn{3}{|c|}{ Variables de salida } \\
\hline VANE & 176,088 & 0 \\
\hline TIRE & $43.55 \%$ & $17.64 \%$ \\
\hline WACC & $17.55 \%$ & $17.64 \%$ \\
\hline
\end{tabular}

De la tabla 176, se determina que la demanda puede dismunir hasta un máximo de $28.05 \%$, manteniendo sin variaciones las demás variables.

\section{Tabla 177}

Análisis de sensibilidad unidimensional para variable costos de material directo

\begin{tabular}{|c|c|c|}
\hline \multicolumn{3}{|c|}{ Variable de entrada - Costo Material Directo (Soles) } \\
\hline & Normal & $\mathrm{VANE}=0$ \\
\hline Aumento máximo del costo del material directo & & $54.19 \%$ \\
\hline Corte de Cabello & 3.95 & 6.09 \\
\hline Planchado & 2.80 & 4.32 \\
\hline Manicure & 4.87 & 7.52 \\
\hline Pedicure & 6.95 & 10.72 \\
\hline \multicolumn{3}{|c|}{ Variables de salida } \\
\hline VANE & 176,088 & 0 \\
\hline TIRE & $43.55 \%$ & $17.66 \%$ \\
\hline WACC & $17.55 \%$ & $17.66 \%$ \\
\hline
\end{tabular}

De la tabla 177, se determina que el costo de la materia prima puede aumentar hasta un máximo de $54.19 \%$, manteniendo sin variaciones las demás variables. 
Tabla 178

Análisis de sensibilidad unidimensional para variable costo de personal

\begin{tabular}{lrr}
\hline \multicolumn{4}{c}{ Variable de entrada - Costo de Personal (Soles) } \\
\hline \multicolumn{4}{c}{ Base } & \multicolumn{1}{c}{ Equilibrio } \\
\hline \multicolumn{4}{c}{ Cosmetóloga } & 1200.00 & $41.07 \%$ \\
Cosmetóloga Supervisora & 1800.00 & 2539.19 \\
Jefe de Administración y Finanzas & 2500.00 & 3526.66 \\
\hline \multicolumn{2}{c}{ Variables de salida } \\
\hline VANE & 176,088 & 0 \\
TIRE & $43.55 \%$ & $17.68 \%$ \\
WACC & $17.55 \%$ & $17.68 \%$
\end{tabular}

De la Tabla 178, se determina que el costo del personal puede aumentar hasta un máximo de $41.07 \%$, manteniendo sin variaciones las demás variables.

\subsubsection{Análisis de escenarios.}

Es usar herramientas para saber el grado de riesgo que representa la inversión, identificando las ventajas y desventajas económicas del proyecto de negocio. Se analizan posibles escenarios del proyecto de inversión como: a) pesimista, b) probable, c) optimista.

En el caso del plan de negocio del salón de belleza móvil se tienen las siguientes consideraciones para cada escenario (ver Tabla 179):

Escenario pesimista, reducción en $10 \%$ de los precios de venta y la demanda y un incremento del $10 \%$ en costos de personal y material directo del servicio.

Escenario Probable, todas las variables se mantienen a lo planificado dentro del proyecto. 
Escenario optimista, se presenta un incremento del $10 \%$ en los precios de venta y la demanda de los servicios

Tabla 179

Análisis de Escenarios

\begin{tabular}{|c|c|c|c|}
\hline \multicolumn{4}{|c|}{ Análisis de Escenarios } \\
\hline Escenario & Pesimista & Probable & Optimista \\
\hline \multicolumn{4}{|l|}{ Variables entrada } \\
\hline Precios & $-10 \%$ & $0 \%$ & $10 \%$ \\
\hline Demanda & $-10 \%$ & $0 \%$ & $10 \%$ \\
\hline Costos materia prima & $10 \%$ & $0 \%$ & $0 \%$ \\
\hline Costos personal & $10 \%$ & $0 \%$ & $0 \%$ \\
\hline \multicolumn{4}{|l|}{ Variables de salida } \\
\hline VANE & $-75,738$ & 186,512 & 386,574 \\
\hline TIRE & $6.30 \%$ & $46.04 \%$ & $74.95 \%$ \\
\hline WACC & $17.68 \%$ & $17.60 \%$ & $17.58 \%$ \\
\hline Escenarios probabilidades & $15 \%$ & $60 \%$ & $25 \%$ \\
\hline VANE esperado & 197,190 & & \\
\hline
\end{tabular}

En un escenario pesismista el proyecto no seria rentable, genera un VANE negativo.

En los escenarios normal y optimista el proyecto es rentable, genera VANE positivos, considerando las probabilidades de ocurrencia de cada escenario, el VANE esperado es positivo, por lo tanto es viable 


\section{Conclusiones y recomendaciones}

\section{Conclusiones}

- El mercado de la belleza en el Perú se encuentra en crecimiento debido a la importancia que las mujeres le dan a su presentación personal y corporal en los últimos tiempos de acuerdo a las nuevas tendencias, el crecimiento anual de este mercado es del $10 \%$.

- Las dificultades que tienen las mujeres para acceder a servicios belleza son: el tiempo de transporte, tiempo de espera y la poca cercanía a las personas que brindan el servicio.

- El mercado se dirigirá a las mujeres de 20 a 59 años, de NSE C, que viven en la Zona Dos de Lima Metropolitana.

- Los servicios que se brindarán son: corte S/15, planchado S/ 30, manicure S/ 15, pedicure S/ 20 (Incluye IGV).

- Los meses de mayor demanda son: enero $12 \%$, julio $12 \%$ y diciembre $17 \%$.

- Para iniciar el negocio contará con dos unidades móviles tipo furgón, con capacidad de dar tres estaciones de servicio que realizarán las atenciones a domicilio y seguirán rutas a centros de gran afluencia de público.

- Para iniciar el negocio se contará con seis colaboradores con estudios en cosmetología, así como estará basado en el régimen laboral especial, remuneraciones y gratificaciones de ley, las cuales se incrementarán de acuerdo a la demanda proyectada.

- El proyecto requiere una inversión total de S/ 211,507.

- El proyecto presenta una viabilidad financiera con una TIRF de $60 \%$ y un valor neto financiero de $S / 164,928$.

- $\quad$ El punto de equilibrio es de 18,852 servicios el primer año.

- $\quad$ El periodo de recupero de la inversión es de dos años y siete meses. 
- La variable más sensible del proyecto es el precio la cual no debe bajar más de $14.15 \%$

\section{Recomendaciones}

- Realizar el seguimiento al desempeño y estrategias de la competencia directa, así como las nuevas tendencias en el sector belleza.

- Mantener conectados a los clientes a través de las redes sociales informando las promociones, ubicación, rutas y recomendaciones sobre las nuevas tendencias de la belleza.

- Implementar estrategias para aumentar el consumo del servicio durante los meses de poca demanda (packs promocionales, ferias, etc.).

- Expandir el negocio en el futuro evaluando dirigirse a otros distritos con similares características de la segmentación actual.

- Capacitar al personal como máximo tres veces al año en las últimas tendencias de la belleza (ferias, congresos, etc.).

- Implementar convenios corporativos para brindar el servicio a empresas en fechas especiales (día de la madre, día de la mujer, aniversarios, galas de fin de año).

- Implementar el plan de negocio antes de finalizar el año 2017. 
Anexos 


\section{Anexo 1. Guías de entrevista a los expertos}

\section{$\underline{\text { Entrevista Expertos }}$}

\begin{tabular}{lc}
\hline Técnica empleada & Entrevista de Profundidad \\
\hline Localización & Lima Metropolitana, Zona Dos \\
\hline Técnica de reclutamiento & Preguntas abiertas y entrevista personal \\
\hline Supervisión & Supervisión continua \\
\hline Objetivo del estudio & $\begin{array}{l}\text { Obtener información de las tendencias y } \\
\text { consumo de los salones de belleza, } \\
\text { demanda, crecimiento del mercado, } \\
\text { innovaciones en este sector, ventajas y } \\
\text { desventajas de los negocios móviles. }\end{array}$ \\
& f) Aspectos generales sobre \\
& las tendencias del sector de \\
Temas estudiados & belleza \\
& g) Demanda del sector \\
& h) Diferenciación de los \\
& servicios de salones de belleza \\
& i) Información de los \\
& servicios o servicios móviles \\
& j) Investigación de otros \\
& negocios móviles \\
\hline Fecha de estudio & Del 12 de marzo de 2017 al 10 de marzo \\
& de 2017 \\
\hline Hora de inicio & $8: 00$ pm \\
\hline Duración & $30-50$ minutos \\
\hline
\end{tabular}

\section{Entrevista a la competencia:}

Ficha Técnica del Entrevistado

\begin{tabular}{ll}
\hline Nombre & \\
\hline Edad & \\
\hline Nacionalidad & \\
\hline Ocupación & $\begin{array}{l}\text { Aquí debe indicar, cuantos locales tiene, } \\
\text { cuantos colaboradores hay, tiempo de la } \\
\text { Profesión }\end{array}$ \\
\hline Distrito de residencia & \\
\hline Breve reseña & \\
\hline
\end{tabular}


1. Según estudios realizados el cuidado de la belleza e imagen personal ha crecido en los últimos años, según su experiencia ¿cuál cree usted que puedan ser la causa de este crecimiento?

2. ¿Cuáles son las tendencias actuales en los servicios de salones de belleza?

3. Para la implementación de un salón de belleza ¿Considera usted que es necesario tener experiencia en el rubro del negocio?

4. ¿Qué lo motivó a usted a ingresar al mundo de los salones de belleza?

5. Para iniciar un salón de belleza, ¿cuál consideraría usted qué es la mejor forma de inversión, capital propio o financiamiento? ¿Por qué?

6. Para la gestión de un salón de belleza, ¿cuáles son las áreas claves para iniciar este negocio? (RHH, Finanzas, Administración, Marketing)

7. Bajo su experiencia, ¿con qué frecuencia asiste una mujer a un salón de belleza?

8. ¿Cuáles considera usted que son los servicios más frecuentes en esta zona?

9. ¿Cuáles considera usted que son las temporadas más altas en los salones de belleza?

10. Bajo su experiencia ¿considera usted que en temporadas bajas se debe realizar algún plan de acción adicional?

11. ¿Considera usted que ha cambiado la relación entre cliente-estilista?

12. ¿Considera usted que debe ofrecer promociones o servicios especiales a sus clientes principales?

13. ¿Qué sugerencias para mejora son más frecuentes en los salones de belleza por parte de los clientes?

14. ¿Considera usted que su negocio se diferencia por lo precios en sus servicios? 
15. Con respecto a los productos que se emplean en los salones de belleza, ¿cuáles son las consideraciones que se debería tomar para brindar los servicios requeridos?

16. ¿Cuáles son las marcas de productos que prefieren los clientes actualmente para servicios de cabello? ¿Porqué?

17. ¿Cuáles son las marcas de productos que prefieren los clientes actualmente para servicios de manicure y pedicure? ¿Porqué?

18. ¿Cuáles son las marcas de productos que prefieren los clientes actualmente para servicios de maquillaje? ¿Porqué?

19. Según su experiencia, ¿qué consideraciones se debe tener en cuenta para la selección de proveedores?

20. Acorde a su experiencia, ¿qué modalidades de negociación de precio existe con proveedores para este rubro?

21. Bajo su experiencia ¿cuál considera usted qué es el mejor medio de publicidad: redes sociales, radio, tv u otro?

22. ¿Cada cuánto se capacita al personal sobre las nuevas tendencias de belleza? ¿Por qué?

23. Según su experiencia ¿considera usted que existe demanda en la solicitud de servicio a domicilio? ¿Por qué?

24. Sobre el servicio a domicilio, ¿qué ventajas y desventajas considera usted sobre este servicio? 
Entrevista al proveedor de productos de belleza:

\begin{tabular}{ll}
\hline \multicolumn{1}{c}{ Ficha Técnica del Entrevistado } \\
\hline Nombre \\
\hline Edad \\
\hline Nacionalidad \\
\hline Ocupación \\
\hline Profesión \\
\hline Distrito de residencia \\
\hline Breve reseña \\
\hline
\end{tabular}

1. Desde su experiencia, ¿cuáles considera usted son los mejores productos en este rubro (importados o nacionales) y cuáles no? ¿Por qué?

2. ¿Cuáles son las diferencias entre los productos que existen en el mercado?

3. ¿Cuáles son las marcas de productos con mayor demanda para servicios de cabello? ¿Porqué?

4. ¿Cuáles son las marcas de productos con mayor demanda para servicios de manicure y pedicure? ¿Porqué?

5. ¿Cuáles son las marcas de productos con mayor demanda para servicios de maquillaje? ¿Porqué?

6. Desde su experiencia, ¿qué servicios en el sector de belleza son las más frecuentes?

7. ¿Quiénes son sus potenciales clientes dentro del sector de belleza?

8. ¿Considera usted que en los salones de belleza de la zona dos de Lima Metropolitana tienen una alta demanda de sus productos de belleza? ¿Por qué? 
Entrevista a especialista del sector de belleza:

\begin{tabular}{ll}
\hline \multicolumn{1}{c}{ Ficha Técnica del Entrevistado } \\
\hline Nombre \\
\hline Edad \\
\hline Nacionalidad \\
\hline Ocupación \\
\hline Profesión \\
\hline Distrito de residencia \\
\hline Breve reseña \\
\hline
\end{tabular}

1. Según estudios realizados el cuidado de la belleza e imagen personal ha crecido en los últimos años, según su experiencia ¿cuál cree usted que puedan ser la causa de este crecimiento?

2. ¿Cuáles son las tendencias actuales en los servicios de salones de belleza?

3. Para la implementación de un salón de belleza ¿Considera usted que es necesario tener experiencia en el rubro del negocio?

4. Bajo su experiencia, ¿con qué frecuencia asiste una mujer a un salón de belleza?

5. ¿Cuáles considera usted que son los servicios más frecuentes?

6. ¿Cuáles considera usted que son las temporadas más altas en los salones de belleza?

7. ¿Considera usted que ha cambiado la relación entre cliente-estilista?

8. Bajo su criterio ¿Qué oportunidades de mejora tienen los salones de belleza (servicio, productos, infraestructura, equipos, etc.)?

9. Con respecto a los productos que se emplean en los salones de belleza, ¿cuáles son las consideraciones que se debería tomar para brindar los servicios requeridos?

10. ¿Cuáles son las marcas de productos que prefieren los clientes actualmente para servicios de cabello? ¿Porqué? 
11. ¿Cuáles son las marcas de productos que prefieren los clientes actualmente para servicios de manicure y pedicure? ¿Porqué?

12. ¿Cuáles son las marcas de productos que prefieren los clientes actualmente para servicios de maquillaje? ¿Porqué?

13. Según su experiencia, ¿qué consideraciones se debe tener en cuenta para la selección de proveedores?

14. Bajo su experiencia ¿cuál considera usted qué es el mejor medio de publicidad: redes sociales, radio, tv u otro?

15. ¿Cada cuánto tiempo se debe capacitar al personal sobre las nuevas tendencias de belleza? ¿Por qué?

16. Según su experiencia, ¿cómo se asegura la fidelidad de los clientes?

17. ¿Qué servicio adicional (valor agregado) considera usted es importante para los clientes?

18. ¿Cuál considera usted que es el factor más importante para los clientes en los servicios de salones de belleza?

19. ¿Considera usted que los paquetes integrales o promociones son más solicitados por los clientes? ¿Por qué?

20. Según su experiencia, ¿existe rotación de los profesionales de belleza? ¿Por qué?

21. Según su experiencia ¿considera usted que existe demanda en la solicitud de servicio a domicilio? ¿Por qué?

22. Sobre el servicio a domicilio, ¿qué ventajas y desventajas considera usted sobre este servicio?

23. ¿Ha visto o escuchado sobre salones de belleza móviles en Lima, Perú o en el extranjero? 
24. Considera usted que un salón de belleza móvil que ofrece los servicios de manicure, pedicure, cabello y maquillaje ¿pueda tener acogida? ¿Por qué? (se le muestra una foto de la propuesta de servicio)

25. Considera usted que, si un salón de belleza móvil está cerca del trabajo, domicilio o estacionado en la calle, ¿las clientas lo visitarían? ¿Por qué?

26. Considera usted que, si un salón de belleza móvil ofrece ir al domicilio de las clientas, ¿lo solicitarían? ¿Por qué?

27. Según su punto de vista, ¿en qué distritos de lima cree que este negocio pueda tener mayor acogida?

28. ¿Cuál cree que es la mejor forma que un salón de belleza móvil pueda hacerse conocida?

\section{Entrevista a especialista en negocios móviles (food trucks):}

Ficha Técnica del Entrevistado

\begin{tabular}{l}
\hline Nombre \\
\hline Edad \\
\hline Nacionalidad \\
\hline Ocupación \\
\hline Profesión \\
\hline Distrito de residencia \\
\hline Breve reseña \\
\hline
\end{tabular}

1. ¿Qué lo motivó iniciar su negocio móvil?

2. Para iniciar un negocio móvil, ¿cuál consideraría usted qué es la mejor forma de inversión, capital propio o financiamiento? ¿Por qué?

3. Bajo su experiencia ¿cuál cree usted que puedan ser la tendencia de los negocios móviles?

4. ¿Cuál considera usted que son los desafíos de este tipo de negocio? 
5. ¿Existe alguna regulación actualmente para este tipo de negocio?

6. ¿Existe proveedores especialistas en implementación de los móviles para este tipo de negocio?

7. ¿Qué consideraciones se debe tener en cuenta para el mantenimiento del móvil?

8. ¿En qué distritos se encuentra su mercado potencial? ¿Por qué?

9. ¿Qué consideraciones tiene usted para elegir la ubicación de su negocio?

10. ¿Cómo da a conocer a sus clientes la ubicación de su negocio?

11. ¿Ha visto o ha escuchado sobre otro tipo de negocios móviles?

12. ¿Ha visto o ha escuchado sobre salones de belleza móviles? En Lima, Perú o en el extranjero.

13. ¿Considera usted que un salón de belleza móvil que ofrece los servicios de manicure, pedicure, cabello y maquillaje ¿pueda tener acogida? ¿Por qué? (se le muestra una foto de la propuesta de servicio)

14. Según su punto de vista, ¿en qué distritos de Lima cree que este negocio pueda tener mayor acogida?

15. ¿Cuál cree que es la mejor forma que este tipo de negocio pueda hacerse conocida? 
Anexo 2. Guía de pautas para focus group

\begin{tabular}{ll}
\hline Técnica empleada & Cualitativa \\
\hline Localización & Lima Metropolitana \\
\hline Universo muestral & $\begin{array}{l}\text { Mujeres de } 20 \text { a } 59 \text { años, pertenecientes } \\
\text { al NSE C que residan en la Zona Dos de } \\
\text { Lima Metropolitana que por lo menos } \\
\text { vayan a un salón de belleza una vez al } \\
\text { mes. }\end{array}$ \\
\hline Técnica de Reclutamiento & Bola de nieve y conveniencia \\
\hline Objetivo del estudio & Recopilar información exploratoria \\
& acerca del sector de belleza y/o cuidado \\
personal para el desarrollo del nuevo & producto/servicio. \\
\hline Temas Estudiados & a) Recordación general \\
& b) Conocimientos generales \\
& sobre el sector belleza \\
& c) Perfil del servicio ideal \\
& d) Relevancia y punto de \\
& vista de los salones de belleza \\
& convencionales \\
\hline Fecha de Estudio & e) Frecuencia de consumo de \\
\hline Segmento de edad del público evaluado & los servicios que ofrece los \\
\hline Duración & salones de belleza \\
\hline & frupo de 20 a 59 años \\
\hline & suevo concepto de \\
\hline
\end{tabular}

\section{Introducción:}

Presentación de la persona a realizar el Focus Group.

\section{Presentación del moderador}

Hola, me llamo...

Tema: Agradecimiento de antemano por participar voluntariamente y darnos su tiempo para este estudio de mercado.

- Reglas de la dinámica: 
○ El tiempo se tomará aproximadamente es de 60 a 80 minutos, agradeceremos mucho su colaboración de antemano.

- Agradeceremos puedan poner en silencio todos sus celulares.

○ Todos deben de tener su sticker con su nombre cada uno, el que no tiene me avisa por favor.

\section{Rompehielos:}

Cuéntenme un poco de Uds.

1. ¿A qué se dedican Uds. trabajan, estudian, son independientes?

2. ¿Qué hacen en sus tiempos libres? ¿Qué es lo que más les gusta hacer?

3. ¿Qué significa para Uds. engreírse?

4. ¿Alguna de Uds. en sus tiempos libres se dedica a su cuidado personal de belleza?

5. ¿Alguna de Uds. van a salones de belleza, peluquerías o spa?

6. ¿Conocen las diferencias de salones de Belleza, Peluquerías y Spa?

\section{Hábitos de Uso:}

7. ¿Con que frecuencia suelen asistir a los salones de belleza?

8. ¿Qué días suelen visitar el salón de belleza? ¿Por alguna razón especial son esos días?

9. ¿En qué horarios acostumbran acudir? ¿Por qué? (verificar si varía días de semana versus fines de semana)

10. ¿Visitan Uds. un salón de belleza debido a que tiene mejores ofertas (precios), buen servicio, buena calidad de productos, los profesionales de belleza que tienen u otros?

11. ¿Qué tipo de servicios suelen usar en el salón de belleza? 
12. ¿Cuánto de su tiempo invierten en cada servicio que se realizan?

13. ¿Cuánto es lo que suelen gastar por cada uno de estos servicios?

14. ¿Hay alguna diferencia de precios entre un salón de belleza y otro? ¿Por qué?

15. ¿Creen Uds. que la zona o distritos donde viven influye: los precios, la atención y calidad de productos u otro? Especificar.

16. La distancia entre el salón de belleza y su domicilio o centro laboral ¿es lejana o cercana?

17. ¿Alguna de Uds. ha sacado cita por teléfono, web, WhatsApp u otro? ¿Por qué? Especificar.

18. ¿Cómo realizan sus pagos? ¿En Efectivo, Visa o MasterCard?

\section{Salones de Belleza}

19. ¿Qué salones de belleza son los que se le viene a la mente en este momento?

20. ¿De todos estos salones de belleza que han mencionado, cual consideran que es la mejor? ¿Porqué?

21. ¿Qué salón de belleza consideran Uds. que ha sabido mantenerse en el tiempo? ¿Por qué?

22. ¿Qué es lo que hace que Uds. Cambien entre un salón de belleza, a otro? Sondear fidelidad, diferencias en el tipo de servicio, precio u otros.

23. ¿Qué hace que un salón de belleza tenga éxito, de que depende?

24. ¿Qué ventajas o beneficios consideran Uds. que tiene los salones de bellezas?

25. ¿Qué errores consideran Uds. que comenten los salones de belleza? ¿qué es lo que hacen mal y no corrigen?

26. ¿Cuál sería su recomendación para no cometer este tipo de errores? 
27. La distancia entre donde se ubica su centro laboral o domicilio y el centro de belleza a donde van ¿suele influenciar en sus visitas? ¿si lo tuvieran cerca irían?

28. Si tuviéramos que describir al salón de belleza ideal, ¿cómo debería ser? Sondear infraestructura, servicios, precios, productos y marcas a la venta, calidad de servicio, presencia del personal, servicios anexos, ubicar u otros.

29. ¿Existen servicios adicionales que Uds. consideran debería ofrecer un salón de belleza?

\section{Negocios móviles (ejemplo Food Truck)}

30. ¿Ha escuchado algún servicio sobre-ruedas (móvil) como los food trucks?

31. ¿Qué opina de este tipo de negocios? ¿Por qué?

32. ¿Alguna vez han consumido en un food trucks que les ha parecido el servicio?

33. ¿Cuál cree que sería la ventaja de este servicio al ser móvil?

34. ¿Por qué irían a un servicio móvil food trucks?

35. ¿Qué es lo que más valoran de este servicio?

36. ¿En qué zona les gustaría que esté este servicio?

37. ¿Cómo les gustaría enterarse la ruta o servicio móvil de food trucks?

\section{Negocio: Salón de belleza móvil}

Estimadas: El siguiente plan de negocio es un salón de belleza móvil:

El nuevo negocio consiste en ofrecer servicios de un salón de belleza móvil a domicilio para mujeres de la ciudad de Lima Metropolitana. Una característica de este nuevo negocio es que el servicio se desarrollará dentro de un bus, camión o furgón, el cual tendrá todas las condiciones y ambientes que tiene un salón de belleza convencional, además dentro del mismo se tendrá un mini-bar, el cual los clientes podrán disfrutar de este servicio. El servicio no se va a 
desarrollar con el bus en movimiento puesto que esto representaría un riesgo para el cliente, el bus se estacionará en las afueras del domicilio del cliente en atención, luego ingresará al bus y se llevará a cabo el/los servicio(s) elegido(s). Los servicios que ofrecerá son los de cuidado de manos, pies y del cabello (se les entrega a las participantes una hoja con la foto del negocio, servicios y precios, del cual se va anexar al presente trabajo)

38. Si Uds. encuentran este nuevo salón de belleza móvil cerca de su trabajo o domicilio, ¿lo visitarían? ¿Por qué?

39. ¿Realizarían reservas o citas a domicilio para poder atender en este nuevo salón de belleza móvil? ¿Por qué? (considerando las características ya mencionadas arriba)

40. ¿Consideran Uds. que los servicios y precios que ofrecemos son los más accesibles para poder iniciar este nuevo salón de belleza móvil? ¿Por qué?

41. ¿Consideran Uds. que debemos incluir como servicio adicional recoger al cliente y mientras se le realizar el servicio lo podemos llegar a su destino final? ¿Por qué?

42. ¿Qué es lo que más le gustaría de este nuevo salón de belleza móvil?

43. ¿Qué es lo que menos le gustaría de este nuevo salón de belleza móvil?

44. ¿Consideran Uds. que este nuevo salón de belleza móvil, es idea de negocio innovadora? ¿Porqué?

\section{Publicidad y promociones}

45. ¿Cuál es la mejor forma que un salón de belleza se haga conocida y famosa, de renombre? 
46. Finalmente, pensando en salón de belleza ¿qué opina de estos nombres: Beauty Car, Fashion Express, Combi De La Belleza, Bella Bus, Belleza Móvil, Estética Móvil o alguna alternativa (Evaluar Individualmente)

¡Muchas gracias por su gentil participación!

(((Se les entrega un incentivo para los participantes $)))$ 


\section{Anexo 3. Cuestionario para encuesta}

\begin{tabular}{ll}
\hline Naturaleza Metodológica & Cuantitativa \\
\hline Técnica metodológica & Encuesta por Internet y personal \\
\hline Tipo de cuestionario & Estructurado de 21 preguntas cerradas \\
\hline Universo & $\begin{array}{l}\text { Mujeres de Lima Metropolitana, Zona } \\
\text { Dos, NSE C, con edad entre 20-59 años }\end{array}$ \\
\hline Ámbito geográfico & Zona Dos de Lima Metropolitana \\
\hline Elementos del muestreo & Mujeres que asisten al menos una vez al \\
& mes a salones de belleza \\
\hline Tipo de muestreo & Muestreo simple \\
\hline Tamaño muestral & 357 mujeres \\
\hline Nivel de confianza & $95 \%$ \\
\hline Margen de error & $5.00 \%$ (Universo $>100,000)$ \\
\hline Tipo de preguntas & Dicotómicas, de opción múltiple, con \\
& Escala de Likert, Escala \\
de importancia y Escala de intención de \\
compra
\end{tabular}

\section{Encuesta Plan de Negocio: Salón de Belleza Móvil}

Estamos realizando una investigación sobre la idea de negocio salón de belleza móvil, la obtención de estos datos es estrictamente académica, los mismos que serán utilizados para la sustentación de la tesis de Magister Ciencias Empresariales en la Universidad San Ignacio de Loyola, agradecemos su tiempo y apoyo.

Edad:

Sexo:

Distrito de residencia:

Email:

1. ¿Es un factor importante para usted asistir a un salón de belleza? 

a) $\mathrm{Si}$
b) No

2. ¿Asiste al menos una vez al mes al salón de belleza?
b) $\mathrm{Si}$
b) No

3. ¿Cuáles son las principales razones por las que asiste a un salón de belleza?

(Marque con una " $\mathrm{X}$ " su respuesta)

\begin{tabular}{l}
\hline Evento o reunión \\
\hline Cuidado personal \\
\hline Moda \\
\hline Espacio para relajarse \\
\hline
\end{tabular}

4. De acuerdo a la pregunta anterior, ¿con qué frecuencia solicita los siguientes servicios en el salón de belleza?

\begin{tabular}{|c|c|c|c|c|c|c|}
\hline Servicios & $\begin{array}{l}\text { No } \\
\text { solicito }\end{array}$ & $\begin{array}{c}\text { Una } \\
\text { vez por } \\
\text { semana }\end{array}$ & $\begin{array}{l}\text { Cada } \\
15 \\
\text { días }\end{array}$ & $\begin{array}{l}\text { Una vez } \\
\text { al mes }\end{array}$ & Trimestral & Ocasionalmente \\
\hline \multicolumn{7}{|l|}{ Corte } \\
\hline \multicolumn{7}{|l|}{ Peinado } \\
\hline \multicolumn{7}{|l|}{ Cepillado } \\
\hline \multicolumn{7}{|l|}{ Planchado } \\
\hline \multicolumn{7}{|l|}{ Alisado } \\
\hline \multicolumn{7}{|l|}{$\begin{array}{l}\text { Extensiones } \\
\text { de Cabello }\end{array}$} \\
\hline \multicolumn{7}{|l|}{$\begin{array}{l}\text { Coloración, } \\
\text { Mechas, } \\
\text { Tintes }\end{array}$} \\
\hline \multicolumn{7}{|l|}{$\begin{array}{l}\text { Tratamiento } \\
\text { capilares }\end{array}$} \\
\hline \multicolumn{7}{|l|}{ Maquillaje } \\
\hline \multicolumn{7}{|l|}{ Depilaciones } \\
\hline \multicolumn{7}{|l|}{$\begin{array}{l}\text { Pestañas } \\
\text { postizas }\end{array}$} \\
\hline Manicure & & & & & & \\
\hline
\end{tabular}


Uñas acrigel

Pedicure

5. De acuerdo a los servicios elegidos, ¿cuál es el tiempo promedio que permanece en el salón de belleza?
a. Hasta 1 hora
b. De 1 a 3 horas
c. De 3 a 6 horas
d. De 6 a más

6. De acuerdo a la pregunta anterior, ¿qué día de la semana y en qué horario suele visitar los salones de belleza? (Marque con una "X" su respuesta)

\begin{tabular}{|c|c|c|c|c|}
\hline Día de semana & $\begin{array}{c}\text { Mañana } \\
\text { 07:00 am 12:00 } \\
\text { pm }\end{array}$ & $\begin{array}{c}\text { Tarde } \\
\text { 12:00 pm a 6:00 pm }\end{array}$ & $\begin{array}{c}\text { Noche } \\
\text { 6:00 pm a } \\
\text { 10:00 pm }\end{array}$ & $\begin{array}{c}\text { No tengo } \\
\text { horario fijo }\end{array}$ \\
\hline \multicolumn{5}{|l|}{ Lunes } \\
\hline \multicolumn{5}{|l|}{ Martes } \\
\hline \multicolumn{5}{|l|}{ Miércoles } \\
\hline \multicolumn{5}{|l|}{ Jueves } \\
\hline \multicolumn{5}{|l|}{ Viernes } \\
\hline \multicolumn{5}{|l|}{ Sábado } \\
\hline Domingo & & & & \\
\hline
\end{tabular}

7. En qué mes del año acude más a los salones de belleza. (Marque con una "X" su respuesta). 


\begin{tabular}{lll}
\cline { 1 - 1 } Enero & & Julio \\
\hline Febrero & Agosto \\
\hline Marzo & Setiembre \\
\hline Abril & Octubre \\
\hline Mayo & Noviembre \\
\hline Junio & Diciembre \\
\hline
\end{tabular}

8. ¿Con quién(es) suele asistir a los salones de belleza?

\begin{tabular}{lll}
\hline Amiga(o) & Familiar & Sola \\
\hline
\end{tabular}

9. ¿A qué salones de belleza de la ciudad de Lima Metropolitana suele asistir?
a. Amarige
b. Tomiko
c. Specchi
d. Montalvo
e. Marco Aldany
f. Aramis
g. Soho Color
h. Scarlet
i. Peluquería Local
j. Servicio a domicilio

10. De acuerdo a la pregunta anterior ¿reserva usted una cita?
a. $\mathrm{Si}$
b. No 
11. Si su respuesta fue afirmativa ¿Por qué medios realiza su reserva?
a. Llamada telefónica
b. Página web
c. Email
d. WhatsApp
e. Facebook
f. Personalmente

12. ¿Qué tiempo suele tomarle a Ud. llegar al salón de belleza?
a. Hasta $30 \mathrm{~min}$
b. De $30 \mathrm{~min}$ a $60 \mathrm{~min}$
c. De 1 hora a más
d. $0 \min$ (servicio a domicilio)

13. ¿Cuánto tiempo está dispuesto a esperar para ser atendido?
a. Hasta $30 \mathrm{~min}$
b. De $30 \mathrm{~min}$ a $60 \mathrm{~min}$
c. De 1 hora a más 
14. ¿Cuál es el tiempo promedio de atención para los servicios?

\begin{tabular}{|c|c|c|c|c|c|}
\hline Servicios & $\begin{array}{l}\text { Hasta } \\
30 \mathrm{~min}\end{array}$ & $\begin{array}{c}30-60 \\
\min \end{array}$ & $\begin{array}{c}1-3 \\
\text { hrs }\end{array}$ & $\begin{array}{l}3 \text { hrs a } \\
\text { más }\end{array}$ & Desconozco \\
\hline \multicolumn{6}{|l|}{ Corte } \\
\hline \multicolumn{6}{|l|}{ Peinado } \\
\hline \multicolumn{6}{|l|}{ Cepillado } \\
\hline \multicolumn{6}{|l|}{ Planchado } \\
\hline \multicolumn{6}{|l|}{ Alisado } \\
\hline \multicolumn{6}{|l|}{$\begin{array}{l}\text { Extensiones de } \\
\text { Cabello }\end{array}$} \\
\hline \multicolumn{6}{|l|}{$\begin{array}{l}\text { Coloración, Mechas, } \\
\text { Tintes }\end{array}$} \\
\hline \multicolumn{6}{|l|}{ Tratamiento capilares } \\
\hline \multicolumn{6}{|l|}{ Maquillaje } \\
\hline \multicolumn{6}{|l|}{ Depilaciones } \\
\hline \multicolumn{6}{|l|}{ Pestañas postizas } \\
\hline \multicolumn{6}{|l|}{ Manicure } \\
\hline \multicolumn{6}{|l|}{ Uñas acrigel } \\
\hline Pedicure & & & & & \\
\hline
\end{tabular}

15. ¿Cuál es su promedio de gasto mensual en servicios de belleza?
a. Hasta S/ 50
b. $\mathrm{S} / 51$ a $\mathrm{S} / 100$
c. S/ 101 a S/ 200
d. S/ 201 a S/ 400
e. S/ 401 a más

f. No tengo un promedio ya que uso el servicio ocasionalmente 
16. De acuerdo a su importancia seleccione los atributos que usted considera para elegir un salón de belleza:

\begin{tabular}{|c|c|c|c|c|}
\hline & $\begin{array}{l}\text { Muy } \\
\text { importante }\end{array}$ & Importante & $\begin{array}{l}\text { Poco } \\
\text { importante }\end{array}$ & $\begin{array}{l}\text { Nada } \\
\text { importante }\end{array}$ \\
\hline \multicolumn{5}{|l|}{ Tiempo de espera } \\
\hline \multicolumn{5}{|l|}{ Precio } \\
\hline \multicolumn{5}{|l|}{$\begin{array}{l}\text { Calidad de } \\
\text { producto aplicados }\end{array}$} \\
\hline \multicolumn{5}{|l|}{ Infraestructura } \\
\hline \multicolumn{5}{|l|}{$\begin{array}{l}\text { Relación cliente- } \\
\text { estilista }\end{array}$} \\
\hline \multicolumn{5}{|l|}{$\begin{array}{l}\text { Calidad de servicio } \\
\text { realizado }\end{array}$} \\
\hline \multicolumn{5}{|l|}{ Personal calificado } \\
\hline \multicolumn{5}{|l|}{ Ubicación } \\
\hline \multicolumn{5}{|l|}{ Referencias } \\
\hline \multicolumn{5}{|l|}{ Limpieza } \\
\hline \multicolumn{5}{|l|}{$\begin{array}{l}\text { Flexibilidad de } \\
\text { horario }\end{array}$} \\
\hline Promociones & & & & \\
\hline
\end{tabular}

17. En su experiencia como cliente, ¿qué tipo de inconveniente ha tenido en los servicios de belleza?
a. Ninguno
b. Poca disponibilidad de horarios
c. Ausencia de especialista
d. Tiempo excesivo de espera
e. Atención deficiente del personal
f. Productos de baja calidad
g. Infraestructura inadecuada 
Estamos evaluando la posibilidad de colocar un negocio de salón de belleza móvil, donde los clientes serán atendidos en un ambiente acogedor, cómodo, con aire acondicionado y no perderán tiempo ya que iremos hasta el lugar donde solicite el servicio. Los servicios que se ofrecerá son: cuidado de manos y pies, del cabello, maquillaje y depilación.

Nota: El servicio no se realizará con el móvil en movimiento puesto que esto representaría un riesgo para el cliente.

18. De salir al mercado nuestro servicio, ¿Usted solicitaría una cita para un servicio de salón de belleza móvil?
a) Si estaría interesado
b) No estaría interesado

19. Si usted reserva una cita para los servicios ¿Estaría dispuesto a garantizar el estacionamiento para que la móvil se ubique y pueda prestar los servicios?
a) $\mathrm{Si}$
b) No

19 ¿Qué servicios solicitaría en el salón de belleza móvil?

\begin{tabular}{lc}
\hline \multicolumn{1}{c}{ Servicios } & $\begin{array}{c}\text { Marque con } \\
\text { una }(\mathrm{X})\end{array}$ \\
\hline Corte & \\
\hline Peinado & \\
\hline Cepillado & \\
\hline Planchado & \\
\hline Alisado & \\
\hline Extensiones de Cabello & \\
\hline Coloración, Mechas, Tintes & \\
\hline Tratamiento capilares \\
\hline Maquillaje \\
\hline Depilaciones \\
\hline Pestañas postizas \\
\hline Manicure
\end{tabular}


Uñas acrigel

Pedicure

20 Estaría dispuesto a pagar los siguientes precios para estos servicios:

\begin{tabular}{|c|c|c|c|c|}
\hline Servicios & Precio & $\mathrm{Si}$ & No & Tal vez \\
\hline Corte & $\mathrm{S} / 25$ & & & \\
\hline Peinado & S/ 40 & & & \\
\hline Cepillado & $S / 30$ & & & \\
\hline Planchado & $\mathrm{S} / 30$ & & & \\
\hline Alisado & $\mathrm{S} / 250$ & & & \\
\hline $\begin{array}{l}\text { Extensiones de } \\
\text { Cabello }\end{array}$ & $\begin{array}{l}\text { S/ } 2.5 \text { por } \\
\text { mecha }\end{array}$ & & & \\
\hline $\begin{array}{l}\text { Tratamiento } \\
\text { capilares }\end{array}$ & $\mathrm{S} / 60$ & & & \\
\hline Maquillaje & $S / 60$ & & & \\
\hline Depilación rostro & $S / 50$ & & & \\
\hline Pestañas postizas & $S / 20$ & & & \\
\hline Manicure & $S / 25$ & & & \\
\hline Uñas acrigel & $S / 75$ & & & \\
\hline Pedicure & S/ 35 & & & \\
\hline
\end{tabular}

21 ¿Cómo le gustaría a Ud. informarse sobre el salón de belleza móvil?

\section{TV/Cable}

Periódico, catálogo, encartes

Redes Sociales

Página web

Correo electrónico

Familiar, amigos

iiiiii Muchas gracias, por su tiempo, que tenga un buen díaiiiiiiiiiii 


\section{Anexo 4. Resultado de entrevista a la competencia}

Ficha técnica de entrevistado de la competencia

\begin{tabular}{ll}
\hline Nombre & Debra Reaño Trigozo \\
\hline Edad & 25 años \\
\hline Nacionalidad & Peruana \\
\hline Ocupación & Administradora \\
\hline Profesión & Administración \\
\hline Distrito de residencia & Los Olivos \\
\hline Breve reseña & Montalvo es una empresa que se dedica al \\
& rubro de la belleza, tiene 15 años en el \\
& mercado y cuenta con 59 salones a nivel \\
& nacional con excelentes profesionales y \\
& 06 sedes de Montalvo Instituto. \\
\hline
\end{tabular}

1. Según estudios realizados el cuidado de la belleza e imagen personal ha crecido en los últimos años, según su experiencia ¿cuál cree usted que puedan ser la causa de este crecimiento?

Se ha incrementado debido a que ahora no solo la mujer se preocupa por su imagen personal, sino también el hombre se está preocupando por su imagen y se ha vuelto una tendencia debido a que ambos quieren verse ver en sus trabajos, eventos o simplemente estar a la Moda. Este crecimiento también se debe a los factores climatológicos están dañando el cabello y la piel, por lo tanto, ambos van a realizarse sus tratamientos respectivos para poder cuidarse y protegerse.

2. ¿Cuáles son las tendencias actuales en los servicios de salones de belleza?

En el área de varonil, la tendencia son las Barberías.

Con respecto a las tendencias de mujeres, son los tratamientos de cabello (todo el año) y manicure y pedicure (en verano).

3. Para la implementación de un salón de belleza ¿Considera usted que es necesario tener experiencia en el rubro del negocio? 
Considero que no es necesario tener experiencia, ya que puedas ir adquiriendo poco a poco la experiencia, mientras visitas a otros salones, vez tendencias, con la Televisión y lo puedes ejecutar o aplicar en tu propio negocio.

4. ¿Qué lo motivó a usted a ingresar al mundo de los salones de belleza?

En principio nunca imaginé estar en este rubro de belleza, pero cuando ingresé a este mundo de belleza y vi tanta demanda de clientes en su cuidado personal, que tan solo ver a cliente ya te das cuenta de que necesita cada uno, que debe utilizar y que no.

5. Para iniciar un salón de belleza, ¿cuál consideraría usted qué es la mejor forma de inversión, capital propio o financiamiento? ¿Por qué?

La inversión es fuerte para poder iniciar un salón de belleza y dependerá de cada inversionista como lo desee manejar, pero si es capital propio es mejor ya que financiarlo con el banco se tiene que considerar los intereses de Banco.

Se tiene que invertir bien en cada de salón de belleza debido a que los clientes esperan tener un servicio desde la atención hasta la infraestructura.

6. Para la gestión de un salón de belleza, ¿cuáles son las áreas claves para iniciar este negocio? (RRHH, Finanzas, Administración, Marketing)

Se debe enfocar en el área de Marketing ya que de ahí nace el Estudio de Mercado y conocer los perfiles de cada cliente, en qué lugares se están realizando los servicios de cuidado personal.

7. Bajo su experiencia, ¿con qué frecuencia asiste una mujer a un salón de belleza? Las mujeres tienen mayor frecuencia de realizarse los servicios de belleza los fines de semana, ya que tienen fiestas, bodas, eventos especiales, entre otros. Del $100 \%$ de mujeres asiste el $80 \%$ de mujeres los fines de semana. 
8. ¿Cuáles considera usted que son los servicios más frecuentes en esta zona?

Tratamientos de Cabello: cortes, tintes, alisados, planchados, mechas Manicure y Pedicure.

9. ¿Cuáles considera usted que son las temporadas más altas en los salones de belleza?

Día de la Madre enmayo.

Mes de Campañas en Julio.

Mes de noviembre, diciembre que son las fiestas de promoción, fin de año

Enero y Febrero - Manicure y Pedicure

10. Bajo su experiencia ¿considera usted que en temporadas bajas se debe realizar algún plan de acción adicional?

Si todos los salones de belleza, lanzamos ofertas campañas en los meses más bajos para poder captar más clientes, pero en general se fideliza y eso nos mantiene en el mercado.

11. ¿Considera usted que ha cambiado la relación entre cliente-estilista?

Sí, porque nos enfocamos más en realizar solo el servicio y la atención del cliente de cómo se siente y hablar con ellos nos podemos estar olvidando. Se tiene que trabajar más con la conexión del estilista con el estilista para que se sientan en cómodas, relajadas ya que en sus trabajos o en donde se encuentren pueden estar estresadas.

12. ¿Considera usted que debe ofrecer promociones o servicios especiales a sus clientes principales? 
Claro que sí, los clientes que son fijos deben ser beneficiados de los que no son tan asiduos a un salón de belleza, para que se sientan como en casa y se le brinda un valor agregado a cada uno.

13. ¿Qué sugerencias para mejora son más frecuentes en los salones de belleza por parte de los clientes?

En un salón antiguo el cliente siempre te va a pedir mejorar en la infraestructura. Para hacer estos cambios se necesita una inversión elevada

14. ¿Considera usted que su negocio se diferencia por lo precios en sus servicios? No creo que por los precios sino por la Atención que Montalvo te brinda, desde que llega hasta que se va.

Nos diferenciamos por los productos, servicios que ofrecemos. Los precios son establecidos con relación a cada Estudio de Mercado que se realiza.

15. Con respecto a los productos que se emplean en los salones de belleza, ¿cuáles son las consideraciones que se debería tomar para brindar los servicios requeridos?

Nosotros utilizamos productos profesionales de calidad internacional como: Kerastase que puedo pocos salones lo tiene, en los tratamientos de cabello es muy bueno. También tenemos otros productos económicos como Revlon y Recamier son bueno de calidad, pero L'Oreal (Kerastase) tiene mejor acabado. Bueno también influye lo que el cliente puede pagar.

16. ¿Cuáles son las marcas de productos que prefieren los clientes actualmente para servicios de cabello? ¿Por qué?

La mayoría es Kerastase (L’Oreal) y de ahí Revlon como 2da alternativa. 
17. ¿Cuáles son las marcas de productos que prefieren los clientes actualmente para servicios de manicure y pedicure? ¿Por qué?

La mayoría de mujeres de esta zona utiliza todo OPI, ya que son productos muy buenos, de durabilidad, diferentes colores.

18. ¿Cuáles son las marcas de productos que prefieren los clientes actualmente para servicios de maquillaje? ¿Por qué?

Actualmente trabajamos con los productos de MAC, pero también tenemos otras marcas de prestigio internacional ya que solo una marca no se puede utilizar, es muy diversificado.

19. Según su experiencia, ¿qué consideraciones se debe tener en cuenta para la selección de proveedores?

Se trata de escoger proveedores de prestigio internacional ya que son lo que tiene mejor acabo y calidad.

20. Acorde a su experiencia, ¿qué modalidades de negociación de precio existe con proveedores para este rubro?

Por ser una cadena internacional de salones de belleza a nivel nacional e internacional tenemos un Departamento de Compras Internacionales que realiza las negociones respectivas y abastece a todos los locales. Estos proveedores nos brindan los mejores precios por volumen y también algunas marcas nos brindan capacitaciones de los mismos productos.

21. Bajo su experiencia ¿cuál considera usted qué es el mejor medio de publicidad: redes sociales, radio, tv u otro?

En la actualidad el mejor medio de publicidad son las redes sociales. 
Utilizamos modelos para nuestros flyers, pagina web. Montalvo no necesita salir en la Televisión como Soho Color con modelos reality ya que nosotros tenemos otro tipo de estrategia en el cual involucramos las experiencias vividas en Montalvo de cada cliente. 22. ¿Cada cuánto se capacita al personal sobre las nuevas tendencias de belleza? ¿Por qué?

Cuando se lanza las nuevas tendencias se capacita a todo el personal tanto estilista como administrativo ya que todos debemos estar involucrados.

23. Según su experiencia ¿considera usted que existe demanda en la solicitud de servicio a domicilio? ¿Por qué?

Si ya que algunas clientas trabajan y al momento de salir el tráfico está muy denso y no se puede llegar a la pactada con el Salón de Belleza, por lo tanto, si hemos pensado en poner un servicio a domicilio ya que es muy solicitado.

24. Sobre el servicio a domicilio, ¿qué ventajas y desventajas considera usted sobre este servicio?

Ventajas: Las clientas se siente en casa y es más privado y personalizado los servicios.

Desventajas: Pueda faltar algún producto o cambia de parecer y no lo tienes a la mano como en el Salón de Belleza. 
Anexo 5. Resultado de entrevista al distribuidor.

Ficha Técnica de entrevista al distribuidor de productos de belleza

\begin{tabular}{ll}
\hline Nombre & Yesenia Rosales \\
\hline Edad & 32 \\
\hline Nacionalidad & Peruana \\
\hline Ocupación & Vendedora \\
\hline Profesión & Ninguna \\
\hline Distrito de residencia & Ate \\
\hline Breve reseña & Vendedora de artículos de belleza y \\
& cuidado personal desde hace cinco años. \\
& Estudiante de Administración en la \\
& Universidad César Vallejo \\
\hline Negocio distribuidor & Cosméticos Alice's S.A.C. \\
& Jr. Cuzco Nro. 572 141 Cercado De \\
& Lima \\
& El Cercado - Lima \\
\hline
\end{tabular}

1. Desde su experiencia, ¿cuáles considera usted son los mejores productos en este rubro (importados o nacionales) y cuáles no? ¿Por qué?

Entrevistada: Mayormente aquí compran más productos internacionales. Porque los precios son más cómodos porque no pagamos impuestos, cualquier producto por ejemplo dicen ah este español o ah este es nacional (hace referencia a que es llamativo la procedencia).

Entrevistadora: ¿es más llamativo que sea internacional?

Entrevistada: Si.

Entrevistadora: Pero hay otros productos en el tema de pestañas, que sí eligen uno nacional.

Entrevistada: Sí (marca) Andrea, porque es tema de pestaña nada más.

2. ¿Cuáles consideras son las características que los compradores buscan en los diferentes productos que existen en el mercado? 
Entrevistada: Los precios, que sea un producto conocido en el mercado y que tenga publicidad (hace referencia a que sea productos conocidos).

3. ¿Cuáles son las marcas de productos con mayor demanda para servicios de cabello? ¿Por qué?

Entrevistada: Por ejemplo, la línea Kativa, pero hay dos tipos los profesionales y los comerciales.

Entrevistadora: ¿Para salones de belleza?

Entrevistada: Kativa, Alfa Pack, Salón In, L’Oreal Profesional.

4. ¿Cuáles son las marcas de productos con mayor demanda para servicios de manicure y pedicure? ¿Por qué?

Entrevistada: Los que más salen son (marca) Masglo, aunque ahora ya no están saliendo tanto porque se va a descontinuar (la marca) están los (productos marca) Maxibelt que también son colombianos.

Entrevistadora: O sea Masglo es el que más sale actualmente.

Entrevistada: Para salones con spa llevan Masglo más que OPI y otras marcas.

Entrevistadora: ¿más que OPI y Vogué?

Entrevistada: Vogué es para... dependiendo de qué tipo de salón (de belleza) tienes, si tienes un público que no te va a pagar mucho

Entrevistadora: Y entre OPI y Masglo cuál es el más caro.

Entrevistada: OPI, es el doble.

Entrevistadora: ¿Y por qué Masglo es uno de los más solicitados?

Entrevistada: Porque su precio es relativamente cómodo y la marca es buena.

Porque son de calidad y bastante conocidos. 
5. ¿Cuáles son las marcas de productos con mayor demanda para servicios de maquillaje? ¿Por qué?

Entrevistada: Maybelline, luego está Vogué y Premier

Porque son de calidad y bastante conocidos.

6. Desde su experiencia en venta de productos, ¿qué servicios en el sector de belleza son las más frecuentes?

Entrevistada: Todos, nosotros trabajamos con productos rotativos, también depende del cliente, nuestros clientes son mayoristas. Así que de todo un poco.

7. ¿Quiénes son sus potenciales clientes dentro del sector de belleza?

Entrevistada: Tenemos de todo, mayormente trabajamos con mayoristas, provincias, hay de todos los distritos aquí.

8. ¿Considera usted que en los salones de belleza de la zona dos de Lima Metropolitana tienen una alta demanda de sus productos de belleza? ¿Por qué?

Entrevistada: De todos, para nosotros más es provincias ya que somos mayoristas. 


\section{Anexo 6. Resultado de entrevista al experto de belleza en el sector de belleza}

Ficha Técnica de entrevistado de experto de sector de belleza

\begin{tabular}{ll}
\hline Nombre & Nancy Gonzales \\
\hline Edad & 34 años \\
\hline Nacionalidad & Peruana \\
\hline Ocupación & Administradora \\
\hline Profesión & Trabajadora Social \\
\hline Distrito de residencia & Jesús María \\
\hline Breve reseña & $\begin{array}{l}\text { Tiene una cadena de 50 salones en todo } \\
\text { el Perú y pronto en Colombia y EEUU, }\end{array}$ \\
\hline
\end{tabular}

1. Según estudios realizados el cuidado de la belleza e imagen personal ha crecido en los últimos años, según su experiencia ¿cuál cree usted que puedan ser la causa de este crecimiento?

Las mujeres y hombres en estos días quieren verse diferente, por ejemplo, las damas quieren las últimas tendencias de otros países, los hombres se preocupan más por su apariencia personal, eso da lugar a la demanda y por ende la oportunidad de abrir negocios los cuales son muy rentables debido a la inversión mínima que se hace en productos y servicio.

2. ¿Cuáles son las tendencias actuales en los servicios de salones de belleza?

Ahora las tendencias son lo que es estilismo: corte, tintes, las mechas, en esta última hay muchas tendencias como la balayage, el hombre, para damas los colores variados como rojo, azul, verde.

3. Para la implementación de un salón de belleza ¿Considera usted que es necesario tener experiencia en el rubro del negocio? 
No necesariamente, por ejemplo, Montalvo tiene estilismo, spa, maquillaje, manicure y pedicure, son franquicia y no todos son especialistas o expertos en belleza, sino que lo ven como un negocio por ser rentable,

4. Bajo su experiencia, ¿con qué frecuencia asiste una mujer a un salón de belleza?

Una mujer asiste a la semana dos o tres veces para diferentes servicios.

5. ¿Cuáles considera usted que son los servicios más frecuentes?

Son el cepillado, el planchado, la manicure, y maquillaje básico.

6. ¿Cuáles considera usted que son las temporadas más altas en los salones de belleza?

Las más altas son abril, mayo, junio, setiembre, octubre, noviembre y diciembre y la temporada baja son enero, febrero, marzo.

Esta información es de acuerdo a la evaluación hecha por el área de Montalvo cada mes en sus diferentes sedes.

7. ¿Considera usted que ha cambiado la relación entre cliente-estilista?

Si ahora se capacita a los colaboradores en atención al cliente basados en la política organizacional de la empresa y en la parte personal y comunicativa con psicólogos para poder saber escuchar al cliente.

Los clientes son atendidos como en forma personalizada debido a la empatía y buen servicio que tuvieron desde el primer día con el cliente.

8. Bajo su criterio ¿Qué oportunidades de mejora tienen los salones de belleza (servicio, productos, infraestructura, equipos, etc.)?

Lo primero para nosotros es el buen servicio, es lo que el cliente busca, la comodidad, comunicación, es por eso que acá en Montalvo el servicio es único para el 
cliente, además de la infraestructura, los equipos o instrumentos con los cuales se trabajan.

9. Con respecto a los productos que se emplean en los salones de belleza, ¿cuáles son las consideraciones que se debería tomar para brindar los servicios requeridos?

La calidad, nosotros trabajamos con marcas como: L'Oreal, Redken, Kérastase, Revlon, estas marcas están estandarizadas en todos los locales, el cliente pide estas marcas es por eso que en otros salones de belleza como Soho, Marco Aldany también usan estas marcas es algo que ya está estandarizado por la calidad del producto.

10. ¿Cuáles son las marcas de productos que prefieren los clientes actualmente para servicios de cabello? ¿Por qué?

La marca es Revlon, es muy buena y tiene buenos resultados con diferente tipo de cabello.

11. ¿Cuáles son las marcas de productos que prefieren los clientes actualmente para servicios de manicure y pedicure? ¿Por qué?

La marca es OPI, es la más conocida y el cliente lo pide.

12. ¿Cuáles son las marcas de productos que prefieren los clientes actualmente para servicios de maquillaje? ¿Por qué?

La marca es Mabe, permanece con buenas tonalidades y no daña la piel.

13. Según su experiencia, ¿qué consideraciones se debe tener en cuenta para la selección de proveedores?

El producto de calidad, la puntualidad para abastecer en forma mensual todos los requerimientos que solicita el cliente, todas las sedes trabajan con un solo proveedor. 
14. Bajo su experiencia ¿cuál considera usted qué es el mejor medio de publicidad: redes sociales, radio, tv u otro?

Definitivamente las redes sociales y la Televisión.

15. ¿Cada cuánto tiempo se debe capacitar al personal sobre las nuevas tendencias de belleza? ¿Por qué?

Se debe capacitar cada tres meses en las nuevas tendencias, además hay clases o talleres que las mismas marcas dan para salones de belleza exclusivos para todos sus estilistas.

16. Según su experiencia, ¿cómo se asegura la fidelidad de los clientes?

La fidelidad del cliente empieza desde el trato que se le da, como por ejemplo desde que ingresa al salón deja sus datos entran a la base de datos, es atendido por el estilista y entabla una comunicación continua con el cliente hasta que salga. Esto nos sirve para después enviarle promociones o paquetes a sus correos o celulares mostrándole que es importante para nosotros el que se vea bien y nosotros le damos as facilidades con estas promociones.

17. ¿Qué servicio adicional (valor agregado) considera usted es importante para los clientes?

Las promociones que se le da en el momento del servicio se les obsequian servicios como una cantidad de horas de masajes, manicure y pedicure o depilación. 18. ¿Cuál considera usted que es el factor más importante para los clientes en los servicios de salones de belleza?

El servicio y el trato que se le da al cliente desde recepción hasta el momento que se retira. 
19. ¿Considera usted que los paquetes integrales o promociones son más solicitados por los clientes? ¿Por qué?

Si por su puesto, debido a que en cada paquete entra de tres a cuatro servicios, haciéndolo mucho más barato para el cliente con un 30\% de descuento.

20. Según su experiencia, ¿existe rotación de los profesionales de belleza? ¿Por qué? Muy poco debido a la fidelidad del cliente que normalmente es de la zona, es por eso que los clientes buscan a su estilista y si no estuvieran lo buscan a donde se haya ido, es por eso que se busca la continuidad en mantener a nuestros colaboradores para no causar incomodidad al cliente.

21. Según su experiencia ¿considera usted que existe demanda en la solicitud de servicio a domicilio? ¿Por qué?

No, solo acá tenemos el servicio a domicilio para novias y personas que están delicadas de salud en etapa fina y por pedido de la familia se realiza el servicio. Pero es muy poco.

22. Sobre el servicio a domicilio, ¿qué ventajas y desventajas considera usted sobre este servicio?

Comodidad para el cliente por no salir de casa, pero para el estilista se le dificulta el no poder tener todas las facilidades de infraestructura y equipos para el servicio.

23. ¿Ha visto o escuchado sobre salones de belleza móviles en Lima, Perú o en el extranjero?

No he escuchado.

24. Considera usted que un salón de belleza móvil que ofrece los servicios de manicure, pedicure, cabello y maquillaje ¿pueda tener acogida? 
¿Por qué? (se le muestra una foto de la propuesta de servicio)

De repente sí, pero tendría que tener mucho cuidado con tener todas las herramientas para dar un buen servicio. Es por eso que el estilista no es de su agrado el salir del salón por no tener las comodidades para dar un buen servicio, y a la vez estaría siempre en duda el servicio de calidad que podría dar.

25. Considera usted que, si un salón de belleza móvil está cerca del trabajo, domicilio o estacionado en la calle, ¿las clientas lo visitarían? ¿Por qué?

Yo creo que sí, porque las clientas siempre son curiosas, van siempre a ver la calidad del servicio, el trato con el cliente y que productos utiliza.

26. Considera usted que, si un salón de belleza móvil ofrece ir al domicilio de las clientas, ¿lo solicitarían? ¿Por qué?

Si, obvio que sí, es la comodidad del cliente, el tener todo a la mano.

27. Según su punto de vista, ¿en qué distritos de Lima cree que este negocio pueda tener mayor acogida?

En los distritos de San Borja, San Isidro, porque acá los clientes son diferentes, varias veces han solicitado el servicio. Hay bastante diferencia en los niveles socio económico, esto influye bastante en las costumbres o solicitudes en el servicio.

28. ¿Cuál cree que es la mejor forma que un salón de belleza móvil pueda hacerse conocida?

Por medio de la publicidad por el Facebook, la televisión en ciertas horas, y otros medios. 


\section{Anexo 7. Resultado de entrevista al especialista en negocios móviles (Food Trucks)}

Ficha técnica de entrevista a especialista en negocio móvil

\begin{tabular}{ll}
\hline Nombre & Ismael Matos \\
\hline Edad & 35 años \\
\hline Nacionalidad & Peruano \\
\hline Ocupación & Administración hotelera \\
\hline Profesión & $\begin{array}{l}\text { Gerente general food trucks } \\
\text { "EL GRINGO" }\end{array}$ \\
\hline Distrito de residencia & Jesús María \\
\hline Breve reseña & Oportunidad de negocio en Lima, Restaurante \\
& móvil con todas las reglamentaciones vigentes \\
& (comprobante de pago salubridad, defensa \\
& civil, implementaciones, con un buen \\
& producto y buen servicio), tres años en el \\
& mercado, con cuatro carros food truck de el \\
& GRINGO incluso se incrementa hoy en día \\
& como crecimiento con Octavio pollos a la \\
& brasa, \\
\hline
\end{tabular}

1. ¿Qué lo motivó iniciar su negocio móvil?

La oferta no atendida de comida ambulante o de ticket promedio bajo, pero de calidad, existía el street food (comida mala en calidad y salubridad), vimos oportunidad en el mercado y nos pareció una idea súper original y emprendedora.

2. Para iniciar un negocio móvil, ¿cuál consideraría usted qué es la mejor forma de inversión, capital propio o financiamiento? ¿Por qué?

Nosotros empezamos con capital propio, con el tiempo el financiamiento siempre te ayuda en lo económico si tienes la facilidad de cumplir a fin de mes dependiendo las condiciones que tengas, por ejemplo, después de la primera unidad con una buena organización todas han sido con financiamiento del banco.

3. Bajo su experiencia ¿cuál cree usted que puedan ser la tendencia de los negocios móviles? 
La tendencia está creciendo, pudiendo estar en el pico, en estos momentos el mercado se ha saturado de trucks, por no haber muchas locaciones, existen muchos camiones de comida que no han desarrollado bien su marca y han ido desapareciendo, vendiendo sus camiones y a la vez están entrando nuevos trucks, el mercado se está abriendo con mayores oportunidades centro comerciales, mayores espacios públicos. 4. ¿Cuál considera usted que son los desafíos de este tipo de negocio?

Dos desafíos claros: Encontrar una buena ubicación, y una buena cartera de clientes que mantenga durante el año con eventos. Otra es saber trabajar un buen producto y un buen servicio en el espacio reducido que te da el food trucks, 5. ¿Existe alguna regulación actualmente para este tipo de negocio?

Todavía no, no hay ninguna regulación, lo más parecidos o con las que nos acomodamos es con la de los ambulantes, lo que le exigen carnet de sanidad, no hay ningún pago solo existe un convenio con la municipalidad de parte de la asociación de food trucks. En las calles era solo un permiso verbal como negocio emprendedor.

6. ¿Existe proveedores especialistas en implementación de los móviles para este tipo de negocio?

Si existe, yo mismo llego a ser un proveedor, dando asesorías para implementar, y los productos que pongo son de calidad, no existe ninguna regulación para el ordenamiento de lo interior en un food trucks., pero en el mercado si hay varios proveedores.

7. ¿Qué consideraciones se debe tener en cuenta para el mantenimiento del móvil? 
Los mismos mantenimientos de un restaurante que sería todo de acuerdo al rubro y en adición la parte mecánica como todo camión.

8. ¿En qué distritos se encuentra su mercado potencial? ¿Por qué?

Nosotros tenemos el mercado $\mathrm{AB}$, cuando empezamos hace tres años no sabíamos a quién nos dirigíamos, pero en el camino por el tipo de eventos que íbamos y por la aceptación del producto. Esto es debido a que tienen mayor conocimiento y aprecian un producto de calidad que en otro segmento. Destinan su dinero a un producto de calidad. Es por eso que ahora todas las estrategias que tenemos van orientadas a ese sector.

9. ¿Qué consideraciones tiene usted para elegir la ubicación de su negocio?

El inicio fue bastante duro, íbamos probando en varios distritos teniendo problemas con serenazgo, éramos informales, las ventas no eran buenas y el horario era de madrugada, pero a la par nos empezaron a salir eventos como en La Chutana y era otro tipo de segmento donde apuntar y nos fue muy bien y empezamos a posicionarnos en ese mercado. Teníamos eventos el fin de semana y durante la semana estaba parado, así que buscamos donde había mayor gente o afluencia y nos ubicamos en la avenida Arequipa haciéndonos conocidos y así empezamos.

10. ¿Cómo da a conocer a sus clientes la ubicación de su negocio?

Por Facebook.

11. ¿Ha visto o ha escuchado sobre otro tipo negocios móviles?

Escuche un fashion trucks, pero nunca lo he visto creo que era alumnos de USIL 12. ¿Ha visto o ha escuchado sobre salones de belleza móviles? En Lima, Perú o en el extranjero.

Solo para mascotas, pero para personas no he visto. 
13. ¿Considera usted que un salón de belleza móvil que ofrece los servicios de manicure, pedicure, cabello y maquillaje ¿pueda tener acogida? ¿Por qué? (se le muestra una foto de la propuesta de servicio)

Me parece que sí, yo siempre les digo a los que preguntan sobre incursionar en el negocio móvil, el negocio no es que tengan ruedas si no que el negocio es un buen producto y un buen servicio al igual que un local fijo. Es una ventaja el tener ruedas porque puedo movilizarlo, pero con un buen producto y servicio. Además, con el salón de belleza por ser los primeros e innovadores se arriesga y pueden tener una mayor ventaja para el negocio por ser novedad para el mercado.

14. Según su punto de vista, ¿en qué distritos de Lima cree que este negocio pueda tener mayor acogida?

Yo creo que en el sector $\mathrm{C}$ y hasta al A, pero tienen que ir viendo, debería estar orientado el B, C y en eventos específicos.

15. ¿Cuál cree que es la mejor forma que este tipo de negocio pueda hacerse conocida?

Yo creo que las campañas de intriga, manejar redes y mostrar promociones, estar en eventos puntuales de la belleza, ferias para poder hacerse conocido y además una buena estrategia de precios. 


\section{Anexo 8. Resultado de Focus Group No. 1}

Rompehielos:

Bueno, ahora cuéntenme un poco de ustedes

1. ¿A qué se dedican? Uds. trabajan, estudian, son independientes?

Elizabeth (40 años), Tania (25 años), Esther (55 años) y Haydee (57 años) trabajan

Ángela (20 años) y Fabiana (20 años), solo estudian

2. ¿Qué hacen en sus tiempos libres? ¿Qué es lo que más les gusta hacer?

Tania, le gusta nadar, salir a pasear ir al cine, esta con amigos

Fabiana, dormir, ver películas

Ángela, en vacaciones escuchar música, le gusta los esmaltes, le gusta pintarse las uñas.

Haydee, manualidades, cosas de casa y creatividad

Esther, ver TV, ver películas, ya que todo el día trabaja

Elizabeth, ver TV, revisar cosas por internet, etc.

3. ¿Qué significa para Uds. engreírse?

Pintarme el cabello, que me hagan masajes

Hacer lo que me dé la gana ya que tengo mucho trabajo.

Salir a comprar, centro comercial, comprar zapatos, ir a lacearme, pintarme, etc.

Es hacer lo que tú quieras, pero normalmente no lo haces, como indican todas, es ir a lacearse, hacerse las uñas, etc.

Salir a comer, comprar ropa

Comprar maquillaje

4. Alguna de Uds. en sus tiempos libres se dedica a su cuidado personal de belleza?

Si todas. 
Usualmente prefiero hacerme en algún sitio.

5. ¿Alguna de ustedes va a salones de belleza, peluquerías o spa?

Si todas.

6. ¿Conocen las diferencias de salones de belleza, peluquerías y spa?

Salones de Belleza, Depilación, maquillaje, tinte, peinados, laceados, manicure, pedicure

Peluquería, corte, teñir cabello, todo lo que es tratamientos de cabello.

Spa, masajes, las piedras, relajarse

Hábitos de Uso:

7. ¿Con que frecuencia suelen asistir a los salones de belleza?

Cuando hay algo importante, una vez al mes aprox.

Seguido por las canas, dos veces al mes

Dos o tres veces al mes

8. ¿Qué días suelen visitar el salón de belleza? ¿Por alguna razón especial son esos días?

Todas van ir fines de semana, y van temprano, porque se llena rápido, no les gusta esperar. Al que van no suelen esperar mucho.

9. ¿En qué horarios acostumbran acudir? ¿Por qué? (verificar si varía días de semana versus fines de semana)

Van temprano no tienen un horario fijo ya que se llena los fines de semana

10. ¿Visitan Uds. un salón de belleza debido a que tiene mejores ofertas (precios), buen servicio, buena calidad de productos, los profesionales de belleza que tienen, entre otros?

Que sean profesionales, el tiempo es importante y que te lo haga bien.

Depende mucho los productos que estén utilizando.

11. ¿Qué tipo de servicios suelen usar en el salón de belleza? 
Maquillajes, laceado, manicure, pedicure, tinte, cepillado, depilación, corte de cabello

12. ¿Cuánto de su tiempo invierten en cada servicio que se realizan?

Se puede estar de dos a tres horas en promedio

13. ¿Cuánto es lo que suelen gastar por cada uno de estos servicios?

Aproximadamente depende de qué servicio, pero un aprox. en S/ 100 a S/200

Cuando es un laceado te incrementa. Una gasta $\mathrm{S} / 450$

14. ¿Hay alguna diferencia de precios entre un salón de belleza y otro? ¿Por qué?

Si hay lugares que te lo hacen más cómodo, pero como tengo un tratamiento continuo tengo que buscar un local donde el producto sea de buena calidad, ya que mi cabello es muy sensible, y los productos son importantes.

He llegado a ir a este salón después de varios salones, es un precio promedio que siente más tranquila.

15. ¿Creen Uds. que la zona o distritos donde viven influye: los precios, la atención y calidad de productos u otro? Especificar.

Los precios influyen por la zona.

16. La distancia entre el salón de belleza y su domicilio o centro laboral ¿es lejana o cercana?

Es relativamente cerca. Muy cerca

Me incomoda la distancia, tomar un carro hasta ir al salón de belleza

Por el tráfico en vez de irte a relajar, en el trascurso, llegas un poco estresada

17. ¿Alguna de Uds. ha sacado cita por teléfono, web, WhatsApp u otro? ¿Por qué?

Casi siempre. Hay varios estilistas y quiero que me atiende cuando este libre, para poder programarse. En el día se tiene que ver y aprovecharse en cuidado personal.

18. ¿Cómo realizan sus pagos? ¿En efectivo, Visa o MasterCard? 
Tarjeta de crédito o débito, Efectivo

Salones de Belleza

19. ¿Qué salones de belleza son los que se le viene a la mente en este momento?

Todas mencionaron Montalvo. Solo una menciono Aramis.

20. ¿De todos estos salones de belleza que han mencionado, cual consideran que es la mejor? ¿Por qué?

Montalvo está ubicado en lugares estratégicos donde hay buena afluencia de gente. Uno está en el centro comercial Mega Plaza, que usualmente todo el mundo va a Mega Plaza, si bien cuando pasas no entrar, pero regresas porque sabes que está ahí. Después hay otro que está ubicado en una zona no muy comercial, pero sus instalaciones son más grandes, son muy cómodas, y el ambiente se presta para relajarse. Dentro de los Olivos y San Martin de Porres, son cuatro establecimientos, pero todos diferentes clientes. Hay uno en Mega Plaza, otro en Palmeras, en Antúnez de Mayolo hay dos locales, hay uno entre tomas valles y universitaria, eso quiere decir que hay cinco locales de Montalvo.

21. ¿Qué salón de belleza consideran Uds. que ha sabido mantenerse en el tiempo? ¿Por qué? Por las sedes, Son los buenos, Mejores estilistas, Tienes buenos estilistas, Buenos productos de calidad. A una persona no le gusta Montalvo, porque tuvo mala experiencia, siento que Montalvo es por moda, que fuera el único local que existiera y me parece que no. No todas las sedes de Montalvo no están bien capacitadas, le dan mucha publicidad. Hay un problema de la frialdad entre el cliente y el estilista. Antes si había una relación amical y buena atención con el cliente y estilista, se pasaba el tiempo al toque, ahora solo hacen el trabajo y se retiran, Ya no hay el vínculo entre el estilista y el cliente. Por la publicidad es una marca posicionada en el rubro. Por publicidad en Televisión y por moda todas van. Montalvo ahora es escuela. Es depende del 
gusto, ya que hay franquicias en varios distritos. Hay diferentes puntos de vista, yo asisto al de Palmeras, podría ir al local que está a una cuadra de mi casa que queda en Universitaria con Tomas Valle, pero prefiero ir con mi auto al que está en Palmeras, más lejos de mi casa porque en realidad está el estilista que quiero y me hace bien el trabajo. Desde que ingresa ya saben su nombre.

22. ¿Qué es lo que hace que Uds. Cambien entre un salón de belleza, a otro? Sondear fidelidad, diferencias en el tipo de servicio, precio u otros.

Para fidelizar a sus clientes en algunos locales, funciona y en otro no. No es lo mismo ser una clienta asidua en un local, cuando vas a un local nuevo que no te conocen, no te reciben igual. 23. ¿Qué hace que un salón de belleza tenga éxito, de que depende?

Sus productos, la atención al cliente y el profesional que te está atendiendo.

24. ¿Qué ventajas o beneficios consideran Uds. tienen los salones de bellezas? Sus productos, Su atención personalizada que no exista la frialdad, Solo algunos profesionales 25. ¿Qué errores consideran Uds. que comenten los salones de belleza? ¿qué es lo que hacen mal y no corrigen?

No hay conexión entre estilista y cliente. En el caso de sus ofertas (correo electrónico) en las palabras chiquitas dice "solo en efectivo", entonces una llega y tiene que volver a salir para buscar un cajero y poder pagar en efectivo porque con tarjeta no se puede pagar. Los tiempos si no reservaste tienes que esperar hasta que terminen. En mi caso es la depilación tienes que esperar al estilista y ya tienes confianza y a veces que esa chica atiende a otra persona y se gasta más tiempo.

26. ¿Cuál sería su recomendación para no cometer este tipo de errores?

Que deben tener las ofertas en tarjeta de crédito o débito porque ya el efectivo. 
27. La distancia entre donde se ubica su centro laboral o domicilio y el centro de belleza a donde van ¿suele influenciar en sus visitas? ¿Si lo tuvieran cerca irían?

Sí, pero si vale la pena si iría hasta donde se encuentre el profesional.

28. ¿Si tuviéramos que describir al salón de belleza ideal, como debería ser? Sondear infraestructura, servicios, precios, productos y marcas a la venta, calidad de servicio, presencia del personal, servicios anexos, ubicar u otros.

Buena música, si deseas algo de tomar, snacks, Muy aparte de calidad y productos Que la atención sea inmediata, La atención es básica, muy independiente de las cosas básicas de productos y servicios. Que el ambiente sea agradable, limpio, A1. Que sea personalizado 29. ¿Existen servicios adicionales que Uds. consideran debería ofrecer un salón de belleza? Que sea frecuente en los snacks. Falta Televisión. El servicio de snacks y si pasas de tres a cuatro horas, elegir para comprar. Es como los casinos donde pasan y te ofrecen.

Negocios móviles (ejemplo Food Truck)

30. Ha escuchado algún servicio sobre-ruedas (móvil) como los Food trucks?

Una no ha utilizado el servicio, pero si han escuchado. Te ayuda a que cuando estás pasando y tienes hambre y compras para poder sacarte de apuro, y los precios son más económicos. No los he utilizado, pero lo veo como buena opción rápida, para que puedan comer al paso.

31. ¿Qué opina de este tipo de negocios? ¿Por qué?

Hay variedad de productos con el carrito, ceviche, ropa, tragos, etc.

32. ¿Alguna vez han consumido en un food trucks que les ha parecido el servicio?

No han consumido.

33. ¿Cuál cree que sería la ventaja de este servicio al ser móvil? 
Tiempo la premura la rapidez, hay muchos carritos y puedes elegir.

34. ¿Por qué irían a un servicio móvil food trucks?

Porque es rápido.

35. ¿Qué es lo que más valoran de este servicio?

Es una tendencia, se inició en estados unidos. Por el tiempo.

36. ¿En qué zona les gustaría que este servicio?

En varias zonas lo podemos encontrar,

37. Como les gustaría enterarse la ruta o servicio móvil de food trucks

No hay existe, ellos se estacionan donde hay concurrencia de público.

Negocio: Salón de belleza móvil (se detalla la descripción del servicio)

38. Si Uds. encuentran este nuevo salón de belleza móvil cerca de su trabajo o domicilio, ¿lo visitarían? ¿Por qué?

Sí, porque llegar a la casa cambiarse la ropa de trabajo e ir hacerse lo que uno quiere, que a las finales lo puedes ahorrar y que venga a tu casa, súper acogedor con tragos y los precios están buenos, y es algo nuevo.

Sí, para probarlo y ver cómo son sus servicios

Sí, se ve algo nuevo novedoso

Sí, me agradaría bastante.

Sí, porque no voy a esperar a otra persona para que me haga el trabajo.

Si, por curiosidad y si me gusta quizás sí.

39. ¿Realizarían reservas o citas a domicilio para poder atender en este nuevo salón de belleza móvil? ¿Por qué? (considerando las características ya mencionadas arriba) 
Si todas, están dispuestas de sacar su cita e ir después de probar los servicios.

40. Consideran Uds. que los servicios y precios que ofrecemos son los más accesibles para poder iniciar este nuevo salón de belleza móvil? ¿Por qué?

Si todas

41. ¿Consideran Uds. que debemos incluir como servicio adicional recoger al cliente y mientras se le realizar el servicio lo podemos llegar a su destino final? ¿Por qué?

Una asesoría personalizada, como un asesor de imagen, para que puedan indicar si estás bien con las tendencias, de acuerdo a tu color de piel, etc.

42. ¿Qué es lo que más le gustaría de este nuevo salón de belleza móvil?

La privacidad, si tienes dificultad en alguna parte de tu cuerpo y para las señoras es súper excelente.

43. ¿Qué es lo que menos le gustaría de este nuevo salón de belleza móvil?

De llegar y que esté lleno y no me puedan atender

Primero lo probaría y luego indicar lo que no me gustaría.

Se pueda tener los errores de un salón de belleza convencional.

Publicidad y Promociones.

44. ¿Cuál es la mejor forma que un salón de belleza se haga conocida y famosa, de renombre?

En sus servicios, un buen servicio y colocar buenos productos

Muchos se las chicas reality y ellas van y todos quieren ir porque ven en las redes sociales y es una manera más de atraer a la gente.

Producto y que la hora de cita se respete. 
45. Finalmente, pensando en salón de belleza ¿qué opinan de estos nombres: Beauty Car, Fashion Express, Combi de la Belleza, Bella Bus, Belleza Móvil, Estética Móvil. (Evaluar Alternativa)

La palabra Express me parece que está bien

Beauty Express, atraería más, puedes relación que es móvil y de belleza.

Votaría por nombre un nombre en español.

Enfocando un nombre de la rapidez, el tiempo, Belleza al instante, Resaltamos tu belleza en pocos minutos. Afianzar el tiempo con la belleza.

\section{Salón Express}

Deben ser cortas y que llegue al consumidor de su segmento.

A todas les gusto el Express.

Figura E le gustó el diseño. 


\section{Anexo 9. Resultado de Focus Group No. 2}

Bueno, ahora cuéntenme un poco de Uds.

1. ¿A qué se dedican? Uds. trabajan, estudian, son independientes?

2. ¿Qué hacen en sus tiempos libres? ¿Qué es lo que más les gusta hacer?

3. ¿Qué significa para Uds. engreírse?

4. ¿Alguna de Uds. en sus tiempos libres se dedica a su cuidado personal de belleza?

5. ¿Alguna de Uds., van a salones de belleza, peluquerías o spa?

6. ¿Conocen las diferencias de salones de belleza, peluquerías y spa?

Mi nombre es Andrea Farfán tengo 30 años trabajo soy contadora, en mis tiempos libres a las 0730 voy al gimnasio, estudio en la Universidad Católica y con relación a los salones de belleza siempre veo temas de manicure y pedicure, planchado una vez al mes o cuando tengo algún evento o reunión familiar, quisiera maquillaje o depilación, pero si más acudo al spa por tema de masajes relajantes.

Mi nombre es Luciana tengo 20 años estudio en la Universidad de Piura, voy a la peluquería una vez al mes y cuando tengo fiestas o eventos para maquillarme, una vez al mes voy por tema de la depilación.

Mi nombre Ana Paula Silva tengo 20 años estudio administración en la Universidad de Piura en los espacios libres de la universidad he tratado ir a las peluquerías, pero no siempre se puede porque no tengo una cerca, pero voy entre dos o tres veces al mes por arreglarme las uñas Mi nombre es Pierina tengo 21 años soy estudiante de la Universidad Científica del Sur, en el tercer año de medicina, en mis tiempos libres trato de ir dos veces al mes a la peluquería por mis manos y pies, también depende de mis compromisos para lo que es peinado y maquillaje, voy 
entre uno y tres veces al mes y cada dos semanas para lo que es depilación, a veces no puedo mucho porque no hay muchas peluquerías cerca del hospital, pero trato de ir lo más posible Mi nombre es Ivette Morales tengo 23 años soy mamá de dos niños soy contadora, con el tema del salón de belleza me hago depilaciones dos veces al mes y manicure dos o tres veces, con los peinados dos o tres veces o cuando haya algún evento.

Hábitos de Uso:

7. ¿Con qué frecuencia suelen asistir a los salones de belleza?

Todas las participantes indican asistir como mínimo una vez al mes a los salones de belleza y estas pueden aumentar de acuerdo a sus actividades sociales (Eventos, reuniones familiares, etc.) 8. ¿Qué días suelen visitar el salón de belleza? Por alguna razón especial son esos días. La mayoría de las participantes indica asistir los jueves o sábados, Manuela manifiesta que depende, si te vas a hacer las uñas para el fin de semana, ya que deberías ir desde el día miércoles, además si tú vas los días de semana los salones tienen horario hasta las nueve de la noche, no hay mucha gente, en cambio si tú vas un fin de semana hay mucha gente y se demoran en atenderte, es un caos, aunque se saque citas.

Luciana indica que aumenta mucho más en verano, media hora de espera a pesar de tener cita. 9. En qué horarios acostumbran acudir. ¿Por qué?

La mayoría indica al término de trabajo.

Pero alguna de Uds. va los fines de semana ¿por qué ya están en casa o prefieren quedarse en casa?

Pierina indica que ella va sábados en la mañana a la peluquería que está cerca a su casa porque de lunes a viernes le resulta imposible, además cuando ella regresa en las noches ya están cerrando. 
10. ¿Visitan Uds. un salón de belleza debido a que tiene mejores ofertas (precios), buen servicio, buena calidad de productos, los profesionales de belleza que tienen, entre otros? Luciana indica que más por la calidad del producto, cuando te hacen las uñas no todos los salones de belleza tienen la misma marca de esmalte, por ejemplo, yo antes de año nuevo me hice las uñas, pero en el camino se malograron, en otra peluquería me hice la misma manicure y me quedaron mejor.

Andrea indica que prefiero el servicio y precio.

El resto de las entrevistadas manifiesta que prefieren la atención.

11. ¿Qué tipo de servicios suelen usar en el salón de belleza?

La mayoría de las entrevistadas indica que se van a realizar manicure, pedicure, depilación facial, corte de pelo y también laceado cuando tienen eventos.

12. ¿Cuánto de su tiempo invierten en cada servicio que se realizan?

La mayoría manifiesta que una hora, por ejemplo, en manos y pies como mínimo una hora, y un par de horas si se desean hacerse algo más aprovechando que se encuentran en la peluquería 13. ¿Cuánto es lo que suelen gastar por cada uno de estos servicios?

Las entrevistadas indican que el maquillaje está entre S/ 120 soles con Mágnum, Pero el precio va de acuerdo a la calidad del producto, así como las uñas: si son uñas espaylo son 60 soles, si es Unilup normal 20 soles o si son acrílicas 80 soles y tips, que son solos los puntitos, 70 soles.

¿Y hay alguno que prefieran?

Ivett indica que prefiere gel que dura como dos meses, además apenas sales de la peluquería ya puedes hacer tus cosas, la duración con el gel es mucho más que con el esmalte normal. 
Todas indicaron que prima la calidad del producto al precio, lo cual a largo plazo es mejor porque dura más.

14. ¿Hay alguna diferencia de los precios entre un salón de belleza y otro? ¿Por qué?

Las entrevistadas indicaron que depende de la marca de los productos que usan en el salón de belleza, incluso también las sedes, por ejemplo, manifestaron que si es Montalvo los costos no son igual en su sede Jesús María como en la de San Isidro.

15. ¿Creen Uds. que la zona o distritos donde viven influye los precios, la atención y calidad de productos y/u otro?

Todas indicaron que sí, porque una marca está supeditada al uso de unos productos como por ejemplo los de Unique que cuestan más barato.

16. ¿La distancia entre el salón de belleza y su domicilio o centro laboral es lejana o cercana? Todas indicaron que las distancias entre un salón de belleza y su domicilio es lejos, Por ejemplo, Ivett optó por conseguir una profesional, pues tiene una amiga que va a su casa desde las siete hasta las nueve de la noche evitando hacer colas o estar esperando, tomando esta opción desde hace cuatro años, ahorrando tiempo considerando que tiene un hijo y no puedo estar todo el día en la peluquería, ya que en una ocasión su hijo soporto estar tres horas en la peluquería antes que se aburriera.

Una de las estudiantes indica que prefiere buscar lugares cercanos a su Universidad para aprovechar más el tiempo en la peluquería si tienen espacios entre sus cursos, mientras que Pierina indica que por su rutina diaria le resulta muy difícil ir a una.

Andrea que trabaja por una zona industrial de Ate, tiene que sacrificar su hora de refrigerio para buscar una peluquería por Salamanca a fin de ser atendida.

17. ¿Alguna de Uds. ha sacado cita por teléfono, web, WhatsApp y otro? ¿Por qué? 
La mayoría indica que usan el internet, WhatsApp y teléfono para reservar sus citas, pero también manifiestan emplear el Facebook.

18. ¿Cómo realizan sus pagos? En Efectivo, Visa o MasterCard

Indican usar tarjetas de débito o crédito Visa y MasterCard, sin embargo, manifiestan que para poder hacer uso de las promociones deben de realizar el pago en efectivo, siendo esto un acto común en la mayoría de peluquerías.

Salones de Belleza

19. ¿Qué salones de belleza son los que se le viene a la mente en este momento?

Montalvo, Marco Aldany, Soho Color, las principales cadenas de peluquería. Sin embargo, también indican ir a salones de belleza cerca a sus domicilios o centro de estudios aprovechando su cercanía y las promociones que puedan encontrar, pero saben que no lo van a encontrar en otros lugares, además de ser más cómodos.

20. De todos estos salones de belleza que han mencionado, ¿cuál consideran que es la mejor? ¿Por qué?

Para Manuela, Montalvo es una mala experiencia porque cada vez que se ha hecho un pintado de uñas no lo hacen como ella desea, en algunos casos se lo vuelven a realizar, pero igual, y en otros no; igualmente, sucede con su corte de cabello, además, indica que le cortan más caro que en otros. Además, considera que el alto costo de su servicio se debe a que cuenta con estilistas reconocidos, quienes según la opinión de la mayoría desean hacer lo que ellos quieren y no lo que el cliente desea.

Andrea indica que prefiere ir a uno cerca de su casa porque es más personalizado, en cambio, en las cadenas por lo que tienen mayor cantidad de clientes no realizan un buen servicio, además no 
tienen la misma confianza, porque se sienten con mayor confianza con la persona que lo atiende en el establecimiento cercano a su casa.

También indican que, si les gusta la atención de una estilista, prefieren esperar o reservar su cita con esa especialista, porque ya saben que les gusta o les agradan las recomendaciones que les hacen.

21. ¿Qué salón de belleza consideran Uds. que ha sabido mantenerse en el tiempo? ¿Por qué? Andrea indica que un salón de belleza de su casa, se mantiene porque se perfeccionan y van actualizando, ofreciendo nuevas técnicas de pintado de uñas o mejoran su servicio al brindar masajes gratis, por ejemplo.

Además, el grupo indica que investigan por el internet y las redes sociales (Facebook) sobre las nuevas tendencias, siendo esta una ventaja a comparación de otros tiempos para mantenerse a la moda.

22. ¿Qué es lo que hace que Uds. cambien entre un salón de belleza, a otro?

Todas buscan la atención personalizada, buscan un lugar donde se sientan cómodas y tengan confianza con la persona que las está atendiendo, además de aceptar las críticas que les dan y tengan la disponibilidad de hacer los cambios. Incluso Ivett manifiesta que por su casa a ella y a su hermana la atendía una especialista, la cual cuando apertura su propio local lejos de su domicilio ella, igual que muchas otras clientas, también la siguieron por su atención. Andrea, manifiesta que no le gusta ir a las cadenas porque considera que paga el doble y que no les gusta el servicio que les dan.

23. ¿Qué hace que un salón de belleza tenga éxito, de que depende?

Todas buscan la calidad del servicio, que nos sintamos cómodas y las asesoren.

24. ¿Qué ventajas o beneficios consideran Uds. que tiene los salones de bellezas? 
Todas manifiestan como ventaja o beneficio la variedad de productos que te puedan ofrecer, los profesionales sepan hacer más peinados o empleen diferentes técnicas.

Algunas consideran al salón de belleza como un lugar para aprovechar en distraerse de su rutina, porque aprovechan en leer una revista o conversar con alguien mientras espera.

25. ¿Qué errores consideran Uds. que cometen los salones de belleza?, ¿qué es lo que hacen mal y no corrigen?

No respetan tu cita, porque programas tu horario y tienes que esperar 40 minutos o 1 hora para ser atendidos, retrasando su tiempo para asistir a sus eventos u otras actividades.

Otro punto negativo, es que los trabajadores discutan problemas internos frente a los clientes, pues hace sentir incomodas a las clientas llevándose una mala imagen.

26. ¿Cuál sería su recomendación para no cometer este tipo de errores?

Las entrevistadas manifestaron que algunos salones le permiten dejarles sugerencias. Andrea manifiesta que los espacios son muy reducidos y que los trabajadores están muy juntos, indicando que no les gusta que los trabajadores conversen entre ellas y no se percaten del trabajo que están realizando.

Debería existir una política organizacional con valores y buenas costumbres las cuales serían de cumplimiento obligatorio para todo el personal que trabaja con la finalidad de dar un buen servicio.

27. ¿La distancia donde se ubica su centro laboral o domicilio y el centro de belleza a donde van, suele influenciar en sus visitas? si lo tuvieran cerca irían?

Si, si estuvieran más cerca irían más seguidos, 
Pierina indica, que en una ocasión tuvo que salir del hospital e ir directo a la Universidad para una exposición, y si hubiera tenido un centro de belleza cerca de la Universidad hubiera ingresado para atenderse.

28. ¿Si tuviéramos que describir al salón de belleza ideal, como debería ser? Sondear infraestructura, servicios, precios, productos y marcas a la venta, calidad de servicio, presencia del personal, servicios anexos, ubicar u otros) Variedad de servicios y productos, calidad del servicio y del producto y precios accesibles. 29. Existen servicios adicionales que Uds. consideran debería ofrecer un salón de belleza Masajes es un servicio que consideran podrían incluirse.

Negocios Móviles (ejemplo Food Truck)

30. ¿Ha escuchado algún servicio sobre-ruedas (móvil) como los food trucks?, comente Si manifiestan haber escuchado este servicio, pero en el rubro de comida rápida, postres, jugos y comida criolla. Andrea manifiesta verlos más en conciertos, dentro de su universidad y por el Pentagonito. La mayoría manifiesta que los productos que ofrecen son frescos, siendo un punto que la mayoría valora además de la limpieza del lugar.

31. ¿Qué opina de este tipo de negocios? ¿Por qué?

Son más económicos que un local.

32. Alguna vez han consumido en un food trucks que les ha parecido el servicio La mayoría indica haber consumido, e incluso les gusta el trato que tienen con las mismas personas que van preparando los productos.

33. ¿Cuál cree que sería la ventaja de este servicio al ser móvil 
La variedad de ofertas que presentan por ejemplo en la mañana desayunos, en la tarde comidas y en la noche hamburguesas. Además, que lo encontramos cerca a nuestro trabajo o evento que se realice.

34. ¿Por qué irían a un servicio móvil food trucks?

Por el tiempo, ya que los productos que ofrecen los preparan más rápido

35. ¿Qué es lo que más valoran de este servicio?

Que se encuentre a la mano

36. ¿En qué zona les gustaría que este servicio ¿?

Cerca al lugar donde pasan mayor tiempo (Trabajo, Universidad, etc.)

37. Como les gustaría enterarse la ruta o servicio móvil de food trucks

A través de Facebook o también a través de un grupo por WhatsApp o por correo electrónico Negocio: Salón de belleza móviles (se le comenta la descripción del servicio)

38. ¿Si Uds. encuentran este nuevo salón de belleza móvil cerca de su trabajo o domicilio, lo visitarían? ¿Por qué?

La mayoría indica que, si lo usaría para probar, y si les parece una muy buena idea e incluso lo recomendarían.

39. ¿Realizarían reservas o citas a domicilio para poder atender en este nuevo salón de belleza móvil? ¿Por qué? (considerando las características ya mencionadas arriba) Todas indican que si

40. ¿Consideran Uds. que los servicios y precios que ofrecemos son los más accesibles para poder iniciar este nuevo salón de belleza móvil? ¿Por qué?

A la mayoría les parece aceptable, además indican considerar la inclusión de promociones permanentes de manicure y pedicure o manicure y laceado. 
Incluso aceptan pagar un precio un poco elevado al del mercado, considerando el servicio a domicilio que se brinda, además, por ejemplo, si van a la universidad tal vez incluyan a más personas para el servicio (grupo de amigas).

41. ¿Consideran Uds. que debemos incluir como servicio adicional recoger al cliente y mientras se le realizar el servicio lo podemos llegar a su destino final? ¿Por qué?

Algunas indicaron que no, los servicios de manicure o pedicure, pero si tal vez los de limpieza facial que sí permiten el poder estar en movimiento, otras indicaron que no por el tráfico, porque es difícil maquillarse o cortarse las uñas en movimiento, manifestando el temor de ser lastimadas.

42. ¿Qué es lo que más le gustaría de este nuevo salón de belleza móvil?

Andrea indica que si ella vive en Los Olivos y tiene un evento en San Isidro le convendría coordinar una cita cerca a san Isidro, así estaría más cerca al lugar del evento y considera que su costo sería más barato.

Corina indica que sería más rápido y más accesible, además que debe ser puntual en su horario. 43. ¿Qué es lo que menos le gustaría de este nuevo salón de belleza móvil? Que se malogre la movilidad o que el tráfico le impida llegar a la hora. Otro punto es la falta de servicios higiénicos, además de la higiene que debe tener la movilidad para la esterilización de los instrumentos empleados.

Publicidad y Promociones.

44. ¿Cuál es la mejor forma que un salón de belleza se haga conocida y famosa, de renombre? 
A través de las redes sociales y de las referencias del servicio que brindan y sus servicios, esto último es lo que llama la atención.

Andrea, recomienda contratar a un estilista reconocido y aprovechar en promocionarlo para ganar gente.

45. Finalmente: pensando en salón de belleza ¿qué opina de estos nombres: Beauty Car, Fashion Express, Combi de la Belleza, Bella Bus, Belleza Móvil, Estética Móvil. (Evaluar Alternativa)

Andrea propone Beauty express, pero la mayoría indica que se debe buscar un nombre que indique el servicio a domicilio, y a otras le gustaron Beauty Car. 


\section{Anexo 10. Resultado de Focus Group No. 3}

1. ¿A qué se dedican? Uds. trabajan, estudian, son independientes?

Estudian, Trabajan, Amas de casas, Independientes/Emprendedoras.

2. ¿Qué hacen en sus tiempos libres? ¿Qué es lo que más les gusta hacer?

Dedicarme a mis hijos, salir a comer, dormir, como todo el día trabajo, salir con amistades, visitar a la familia, engreírse con sus cosas, salir a jugar, pasear, pasear a mis perritos, ir a la peluquería, se hace todos los servicios de belleza.

3. ¿Qué significa para Uds. engreírse?

Para todas es ir al salón de belleza y hacerse todos los servicios.

4. Alguna de Uds. en sus tiempos libres se dedica a su cuidado personal de belleza?

Si todas.

5. ¿Alguna de Uds., van a salones de belleza, peluquerías o spa?

Si todas.

6. ¿Conocen las diferencias de Salones de Belleza, Peluquerías y Spa?

Salones de Belleza, Depilación, maquillaje, tinte, peinados, laceados, manicure, pedicure

Peluquería, corte, teñir cabello, todo lo que es tratamientos de cabello.

Spa, masajes, relajarse

Hábitos de Uso:

7. ¿Con que frecuencia suelen asistir a los salones de belleza?

Dos o tres veces al mes, Por acontecimiento especial

Una participante va inter-diario para hacerse, servicios de belleza.

8. ¿Qué días suelen visitar el salón de belleza? ¿Por alguna razón especial son esos días? 
Iba a Montalvo por el especialista y el servicio, productos. Pero se cambió de salón de belleza y ya no voy, estoy buscando un salón de belleza con un buen estilista.

Le gusta la persona que le realiza los servicios

Por sentirse bien

9. ¿En qué horarios acostumbran acudir? ¿Por qué? (verificar si varía días de semana versus fines de semana)

No tiene tiempo definido.

10. ¿Visitan Uds. un salón de belleza debido a que tiene mejores ofertas (precios), buen servicio, buena calidad de productos, los profesionales de belleza que tienen u otros?

Que sean profesionales, el tiempo es importante y que te lo haga bien.

Depende mucho los productos que estén utilizando.

11. ¿Qué tipo de servicios suelen usar en el salón de belleza?

Maquillajes, laceado, manicure, pedicure, tinte, cepillado, depilación, corte de cabello, rizado de pestañas

12. ¿Cuánto de su tiempo invierten en cada servicio que se realizan?

Se puede estar de dos a tres horas en promedio

Una participante se demora de cinco horas a más.

13. ¿Cuánto es lo que suelen gastar por cada uno de estos servicios?

Aprox. Depende de qué servicio, pero un aprox. en S/ 100 a S/200

Cuando es un laceado te incrementa

Una gasta S/ 400 porque se hace todos los servicios

14. ¿Hay alguna diferencia de precios entre un salón de belleza y otro? ¿Por qué?

Precios y atención 
15. ¿Creen Uds. que la zona o distritos donde viven influye: los precios, la atención y calidad de productos u otro? Especificar.

Sí hay diferencia y van buscando las ofertas.

En cadenas por ejemplo en Montalvo, las zonas son diferentes dueños y el costo es diferente.

16. La distancia entre el salón de belleza y su domicilio o centro laboral ¿es lejana o cercana?

Es lejos, prefieren domicilio

En su mayoría está lejos

Es cerca no se complica y va a la peluquería de su barrio

17. ¿Alguna de Uds. ha sacado cita por teléfono, web, WhatsApp u otro? ¿Por qué?

Casi siempre. En Navidad, Año nuevo, o eventos especiales.

18. ¿Cómo realizan sus pagos? ¿En Efectivo, Visa o MasterCard?

Tarjeta de crédito o débito, Efectivo

Salones de Belleza

19. ¿Qué salones de belleza son los que se le viene a la mente en este momento?

Soho, Montalvo, Aramis, Marco Aldany, Thomas, Toque X, Santa María, Salones de belleza local,

20. ¿De todos estos salones de belleza que han mencionado, cual consideran que es la mejor? ¿Por qué?

Los salones de Belleza de cadena (Montalvo, Soho, Marco Aldany) se han posicionado por sus productos, servicio, imagen y el nombre. Por la atención y productos.

21. ¿Qué salón de belleza consideran Uds. que ha sabido mantenerse en el tiempo? ¿Por qué? Montalvo, Tiene buenos estilistas, Buenos productos de calidad 
22. ¿Qué es lo que hace que Uds. Cambien entre un salón de belleza, a otro? Sondear fidelidad, diferencias en el tipo de servicio, precio u otros.

Que me cambien de estilista, porque ya vivió una experiencia donde le cambiaron y no la atendieron igual, busco una por su casa y le hizo igual, con el mismo producto y bajo precio. El motivo para que se cambien es que, si le realizan algo que está mal, ya no regresan al mismo lugar.

23. ¿Qué hace que un salón de belleza tenga éxito, de que depende?

Productos, Atención, la presencia del estilista, el Local, el nombre (para estar en el top mind de la gente)

24. ¿Qué ventajas o beneficios consideran Uds. que tiene los salones de bellezas?

Sus productos

Te dan snacks, a los niños le dan su chupetín. Descuentos, promociones por empresas

25. ¿Qué errores consideran Uds. que comenten los salones de belleza?, que es lo que hacen mal y no corrigen?

Un salón de belleza le realizó un balayage y le hicieron mal, con un tinte que no era el color que indico, quedo como verde, y nunca más volví, fue recomendado, no me reconocieron nada.

26. ¿Cuál sería su recomendación para no cometer este tipo de errores?

Cambiar de salón de belleza.

27. La distancia entre donde se ubica su centro laboral o domicilio y el centro de belleza a donde van, ¿suele influenciar en sus visitas? ¿Si lo tuvieran cerca irían?

Sí influye, claro si tienen los productos, servicios y estilistas. 
28. Si tuviéramos que describir al salón de belleza ideal, ¿cómo debería ser? Sondear infraestructura, servicios, precios, productos y marcas a la venta, calidad de servicio, presencia del personal, servicios anexos, ubicar u otros.

Buena música, WIFI. Si deseas algo de tomar, snacks. Muy aparte de calidad y productos Que la atención sea inmediata. La atención es básica, muy independiente de las cosas básicas de productos y servicios. Que el ambiente sea agradable, limpio, A1. Que sea personalizado y que sea especializado en lo que realiza.

29. ¿Existen servicios adicionales que Uds. consideran debería ofrecer un salón de belleza? Brindar ofertas para un cliente fidelizado

Dar un carnet con sellos con cinco manicure y una sale gratis.

Cuando eres cliente especial y te lo ofrecen gratis.

Negocios móviles (ejemplo Food Truck)

30. ¿Ha escuchado algún servicio sobre-ruedas (móvil) como los food trucks?

Todas si conocen los food truck.

31. ¿Qué opina de este tipo de negocios? ¿Por qué?

Interesante. Visto de Comida

32. ¿Alguna vez han consumido en un food trucks que les ha parecido el servicio?

No han consumido.

33. ¿Cuál cree que sería la ventaja de este servicio al ser móvil’

Tiempo la premura la rapidez, hay muchos carritos y puedes elegir.

34. ¿Por qué irían a un servicio móvil food trucks?

Porque es rápido. 
35. ¿Qué es lo que más valoran de este servicio?

Es una tendencia, se inició en estados unidos. Por el tiempo.

36. ¿En qué zona les gustaría que este servicio?

Por los Olivos.

37. ¿Cómo les gustaría enterarse la ruta o servicio móvil de food trucks?

No hay existe, ellos se estacionan donde hay concurrencia de público.

Negocio: Salón de belleza móviles (se explica la descripción del servicio)

38. Si Uds. encuentran este nuevo salón de belleza móvil cerca de su trabajo o domicilio, ¿lo visitarían? ¿Por qué?

Si, para probar los servicios y por curiosidad

39. Realizarían reservas o citas a domicilio para poder atender en este nuevo salón de belleza móvil? ¿Por qué? (considerando las características ya mencionadas arriba) Si todas, están dispuestas de sacar su cita e ir después de probar los servicios.

40. Consideran Uds. que los servicios y precios que ofrecemos son los más accesibles para poder iniciar este nuevo salón de belleza móvil? ¿Por qué?

Si todas

41. ¿Consideran Uds. que debemos incluir como servicio adicional recoger al cliente y mientras se le realizar el servicio lo podemos llegar a su destino final? ¿Por qué?

Un laceado, un planchado o algún servicio que no tenga mucha complejidad.

42. ¿Qué es lo que más le gustaría de este nuevo salón de belleza móvil?

El tiempo es fundamental porque no quieren esperar.

(Les gusta el diseño que tiene minibar) 
43. ¿Qué es lo que menos le gustaría de este nuevo salón de belleza móvil?

Primero lo probaría y luego indicar lo que no me gustaría.

Publicidad y Promociones

44. ¿Cuál es la mejor forma que un salón de belleza se haga conocida y famosa, de renombre?

Publicidad por medios de redes sociales,

El móvil tiene que llamar la atención al público en la calle.

45. Finalmente: pensando en salón de belleza ¿qué opina de estos nombres: Beauty Car, Fashion Express, Combi de la Belleza, Bella Bus, Belleza Móvil, Estética Móvil. (Evaluar Alternativa)

Les llama la atención B, C, D y Beauty Express.

También seria Star Nice Express, como alternativa de nombre. 


\section{Anexo 11. Resultado de Focus Group No. 4}

1. ¿A qué se dedican? Uds. trabajan, estudian, son independientes?

Todas trabajan

2. ¿Qué hacen en sus tiempos libres? ¿Qué es lo que más les gusta hacer?

Dedicarme a mis hijos, salir a comer, salir con amistades y visitar a la familia.

De compras ropa, ir al cine, ver películas, escuchar música y leer.

3. ¿Qué significa para Uds. engreírse?

Ir hacer masajes, comprar vestidos, zapatos, ir a hacerme laceado, mechitas y manicure.

Tener un día para mí, ir al cine sola e ir de compras sola.

4. Alguna de Uds. en sus tiempos libres se dedica a su cuidado personal de belleza? Sí todas.

5. ¿Alguna de Uds., van a salones de belleza, peluquerías o spa?

Sí todas.

6. ¿Conocen las diferencias de Salones de Belleza, Peluquerías y Spa?

Salones de Belleza, depilación, maquillaje, tinte, peinados, laceados, manicure, pedicure Peluquería, corte, teñir cabello, todo lo que es tratamientos de cabello.

Spa, masajes, relajarse, reductores.

7. ¿Con que frecuencia suelen asistir a los salones de belleza?

Cada mes y cada tres meses

Cada tres meses

dos a tres veces al mes

Cada tres meses

Cada mes 
8. ¿Qué días suelen visitar el salón de belleza? ¿Por alguna razón especial son esos días?

En la noche de lunes a viernes.

Fines de semana es temprano.

Todo un domingo.

9. ¿En qué horarios acostumbran acudir? ¿Por qué? (verificar si varía días de semana versus fines de semana)

En la noche

Temprano

Todo un domingo.

10. ¿Visitan Uds. un salón de belleza debido a que tiene mejores ofertas (precios), buen servicio, buena calidad de productos, los profesionales de belleza que tienen, entre otros?

Tiene dos salones de belleza, en donde lo segmenta por servicios, los servicios más complicados se van más lejos y los servicios básicos cerca de su casa.

Tiene una amistad que tiene su salón de belleza que está lejos de su casa y cerca de su casa son servicios básicos

Encuentra promociones en las cadenas de salones de belleza, y el servicio básico también voy al salón de belleza de su casa.

Se inclinan por un tema de precios, servicios y productos.

En casa se atiende.

11. ¿Qué tipo de servicios suelen usar en el salón de belleza?

Maquillajes, laceado, manicure, pedicure, tinte, cepillado, depilación, corte de cabello, rizado de pestañas, mechitas 
12. ¿Cuánto de su tiempo invierten en cada servicio que se realizan?

Se puede estar de dos a tres horas en promedio

Una participante se demora de cinco horas a más.

13. ¿Cuánto es lo que suelen gastar por cada uno de estos servicios?

Aprox. Depende de qué servicio, pero un aprox. en S/ 50 a S/200

Cuando es un laceado te incrementa

Una gasta S/ 400 porque se hace todos los servicios

14. ¿Hay alguna diferencia de precios entre un salón de belleza y otro? ¿Por qué?

Precios y atención por las zonas

15. ¿Creen Uds. que la zona o distritos donde viven influye los precios, la atención y calidad de productos u otro? Especificar.

Sí hay diferencia y van buscando las ofertas.

En cadenas por ejemplo en Montalvo, las zonas son diferentes dueños y el costo es diferente.

16. La distancia entre el salón de belleza y su domicilio o centro laboral es lejana o cercana?

Es lejos, prefieren domicilio

En su mayoría está lejos

Es cerca no se complica y va a la peluquería de su barrio

17. ¿Alguna de Uds. ha sacado cita por teléfono, web, WhatsApp y otro ... (especificar)? ¿Por qué?

Casi siempre. En Navidad, Año nuevo, o eventos especiales.

18. ¿Cómo realizan sus pagos? ¿En Efectivo, Visa o MasterCard?

Tarjeta de crédito o débito. Efectivo 
19. ¿Qué salones de belleza son los que se le viene a la mente en este momento?

Soho, Montalvo, Marco Aldany, Salones de Belleza local, ninguno.

20. ¿De todos estos salones de belleza que han mencionado, cual consideran que es la mejor? ¿Por qué?

Soho por un tema de publicidad. Soho tiene buenos precios

21. ¿Qué salón de belleza consideran Uds. que ha sabido mantenerse en el tiempo? ¿Por qué?

Soho ha sabido mantenerse en el tiempo porque hace canjes con modelos y chicas reality.

22. ¿Qué es lo que hace que Uds. Cambien entre un salón de belleza, a otro? Sondear

fidelidad, diferencias en el tipo de servicio, precio u otros.

El motivo para que se cambien es que, si le realizan algo que está mal, ya no regresan al mismo lugar. Fidelidad es la química que tienes con el estilista.

23. ¿Qué hace que un salón de belleza tenga éxito, de que depende?

Fidelidad (relación entre cliente y profesional)

Servicio

Producto aplicar

24. ¿Qué ventajas o beneficios consideran Uds. que tiene los salones de bellezas?

Sus productos

25. ¿Qué errores consideran Uds. que comenten los salones de belleza?, que es lo que hacen mal y no corrigen?

La buena atención al cliente, debe sentir en casa, te van a tratar bien, debe hacer un tema de un coach para atención al cliente. El producto/servicio va de la mano y deben tener cuidado

26. ¿Cuál sería su recomendación para no cometer este tipo de errores?

Cambiar de salón de belleza. 
27. La distancia entre donde se ubica su centro laboral o domicilio y el centro de belleza a donde van ¿suele influenciar en sus visitas? si lo tuvieran cerca irían?

Si influye.

Claro si tienen los productos, servicios y estilistas.

28. Si tuviéramos que describir al salón de belleza ideal, ¿cómo debería ser? Sondear infraestructura, servicios, precios, productos y marcas a la venta, calidad de servicio, presencia del personal, servicios anexos, ubicar u otros.

Muy aparte de calidad y productos

Que la atención sea inmediata

Que sea personalizado y que sea especializado en lo que realiza.

29. ¿Existen servicios adicionales que Uds. consideran debería ofrecer un salón de belleza? Brindar ofertas para un cliente fidelizado

Negocios móviles (ejemplo Food Truck)

30. ¿Ha escuchado algún servicio sobre-ruedas (móvil) como los food trucks?,

Todas si conocen los food truck y de tan solo verlo abren el apetito.

31. ¿Qué opina de este tipo de negocios? ¿Por qué?

Interesante.

Hay de Comida, Ropa en la playa, de wetsuit,

Son súper prácticos, innovadores.

32. ¿Alguna vez han consumido en un food trucks que les ha parecido el servicio?

No han consumido. 
33. ¿Cuál cree que sería la ventaja de este servicio al ser móvil

Es que no es estático sino movible ya que se va de un lado a otro.

34. ¿Por qué irían a un servicio móvil food trucks?

Porque es rápido.

35. ¿Qué es lo que más valoran de este servicio?

Debe ser rentable.

36. ¿En qué zona les gustaría que este servicio?

Esta por todos lados, hasta en la playa

37. ¿Cómo les gustaría enterarse la ruta o servicio móvil de food trucks?

No hay existe, es masivo.

Negocio: Salón de belleza móviles (se explica negocio)

38. Si Uds. encuentran este nuevo salón de belleza móvil cerca de su trabajo o domicilio, ¿lo visitarían? ¿Por qué?

Si, para probar los servicios y por curiosidad

Comenzaría con la manicure.

Ver la presencia de las estilistas, la imagen.

Tema de la decoración de la móvil.

39. Realizarían reservas o citas a domicilio para poder atender en este nuevo salón de belleza móvil? ¿Por qué? (considerando las características ya mencionadas arriba)

Si todas, están dispuestas de sacar su cita e ir después de probar los servicios.

40. Consideran Uds. que los servicios y precios que ofrecemos son los más accesibles para poder iniciar este nuevo salón de belleza móvil? ¿Por qué?

Si todas 
41. ¿Consideran Uds. que debemos incluir como servicio adicional recoger al cliente y mientras se le realizar el servicio lo podemos llegar a su destino final? ¿Por qué?

Solo servicios básicos

42. ¿Qué es lo que más le gustaría de este nuevo salón de belleza móvil?

Es importante que estén con las tendencias de moda.

Recomendaciones del estilista cuales son las tendencias y te recomiende.

Confianza y sensibilidad con el estilista y cliente.

43. ¿Qué es lo que menos le gustaría de este nuevo salón de belleza móvil?

Primero lo probaría y luego indicar lo que no me gustaría.

Publicidad y Promociones

44. ¿Cuál es la mejor forma que un salón de belleza se haga conocida y famosa, de renombre?

Publicidad por medios de redes sociales,

Les gustaría saber las rutas.

Promociones con empresas

45. Finalmente, pensando en salón de belleza ¿qué opina de estos nombres: Beauty Car,

Fashion Express, Combi de la Belleza, Bella Bus, Belleza Móvil, Estética Móvil, Beauty Móvil, Salón Express u otro?

Corona encima del carro, que somos reinas de la belleza 


\section{Referencias}

Alonso, Y. (2014). Plan de empresa para la creación de un salón de peluquería y estética en Bétera. Obtenido de https://riunet.upv.es/bitstream/handle/10251/45453/TFC\%20YLENIA\%20ALONSO.pdf ?sequence $=1$

ambito.com. (2017). Perú - Riesgo país. Obtenido de http://www.ambito.com/economia/mercados/riesgo-pais/info/?id=13 apeim.com.pe. (2016). Niveles Socioeconómicos 2016. Obtenido de http://www.apeim.com.pe/wp-content/themes/apeim/docs/nse/APEIM-NSE-2016.pdf Asociación Pro Bienestar y Desarrollo. (2015). Manual de Emprendedores. Obtenido de http://www.probideperu.org/index.html bbc.com. (2017). ¿Cómo afecta a América Latina que Donald Trump retire a Estados Unidos del TPP? Obtenido de http://www.bbc.com/mundo/noticias-38067701 bcrp.gob.pe. (2016). Reporte de inflación. Diciembre 2016. Obtenido de http://www.bcrp.gob.pe/docs/Publicaciones/Reporte-Inflacion/2016/diciembre/reportede-inflacion-diciembre-2016.pdf

Benassini, M. (2014). Introducción a la Investigacion de mercados. México: Pearson Educación. Cámara de Comercio de Lima. (2016). El presupuesto público 2017 al detalle. La cámara. Chan, W., \& Mauborgne, R. (2005). La Estrategia del Océano Azul. Bogotá: Editorial Norma. Chuquinaupa, R., Ortiz, P., Osso, J., \& Ñopo, V. (2013). Plan de Negocio: Servicio Educativo de Música Online. Obtenido de http://repositorio.usil.edu.pe/handle/123456789/1776 
Cohen, S. (2013). Caso Très Chic (Intervención de un Director de Arte). Obtenido de http://fido.palermo.edu/servicios_dyc/proyectograduacion/archivos/2394.pdf correo.pe. (2015). http://diariocorreo.pe/edicion/huanuco/la-basura-apreciada-como-unrentable-y-util-negocio-611755/. Obtenido de http://diariocorreo.pe/edicion/huanuco/labasura-apreciada-como-un-rentable-y-util-negocio-611755/

Cuervo, S., Cárdenas, V., García, C., \& Limo, C. (2014). Hábitos de consumo y comercio electrónico: el caso de la mujer moderna en Lima Metropolitana. Lima: Universidad ESAN.

D'Alessio, F. (2013). El Proceso Estratégico: Un Enfoque de Gerencia. Lima: Pearson.

Damodaran online. (2017). Obtenido de http://www.damodaran.com

David, F. (2003). Conceptos de Administración Estratégica. México: Pearson Educación.

David, F. (2013). Administración Estratégica. México: Pearson Educación.

Ebooks, F. M. (2013). Ansof Matrix. Startegy Skills. Obtenido de http://www.free-managementebooks.com/dldebk-pdf/fme-ansoff-matrix.pdf

elcomercio.pe. (2015). Consumidores peruanos destinan entre $10 \%$ y $15 \%$ en belleza. Obtenido de http://elcomercio.pe/economia/negocios/consumidores-peruanos-destinan-entre-10-y15-belleza-noticia-1795697

elcomercio.pe. (2016). Salones de belleza: ¿Cuáles son los preferidos y por qué? Recuperado el 2017, de Diario el Comercio: http://elcomercio.pe/economia/dia-1/salones-bellezacuales-son-preferidos-y-que-noticia-1934473

ElIntransigente.com. (2017). Uno de cada tres consumidores busca marcas de producción ecológica. Obtenido de http://www.elintransigente.com/sociedad/2017/2/20/cada-tresconsumidores-busca-marcas-produccion-ecologica-423934.html 
Escalante, E. (2016). Promulgan Ley $N^{o} 30056$ que modifica la actual Ley MYPE y otras normas para las micro y pequeñas empresas. Obtenido de http://mep.pe/promulgan-ley-no30056-que-modifica-la-actual-ley-mype-y-otras-normas-para-las-micro-y-pequenasempresas/

Euromonitor International. (2014). Las cinco principales tendencias en la industria de belleza y cuidado personal en Norte y Sudamérica. Obtenido de http://www.americaeconomia.com/negocios-industrias/conozca-las-ultimas-tendenciasen-la-industria-de-belleza-y-cuidado-personal-en-

Flores, C. (2015a). Rubro de belleza mueve 50 mil locales en Perú. Obtenido de Diario Correo: http://diariocorreo.pe/economia/belleza-mueve-50-mil-locales-en-peru-567624/

Flores, C. (2015b). Una peluquería genera ganancias desde S/. 9 mil. Obtenido de Diario Correo: http://diariocorreo.pe/economia/una-peluqueria-genera-ganancias-desde-s-9-mil$573947 /$

Garijo, M. (2014). Las camionetas 'vintage' son los nuevos salones de belleza. Obtenido de http://www.revistavanityfair.es/moda/tendencias/articulos/las-camionetas-vintage-sonlos-nuevos-salones-de-belleza/18621

gestion.pe. (2016a). Copecoh proyecta que sector cosméticos e higiene crecería $6 \%$ este año. Obtenido de http://gestion.pe/economia/copecoh-proyecta-que-sector-cosmeticoshigiene-creceria-6-este-ano-2171282 gestion.pe. (2016b). Tasa de desempleo en el Perú pasó a 4.4\%, señaló la OIT. Obtenido de http://peru21.pe/economia/tasa-desempleo-peru-paso-44-senalo-oit-2264985 
gestion.pe. (2017a). Gobierno publicó Ley de Presupuesto del sector público para el año fiscal 2017. Obtenido de http://gestion.pe/economia/congreso-publico-ley-presupuesto-sectorpublico-ano-fiscal-2017-2176254

gestion.pe. (2017b). BCR: Déficit fiscal fue de 2.7\% del PBI en el 2016. Obtenido de http://gestion.pe/economia/bcr-deficit-fiscal-fue-27-pbi-2016-2179503 gestion.pe. (2017c). Balanza comercial registró superávit de US\$150 millones en enero. Obtenido de http://gestion.pe/mercados/balanza-comercial-registro-superavit-us-150millones-enero-2184205

gestion.pe. (2017d). INEI: Se crearon 92,300 empleos durante el año 2016 en Lima. Obtenido de http://gestion.pe/economia/inei-se-crearon-92300-empleos-durante-ano-2016-lima2179748

Gitman, L. J., \& Zutter, C. J. (2012). Principios de Administración Financiera.

Gonzalez, T. (2015). El mercado de la belleza presupuesta crecimiento en el Perú. Obtenido de Fashion Network: http://pe.fashionnetwork.com/news/El-mercado-de-la-bellezapresupuesta-crecimiento-en-el-Peru,575742.html\#.WJv3BFXhDIV

Hair, J., Robert, B., \& Otinau, D. (2010). Investigación de Mercados - En un ambiente de información digital. México: Mc Graw Hill.

Hernández, R., Fernández, C., \& Baptista, M. (2010). Metodología de Investigación. México: McGraw Hill Educación.

INEI. (2016). Más de 7 millones de mujeres conforman la fuerza laboral del Perú. Obtenido de https://www.inei.gob.pe/prensa/noticias/mas-de-7-millones-de-mujeres-conforman-lafuerza-laboral-del-peru-8943/ 
INEI. (2017a). Obtenido de Comportamiento de la Economía Peruana en el Cuarto Trimestre de 2016: https://www.inei.gob.pe/media/MenuRecursivo/boletines/01-informe-tecnicon01_producto-bruto-interno-trimestral-2016iv.PDF

INEI. (2017b). Lima tendría 9 millones 111 mil habitantes. Obtenido de http://m.inei.gob.pe/media/MenuRecursivo/noticias/nota-de-prensa-n012-2017-inei-2.pdf INEI. (2017c). Informe Técnico $N^{\circ} 01$. Estadísticas con Enfoque de Género. Obtenido de https://www.inei.gob.pe/media/MenuRecursivo/boletines/01-informe-tecnicon01_estadisticas-genero-oct-dic2016.pdf

INEI. (2017d). Estimaciones y Proyecciones de Población. Obtenido de Población total al 30 de junio, por grupos quinquenales de edad, según departamento, provincia y distrito: https://www.inei.gob.pe/estadisticas/indice-tematico/population/

Kotler, P., \& Armstrong, G. (2012). Marketing. Mexico: Pearson.

Kotler, P., \& Keller, K. (2016). Dirección de Marketing. Mexico: Pearson Educación.

Krajewski, L., Ritzman, L., \& Malhotra, M. (2013). Administración de Operaciones. México: Pearson Educación.

Lambini, J. G. (2009). Dirección de Marketing. Mexico DF.: McGraw-Hill/Interamericana Editores S.A.

larepublica.pe. (2015). Uso de smartphones en Perú es uno de los más crecientes en Latinoamérica . Obtenido de http://larepublica.pe/marketing/4540-uso-de-smartphonesen-peru-es-uno-de-los-mas-crecientes-en-latinoamerica

LaRepublica.pe. (2017). Casos de corrupción golpean la economía y el crecimiento de 2017 rondaría el 3,9\%. Obtenido de http://larepublica.pe/impresa/economia/849785-casos-decorrupcion-golpean-la-economia-y-el-crecimiento-de-2017-rondaria-el-39 
limacomovamos.org. (2015). Como vamos en demografía. Obtenido de http://www.limacomovamos.org/cm/wpcontent/uploads/2016/07/Demografia2015final.pdf

Lovelock, C., \& Wirtz, J. (2015). Marketing de servicios. México: Pearson Educación.

Ochoa, V. (2013). El 43\% de los 15 mil centros de belleza en Lima es informal. Obtenido de Gestión: http://gestion.pe/empresas/lima-existen-15-mil-centros-belleza-43-soninformales-2058975

peru21.pe. (2013). La belleza es un buen negocio. Obtenido de http://peru21.pe/emprendedores/belleza-buen-negocio-2151516 peru21.pe. (2016). Población ocupada en Lima Metropolitana creció 0.6\%, anunció el INEI. Obtenido de http://peru21.pe/economia/inei-poblacion-ocupada-lima-metropolitanacrecio-06-2265050

Peruanos Por el Kambio. (2016). Plan de Gobierno 2016-2021. Obtenido de http://ppk.pe/documentos/plandegobierno.pdf

Piergiorgio, S. (2012). Siglos de coquetería. Obtenido de http://www.lavanguardia.com/estilosde-vida/20120824/54340841579/siglos-de-coqueteria.html

Polo, D. (2015). Top 12 de los negocios más rentables en Lima-Perú. Obtenido de Emprender fácil: http://www.emprender-facil.com/es/lima-peru/

Render, B., Stair, R. M., \& Hanna, M. E. (2012). Métodos cuantitativos para los negocios. México: Pearson Educación.

rpp.pe. (2015). Peruanas invierten 600 dólares al año en productos de belleza. Obtenido de http://rpp.pe/lima/actualidad/peruanas-invierten-600-dolares-al-ano-en-productos-debelleza-noticia-767958 
rpp.pe. (2016). MEF subió el valor de la UIT para el 2017 a S/4,050. Obtenido de

http://rpp.pe/economia/economia/mef-subio-el-valor-de-la-uit-para-el-2017-a-s-4050noticia-1018398

Santesmases, M. (2012). Marketing, Conceptos y Estrategias. Madrid: Ediciones Pirámide.

Sapag, N. (2011). Proyectos de Inversión: Formulación y Evaluación.

Sapag, N., \& Sapag, R. (2008). Preparación y evaluación. Bogotá: McGraw-Hill Interamericana.

Semana Económica. (2017). La inflación fue de 0.24\% en enero, por debajo de lo esperado.

Obtenido de http://semanaeconomica.com/article/economia/macroeconomia/212515-lainflacion-fue-de-0-24-en-enero-por-debajo-de-lo-esperado/

Semana Económica. (2017a). MEF: PBI crecerá hasta un punto menos este año por suspensión del Gasoducto. Obtenido de http://semanaeconomica.com/article/economia/macroeconomia/211465-mef-economiaperuana-creceria-alrededor-de-3-8-este-ano-tras-suspension-del-gasoducto-sur-peruano/ Semana Económica. (2017b). ¿Por qué el IGV no se reducirá a 17\% en el 2017? Obtenido de http://semanaeconomica.com/article/economia/macroeconomia/209340-por-que-el-igvno-se-reducira-a-17-en-el-2017/

Soonthorndhada, A. (1989). Construcción De Guías De Entrevistas para La Investigación Cualitativa.

Stickney, C., Weill, R., Schipper, K., Francis, J., \& Avolio, B. (2011). Contabilidad Financiera: Una introducción a conceptos, métodos y usos. 